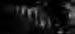



HUMAN BEHAVIOR 


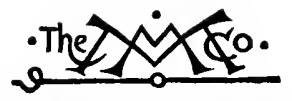
THE MACMILLAN COMPANY NEW YORK - BOSTON - CHICAGO DALLAS - SAN FRANCISCO
MACMILLAN \& CO., LIMITED
LONDON - BOMBAY - CALCUTTA MELBOURNE

THE MACMILLAN CO. OF CANADA, Ltr. TORONTO 


\section{HUMAN BEHAVIOR}

A FIRST BOOK IN PSYCHOLOGY

FOR TEACHERS

\section{, BY \\ STEPHEN SHELDON COLVIN}

PROFESSOR OF EDUCATIONAL PSYCHOLOGY, BROWN UNIVERSITY AUTHOR OF "THE LEARNING PROCESS"

\section{AND}

\section{WILLIAM CHANDLER BAGLEY}

PROFESSOR OF EDUCATION, UNIVERSITY OF ILLINOIS

AUTHOR OF "THE EDUCATIVE PROCESS," “CLASSROOM MANAGEMENT"

" EDUCATIONAL VALUES"

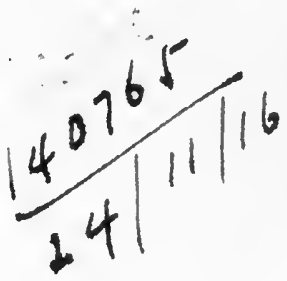

New Mark

THE MACMILLAN COMPANY

1916

All rights reserved 
CoPYRight, 1913,

BY THE MACMILLAN COMPANY.

Set up and electrotyped. Published March, 1913. Reprinted June, August, rgr3 ; January, June, December, 1914; May, December, Igr5; May, rgr6. 


\section{PREFACE}

THE study of psychology has for a long time been looked upon as an essential phase of the professional preparation of the teacher. The following chapters represent an attempt to formulate psychological principles in terms of conduct or behavior. The authors believe that this "functional" point of view in psychology offers a helpful perspective upon the problems of classroom teaching, explaining many of the phenomena with which every teacher must deal, and which, unexplained, tend to irritate and confuse; and providing at least a few guiding principles that may be directly applied to the solution of troublesome problems in instruction and management.

It is hoped that the book may prove useful to the large numbers of young men and young women who each year enter the service of the public schocls. It has, indeed, been written with a distinct recognition of the immaturity and inexperience which these beginning teachers represent. Every effort has been made (I) to select the topics that are most closely related to the work of teaching; (2) to treat these topics concretely, enforcing each principle with a wealth of illustration drawn partly from classroom practice, and partly from the affairs of everyday life; and (3) to simplify the 
terminology, without, at the same time, sacrificing accuracy of statement.

The materials have been organized somewhat upon the "spiral" plan. The first chapter embodies a concrete case of human behavior, described in non-technical language, and illustrating the various factors that condition behavior and control conduct both in customary and in unusual situations. Thus an initial "bird'seye" view of the treatment is given at the outset. The remaining chapters of Part I are also general in their nature, treating upon a simpler and more primitive plane the topics that are later analyzed more minutely. This plan of organization obviously involves a certain amount of repetition; but the repetition, it is believed, will serve a useful purpose in impressing upon the student the fundamental fact that the higher and more complicated forms of behavior have grown out of the simpler forms, and involve these simpler forms as indispensable elements.

The authors have emphasized certain phases of psychology that have hitherto been treated very briefly in textbooks for teachers. Among these are instinct, habit, feeling and emotion, memory, and the economical methods of learning. The treatment of sensation is much briefer than in many other texts, and the discussion of the anatomy and physiology of the nervous system has been limited to the facts of structure and function that are essential to an understanding of the mechanical modes of behavior. 
The "Questions and Exercises" appended to each chapter have been constructed chiefly for the purpose of encouraging the student to study behavior in the concrete, and especially to observe the factors that operate in determining his own conduct.

The authors are deeply indebted to Mr. W. S. Miller, Secretary of the School of Education, University of Illinois, for assistance rendered in revising the manuscript.

The authors further desire to express their thanks to Professors H. S. Jennings, W. B. Pillsbury, J. R. Angell, E. B. Titchener, to Dr. L. F. Barker, and to Henry Holt and Company for permission to use various illustrations accompanying the text.

S. S. C.

W. C. B.

February 1, 1913. 


\section{CONTENTS}

\section{PART I \\ GENERAL PRINCIPLES OF BEHAVIOR}

CHAPTER I

Consciousness and Conduct.$\quad$. $\quad$. $\quad$.

Psychology the science of consciousness - Meaning of the term "consciousness"- The service of consciousness in controlling action - Illustration of a typical set of conscious activities - Important characteristics of consciousness : $(a)$ It varies with varying purposes-(b) Attention and interest determine its changes $-(c)$ Affection or feeling is essential -(d) Consciousness is at a low ebb when acts are mechanical-(e) Sensation is basal to consciousness - $(f)$ Sensation with meaning attached is perception - $(g)$ Imagination as reconstructed experience - $(h)$ Memory and association - (i) Conception, judgment, and reasoning - Summary Relation between consciousness and behavior-Consciousness is at its maximum in a thought crisis - The problem of psychology - Definitions and explanation of technical terms - Questions and exercises.

\section{CHAPTER II}

Brhavior AND LEARNing

New situations make learning necessary - Learning signifies a modification of behavior - Methods of learning: (a) Trial and error-(b) Imitation - (c) "Free" ideas Definitions and explanation of technical terms - Questions and exercises. 


\section{CHAPTER III}

UNLEARNED Behavior • • • . • . • .

Problem of the chapter - "Unlearned" behavior and its significance - Play as a type of instinctive behavior - The value of play as a preparation for later life: Groos's theory of play - Imitative and instinctive plays: Hall's theory The limitations of play as an educative agency - Curiosity as an aid in learning - Definitions and explanation of technical terms - Questions and exercises.

\section{CHAPTER IV}

\section{Attention AND Behavior.}

Problem of the chapter - Definition of attention - Kinds of attention: passive, active, secondary passive - Laws of passive attention - Value of passive attention - Law of active attention - The rise of secondary passive attentionThe rhythmic character of attention - Variety in unity the secret of sustained attention - Attention and fatigue - The conditions of effective work - The span or range of attention - Attention and behavior - The bodily attitude in attention - Definitions and explanation of technical terms - Questions and exercises.

\section{CHAPTER V}

Behavior and the Feelings • • . • - • •

Problem of the chapter - The nature of feeling or affection - Affection as a conscious element - The function of the unpleasant and of the agreeable-Affection and efficiency - Complex forms of affection : the emotions - Characteristics of an emotion - The James-Lange theory of the emotions - Behavior and the emotions - Confused thought and abortive behavior accompany a typical emotion - Clear thought and definite action kill the emotion - Situations suddenly presented may give rise to emotions - Emotions may be aroused by imagined situations - Summary: definition of emotion - A mood as the residuum of an emotional storm - Temperament - Definitions and explanation of technical terms - Questions and exercises. 


\section{CHAPTER VI}

The Practical Significance of the Affective Life .

Problem of the chapter - Affection and attention - The importance of insuring pleasurable outcomes - Pleasure accompanies instinctive and habitual activities - The practical significance of the emotions - The value of the emotion must be sought in its outcome - Emotions induce new modes of behavior - The theory of consequences holds for all emotions - The affective element in teaching - The emotional element in teaching - The emotional element in religious education - Moods and their use in education - Should the teacher show emotion?-Questions and exercises.

\section{PART II \\ MECHANICAL MODES OF BEHAVIOR}

\section{CHAPTER VII}

The Nervous System as the Organ of Behavior • • 106

Problem of the chapter - The nervous system and behavior - The simplest type of behavior: the amœba-Complex behavior requires complicated structures - The simplest form of nervous system-Complex nervous systems - Preferred paths of conduction in the nervous system-The neurone as the unit structure of the nervous systemThe synapse as the mode of conduction between neurones - Classes of neurones : sensory, associative, motor-The central nervous system in man - The functions of the central nervous system: (a) The spinal cord $-(b)$ The cerebral cortex - Consciousness correlated with cerebral activity Inhibition and facilitation as functions of neural activityDefinitions and explanation of technical terms - Questions and exercises. 


\section{CHAPTER VIII}

Reflex AND InStinctive Behavior - • • • •

Problem of the chapter - Reflex movement as a type of behavior - Instinctive behavior as a combination of reflexes - Characteristics of instinctive behavior: conscious accompaniment, reflex constituents, mechanical control, dependence upon inherited neural connections, affective quality Types of instinctive behavior: the adaptive instincts - The individualistic instincts - The sex and parental instincts The social instincts - The religious and æsthetic instincts Summary and table of human instincts, with the corresponding expressions, feelings, and emotions - Definitions and explanation of technical terms - Questions and exercises.

\section{CHAPTER IX}

The Value of the Human Instincts . . . .

Problem of the chapter - The value of the adaptive instincts - The value of the individualistic instincts - The value of the social instincts - The value of the religious instincts - Questions and exercises.

\section{CHAPTER $\mathrm{X}$}

How Instinctive Behavior may be Changed • • • 149

Problem of the chapter - All education must begin with instinct - The modification of instinct: (a) The attachment of another feeling and its appropriate response to an object which naturally arouses an undesirable instinct - The significance of the unpleasant in education - The doctrine of natural punishments - Pleasure $v s$. unpleasantness in learning - The modification of instinct: (b) The attachment of another response to an object and the feeling that the object instinctively arouses - The modification of instinct: (c) The detachment of a feeling from its natural object and response, and its attachment to other objects and responses - The relation of attention to the modification of instincts - Ideals in relation to instincts - Definitions and explanation of technical terms - Questions and exercises. 


\section{CHAPTER XI}

Habitual Behavior and the Law of Habit-building

Problem of the chapter-Habitual behavior contrasted with instinctive behavior - The affective element in habit: the propensity - The importance of habit-formation - The law of habit-building: $(a)$ focalization; $(b)$ attentive repetition; (c) permitting no exceptions - The importance of initiative in habit-building - Value of motives closely related to the child's interests - The significance of the right start The phenomenon of interference in habit-building - The "practice curve" and its "plateaus" - The significance of plateaus in habit-building - The treatment of habit upon the plateau level-The importance of intense effort in habitbuilding - Rapidity $v s$. accuracy in habit formation - The specific character of habits - The "transfer" of habits: (a) through identical elements - $(b)$ through ideals - The limitations of habit - The importance of teaching the pupil how to form habits - Definitions and explanation of technical terms-Questions and exercises.

\section{PART III}

\section{CONSCIOUSLY CONTROLLED MODES OF BEHAVIOR}

\section{CHAPTER XII}

Sensation AND Behavior . . • • • • • • ;

Problem of the chapter - The elements of consciousness - The organs of sensation-Definition of sensation"Pure" sensation an abstraction-Sensation incomplete without response - The attributes of sensation: intensity, duration, quality, clearness - Classes of sensations : $(a)$ visual sensations - The color qualities - Contrast and adapiation - After-images - The color zones of the retina - Perception of form involves other than visual sensations - (b) Auditory sensations - Tonal sensations and their characteristics 
- (c) Taste or gustatory sensations and their characteristics - (d) Olfactory sensations and their characteristics - (e) Dermal sensations : pressure, temperature, and pain - $(f)$ Kinæsthetic sensations - $(g)$ Organic sensations - The significance of sensory defects - Color blindness and tonal deafness - The place of "sense-training" in education - Definitions and explanation of technical terms - Questions and exercises.

\section{CHAPTER XIII}

PERCePtION AND Behavior . . . . . . . .

Problem of the chapter - " Meaning" as the chief mark of a perception - Meanings come from adjustment - Meanings are individual - Objective teaching as a means of developing meanings - Apperception - True and false perceptionBehavior the criterion of true and false - Illusions and hallucinations - Classification of illusions - Hallucinations as a symptom of mental disturbances - Definitions and explanation of technical terms - Questions and exercises.

\section{CHAPTER XIV}

\section{IMAGINATION AND BEHAVIOR}

Problem of the chapter - Imagination contrasted with perception, false perception, and hallucination-Definition of imagination - Truth and falsity of imagination - Reproductive and productive imagination-Mental imagery and its significance-Concrete and symbolic imagery-Imaginal types - The educational significance of imagination - The child does not often confuse the real with the fancied - The world of imagery a privilege of childhood - The world of fancy must be limited - Imaginary achievement must not replace real achievement-Definitions and explanation of technical terms - Questions and exercises. 
The wider use of the term "memory" - The narrower use of the term "memory"- Recollection - Recall and recognition - Impression and association - The tests of memory and their employment in education : (a) The method of retained members - (b) The saving method - $(c)$ The method of right associates $-(d)$ The method of recognition $-(e)$ The method of reconstruction - Retentiveness and its measure The laws of forgetting and their educational applications Faulty observation and its relation to defective memory -Distortion and confusion as sources of weakness in memory - Suggestion as a factor in distorting memory - Factors conditioning accuracy of memory - The function of forgetting - The question of improving memory - Definitions and explanation of technical terms - Questions and exercises.

\section{CHAPTER XVI}

\section{Association AND BeHavior}

Problem of the chapter - "Simultaneous" and "successive" associations - The primary laws of association: continuity and similarity - Mental attitude or purpose determines associations - Secondary laws of association : frequency, primacy, recency, and vividness - Mental attitude or purpose determines operation of secondary laws-Emotional congruity as a principle of association - Summary : educational applications - The importance of prejudices-Definitions and explanation of technical terms - Questions and exercises.

\section{CHAPTER XVII}

\section{ECONOMY IN LEARNING}

Problem of the chapter - Learning by wholes $v s$. learning by parts - Advantages and disadvantages of the "whole" method - The best length of learning periods - The importance of recall in learning - The value of the recitation The phenomenon of interference in learning - The value of 
thorough learning - Rote learning $v$ s. rational learning The value of mnemonic devices - The " warming up "period in learning - The most favorable rate of learning - Summary: a general rule for learning-Definitions and explanation of technical terms - Questions and exercises.

\section{CHAPTER XVIII}

Behavior and the Higher Thought Processes.

Problem of the chapter - The thought crisis and its significance to behavior - Real thinking always involves a real difficulty - Thinking always involves past experience revived as "meaning"- Meanings vary with the problem in hand Meaning is fundamental to behavior - Why meanings attach to qualities as well as to acts - The development of symbols that stand for qualities - The value of thinking in symbols Conceptual and perceptual attitudes - The economy of conceptual behavior - The judgment - Reasoning and the syllogism - Both induction and deduction characterize thinking - Inductive teaching and its place in education-Educational applications : $(a)$ The pupil should be confronted with actual problems - $(b)$ The development of meanings is fundamental to effective reasoning $-(c)$ General meanings or concepts the most important " resources" $-(d)$ The tentative hypothesis: its value and its dangers - The problem of "training the power of reasoning": $(a)$ The importance of understanding the methods of logical thinking - (b) Ideal schemata of thinking and their development in education (c) Developing an appreciation of the rational method of solving problems $-(d)$ The relation of information to reasoning ability-Definitions and explanation of technical terms - Questions and exercises.

APPENDiX : Suggested collateral Readings . 
HUMAN BEHAVIOR 
- I 


\section{HUMAN BEHAVIOR \\ PART I}

\section{GENERAL PRINCIPLES OF BEHAVIOR}

\section{CHAPTER I \\ CONSCIOUSNESS AND CONDUCT}

Psychology the Science of Consciousness. - Psychology is the study of mind. It presents the facts and laws that men have found out about mind and about the way in which mind works. We all know something about mind, but this knowledge in itself does not make us psychologists, any more than an acquaintance with flowers and plants necessarily makes us botanists, or an acquaintance with animals, zoölogists. Both the botanist and the zoölogist not only know certain facts and laws in their respective fields, but they have organized these facts and laws. We cannot become psychologists until we have so arranged and organized the facts and laws of mind that we may gain a systematic idea of what these are and how they work. In this sense of an organized body of knowledge about mind, psychology is a science.

What do we mean by "mind"? At the outset we 
may content ourselves by saying that mind is "consciousness." This is not a definition of mind ; it simply gives another word, a word which we all use in about the same sense, while the word "mind" is used in somewhat different meanings by different people. When we say that a person loses consciousness, we all know what is meant, - for we all lose consciousness when we fall into a sound sleep. When we awake we "return to consciousness," we "become conscious" of some of the things about us. Yet even when we are awake, we are "unconscious" of some of the things about us. These are not " in mind."

The Service of Consciousness in Controlling Action. We are all of us conscious to a greater or less extent during our waking life, and we may well ask, "Of what use is this consciousness; what good does it do us; what service does it render?" This is the question with which we shall be chiefly concerned in this book, for while we shall try to find out what consciousness is and how it acts, we shall further inquire, "What value has it in our lives?" We might live - after a fashion - without consciousness. In deep sleep it does not appear to be a necessity. The heart still beats, we still breathe, and we sometimes make slight movements. With the first sign of returning consciousness, however, we make definite movements of some sort, and when we are wide awake, our movements become more varied and more definite. It is our general experience that movement 
and consciousness are closely related, and we may say here at the outset that consciousness operates primarily in directing our movements and controlling our behavior.

We may get a clearer notion of what consciousness is and what value it has in directing our acts by taking a concrete illustration of a typical set of conscious states, or "consciousnesses," as they follow one another in a day's experience.

Illustration of a Typical Set of Conscious Activities. During a recent summer's vacation, I took a day's sailing trip with a companion down Narragansett Bay to Newport. Because of a continuous head wind, we arrived late in the afternoon, and were forced to make the return trip to Providence after sunset. Soon darkness overtook us, but with a brisk breeze blowing and with a full moon shining from a cloudless sky, this fact gave us little concern. However, although we were quite familiar with the bay as it looked in daylight, it was not so easy a matter to steer our course at night, guided only by the various lights that dotted the shore, or marked some dangerous reef or shoal. And so it happened that we "picked up " the wrong light and left our course, sailing in close to a ledge of rocks, which, with their jagged teeth, projected at the half-tide just a few feet above the surface of the tumbling and surging sea.

I was at the helm of the small catboat, which was sailing easily, the breeze filling her bellying sail. Clear consciousness was at a low ebb. I "sensed" the tug 
of the wind and the pressure of the tiller and drank in the beauties of the August evening, - the glistening of the waves in the glorious moonlight, the dancing of the lights on the shore, the toll of a near-by bell buoy and the weird cries of sea birds. It all might have been an exquisite dream, as the moments glided by and as under the splendor of the sky and on the shining sea the small craft rose and fell with steady monotonous motion.

But suddenly all this is changed! Just over the bow appears a dark object, lying low and extending many feet on either side. In a moment the beauties of the night are lost from consciousness, and there stands out in the mind one insistent question, - "What is it? Perhaps a fisherman's net? No, it looks too bulky for that. Then a watch boat of the oystermen?" Rapidly various possibilities come into mind, and then as the boat sails nearer there is an end to this silent debate. The waves are seen foaming white as they break upon the reef, for this it is that stands in our course. Now we are almost on the rocks, and quickly the attention is fixed on the boat, as mechanically I tug at the sheet and jam the tiller hard over, in a fruitless attempt to pass to the windward of the peril. No, this cannot be done; we cannot sail around the rocks, and soon we shall be thumping on them! There is another moment of rapid debate. Shall I take the boat hook and run to the bow and try to ward the boat off the reef? No, we are sailing too rapidly for that. There is just one chance left of saving 
ourselves from wreck; it is to check the speed of the boat by letting the sail run out, so that the breeze will not fill it, at the same time trusting to the wind to blow us away from our danger. In a flash these possibilities run through my mind. Then out goes the sail until it flaps in the wind, the boat loses head, but there is scarcely an inch to spare as her bow drifts away from the reef and she passes out of danger.

Some Important Facts about Consciousness. (a) It constantly Changes in Terms of Purpose. - In this example of an actual situation we find on examination a very complex set of conscious states, that well illustrate the problems with which this book is to deal. It will, therefore, be worth our while carefully to analyze the elements and find what they show in regard to the nature of consciousness and the way in which it aids us to direct our actions. As far as the nature of consciousness is concerned, we may observe in the first place that it is in a state of continual fluctuation and change. Yet, in spite of this fact, it is always moving on in a more or less definite direction. It is going somewhere. These changes and shifts in our consciousness mark various phases of attention, as it now turns to one aspect of experience and now to another. The moving on of consciousness in a more or less definite direction indicates the general aim or end of the whole thought process. We invariably " think about" something, and it is this something that we have clearly. or vaguely in mind 
that decides in just what direction our thoughts shall move.

In the example just cited, the consciousness of those in the boat moves in the direction that the purpose of the trip and the interests centered around it suggest. It is not anything or everything that comes into consciousness. The parts that compose it at any one moment have a definite relation to the total thought. Nothing comes in a haphazard fashion. Into my mind at one moment come the lights on the shore, for by them I am steering, and my main purpose is to sail the boat safely to its mooring. Or again I listen to the sound of the bell buoy, for that too has a significance in relation to the sailing of the boat. So, also, objects on the water catch my attention and hold it, because they have a meaning. I notice the red light of a passing motor boat and fix it in attention sufficiently to alter my course so that there will be no danger of a collision. And since my general purpose is not merely sailing the boat, but getting my fill of enjoyment out of the day's outing as well, there also come into my mind many things that have but little to do with the actual sailing of the boat. So I drink in the beauties of the evening and enjoy to the fullest extent the exhilaration of the surroundings.

(b) Attention and Interest Determine these Changes. - Thus my attention and my interests determine the elements that enter into my consciousness, the manner in which they work together, and the course that they take. 
Further, as has been said, the attention varies with each succeeding change and fixes the character of these changes. I am now looking at the lights on the shore; now I recognize the cry of the sea bird; again I feel the dash of the spray in my face and now the tug of the tiller. There are brief periods of relative inattention between these shifts from one aspect of the scene before me to another. Here the mental processes "let up" for a moment, so to speak, before they grasp another phase of the experience.

It may be seen from this brief discussion that attention is an accompaniment of all states of consciousness. Without this onflowing of consciousness and its fluctuation from moment to moment, there would be no mental life, at least as we know it. We shall later discuss in a separate chapter the nature of attention and the laws that govern its manifestations. Suffice it to say for the present that attention is an invariable characteristic of mental life.

(c) Affection or Feeling is Essential to Consciousness. - My total consciousness is characterized not only by states of attention; equally fundamental to it is what is technically known as "affection." By affection the psychologist understands all states of feeling; that is, those states that we can speak of as pleasant or unpleasant, as well as more complex states that are given the name of the emotions. We not only recognize the existence of an object; we attach some value to it. It means 
something to us. We like it or dislike it; we dread it, or rejoice in its presence; and so on. I am not only conscious of the splendor of the evening, but I am thrilled by it; I not only sense the pressure of the tiller against my thigh, but I enjoy the sensation with the impression that it gives me of my own strength and skill in steering the boat through the rough seas. I do not merely see the rocks ahead, but I have an emotional state in reference to them. They cannot be a matter of mere intellectual indifference to me, for they make a difference in the situation. They are objects to be dreaded. And so it is with the whole series of conscious states. None are totally indifferent; all have more or less "feeling" attached to them, just as they are characterized by a greater or less intensity of attention. Affection, then, like attention, is an unvarying accompaniment of all consciousness of any degree of complexity. It, too, will be discussed in a subsequent chapter.

(d) Consciousness is at a Low Ebb when Acts are Habitual, Reflex, or Instinctive. If I consider once more the experience above outlined, I cannot fail to notice that certain aspects of it are more vividly conscious than are others. For example, I am definitely and painfully aware of the presence of the dangerous reef. It stands out in the clearest way; but the pressure of the tiller barely enters the state of clear consciousness at all. Notwithstanding this fact, I steer the boat without difficulty, for through many years of experience I 
have succeeded in doing this with very little thought. Indeed, I can thoroughly enjoy the beauties of the evening and attend to the sights and sounds about me, even listening to the conversation of my companion, without letting the boat "fall off." I hold her to her course, because steering has become for me a matter of habit. At first it required all my attention, because I did not know how ; but when we finally "learn how" we require little or no consciousness to carry on those activities in which we are skilled. Habit is basal to all learning and weaves itself into all of our acts. Its nature and importance are to be subsequently discussed.

There are many acts, however, which are for the most part, or wholly, unconscious and which, nevertheless, are not matters of habit. For example, if $I$ had examined the size of the pupil of my eye before nightfall and then again after darkness had set in, I should have found that it was considerably smaller in the daylight than in the night. The reason for this is to be found in the structure of the eye itself and the nervous mechanism that controls it. The change that here takes place is termed in psychology a reflex activity. It differs from a habitual activity, as will later be pointed out, in that it is inborn and not gained through experience. Like habit, it is essential to learning, and forms an important part of our activity.

When these reflex acts cease to be simple, they are often given the name instincts, especially if they are 
joined with a considerable element of feeling. For example, when I first recognized the dangerous shoal, I felt a shrinking and a tendency to let go of the tiller, clamber over the stern of the boat, and seek safety in the skiff we had in tow. This was due to the tendency inherited by all living organisms to shrink away from a dangerous object. This is inborn; we may learn to control it, but we can never entirely get rid of it. The instinct to get away from danger stampedes herds of cattle, puts armies of valiant men to utter rout, and turns into a disorganized and brutal mob the passengers on the deck of a sinking vessel. Instinct weaves itself into all of our acts, and modifies our consciousness in many ways. It is sometimes manifested in intense emotional "storms." Like reflex action and habit, it is fundamental in our behavior and often determines what we shall do in a given situation. It will be fully discussed in its appropriate place.

(e) Sensation is Basal to Consciousness. - It can be easily seen on analyzing consciousness that at its basis there is always to be found what we call a "sensory" experience. My eyes beheld the splendor of the evening; my ears received the sounds that came from land and sea; I tasted and smelt the salt spray and my skin sensed its coldness. My hand touched the tiller and my thigh received its pressure. As I steered the boat, I was conscious of the contraction of my muscles and the movements of my wrist and elbow joints. This con- 
sciousness helped me to give the right motion to the tiller. I did not need to look at it in order to tell how to steer the boat, for these sensations of movement gave me the cue. Further, when I became conscious of the dangerous rocks, there was a sensation of "sinking " in the pit of my stomach, which was a part of my experience of dread. Thus into my consciousness there came, from time to time, sensations of sight, of hearing, of taste and of smell, of pressure and warmth and cold. There were sensations, too, from the muscles, joints, and tendons, as well as from the internal organs. From these examples it can be seen that interwoven in all of our experiences and essential to them is sensation, and if we were incapable of sensation we should have no experiences whatsoever.

(f) Sensation with Meaning Attached is Perception; it is Characteristic of all Developed States of Consciousness. - However, the mere sensation is not sufficient. These sensations must be given a meaning before they can be of service in any large degree. I not only hear the toll of the bell buoy, but I recognize what it is; I not only see the revolving light from the lighthouse, but I know that it is a light of a certain character and not a star, for example. Sensation would be a worthless thing as mere sensation. It must be interpreted to be of use. This interpretation is known as meaning. Sensation, with meaning attached, is called perception. It is to be found in all states of consciousness of any degree of 
complexity and must be considered in a following chapter.

(g) Imagination Essential to Consciousness. - In the consciousness of the moment there is always much that enters in that does not belong to the moment. When today I recall the events of the August evening previously described, I do not have them actually before me; they exist only in my imagination. So, too, when $I$ saw the reef ahead of the boat, I experienced the emotion of terror because I imagined what would happen if the boat kept on her course. I saw in my mind's eye the boat beating on the sharp rocks, I heard the crunching of her keel and felt the list, as in imagination I slipped on the deck. I even seemed to experience in advance the chill of the water as the boat capsized and we were plunged into the sea. Indeed, the situation would have lost a large part of its meaning had it not been for the "images" drawn from the past, or projected into the future. Imagination, then, is fundamental to all experiences that go beyond the present moment and must therefore be given careful and ample consideration in our subsequent discussion.

(h) Memory and Association Phases of Consciousness. - When I recall past experiences, as, for example, when I try to picture how the bay has looked on some previous occasion, I am not only reviving images that belong to the past; I am giving them a particular setting in relation to a definite past experience. This recall is known as 
memory. In connection with any experience, I tend to recall previous experiences of a similar nature, or experiences in some way connected with the present. As I hear the toll of the bell buoy my mind goes back to an earlier trip along the same course, when I had noticed the doleful sound particularly, and spoke about it. Then there comes to mind a distinct recollection of this earlier trip, and many details of it are revived by' the associations called up by the sound of the bell. Thus the present experience is united to the past by innumerable bonds. This ability to call up the past through association gives the present its meaning, for without memory there would be no background to the experiences of the moment. Later we shall consider what memory is and by what means associations are formed.

(i) Conception, Judgment, and Reasoning, Important Aspects of Consciousness. - When I first saw the reef, a doubt came into my mind as to what it was. When I finally recognized it, there passed through my mind the thought, "This is a ledge of rocks." I do not mean that I actually gave expression to this thought. Events moved so rapidly that there was no time for words. However, the idea contained in these words came into consciousness. Such a state of consciousness is called a judgment and the thought "rock" a concept. Judgment and conception may be considered economical ways by which the consciousness of the present moment comprehends something more or less new. In a judgment 
I recognize the immediate experience as having points of similarity with past experiences. Hence I am not obliged to treat what is now occurring for the first time as if it were a completely novel experience. If I were obliged so to treat it, I should not know how to behave. I should be compelled to act without foresight and without a plan. But when I recognize that the dark mass before me is an object that belongs to a certain class of objects called reefs, I know how to act, because although I know nothing about this particular reef, I do know what reefs are in general. It is for this reason that I understand that the particular reef is a menace and that I must act quickly to escape from danger. My behavior in this new situation is directed by my knowledge gained from other experiences that have points of similarity with the present. Thus it can be seen that conception and judgment are most important states of consciousness in a situation that calls for intelligent action. Without states of consciousness involving these mental attitudes, we could perform only the simplest and most habitual acts.

When I finally realize that the object in the course of the boat is a reef, then there comes to my mind the question, "How shall I escape from the difficulty?" Rapidly I consider possibilities and accept or reject them, as they seem practical or the opposite. Shall I attempt to sail around the rocks, or shall I let the boat drift, in the hope that I may be carried away from the 
rocks by the wind and tide? What are the relative possibilities of success in either case? Finally, I select one mode of action and follow it, but I do not act blindly. I reason out what is best to do. This places me at a tremendous advantage over the person who cannot reason, for he is helpless. He cannot see ahead and must trust to blind chance to get him out of his diffculty. So important are these so-called higher mental processes of conception, judgment, and reasoning that no discussion of behavior can ignore them. In the appropriate place they will be given careful consideration.

Summary of Preceding Sections. - Up to this point we have considered the nature of consciousness through the analysis of a complex mental state. We have seen that consciousness is always moving onward and is invariably characterized by some degree of attention and tinged with states of feeling and emotion. We have further seen that all mental states have at their basis sensations, which, when interpreted in the light of past experience, become perceptions. Sensory experience when not actually present may be called back in imagination, which looks to the past and points ahead to the future. Past experiences when definitely recalled become memories. Such recall is made possible through associations, by means of which the present is joined to the past by countless links. Sensation, perception, imagination, and memory and association are the chief 
characteristics of mind in its more simple forms. These, however, are not adequate to deal with more difficult situations in which conception, judgment, and reason are needed. These " higher" forms of mental life enable the individual to act in a present situation with a clear understanding of its relation to his past experience and its bearings on the future.

Relation between Consciousness and Behavior. This latter consideration brings us at once to our chief question in regard to consciousness, - namely, "What is its use? What service does it render?" We suggested at the outset that consciousness helps by guiding our movements and directing our behavior. The word "behavior" is used by psychology as equivalent to movement. This is a characteristic of all animal life from the lowest to the highest. In the most simple organisms there is but a slight range of action, and the consciousness accompanying such action is likewise slight, if indeed it exists at all. With the higher animals, however, the behavior is more complicated, and there are innumerable possibilities of different sorts of behavior. It seems certain that as behavior becomes more complex and more difficult to regulate, consciousness likewise increases in complexity. It is, therefore, reasonable to assume that consciousness puts in an appearance when it is required to aid behavior. The service that consciousness renders is to adjust the organism better to its surroundings. When there is perfect adjustment there is no need of consciousness; 
when, however, the organism is not so adjusted, then consciousness is necessary in securing a better adjustment.

Consciousness at its Maximum in a Thought Crisis. Now, what is true of animal life in general is likewise true of the individual. Consciousness is not equally present at all times. We know that some acts are performed entirely without the direction of consciousness, while others require the fullest knowledge for their execution. If we turn again to a consideration of the situation that we discussed at the beginning of the chapter, we can see at once that this is the case. In sailing the boat, many of the acts that I performed were done with little or no thought. It required slight attention to steer the boat, because I had learned to do this by long years of practice. I had acquired a habit. Again, when I saw the rocks ahead I had a tendency to escape from the boat. This came without any thought on my part, since it is instinctive to avoid danger. If all of my acts were of this simple character, I should need little consciousness. However, when the question arose of how to get out of the difficulty that confronted me, then there was need of the highest grade of consciousness. I could not then rely on instinct or habit. I was obliged to attend, judge, reason. When the situation became difficult, consciousness became very clear. In those moments of our life, then, when we are in real difficulties, when we face new and pressing situations, then in a large measure we throw over 
instinct and habit, and consciousness reaches its max. imum of clearness and intensity. Attention is marked, and the rational processes are called into play. We have in a situation of this character what may be termed a " thought crisis." When a thought crisis arises, there is always a problem to be worked out, a situation to be faced, a difficulty to be surmounted. If our lives could go on in dull, unvarying routine, we should need little conscious direction. We should pass a sort of slumber existence, our behavior being conducted on the plane of instinct and habit. Some persons undoubtedly live at this level of consciousess a large part of the time; all of us do some of the time. However, if we are really alive, we find many things to "stir us up," and on such occasions our consciousness is clear, our attention concentrated, for we need to act in an intelligent manner.

The Problem of Psychology. - Throughout the entire discussion we shall hold to the point of view that consciousness is practical, i.e., that it directs conduct, that it makes possible a more satisfactory type of behavior than could exist without conscious control. Whenever behavior is at all varied and complicated, we shall take this as an indication that consciousness accompanies it. However, we shall consider not merely those modes of behavior that are connected with the higher forms of intelligence, but also those that exist with low grades of consciousness, and even those in which consciousness is probably lacking, for from these 
latter, more complicated forms of behavior are developed and with them those mental states that direct and control them. Thus it can be seen that the problem of psychology is not simply the analysis and description of consciousness and of the laws that govern it, but also an inquiry into the relation of consciousness to behavior and the interpretation of consciousness from the standpoint of behavior.

\section{Definitions and Explanation of Terms Used}

Organism. - A term used in biology to represent any living animal or plant.

Adjustment. - The response of the organism to a situation that confronts it. Adjustment may be relatively perfect or imperfect. In the former case it requires little or no conscious direction, but in the latter case consciousness must aid in securing a more satisfactory adjustment.

Behavior. - All activities of animal forms from the amœeba to man, including the simplest movements like contraction, breathing, the winking of the eye, and the most complex activities like composing an address or painting a picture.

Consciousness cannot be logically defined, but merely described and its states enumerated. It is the sum total of mental states, such as sensing, perceiving, imagining, recalling, judging, willing. When present, it may direct or control behavior.

Experience is that which occurs. The entire conscious 
life of the individual is his experience. Experience in general signifies the totality of consciousness in all organisms capable of it. This, experience may be actually existent at the moment, may have existed at some former time, or may be a possible experience in the sense that it can at some future time take place.

Practical value of consciousness signifies that consciousness does something, i.e., is an aid in adjustment. It exists to help the organism.

Purpose is the end or aim of a conscious process. My present purpose, for example, is the interest that dominates me, the problem I have in mind. My mental states arise, assemble themselves, and move on in terms of this purpose.

Situation. - That which confronts an individual, requiring him to act or to adjust himself. Situations increase in definiteness when difficulties arise. A situation of any degree of complexity requires thought. It exists merely as a possibility when it can be met in an instinctive or habitual manner.

Thought crisis. - A mental state involving a relatively high degree of attention, perception, judgment, and reasoning. The term "crisis" is used to signify that the thought can no longer move along in a relatively simple way. We cannot rely on instinctive and habitual modes of behavior. There is a situation present, a difficulty confronts us, a problem is to be solved. We must wake up and attend to the business at hand. 
(Instinct, habit, attention, affection, emotion, sensation, perception, imagination, memory, conception, judgment, and reason, that have been briefly discussed in the present chapter, will each be more accurately defined in the separate chapters in which they are to be fully considered.)

\section{Questions and Exercises}

I. What is necessary in order to make a body of facts and laws a "science"? Name several sciences and state the kind of facts and laws with which each is concerned.

2. What word may be used as equivalent to the word "mind"? State some facts that you knew about mind before you read this chapter. State some facts about mind that you have learned from this chapter.

3. State some important differences between our waking life and our sleeping life.

4. Find in your experience of to-day some cases in which your consciousness has directed or controlled your action. Can you find any instances of action or behavior that have not been directed by your consciousness?

5. What is meant by the statement that consciousness is always moving in a more or less definite direction? Examine your own consciousness just after you have solved a problem in arithmetic or algebra. What came into consciousness while you were solving the problem? What things can you detect afterward that you were not fully conscious of then?

6. What is meant by "affection" as the word is used in this chapter? Contrast the affective consciousness when you are play. ing a game that you thoroughly enjoy with the kind of consciousness that you have when you are doing a disagreeable task.

7. Can you find any part of your daily experience that is "indifferent" from the point of view of "affection" - something that you neither like nor dislike? 
8. What is meant by a "sensory experience"? Name some of the sensory experiences that you have in walking to school; in studying a lesson; in writing; in eating a meal; in playing a game.

9. Find an illustration of "perception" in your present consciousness. What part does "sensory experience" play in the perception? What is there in the perception besides the immediate sensory experience? You might have the same sensory experiences when you look at a book as a little child or a savage would have in looking at the same book; what would be the difference between your perception and his perception?

Io. What is meant by "imagination"? Try to imagine clearly some house that you pass on your way to school. How many windows has it on the side that faces the street? If there is a porch or a piazza, how many pillars support its roof? How many steps lead up to it? When you pass the house again, note how trustworthy your imagination was in these and other details.

II. Look at some object in the room and let it suggest some definite past experience. What "memories" are revived in your consciousness? What is this connection between a present experience and past experiences called?

12. When I first saw the reef, I did not recognize it as a reef; the light was dim and I could not make it out. When, after some hesitation and careful inspection, we finally "make out" what a group of sensory experiences mean, what do we call the process? Can you find an example of this in your own daily experience?

13. What do you mean by the term "behavior"? Give some examples of behavior in animals like the dog or the horse; in animals like the ants and bees. In what ways does the behavior of very young children differ from that of adults. Give an illustration of instinct.

14. What is meant by a "thought crisis"? Can you find an example in your daily life? If so, describe as accurately as possible your consciousness at the time. 
15. In going over the experiences of a day, do you find relatively many thought crises, or does your life flow on for the most part in such a way that you do not need to think definitely about what you are to do next?

To ThE Teacher. - The above questions should be used to encourage the student to examine his own experience in order that he may find there the facts with which psychology is concerned. The student, therefore, should not be expected to answer all of them in conventional psychological terms. As the treatment proceeds and his conceptions become clarified, his language should become more exact and his descriptions more nearly accurate. 


\section{CHAPTER II}

\section{BEHAVIOR AND LEARNING}

New Situations Make Learning Necessary. - At the close of the preceding chapter we emphasized the fact that consciousness exists in order to adapt better the organism that possesses it to its environment. In other words, consciousness meets a need, and the chief problem of psychology is to show how consciousness meets this need, - how it helps the animal to act. Let us remember, also, that this need would not exist if the conditions of life were unchanging. It is because conditions vary from time to time that new kinds of behavior are demanded. These conditions, although changed, are not absolutely new, and they require behavior that is only in part different from former behavior. The fact that they are different and yet in some respects similar, makes learning possible. If there were no change, if the surroundings were always constant, if the situations were forever the same, there would be no necessity of learning after the first responses had been mastered. On the other hand, if the conditions of each succeeding situation were absolutely new, then learning would be impossible, for nothing gained in a past experience could 
be employed in the future, since the two experiences would be totally dissimilar. It is likewise true that no conscious life could appear under either of the above conditions, since in the first instance consciousness would be unnecessary, no change in behavior being required; and since in the second instance no consciousness would be possible, the present moment being absolutely separated from the past and from the future. This separation would mean that there could be no continuity of conscious states and hence no mental life, at least as we know it. Thus it may be seen that consciousness and learning rest largely on the same necessary conditions, and that what makes possible the one also makes possible the other. Indeed, so closely are they connected that ability to learn has been taken as the chief evidence of the existence of mind; when such ability is absent, mind has usually been considered absent.

Learning signifies the modification of the behavior of an organism in the light of experience. It occurs somewhat in the following manner. The behavior of an organism may fit well a certain situation until the situation is changed in some important detail. Then the customary actions are no longer suitable, and the organism must change its actions to meet the new conditions. When this has been done, something has been learned. It can be seen that it is exactly under these conditions that consciousness puts in its appearance, for here is a new situation and here a "thought crisis" is certain to appear. 
An example of learning in its most simple form is found in the actions of a perch when placed in a tank with a number of minnows. The perch darts after the minnows and devours them according to a deep-seated instinctive tendency. After a time, a glass slide is placed in the tank so as to separate it into two parts. On one side of this invisible partition is placed the perch and on the other side, the minnows. The perch darts at his prey as before, but strikes his nose against the glass. He tries this again and again, with the same unpleasant results. After a while, however, he so modifies his behavior that even when he is in extreme hunger he remains quiet on his side of the partition, for he has learned that his earlier instinctive actions result unpleasantly. This experience has so modified his conduct that even when the glass partition is removed, he remains motionless, while the minnows swim in safety near by. If, however, the perch had continued to dash at the minnows, in no way changing his actions in face of the new situation, we should have considered learning under such conditions impossible.

Modification of Behavior. (a) Through Trial and Error. - Behavior may be changed or modified through experience in several ways. The simplest and most general of these is by "trial and error." The individual attempts to do one thing and does not succeed, then he tries another and perhaps another, so continuing until the proper act is hit on to bring about the desired result. The trial and error may be quite a hit-and-miss process, as it invariably is with lower animals and often is with man. It may, however, be directed in some measure by intelligence, as when a person goes about by trial to find out which one of several possible modes of action will work best. 
An example of trial and error of the former sort, where the action is simply a blind groping, is found in the "maze experiment" in animal psychology. The animal is placed at the entrance of a specially constructed maze, at the center of which is food. The

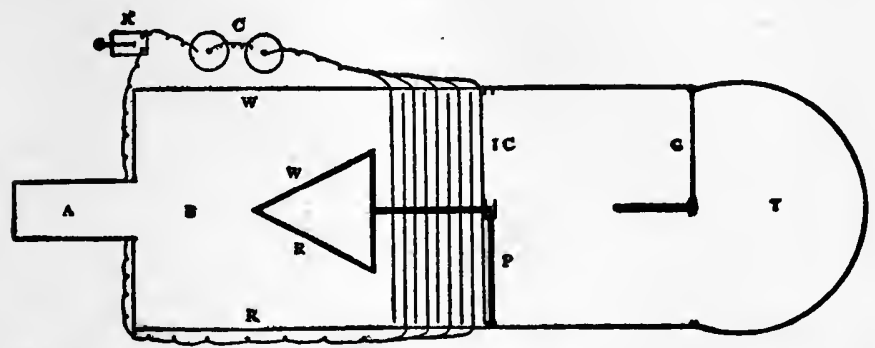

Fig. I.- Simple labyrinth used by Yerkes in experiments with frogs. A, box leading into maze at entrance $\mathrm{E} ; \mathrm{W}, \mathrm{W}$, white card-board ; R, R, red card-board ; P, partition; G, glass plate; T, tank; C, K, cells and key for electric circuit I $\mathrm{C}$ whereby animal received shock on entering wrong passage. (From Washburn, "The Animal Mind," Fig. 14.)

animal, urged on by hunger, attempts to secure the food, moving about in an aimless manner, encountering here a blind alley and there another, until after many failures it finally reaches the center and secures the food. If this test is tried day after day, the animal will sooner or later learn the direct way to the center and secure the food without difficulty.

This purely chance method of learning is not infrequently used by human beings as well as by lower animals. If a person is given a complicated puzzle to solve, he sometimes employs one method and then another, continuing in a quite haphazard way until by chance he hits upon the right one. However, he may restrict his range of trial by studying out the various possibilities and then discovering which will work. An example of trial and error of this latter sort may be found by turning again to the situation described in the first chapter. When I discovered that the boat was sailing directly for the reef, several possibilities occurred as to how best to get out of the difficulty. One plan was to head the boat up and 
sail around the rocks to the windward; another was to let go the "sheet" and try to drift out of danger; and still a third, if these did not work, was to run to the bow and attempt to hold the craft off from the reef with a boat hook. As has already been said, the first of the $:$ attempts failed, while the second fortunately succeeded. This restriction of the trial-and-error process was made possible because of intelligent direction of acts called out by the situation. If a person who knew little about the sailing of a boat had been at the helm, he would have tried blindly, and with no plan, to escape from the danger. If he had succeeded, it would have been solely by a lucky chance.

From the above discussion it is clear that the process of learning by blind trial and error is tremendously wasteful. It must be limited and controlled wherever possible by intelligent direction. The adult must do this for himself, but for the child a large part of this direction must come from parents, friends, and teachers. If the child at school and in the home were permitted to act merely according to his own interests, or according to the necessities arising from his immediate surroundings, he would doubtless stumble on many things of advantage and would learn many satisfactory modes of behavior. This, however, would take a long time, and there would be many mistakes, some of them perhaps serious. Simply because the race has learned largely in this way, it does not follow that each individual should laboriously plod the same path. There will always be some trial and error in all learning, but it is the business of the parent and the teacher to reduce this by pointing out to the child proper methods of procedure, thus relieving him 
trom the necessity of making many failures in learning. when only a few are necessary. It must be remembered, on the other hand, that we all learn by doing, and there will always be a place in the school, as well as in the world at large, for the individual to find for himself just how things work.

(b) Through Imitation. - A second method of learning that has been of great service both to the race and to the individual is imitation. We ordinarily understand by imitation the conscious following of a copy. We see something that we wish to reproduce, and we set about copying it in a more or less definite manner. However, there is a vast amount of imitation that is not of this sort. The individual scarcely knows, or perhaps is entirely unconscious, that he is imitating. At any rate, his consciousness plays no directive part in the process. This imitation has been called, for this reason, purposeless or instinctive imitation. The bellwether jumps over the wall and the entire flock of sheep follow; the leader of the mob starts to run toward the jail where the victim is confined, and the rest, without any resolve on their part, do the same; a boy in the school begins to "pick on " a new pupil, and soon the rest take it up; one pupil in the class raises and waves his hand; in an instant all the others are doing it, although they may not know the answer to the teacher's question and may not really wish to recite.

Another form of learning is closely related to imi- 
tation. It consists in the tendency of the individual to continue the execution of a simple act when once it has been performed successfully. The individual instinctively copies again and again his own movements. This sort of imitation has been termed "circular activity." It is well illustrated by the young child in his acquisition of spoken language. He repeats over and over again some sound that he at first utters quite spontaneously. This explains the seemingly meaningless ma-ma-mas, pa-pa-pas, da-da-das, and other similar babblings of the infant in the second half year of his life. We may look upon this instinctive repetition as nature's provision for that type of learning that in school life we call "drill."

Illustrations of these three levels of imitation may be found in the situation described in Chapter I. We were well on our way on the return trip, darkness had fallen, and the moon was sending its first rays over the hills on the eastern shore of the bay. Save for the splash of the water and the rustle of the cordage, all was profoundly quiet. Just then the stillness of the evening was broken by a ringing, exultant note from my companion, uttered in mere exuberance of spirits, a glad "ye-ho." This evidently was satisfying to him, for it rang out again and again. The cry had no evident purpose save the pure pleasure that it gave. But this called for its repetition. Soon I found myself taking up the cry; yes, literally "found" myself doing this, for I had not the slightest conscious desire to do so; my imitation was purely instinctive. Then my companion changed his cry, introducing a slide and a high note at the end. This I found difficult to follow, and in an instant my instinctive imitation was changed to a conscious attempt to follow him in his vocal gymnastics.

Later in the evening when the boat was in danger, I almost left 
the tiller, partly because of the instinctive tendency, previously discussed, to get away from danger, and partly because my companion, responding to the same instinct, had jumped up and started for the stern, and I instinctively tended to follow his example. A moment later, as I tried to haul the sail close, and as I tugged at the ropes with all my strength, I called, - "Come, lend a hand; do as I am doing!" My companion, springing to my assistance, intentionally imitated my actions.

(c) Through Forming "Free Ideas" - The highest form of learning is found in consciously bringing the past experience to bear on the present. The individual learns how to conduct himself in a given situation. Later a new situation is presented that has elements similar to the previous situation, and knowingly he uses the experience gained in the former situation to aid him in solving the new. He has taken certain "ideas of procedure " gained through one experience and intelligently applied these to the novel conditions in so far as they will fit. When we say that he has an "idea of procedure," we mean that he consciously "knows how" certain things are done. He does not need to begin entirely anew; what he has before done comes to his aid, although the situation is not the same. This ability to apply consciously elements of a past experience to an experience that differs in essential details from the earlier one has been termed by psychologists the power of forming "free ideas." The term "free" indicates that the idea in question has been detached from the situation in which it first arose and can be used under other conditions. 
It has been held by some psychologists that animals lower than man are incapable of forming such ideas. A dog is confined in a "puzzle box." He is tired of confinement, and he is hungry. Food is placed just outside, and he eagerly sniffs it. Then he tries to escape from the box to satisfy his hunger, but to do this, he must turn a button and pull a latch by placing his paw in the loop of a string, running over a pulley and attached to the latch. He makes all sorts of aimless pawings in his efforts to escape, and after a long series of trials and failures at last hits upon the right combination and gets out. His reward is the food. Again he is placed in

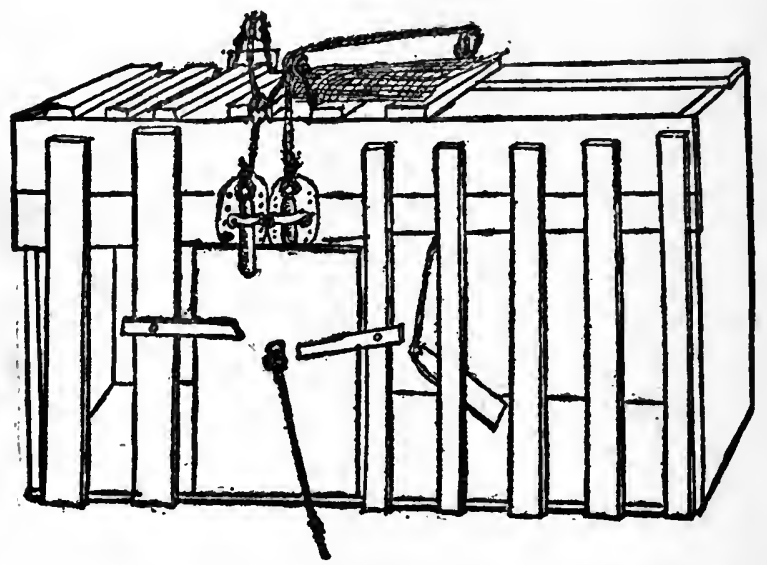

Fra. 2. - Puzzle box used by Thorndike in experiments with cats. (From Washburn, "The Animal Mind," Fig. 17.)

the box under identical conditions, and again he tries to get out. Perhaps this time he does better, because of his previous experience. At any rate, sooner or later he learns to escape from his confinement in a few seconds, effecting his release with no difficulty. Now the combination on the box is changed. The button is replaced by a bolt; the string is removed from the latch, which is now so arranged that it must be pushed up from below. The animal is "all at sea." He must begin again and master the situation anew, and he 
does this in the same aimless way as before, for he has not been able to "abstract" any idea of procedure from his previous experience to apply to the new problem that he must work out.

If a human being were placed in an analogous position, he would probably proceed in a different manner in the face of the changed situation. He has learned to pick a complicated lock; perhaps in the first instance he went about the task in a quite aimless way. Like the animal, he may have finally succeeded purely by a lucky stroke. However, as he becomes more perfect in the manipulation of this particular lock, he gradually acquires the notion of "how it is done." This notion or idea he can recall to consciousness at a later time. Hence, when he is given another lock of a somewhat different make, he sits down and "studies it out" in the light of his previous experience. In this way he greatly shortens the time of picking the second lock. As he has wider and wider experience with locks, he gains greater facility in opening them. The most complicated safety locks are now no longer a mystery, and he may even be able to open the bank safe, the combination to which has been lost. On the other hand, the dog might be "tried out" with all sorts of puzzle boxes and still never get an "idea of procedure" that would apply to such boxes in general. In other words, he cannot take the essential method out of its original setting, and hold it in consciousness as a "free idea."

Let us suppose for the moment that in the danger confronting the boat as it sailed toward the reef, we had been unable intelligently to apply our past experience to the immediate situation. We had never been in the difficulty that now confronted us. It had many new features. However, we had handled boats, and we knew of certain possibilities of action. These were general ideas that we had gained from all sorts of circumstances, and rapidly and consciously we recalled them to con- 
sciousness in the effort to escape from the pressing danger. We had little time for simple trial and error. A mistake might prove fatal. We were obliged to "think," and we could do this only in terms of general ideas gained from our past experience. It was lucky for us that some of these at least had been freed from the particular situations in which they had arisen and were now at our service in the emergency that confronted us.

Trial and Error can be Reduced but not Eliminated. What has just been said emphasizes the importance of learning by gaining general notions or ideas of procedure. There will never come a time when the process of trial and error can be entirely eliminated from our behavior. It must always form a substantial part of our learning. Imitation, too, both intentional and instinctive, is both necessary and desirable. Yet if the human race were limited to these two methods of learning, all higher forms of intellectual life, all important social advancement, would be retarded for centuries, perhaps rendered forever impossible. There would beno place for deliberation, no weighing of possibilities, no argument as to proper methods of conduct. Slowly and laboriously through the maze of the world, with its millions of blind alleys, man would move about. The fortunate discoveries of one generation might be transmitted through imitation to the next, and so all would not be lost; and yet with what infinite pains and at what a cost advance would be achieved! 


\section{Definitions and Explanation of Terms Used}

Learning. - The modification of behavior due to individual experience. Because the individual is confronted by new situations he must modify his behavior to suit these situations. Such a modification must be acquired gradually; this acquisition is learning.

Trial and error. - This term is applied to the attempts of the organism to adjust itself to a situation that presents novel features, when such an attempt is made without a definite idea as to what the result will be. One means is tried and then another, until the proper adjustment is secured. Trial and error may be a completely blind, hit-and-miss procedure, or it may in part be controlled by consciousness.

Imitation. - The intentional or unintentional copying of the behavior of one or more individuals by another. The term "behavior" is used here in its widest sense, and indicates not only specific acts, but also the products of such acts. For example, the movements made in writing are to be considered as acts. The result is the product of these acts. Either the acts, or the product, or both may be copied.

Free ideas. - Notions of procedure taken from one situation and capable of being applied to other situations differing in some measure from the first. The term "free" is used to signify that the idea in question separates itself from the situation in which it was originally 
found, and thus is available for application to other situations.

\section{QUESTIONS AND EXERCISES}

I. In what way is the term "learning" used in this chapter? How does this differ from the way in which you have been accustomed to use the term?

2. When we "learn" a lesson in grammar, is our conduct or behavior modified in any way? How may "learning". history modify conduct? Learning arithmetic? Learning spelling? Learning physiology?

3. What is the relation of consciousness to learning? How could you judge whether an animal possessed consciousness?

4. Find in your own experience an example of the "trial-anderror" method of learning? Why is this sometimes called the "blundering" method? Under what conditions might this method be employed in the school?

5. What is the distinction between instinctive imitation and purposive or intentional imitation? Illustrate from your own experience.

6. What is meant by the "circular reaction"? Why has it been termed "Nature's method of drill" ?

7. What is meant by learning through "ideas of method"? Illustrate from your own experience. In what sense are these ideas of method "free"? Watch the behavior of a dog or a horse, and see whether you can find any evidence that these "free ideas" are utilized.

8. In what sense does "trial and error" still persist, even though "free ideas" are utilized?

9. Illustrate the use of "trial and error" when combined with intentional imitation in such subjects as writing, drawing, and manual training. 


\section{CHAPTER III}

\section{UNLEARNED BEHAVIOR}

IN the two preceding chapters the practical significance of consciousness has been emphasized, - how it appears in the process of learning and how it is made necessary because the individual is confronted from time to time with new situations which must be responded to in new ways. It would be a mistake, however, to assume that all learning is conditioned by immediate practical necessities. It is true that the animal never attempts to overcome a difficulty by the process of trial and error unless that difficulty is actually present and demands instant attention; conscious or purposive imitation arises in response to a felt need of acquiring an adjustment either entirely absent, or imperfectly present; and surely the higher processes of intelligence are employed for the purpose of solving problems or overcoming obstacles. Yet, as we have already seen, instinctive imitation may occur when there is no pressing necessity of action. The sheep that imitate their leader might, perhaps, just as well stay on the other side of the wall; at least the necessity of their behavior is not a necessity for them, i.e. they do not recognize it; the mob that blindly follow' at the sug- 
gestion of one of their number might better disperse and return to their homes; the babblings of the infant, the repetitions of his own vocalizations, serve no immediate practical purpose.

"Unlearned" Behavior and its Significance. - We have, then, in these instinctive and unintentional tendencies to imitate, illustrations of an important principle of learning. Certain actions that are either immediately or ultimately necessary for adequate adjustment, but the necessity for which is not at the time felt by the organism, are provided by nature as a means of better suiting the organism to the conditions under which it must live. Instinctive imitation in the early stages of development is beneficial. Its value may never be recognized by the individual who imitates, yet without this tendency the individual would be seriously out of adjustment on many occasions.

Instinctive imitation may be of practical significance for behavior in two different ways. First, it may be of immediate benefit. When one person starts back to avoid an approaching danger and others instinctively follow his action without knowing why, all are at once benefited thereby. In the second place, this type of imitation may be of value, not for the immediate situation, but because it starts a set of useful acts that will later be serviceable. This latter principle is particularly well illustrated by the self-imitation of the infant, previously discussed. The vocalizations of the little child 
for the time being serve no useful purpose, yet through them he gradually gains a stock of sounds and a control over his voice that are to be of immense benefit in his acquisition of speech. Were it not for these beginnings, seemingly without value, and certainly of no immediate practical significance for the child, he would never learn to talk.

When I first learned to sail a boat, there were many things that I purposely acquired under the spur of an immediate necessity. Their recognized value made me learn them. I remember in particular that this was true in regard to the use of the "centerboard," and I was in imminent danger of upsetting several times before I finally knew just what to do with it. I finally learned under what conditions to lower it and under what conditions to raise it. The same was true about the unfurling and the reefing of the sail, the hoisting and the lowering of the "peak," and so on. Yet I learned the value of many things which I did not at the time recognize and quite without any purpose to learn, as it now seems to me. Some of these were acquired through instinctively following the example of others, when they were sailing the boat. I did things that they did unthinkingly and never knowing exactly why. For example, one of these was the proper way to "come about" and stand off on another tack. I am sure I was never instructed in this, nor do I remember trying to follow the example of others in the matter. I did not knowingly learn the right way of handling the boat in this respect. I simply "drank it in," so to speak, and yet what could be of more practical significance in seamanship? Of course, I might have learned this particular detail in some other way, as, for example, by being told definitely by others, or, after "jibing" several times in a stiff wind and nearly losing the mast, by being impressed with the necessity of coming about in the proper way. The point is, however, that while I did not learn this because I 
had to at the moment, its practical value was for this reason none the less.

Play as a Type of Instinctive Behavior. - The acquisition by the child of spoken language in its initial stages, as has been said, is an admirable example of learning in advance of any necessity that is actually present in the environment. Not only are the babblings of the infant of no significance to him; they are furthermore of no immediate practical value. They do not bring him into better relations with his surroundings; they give no information as to his needs; they satisfy no demands. These instinctive vocalizations may be regarded as a sort of play, since they are quite spontaneous and performed with no other purpose than the immediate satisfaction that the activity itself affords. They, therefore, naturally bring us to the question of play and its value in the process of learning.

Play may be considered as a series of more or less related activities that are performed quite spontaneously and for no other reason than the mere satisfaction that these activities yield. Play differs from work, not in the obstacles surmounted nor in the amount of energy expended, but in the spirit in which it is done. When the immortal Tom Sawyer started out to whitewash his fence, it was work for him. He went about his task with reluctance; he did not want to doit. But he made the onlooking boys think it was a holiday pastime, and they took up the job in the spirit of fun. For them, then, the task was play. It was just 
the same set of activities that it was for Tom. It was their attitude toward the activities, however, that made them different, - that turned them from work to play.

The Value of Play as Preparation for Later Life: Groos's Theory. - For a long time the real significance and value of play were not understood. Because it was mere enjoyment, pure fun, it was regarded as trivial and even unworthy by our Puritan ancestors, and there was little place for it in the home and none in the school. In those days it would have been a rash person who would have advocated it as a means of education. Even when play was not regarded as particularly undesirable, it was generally considered as quite unimportant, the mere expression of animal spirits and excess energy of the individual. Thus it happened that no one knew just what to do with play. Considered either as a necessary evil, at the most only to be tolerated, or as merely the indication of vitality and excellent spirits, no real place was found for it in the world of serious endeavor. The discovery by Karl Groos that play was actually a preparation for the business of later life was almost revolutionary from the standpoint of educational theory and practice.

This new theory in regard to the meaning of play at once gives it a place of high importance in the processes of learning. Watch the kitten as it runs after its tail, or, hiding behind a chair, springs at the rubber ball on the floor, or knocks about a spool of thread; see the puppy 
as it growls and barks at some meaningless object, or as it engages in a mock encounter with its mother or brother. In these activities you can without difficulty recognize many acts that at maturity will be useful to these animals; for they must hunt and fight if they are to survive.

Of similar significance in the human race are the hiding and stalking plays, such games as " hide-and-seek," "puss-in-the-corner," and "prisoner's base." While most of the activities exercised by these games have lost their original value in civilized communities, they might serve as an excellent preparation for war and hunting, the chief business of the savage. Of more importance at the present time in the preparation for life are such games as playing store and house, and, among girls, the doll plays. The last named may be regarded as the instinctive expression of the maternal instinct.

Imitative and Instinctive Plays: Hall's Theory. It is to be borne in mind that, while such plays as those above indicated have as their basis a deep-seated instinct, they are not spontaneous to the same degree as are the plays of animals. Children's games are usually more or less organized in their character; they are to an extent conventional and imitative; they are handed down from generation to generation, the younger children copying the older either purposely or unintentionally. There are, however, children's plays that are less highly organized and which more closely correspond to the play of an- 
imals. Examples of these are the aimless shouting, running, and tussling of little children.

Since such plays as these are of no particular use for the adult in civilized communities, President G. Stanley Hall has advanced the theory that the purely spontaneous plays of childhood are to be considered as activities that, while wholesome and desirable, merely represent at present certain impulses that were necessary to the training of the young under primitive conditions, but which must now be considered as mere survivals of the past, as "vestigial organs of the soul," to use Dr. Hall's picturesque expression. Some of these, like teasing and bullying and fighting, may, perhaps, be worse than useless at present. They are survivals of the brute stage of human life; like the vermiform appendix, they are troublesome, but must be reckoned with. Dr. Hall holds that such barbarous behavior should not be too suddenly repressed. By giving vent in play to these savage impulses, the child frees himself from them in a relatively harmless manner. If, however, these tendencies are too rigorously and suddenly checked, the instincts behind them may, Dr. Hall says, break out in later childhood or in adult life, with serious results. Free play, therefore, even though it be crude and perhaps somewhat savage in character, should be permitted within certain bounds.

Nevertheless, the theory that the child is purely a little savage may be carried to extremes, as it doubtless has been in certain 
quarters. Although "hazing" the new pupil may be quite normal, the teacher must not allow the life of the unfortunate child to be made utterly miserable on this account. An occasional "tussle" in the schoolyard is a "natural" thing; yet the principal cannot permit fighting to become general in the school. We should not, on the one hand, regard with too much concern these savage tendencies in boys; yet on the other we must, as sensible persons, recognize the fact that we are living in a civilized community and that both children and adults must conform to its demands in a reasonable way.

While many of the spontaneous plays of childhood are either valueless or worse than useless as a preparation for life under modern conditions, we must recognize the fact that play, a purely spontaneous and aimless activity as far as the individual is concerned, may be of the greatest practical significance, if properly utilized and directed. Play is no longer to be considered as something trivial and unworthy. One of the greatest achievements of the "new education" is the discovery that the play spirit has a place even in the schoolroom. If the child performs his task, not as a task, but because he likes to, he accomplishes more in the end than if he is spurred on to it by hope of high marks or fear of punishment. When there is pleasure in the work, when it becomes to an extent play, the whole tone of the schoolroom is raised. Pupils stay in school longer and do better work when there is a certain amount of pleasure that comes merely from the work itself.

The Limitations of Play as an Educative Agency. However, like many other good things, this idea of play in school has been carried too far by many enthusiasts. It is true that the teacher should make the school activities as pleasant as possible, but he should not avoid the essential work or make the tasks too easy simply to please the child. It is not true that the child should never 
be forced to do anything that he does not like. He is to be prepared in the school for life. That is why he is being educated. There are many things that he must know if he is to get on. He may not like number work and spelling, but we are not for that reason to allow him to grow up in ignorance of these elements of knowledge. Further, not only is it necessary to teach the child to do certain things that are valuable on the content side of learning, it is also desirable to teach him the value of sacrificing immediate for remote ends. He must do many things in adult life, not because he likes these things, but because the doing of them is bound up with other things that he wants. The mother may not like the drudgery and routine of the household, but she does value an orderly and comfortable home; the business man may not care about adding his accounts, but he does wish his business to be successful. Certain immediate tendencies must be held in check; we must keep our eyes on the "future desirable" as well as have regard for the "present agreeable."

Both in the school and in life, then, we should foster the play spirit whenever possible; we should recognize that anything done is better done when there is joy in the doing; we should, however, never sacrifice the ultimately valuable for that which may give us pleasure for the moment, but which is in the long run of slight significance. The animal acts only under the spur of immediate compulsion. It is the chief distinction of the 
human race that it is able to keep an eye on the future; to sacrifice the immediate for the remote end, - and this is work. Let those who will, advocate the "return to nature," to that state of paradise where all did just as the spirit prompted, without thought, without care. Let us remember, however, that the human race has been ascending through countless ages from this state of animal contentment to a higher plane of thought and endeavor. If we wish to go back, we must accept the consequences and live as the brute lives.

Not only is the play spirit, when held within reasonable bounds, a most valuable attitude for learning, but the organization of certain play activities in the school may be made of service in indirect instruction. Children in the kindergarten may, for example, learn essential facts about color, number, and form, by playing with blocks, balls, and similar toys. In the more formal instruction of the elementary school, similar devices may be employed to advantage to teach indirectly important facts and principles. Such devices naturally suggest themselves, particularly in geography and nature study. The sand pile may be used to represent mountains, the configuration of continents, the nature of river systems, and so on; through the cultivation of the school garden and the observation of household pets and of animals in the "Zoo," valuable information may be obtained in regard to natural history. In the same way the use of charts, lantern slides, the hand stereo- 
scope, and, above all, the moving picture may, as almost pure play activities, yield much valuable information about school subjects.

There is, however, a danger here that should be pointed out. These various free activities and entertaining occupations and amusements should be utilized in the formal work of the school only with a clear idea both as to methods employed and as to results to be obtained. If you send the children to the "Zoo" or the museum, you should send them with an idea of finding out something of particular importance for the school work in regard to the animals and specimens on exhibition. They are not only to see; they are to think as well. The examination of stereoscopic slides and the exhibition of moving pictures are excellent forms of entertainment for children and for adults as well. We could keep our schools and our churches too, full in this way. Pictures are more interesting than the facts of geology or the hopes of a future life. But in education they are not to be used as forms of entertainment solely; they are to be employed to illustrate important and essential facts. If the school is studying about the mode of life among the Eskimos of Labrador, let the children see the stereograms that illustrate the customs of these tribes; if we desire to bring home a clear-cut moral lesson in regard to the value of kindness, let us exhibit a film planned with this distinct purpose in view and executed by players competent to convey the lesson. To permit 
such exhibitions without clear ideas as to what is to be taught and how to teach it, and merely for the purpose of entertainment, is to turn the school and the church into vaudeville theaters, when they should be places of instruction and houses of worship.

Curiosity as an Aid in Learning. - What is true of play and instinctive imitation as means of learning beyond the immediately recognized necessities of the situation, applies to other instinctive tendencies of the individual. Chief among these is curiosity. Curiosity is an impulse to discover merely for the sake of finding out. It seeks knowledge for its own sake and for no ulterior purpose, and is to be contrasted with the tendency to find out facts because we vaguely or clearly realize that by so doing we shall be better aided in accomplishing some purpose that we have in view.

It was for this latter reason that I carefully studied the lights on the bay during the trip from Newport to Providence, previously described. I wished to steer a straight course and was obliged to attend to the lights. If, however, I had been in no way responsible for the safe handling of the boat, if $I$ had been merely a passenger without care or worry, probably I should have looked at the lights in a purely inquisitive way, with no thought of their practical significance. In this way, it is true, I might have gained a knowledge of the bay that would have been of advantage later on. The point is, however, that while for the time being my idle curiosity would have been of no particular advantage, it might have given me a store of possibly useful information for a future need. Indeed, as events turned out, I could but wish that I had had opportunity and desire to employ this idle curiosity on previous trips 
at night on the bay. Then I might not have picked up the wrong light and have suffered imminent danger of shipwreck.

We can see on all sides the manifestation of this tendency of curiosity, particularly in the child. At a certain age the little one asks innumerable questions, not waiting for answers and apparently not consciously caring for them. The small boy investigates all sorts of objects, and his desire to do this causes him to take them apart and even to destroy them, for he is impelled to know just what they are and how they work. This instinct of curiosity is responsible for some of the cruelty that the child unwittingly inflicts on bugs and flies. He does not want to hurt them, but he is impelled by the desire to see how they are put together.

Curiosity, then, gives us a stock of knowledge that some day may be useful, though just at present it may seem dead lumber, which cannot be economically kept in the storehouse of the mind. Indeed, a great deal of it that is acquired in a haphazard way may never be of the least earthly service, such is the prodigality of nature in providing for the future. It is, however, evident that this curiosity, if directed toward the.learning of useful facts, may be of the greatest educational significance. Of course it is just at this point that the wise teacher determines what things his pupils should know, and stimulates curiosity in regard to them by all legitimate means. If the child can only be made to feel that there is something in what he is studying that is 
sufficiently interesting and even mysterious to warrant an investigation, the rest will take care of itself. The average boy is curious enough about electricity to work out its fundamental principles, when once he has been started on the right road; most school girls are sufficiently endowed with a native stock of inquisitiveness to learn about the customs of the early American colonists if they are properly introduced to the subject. We must, in view of these facts, forever give up the notion that the pupil will learn with interest only that for which he sees an immediate and practical use. He will learn much because he likes to learn, simply because he is curious, and if properly controlled this learning may be as practical and useful as any other.

\section{Definitions and Explanation of Terms Used}

Instinctive. - Inborn, innate, unlearned; the term is applied to movements and to tendencies toward movement which are not learned or acquired through experience, but which form part of the inherited endowment of the organism.

Play. - An activity performed quite spontaneously and for no conscious purpose beyond the activity itself. Both curiosity and play have been termed "adaptive instincts," since they provide the individual in advance of any practical necessity with a set of activities that may serve some useful end. Both play and curiosity are 
pleasurable activities, and the spirit that accompanies them is a valuable stimulus to learning.

Work. - An activity not pleasurable in itself, and hence not undertaken for its own sake, but for an ulterior purpose. It has to do with ends relatively remote. In man it is usually accompanied by "active attention," as will be pointed out later.

Curiosity. - An instinctive tendency to acquire knowledge for its own sake and in reference to no recognized practical end.

\section{QUESTIONS AND EXERCISES}

I. In what way may an activity for which one does not see a present practical use be beneficial? Give illustrations of the usefulness of instinctive imitation; of instinctive repetition.

2. Define play. Explain how the playful activities of young animals, such as the kitten or the puppy, may be useful in preparing for the later activities of the animal.

3. What are some of the useful results of play in childhood? Name some common games of childhood (hide-and-seek, prisoner's base, etc.), and show how the movements that these games exercise might have been useful to a man living under primitive conditions.

4. Discuss Hall's theory of play. What games of childhood are important from the point of view of Hall's theory? What should be the attitude of the teacher toward the rougher plays of the school-ground?

5. What is meant by "spontaneous" play? Under what conditions may games that are directed by adults be valuable for children?

6. Under what conditions may the "play attitude" be employed in the actual work of instruction in the school? Give 
illustrations of games that might be employed to advantage in some phases of teaching language, arithmetic, geography, spelling.

7. State some dangers of overemphasizing the play element in education. Can you justify the statement: "The child must often be encouraged to do tasks that he does not wish to do"?

8. What play elements are involved in the educational use of museum materials, stereopticon pictures, the stereoscope, moving pictures, etc.? What principle should govern the use of these materials in the school?

9. Why should playgrounds be supervised by adults?

Io. Define curiosity. Of what value would this "prying" instinct be to primitive man?

II. Give instances of facts that you have learned merely because you were "curious to know." Have any of these facts proved valuable to you later?

I2. In what ways may the curiosity of children be properly and helpfully stimulated in school work? (Take specific subjects such as arithmetic, geography, natural science, spelling, drawing, etc., giving illustrations of useful knowledge that may be gained under the spur of curiosity.)

- I3. Can you think of any circumstances under which curiosity should not be given free scope? In the physical or chemical laboratory, would it be well to let the pupil "pry" into all sorts of things, without some guidance on the part of the teacher as to bow he should go about his investigations? 


\section{CHAPTER IV}

\section{ATTENTION AND BEHAVIOR}

IN Chapter I the fact was emphasized that attention is the invariable accompaniment of consciousness. An absolutely inattentive state of consciousness does not exist. We are merely relatively inattentive. In states of day-dreaming and the like, when our,thoughts are " woolgathering," the crest of the conscious wave is low and broad. Such a state may be described as inattentive in comparison with a state of concentrated attention, when our entire thought is focused on some problem to be solved and when the wave of consciousness may be represented as high and narrow. However, in any state of consciousness there is a degree of concentration and hence at least a minimum of attention. It is further to be remembered that we often speak of a person as being inattentive when he is simply not attentive to a certain aspect of the situation that we think should be emphasized. The man who forgets to execute the little commissions intrusted to him in the morning, is inattentive in regard to these matters, for his thoughts are buried in his business; he may be highly attentive as far as the affairs in the office are concerned. The teacher , says, " Pay attention," when perhaps the pupil is giving 
his very best attention, but not to the lesson at hand. $\mathrm{He}$ is listening to the tune of the street piano outside, or thinking of a ball game to be played after school is over, and his highest attention is directed toward these things.

Definition of Attention. - In attempting to define attention, two questions must be considered: (I) what attention is; and (2) what it does. From the first point of view, attention may be defined as a state of consciousness, certain parts of which are either relatively clear or relatively vivid, while other parts are obscure, unclear, indistinct. From the second point of view - what attention does - it may be thought of as the selective function of consciousness, serving to emphasize certain details and to ignore others. Still we should be careful when we use the term "selection" not to think that this implies some mysterious mental " power." We can mean merely that in all our experience we find certain parts of consciousness standing out clear, or coming before us with an emotional intensity, while other parts are relatively obscure, or without significance. The "choice" that is exercised is that of consciousness itself over the processes that are entering into it or tend to enter in. What is attended to is determined by the purposes, the aims, the interests, the instinctive desires, that exist in consciousness, either dimly or clearly at the given time.

For example, my present state of consciousness decides whether a faint noise that I barely hear shall be attended to or not. If it is of some interest, if it has a meaning and significance, if it fits 
into the purposes that dominate me, then it comes clearly into my experience; if it has no such interest and no such meaning, it drops out. The mother hears the faint cries of the infant in an adjoining room, and immediately she is "all ears," because the sound means something to her; on the other hand, she is but vaguely aware of the fact that a heavy wagon is rattling over the pavement just outside, for this latter noise is of no significance to her at the moment in question. I have a task before me which I wish to finish; it is my purpose to accomplish it, and I refuse to attend to various kinds of distracting experiences, because these do not fit into what $I$ have in mind to accomplish. Hence I do not listen to the band that is playing, nor gaze at the procession that happens to be passing my window at that particular time. But my boy, who is going to the circus in the afternoon, rushes eagerly to the door to look at the parade, for this fits into his particular purposes and agrees with the interests and instincts of the time being.

Kinds of Attention. - It is an important fact to keep in mind that we always attend to those details of an experience that have for us some interest or value. However, this attention may be of two sorts, depending on whether the interest that calls it forth is immediate or whether it is relatively remote. If the object attended to has an immediate value, then we give what is usually called passive or involuntary attention. In this instance the object seems to seize upon the mind, and control it. We cannot help giving our attention. When the mother listens to the cries of the child, she is giving this passive variety of attention. There is no effort on her part; she has to attend, she wants to attend. The same is true of the boy who hurries to the door to see the procession go by. 
However, seated in my study, I am attending to the task that I have before me, not because of its immediate interest, but because of an end that I wish to accomplish. As a matter of fact, I should like very much to go to the window and see the parade myself, but I am kept at my desk because I know that I must finish my work at a certain time, if I am to accomplish what I have set out to do. My mind is on the remote rather than the immediate end. I am not giving passive or spontaneous attention, but active attention. I hold my mind to what I am doing with a certain consciousness of effort. I am aware that I am controlling my own thought processes. They are not being directed from without.

Laws of Passive Attention. - With the little child and with the animal, all attention is of the passive, spontaneous, involuntary type. We start out in life by attending in this passive way to various experiences that have for us some immediate interest. Bright lights, loud noises, and other intense sensations possess originally this power of calling forth attention. They make the infant notice them. We also are interested in this purely passive way in objects in motion. Further, we always attend when there is any marked change in the situation, when it offers novel features, either because something has been added or taken away. In the latter case we attend to that which is absent and recognize it by its lack. We perhaps do not notice the tremor of the boat 
directly, but remember it when the engines have stopped. This is because we ignore the customary and attend to the unusual. Further, we invariably give attention to unpleasant experiences and to our organic needs and wants. If we are hungry or are suffering from a toothache, we are quickly aware of the fact. When the digestive processes are going on normally, we are a.ite unconscious of them, but an attack of indigestion may make us unpleasantiy aware of the existence of a stomach and a liver. Among other experiences that tend to call forth spontaneous attention are those that come in a rhythmic manner. Many a child gives heed to rhyme and jingle when he has no comprehension of, or interest in, the meaning of the stanza of poetry that he is asked to commit to memory.

Consequently we may say that attention of this passive type is given to intense, moving, novel, unpleasant, contrasting, and rhythmic stimuli, and to stimuli arising from the vital bodily functions.

It is also true that, under certain conditions, faint stimuli when oft repeated will force themselves upon attention. This "summation of stimuli," as it is called, really has the effect of intensifying what would $o \%$ erwise be a series of weak impressions. We may not attend io the first cap that we hear on the door, but, if the tapping is long contiruec, the noise forces itself into the center of our consciousness.

The Significance of Passive Attention. - Experience is first built up through these original and instinctive 
tendencies to attend. They may be thought of as racial rather than individual in their character. It can easily be seen that, under primitive conditions of life, the animal that did not attend to intense experiences of various sorts would be likely to be eliminated in the struggle for existence. The very intensity of these experiences is an indication that they are right at hand to be counted with. Repetition likewise indicates that there is something present that is not to be ignored; this is also true of movement. Likewise the new and the strange must be counted with. The young bird at first fears everything; it learns what is safe only through experience. It seems necessary for the primitive consciousness to assume that the new is unfriendly and unsafe until its innocuous character has been established. Unpleasant experiences are usually harmful, and the organism that ignored them would not survive. Likewise hunger and thirst and the other organic sensations represent nature's demands that something be done to satisfy certain organic needs. They must be attended to. Finally, while rhythmic experiences do not in the same way seem vital to life, and while no one knows with certainty the reason why rhythm instinctively attracts us, it is to be remembered that the whole organization of the world, both internally and externally, is expressed in rhythms. Things come and go in a regular order. Night and day alternate, the seasons change, as the earth, circling around the sun, comes back to the same relative position from which 
it started. Within the human body there are also rhythms and periodic changes, some brief and others extending over years. As will be pointed out later in this chapter, attention is itself a rhythmic process. No wonder, then, that rhythm means so much to the race.

So important are these fundamental, instinctive tendencies that they never can be entirely overcome. We attend against our wish to the flashing of the lightning and the crashing of the thunder. The constant drip of the water on the pavement outside our window, we cannot ignore, and it keeps us awake. Some one moves across the room and we turn from our task to look, even against our wish. And so it is with the rest of these tendencies, planted deep by inheritance in our very being and as old as the race itself. We begin life with them; they first build up our world; and, though we may go beyond them, we can never put them entirely aside. Experience has shown that, when other means of calling forth attention fail, these primitive tendencies must be brought into play to assist in directing the mind into desirable channels.

If the child's interests lag, make vivid the object that he is to attend to, and his wandering thoughts will return to their proper place. Emphasize, repeat, reiterate, and gradually the desired attention will be called forth. If the lesson is dragging, do something to awaken interest, even if it is nothing more than to go to the blackboard and draw a diagram. Better still, get the pupils to do something, for there is always interest in self-activity. Facts cast in the form of verse are often more easily learned than when 
presented without such aid. A painful experience is sometimes the only thing to impress the dull mind. It has been found in studying the behavior of animals that they learn more quickly by being punished for failures than by being rewarded for successes. The rat that is learning to thread his way to the center of the maze will get there more quickly, if he is given an electric shock every time he enters a blind alley than if the stimulus of the food solely is relied on. What is true of the animal is probably to an extent true of the child. That is to say, education cannot entirely dispense with pain as a stimulus.

The Law of Active Attention. - As development goes on, these crass and insistent objects of attention lose some of their force and we acquire the ability to attend to those parts of a situation which have in themselves no immediate interest, but which lead to something desirable that is ultimately to be attained. The bank clerk takes no pleasure in adding up the long column of figures, although as a child this activity may have given instinctive pleasure; but he keeps at his task because he desires to be efficient in his calling or perhaps because he hopes that his diligence will secure him promotion. Thus, he gives active attention, and sacrifices the immediate pleasure for a remote end. And this is the fundamental principle of human progress, this ability to hold the attention to that which at present exists only as an aim to be achieved or an ideal to be realized.

An idea of an end to be gained which thus stimulates us to attend to tasks that are not themselves attractive is called an incentive or a motive. 
The Rise of Secondary Passiv. ittention. - At length, however, a change takes place in our mental attitude. In all learning, remote ends are gradually replaced by immediate ends. The clerk first works because of the ideas of the future; at length, he does his task because he is immediately interested in it. His attention is no longer active; it is again of a spontaneous variety. It is an underlying fact of mental life that this substitution is made. Invariably that to which we gave active attention at one stage of our development is finally attended to through "secondary passive attention." Secondary passive attention is like primary passive attention, except that the latter is instinctive while the former has been acquired through a preceding period of active attention. Thus we start out in life equipped solely with primary passive attention; then we acquire the ability to give active attention; this in turn is transmuted into secondary passive attention, and the whole process is begun again. Thus it is that both active and passive attention are necessary to all higher learning and worthy achievement. Neither should be emphasized at the expense of the other.

Rhythmic Character of Attention. - At the outset of this chapter it was suggested that the stream of consciousness may be likened to a series of waves, each with its crest and valley. These waves correspond to the shift in attention, and this rhythmic rise and fall of the attentive consciousness is one of its chief characteristics. 
There are rhythms of a few seconds of duration, others of minutes and even hours; there is also evidence of even more extended rhythms. Thus there are waves within waves, and the conscious stream must be considered as extremely composite.

A simple experiment will convince us that it is impossible to keep the mind concentrated upon any one object, or upon a single phase of a situation for any length of time. If we try to look continuously at a spot on the wall, it will after a short period become blurred and indistinct, and we can get it back into clear vision again only by winking or by momentarily shifting the gaze. If a watch is removed to the limits of audibility, i.e., to a point where we can just barely hear its ticking, the sound will be distinct for a brief interval; then it will "die out"; after two or three secn ${ }^{-}$it will again be heard; and so on. These periods of audibility and silence are fairly regular in their occurrence, and correspond to the fluctuation of attention. Objectively considered, the watch is ticking all the time with the same degree of intensity. When we fail to hear it, it is because our attention has "let up" for the moment. What is true of physical objects of attention is likewise true of ideal objects. If the thought that we are turning over in our mind is relatively simple, we can hold it in attention for only a relatively brief period.

Variety in Unity the Secret of Sustained Attention. It seems certain that the more complex a physical object, or the richer in content an idea, the longer attention of $a$ sustained character can be given. The application of this principle to school procedure is obvious. If the teacher wishes a topic to be held in attentive consciousness by the pupil, he must develop it in a variety of ways. When the attention "lets up " in one direction, it will then focus 
itself on another detail of the topic, and thus the mind will be constantly held within the circle of the subject under discussion. This in part explains the growth of attention and interest as the pupil learns more and more about any of the school subjects. There is always a new aspect that can be attended to when there is sufficient variety in the subject matter. It should be kept in mind, however, that, if progress is to be made in learning, this variety must be a variety of related topics. The various aspects of the study must be organized in such a way that they form one coherent whole.

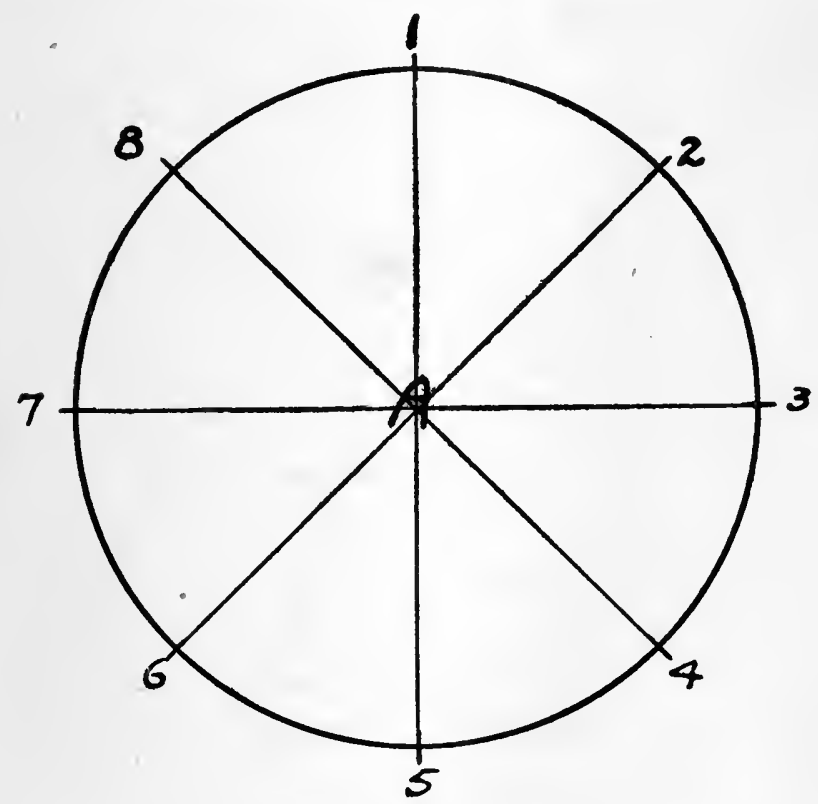

Fio. 3 . 
The accompanying diagram will illustrate the principle here involved. The circle may serve to represent a complete topic or subject of study. This topic centers in the central idea, "A," and there are various divisions or phases of it, as indicated by the numerals just without the circumference. As the attention turns from one, it falls upon another, but it does not wander away from the topic, since all the parts are related. Thus nothing is actually lost in the fluctuation of attention under such circumstances. It is evident, however, that if the various subtopics were not definitely related, the normal fluctuation of attention would be disastrous to a genuine comprehension of the subject matter.

Attention and Fatigue. - What is often thought of as fatigue is really a form of the fluctuation of attention. After the mind has been busy for some time on a mental task, attention decreases, not because there is genuine weariness, but because the individual gets " tired of" the task. The remedy for this ennui is obvious. On the one hand, genuine interest in the task must be increased, and, on the other hand, the pupil must be accustomed to ignore those distracting influences that in a short time set in to make mental work distasteful and to lure him away from it. When a task is undertaken, it is usually approached with a degree of reluctance. The mind requires a short time to get " warmed up," so that attention can be properly concentrated. This "warmingup process" takes a longer time with some individuals than with others, but it is present with all.

The Conditions of Effective Work. - For this reason the first stages of the task should be made as clear and interesting as possible. Above all, the pupil should be, made to real- 
ize that he should never yield to the initial lack of interest and that he should cultivate in his school work the ideal of settling down at once to aggressive effort on a given task. Often half of one's time and energy is wasted in " the agony of starting." After the warmingup stage has passed, most of us continue to work steadily for a longer or shorter period. If we learn to ignore distractions and are thoroughly interested in what we are doing, we may continue to hold our attention on our task and to keep our interest alive until really fatigued or "worn out."

Obviously this period of effective mental work varies with the disposition of the individual and with his age. Young pupils cannot, as a rule, work uninterruptedly so long as can older pupils and adults. School children should, however, be encouraged to keep at their study over a considerable period, and not think that because they have worked fifteen minutes or even an hour it is time to quit. We often get the idea that we have worked long enough, and then we begin to feel fatigued. There is little danger of the normal child seriously overworking in school. Authorities are at present of the opinion that dangerous fatigue among American school children is rare.

How Many Objects can be Attended to at Once?The question of the span of attention, i.e., of the number of objects that can be held in the mind in a single moment of attention, is not altogether settled. If a 
person is shown a number of dots for an instant, he will be able to recognize five or six correctly. Above that, he becomes confused; and if the number is to be known accurately, the dots must be exposed long enough to enable the observer to count them. If, instead of dots, characters differing among themselves are shown, one can grasp a smaller number in a single instant, particularly if they are unfamiliar. One can recognize more letters of the Roman alphabet, or more numerals, than Chinese characters, and one can distinguish more letters when they spell syllables and words than when they are unrelated. In general it may be said that surprisingly few elements can be recognized in an instant of attention unless they are in some way joined together in a significant whole. This fact once more emphasizes the importance of organizing and relating to the greatest possible extent all parts of the materials of instruction.

Attention and Behavior. - Up to the present point in this chapter, attention has been considered solely on its subjective side, i.e., from the standpoint of its conscious aspects. Equally important is its consideration as an aspect of behavior. It is to be remembered that we interpret attention in others through their behavior. Further, effective conscious behavior is always conditioned by properly concentrated attention. If we watch a dog that is trying to open a puzzle box, we shall observe that his relative lack of success is due largely to his inability to keep to his task. He attacks it vigorously for 
a moment, then perhaps he gives it up entirely for the time, to renew it later in the same haphazard and desultory manner. Every teacher in the primary grades must be impressed with the fact that one of his chief problems is to secure sustained attention. The little child, both in his work and in his play, resembles in his behavior the lower animals. He cannot keep at one thing for any length of time. Defectives and, in general, weak-minded individuals, show by their actions how difficult it is for them to give attention to anything for more than a brief moment. It is the mark of a developed mind to be able to stick to a difficulty that one is attempting to master. When the attention is firmly fixed on the end in view, and when it is consistently held to that end, the behavior is definite and works out in a practical way. All complicated modes of behavior are conditioned in their effectiveness by sustained and well-organized attention.

The Bodily Attitude in Attention. - Not only is conscious behavior conditioned by attention, but attention is aided by the proper sort of bodily attitude. We must look at an object, if we wish to find out what it is, and looking means not only that our eyes are turned in the right direction, but that we sit or stand erect and hold our heads properly. We cannot give a maximum of attention unless our bodies are in the proper posture. This applies not only to physical objects, but to thought objects as well. A listless attitude may or may not be hygienic, but it certainly is not conducive to effective 
study. The teacher is right in demanding that his pupils sit at their desks properly, that they stand erect and move about with energy. In fine, not only does a proper attitude mean that the attention has been properly secured, but also that it will be properly secured. In other words, attention is so closely related to effective behavior that the presence of one necessarily means the presence of the other. The behavior may be the result of the attention, or equally well the attention may be the result of the behavior, and thus it happens that the teacher may secure attention by insisting that his pupils assume the attitudes and perform the acts that are the natural accompaniments of well-concentrated and adapted attention.

\section{Definitions and Explanation of Terms Used}

Attention.-A state of consciousness, one part of which is relatively clear or relatively vivid, while the other parts are relatively obscure.

Varieties of attention. - Passive attention is a state of consciousness in which the object attended to claims the entire interest. There is no sense of effort, no tendency to turn away from the object in the focus of consciousness. All attention is originally passive. Active attention is accompanied by a distinct sense of effort. This form of attention is given when immediate interests tend to lead us away from the object attended to. In this form of attention, remote rather than immediate ends 
are-held before consciousness. Secondary passive attention resembles primary passive attention in that it is spontaneous and without effort. On the other hand, secondary passive attention has been developed from active attention. It is acquired, not inborn.

Incentive or motive. - The idea of an end or goal which impels one to active attention; which impels one, in other words, to sacrifice the immediate for the remote.

Fatigue. - Mere lack of interest and ennui must be distinguished from actual fatigue in the sense of exhaustion. A large amount of so-called mental fatigue is of the former sort. Few school children suffer from injurious fatigue.

Fluctuation of attention signifies the rhythmic character in which attention manifests itself ; now a certain aspect of consciousness is emphasized, now another.

Span of attention. - This refers to the number of distinct objects that can be grasped in consciousness in any one moment. When such objects are similar and are joined in a significant whole more can be grasped than when they are relatively unorganized.

\section{Questions AND Exercises}

I. Illustrate from your own experience how attention selects and emphasizes certain elements of consciousness. Fix an object in your attention; note some of the differences between your consciousness of the object attended to and your consciousness of the objects of which you are still aware, but not attentively.

2. Note during a period of five minutes the different objects 
and ideas that you attend to. Determine as far as possible why attention is given to these objects and ideas rather than to others.

3. As you are working on some definite problem, note the objects and ideas, unrelated to the problem, that tend to distract you. Can you tell in each instance why these tend to attract attention to themselves?

4. Note in a schoolroom or at church the factors that seem to distract the attention of a number of persons from the exercises in hand. Can you tell why these elements distract?

5. Make a list of the stimuli that appeal to primary passive attention.

6. Illustrate the useful employment of primary passive attention in the school.

7. Define active attention. Find illustrations in your own experience. Why is it difficult to give active attention?

8. In what way is the ability to give active attention the condition of human progress?

9. What is meant by secondary passive attention? How does it differ from primary passive attention? From active attention?

ro. Can you find an instance in your own life where a permanent and valuable interest has been developed without passing through a stage of effort and struggle, - that is, through a period of active attention?

II. Name some more or less "remote" ends that have, in your experience, governed active attention. Is the idea of an examination a more effective "incentive" to active attention than the idea that a study may be helpful to you in later life? Which is the more effective as an incentive with you, the hope of some reward or advantage to be gained from effort or the fear of some punishment or disastrous consequence of not putting forth effort?

I 2. Name some incentives that you consider legitimate to utilize in schoolwork as spurs to active attention. Name some that you believe to be dangerous or undesirable. Give reasons for your choice.

I3. Can you find in your daily experience illustrations of 
rhythms or fluctuations of attention? Fixate some object and try to hold it in attention just as long as you can. Have you attended in this case to one single aspect of the object for the entire time? Describe as accurately as you can what has gone on in your consciousness during this act of attention.

I4. What steps may the teacher take to utilize the rhythms of attention?

I5. What is meant by the "span" or "range" of attention? What suggestion can you find for teaching in the fact that we can attend to a wider range of objects when they are related or organized than when they are unrelated?

I6. Test in your own experience the statement that an appropriate bodily attitude aids in concentrating attention.

I7. Make a note of some of the bodily attitudes that pupils assume which are not conducive to school work. What sort of attitude should the pupils have while studying in their seats; while standing to recite; when passing to the board ? 


\section{CHAPTER V}

\section{BEHAVIOR AND THE FEELINGS}

IN an earlier part of this discussion the rôle that the feelings play in consciousness has been referred to. The present chapter will consider more in detail the nature of the feelings, both in their simple and in their more complex forms. The term "feeling" is used rather indefinitely both in daily life and in the discussions of the psychologist. In the present discussion it will be employed, in accordance with the best usage, in a more restricted and definite sense. By it will be understood what is technically known as " affection."

The Nature of Feeling or Affection. - The affective aspect of consciousness is that which gives value or worth to an experience. I not only know something, but I am affected in a certain way as well. I look at a bright and rich color. I recognize it as a gorgeous purple and at the same time I experience pleasure in seeing it. I learn of the death of a friend and, in addition to my knowledge of the event, I feel sorry. We not only know the events in the life of Abraham Lincoln, but we admire the man that lived this life. The feelings give the personal "tone" to our consciousness; they touch what would 
otherwise be the indifferent grays of the pictures of the mind with bright or with somber hues. Without feeling, life would be devoid both of pleasure and of unhappiness; joys and sorrows would vanish, and good and bad would be meaningless terms. Experience would be bereft of all human values, and we should gaze with the eye of calm indifference on the unfolding of the world's events. Nothing would make a difference, for we should not care. The most trivial event and the most terrible catastrophe would find us alike unmoved.

It would seem then quite necessary that feeling, like attention, should be a characteristic of all of our conscious experiences, and hence a mental state that is not in some way colored affectively is an impossibility. It is true that many psychologists hold that there are numerous mental states that are "indifferent," or unaccompanied by affective elements. The fact seems to be, however, either that such states are relatively not rich in feeling, or that certain aspects of them are indifferent, while others have a feeling value. In any case, feeling is so definitely related to conduct that, for all practical purposes, we may assume it to be an invariable ingredient of conscious states.

Affection as an Element of Consciousness. - Affection or simple feeling, like sensation, which we shall discuss later, is a fundamental element of consciousness. It seems never to occur alone, but always in connection with some sensory experience, and its function is to in- 
dicate the worth of that experience, - whether it is "good" or "bad" for the organism.

Feelings vary in two ways. They are either pleasant or unpleasant. The earliest and most fundamental form of unpleasantness is that which accompanies the sensation of pain.

Pain, however, is not to be used as a synonym for the unpleasant, since the word "pain" is used in psychology to designate a distinct type of sensation. There are also many unpleasant experiences that are only painful in a figurative sense, and, further, certain mild pains of short duration may be not only not unpleasant, but slightly agreeable. However, pain may be considered for practical purposes as unpleasant. On the other hand, there seems to be no sensation that is as uniformly pleasant. Even such experiences as tickle, while generally agreeable, may become, if intense enough, or if long continued, unbearable.

The Function of the Unpleasant and of the Agreeable. - Unpleasant experiences may be taken as indications that the organism possessing them is in some way out of adjustment with its environment. They demand that a change be made, that a better adjustment be secured. On the other hand, pleasure would indicate a satisfactory adjustment. Since, however, a satisfactory adjustment, particularly if continued for any length of time, means a loss of consciousness, it would seem that an original pleasurable experience would be practically impossible; a state of well-being would be accompanied at the most by the vaguest of conscious states. States of pleasure occur in their clearest form as antitheses to previously 
unpleasant states. They come to stamp with approval behavior that has resulted satisfactorily. They tend to continue, at least until this behavior has been permanently established.

Affection and Efficiency. - Pleasurable experiences raise the tone of the organism; there is a more intense vitality and correspondingly greater possibilities of accomplishment. On the other hand, the unpleasant is depressing in its effect; it lowers vitality and generally reduces efficiency.

Not only do the pleasant and the unpleasant have marked effects on bodily conditions, but likewise the bodily condition works directly to produce states of agreeableness or disagreeableness. A piece of bad news may bring on an attack of indigestion, while equally well a digestive disturbance may cause a period of mental depression. It can easily be seen from the above that pleasure considered in its immediate results is always good and the unpleasant is always bad. However, since the latter serves as a warning and ultimately may lead to a better adjustment, it has its place and justification in the scheme of things. Without it the race would long since have perished. It is also true that certain forms of behavior that were "good" for the organism living under primitive conditions are no longer "good" when the conditions of life have been modified. The "pleasant" continues to attach to them, however, and the "unpleasant" similarly attaches to forms of behavior that 
were once ineffective or dangerous, but are now perhaps effective and valuable.

We may lay down the general principle that necessary unpleasant experiences should never be avoided, while pleasures that lead to no harmful results should be encouraged. Pleasure is often to be justified as an end in itself, the unpleasant never as an immediate end, but only by its ultimate results. The misdirected sympathy which would eliminate all unpleasantness from an imperfect world that demands the directive influence of pain and suffering is misguided; but no more so than the harsh Puritanism that sets a value on the hard aspects of life, apparently for the sake of the unpleasantness that they bring into being. It is a safe maxim for both the teacher and the parent to follow, - "Surround the child with all the pleasurable experiences, all the happiness possible, to the end that his accomplishment may be great; but never hesitate to bring the unpleasant into his life if, by so doing, a permanent good may be accomplished."

Complex Forms of Affection: the Emotions. - The simple affections of pleasantness and unpleasantness, as they develop in the experience of the individual, are worked over into more complex affective states, of which the emotions are the most striking and the most important.

We all recognize that there are in our lives two kinds of experiences. For the most part, our conduct is ordered on a routine plan. We meet the ordinary situations of life in a conventional manner. It is true that we 
solve new problems, and deal with situations that are somewhat novel ; but, in general, we live the customary, humdrum life of civilized society.

But, standing forth clear and sharp against this background of the conventional, are the periods of storm and stress, - great crises, marked by intense, though confused, mental activity; by violent, though abortive, bodily expressions. Our lives are no longer calm and placid. The customary channels of habit and thought are blocked. Turbulence and confusion reign supreme; and from these storms, the individual may emerge, as it were, into a new world, his mode of life transformed, his standards and sanctions set anew, his perspective readjusted, and his vision clarified. These are the moments when we are paralyzed by fear, overwhelmed by anger, thrilled with joy, bowed down in grief, exalted with elation, surcharged with sympathy, maddened with hate and malice, deadened by despair, rejuvenated by hope, or awed with reverence. And to these turbulent experiences the name "emotion" is applied.

Characteristics of an Emotion. - The emotions have been considered in different ways by different writers in psychology. Some regard them as intensified feelings feelings that stir the individual profoundly and leave his mind in a state of turmoil. There is a certain justification for this view. It is a common experience that anger and fear, for example, when at all intense, quite upset us.

Other psychologists emphasize the strong instinctive 
basis of the emotions, and hence regard them as native or inborn feelings. Here, again, there is a truth. Any one of the human instincts may work itself out in strong emotional expression under certain circumstances. An instinct when checked in its normal expression always sets up a disturbance in consciousness and in the behavior accompanying it, and this disturbance is clearly an emotion. But an acquired desire, when blocked, may also give rise to an emotional disturbance.

Again, it has been pointed out that in an emotion there is always some object that is related to it, while in simple feeling no such object need be present. I may feel unpleasant without being aware of any object to which the unpleasantness attaches itself, but if I am angry, I must be angry at something, if I fear there must be something that is connected with this fear.

The necessity of an object toward which an emotion is directed is well illustrated in the case of certain mental diseases that have marked emotional accompaniments. The patient is in constant terror, for example, and yet there is nothing in the external world that should arouse this terror. It is the invariable case, however, that the person afflicted finds something in his surroundings that he fears. Otherwise the emotion could not complete itself. His mental condition arouses a complex feeling state, which becomes a genuine emotion only when there is a fancied object to which the terror attaches itself. When there is no object, there is in the proper sense of the term no emotion. We cannot therefore properly speak of instinctive fears or angers, since at the beginning of life there is no known object that is to be feared or hated. It is only as experience grows that these instinctive tendencies become attached to objects and actual emotions are set up. 
The James-Lange Theory of Emotions. - An important theory in regard to the nature of the emotions was set forth in its original form by Professor James more than twenty-five years ago, and later elaborated by him. Similar conclusions were reached independently by Carl Lange, a Danish psychologist, at about the same time, and hence this theory is known as the "James-Lange theory." It is based on the recognized fact that in emotions of any intensity there is a strongly marked accompaniment of certain bodily sensations, such as trembling of the knees, chills running down the spine, "goose flesh," palpitation of the heart, a sinking in the stomach, and the like. These bodily sensations were formerly thought of as the result of the emotional excitement, but according to the James-Lange theory they are rather the cause. They constitute the very essence of the emotion, - in reality are the emotion. According to James, they form the substance of all the emotions, not only of the grosser ones like fear and hate, but also of the more exalted, such as the religious, the moral, and the æsthetic. This theory has caused a great deal of discussion; but while many psychologists would, be unwilling to go to the extent of saying, as does James, that the sensations accompanying these bodily changes are the emotion, most would agree that they constitute a very important and probably an indispensable element in our emotional experiences.

Behavior and the Emotions. - The most helpful 
point of view from which to regard the emotions is not from any one of the standpoints discussed above, however, but from the standpoint of the behavior accompanying emotional expression. It is doubtless true that with the emotion there is to be observed an intensity of feeling; that emotions have a marked instinctive basis; that they always relate themselves to some object that is regarded as arousing them, and that they are accompanied by sensations of bodily excitement. More important than all these, however, is the fact that an emotion never arises except under conditions of unsatisfactory and incomplete adjustment.

In an earlier part of the present chapter it was held that unpleasant feelings were the accompaniment of unsatisfactory adjustment, i.e., of behavior that did not work out in such a way as to bring the organism into entire harmony with its environment. Mere unsatisfactory adjusiment, however, does not give rise to an emotion. There must be added the fact that the behavior is not sustained in any one direction for any length of time and that it is incomplete in the sense that it fails to attain any result, whether pleasant or unpleasant. There is more or less suspense in behavior under the stress of the emotion. It is uncertain and fluctuating. There are rapid shifts in attention and, connected with this, relative confusion in the thought processes.

Confused Thought and Abortive Movement Characterize the Emotion. - It is a fact that has. long been ob- 
served that emotion is opposed to clear thinking. It is likewise true that it is at variance with the certain and sustained execution of any act. If the person under the influence of the emotion can only succeed in doing something definite, the emotion will tend to disappear.

Clear Thought and Definite Action Kill the Emotion. - That is why the expression of an emotion tends to drain it off and restore the individual experiencing it to a calm state of mind. This view of the emotions helps to explain the feelings of bodily disturbance accompanying them. The intense feelings for the time being are unable to work themselves out in proper behavior, and there is a discharge of nervous energy throughout the entire body, setting in commotion heart and lungs, upsetting circulation and digestion, making the body tremble and the very hair stand on end. Perhaps some one insults me and I am so wrought up that I do not know what to do for the moment. I cannot adequately deal with the situation. An intense feeling of rage possesses me; deep-seated instincts harking back to the primeval jungle surge through me, as I shiver and thrill with the ebullitions of my passion. Then I strike out at the object of my rage at first blindly, but later perhaps effectively; and, as I become master of the situation, my emotion vanishes. Or perhaps I yield to less savage instincts, and master the situation with the thoughts of my superiority over my aggressor, and so turn away with a smile 
of contempt on my lips. Whatever happens, however, $I$ do not rid myself of the emotion until in some way by a definite act or by a train of ideas that stand for acts, I become master of the situation, and happily or unhappily cope with it.

The significance of sustained and definite behavior in the presence of a complicated situation, in preventing or in working off an emotion, may be further illustrated by the following example: An Atlantic liner encounters a fearful storm, and there is great danger that the vessel may be lost. There are brave men among the passengers as well as among the officers and crew, yet the latter remain calm, while the passengers are on the verge of a panic. The captain on the bridge knows equally as well as the merchant in the cabin what the storm means, but the captain is without emotion, as he firmly issues his orders, while the merchant is so nervous that he cannot follow the hand at cards which he is playing. The difference in the conduct of these two men is to be explained largely by the fact that the officer on the bridge is doing something to help the situation, while the man below deck is helpless. He has no effective mode of action to meet the situation, hence his strong feelings discharge themselves ineffectually and fill him with emotional excitement. If he could do something, he would at once become a brave man. Effectual doing always removes fear. It takes a hero indeed to remain quiet under the fire of the enemy. It is easier to be brave when ordered to charge the enemy even in the cannon's mouth.

Situations suddenly Presented may Cause Emotions. - It is important to remember that the situations in which the individual finds himself incapable of any sustained and effective action are those which come upon him suddenly and develop rapidly. He has not had time to prepare for the emergency, to devise plans and think 
out methods of meeting them. If they had grown up gradually, he would not have been so overcome when actually confronted with them.

Emotions may be Aroused by Imagined Situations. It further should be borne in mind that the situation need not be really present, but may exist oniy in imagination. While in the latter.case the emotion is generally weaker than if the conditions for its arousal were present objectively, still it may reach an appreciable intensity. Fear of something that may happen, doubt as to the outcome of a course of events whose end is merely imagined, may become very disturbing. Another fact to be kept in mind is that I may not be confronted with a situation to be dealt with personally, but that through imagination I may place myself in the position of some one else and thus experience in sympathy an emotion, although the event does not in any way concern me, and even though I have no personal interest in the individual whom I picture as confronted by the imagined difficulty. Thus through the mechanism of imagination the scope of the emotions may be greatly extended and a person may experience in an ideal world these situations that call forth emotional experiences.

This possibility of experiencing an emotion imaginatively or vicariously is of fundamental importance in education. As will be pointed out in a later section, the most profound lessons of human life have been wrought out of emotional experiences, and since it is one important duty of education to conserve and transmit these lessons, it is fortunate that the experiences can be effec- 
tively re-lived by each generation. The art of the poet, the dramatist, and the novelist centers upon this problem ; and the function of literature in education is primarily to insure in the pupil an emotional reaction which will leave as a residuum certain of the great ideals which constitute the most precious part of our heritage from past generations.

Summary: Definition of Emotion. - In accordance with the various facts emphasized in the foregoing pages, we may define an emotion as a complex state of consciousness of high affective coloring, involving an intellectual and a will attitude; appearing under sudden stress in a rapidly developing situation, either actually present or ideally represented, to which situation adequate adjustment is temporarily blocked; and accompanied by bodily sensations of considerable intensity. In this statement are embodied the facts: (I) that an emotion always has strong feeling elements; (2) that there is a recognized object toward which the emotion is directed and in the presence of which some activity is demanded; (3) that there is always a difficulty to be faced and that this difficulty is suddenly presented to the individual; (4) that the emotion may be the result of a situation not concretely present but brought up through imagination; (5) and finally that the organic sensations accompanying the emotion are important elements in it.

A Mood as the Residuum of an Emotion. - When the emotion has run its course, there is often left a permanent residue, a long-continued affective coloring to consciousness, that may be designated as a mood. This mood 
may be vague and uncertain as far as its object is concerned, or definite and clear. In the latter instance it may be termed an "emotionalized prejudice"; that is, a predisposition to act in certain characteristic ways in the presence of an object around which center marked feeling values. Prejudices of this sort are easily found in politics, morality, and religion. When once formed they are extremely difficult to overcome.

Not only may a mood be the result of an emotional upheaval; it may become the starting point of a new expression of the emotion. Fits of anger often leave a tendency to become angry again on the slightest provocation, while a joyous overflowing of spirits leaves a feeling of happiness that readily again finds emotional expression when the least opportunity offers.

Temperament. - Permanent inborn tendencies that characterize the emotional attitude of an individual are called temperament. The four traditional temperaments, which still to an extent are recognized by psychologists, are the sanguine, choleric, melancholic, and phlegmatic. The sanguine and the choleric temperaments are easily excited, though the latter is much more vehement in its expression than the former. Both the melancholic and the phlegmatic are slow in action, but the melancholic is weak while the phlegmatic is strong. This classification may be considered as a general sketch, rather than an exact statement of temperamental differences. 


\section{Definitions and Explanation of Terms Used}

Emotion. - A complex state of consciousness of a high affective coloring, involving an intellectual and a will attitude ; appearing under sudden stress in a rapidly developing situation, either actually present or ideally represented, to which situation adjustment is temporarily blocked; and accompanied by bodily sensations of considerable intensity.

Feeling is used in this discussion as identical with affection. It has been previously defined (see Chapter I).

Mood. - A relatively permanent state of mind that results from a previous emotional experience, or serves as a predisposition for another emotional outburst. Unlike the emotion, the mood is sustained and consciousness is not in a state of turmoil.

Temperament. - An inborn affective attitude that resembles a mood in many respects, but is more permanent and fundamental.

\section{QUESTIONS AND EXERCISES}

I. Distinguish in your own experience the sensory and affective elements. What colors do you like best? What colors do you find unpleasant? What colors would you describe as "indifferent" from the affective point of view? Arrange the colors of the spectrum (violet, blue, green, yellow, orange, and red) in the order of their affective value to you (that $\mathrm{Is}$, in the order of their pleasantness). Would you characterize the odors of the following substances as pleasant, unpleasant, or indifferent: tar, rose- 
water, camphor, musk, coffee? What, to you, is the affective value of the taste sensations - sweet, sour, salt, bitter?

2. Can you find in your experience an instance of a "pleasant pain"? Give instances of sensations ordinarily pleasant in their tone that may, because they are too intense or too long in duration, become unpleasant.

3. What is the relation of affection or feeling to behavior? Under what conditions should unpleasant experiences be avoided? Under what conditions should such experiences be sought and encouraged? What is the function of pain and suffering in life? Some one has said that pain has been the "schoolmaster of the race"; can you justify this assertion?

4. What are the important differences between the simpler forms of feeling or affection on the one hand and emotion on the other hand? Can you recall from your own experience marked instances of anger, fear, joy, or griei ? Can you find an example of an emotion that was not directed toward an object?

5. Give a statement and an illustration of the "James-Lange" theory of emotion.

6. Revive as far as you can the experience of a pronounced emotion. Can you justify from this experience the statement that emotion is opposed to "clear thinking"? What was the effect upon the emotion when you acted in a definite way with regard to its object?

7. What situations arouse emotions with you? Will the idea of the situation arouse a similar emotion? In what respect does it differ from the emotion aroused by the "real" situation?

8. Compare the emotions that you experience when you witness emotion in another person and the emotions that you yourself have in confronting the same situation. (Take, for example, witnessing a burst of grief or of anger in another person.)

9. What is meant by a mood, and how does it differ from an emotion? (Compare in your own experience the mood of happiness that follows from a pronounced emotion of joy with that emotion; or the mood of sorrow with a pronounced emotion of 
grief.) Can you find instances of alternating emotions or moods - joy with grief, sorrow with happiness, etc.?

Io. What is meant by "temperament"? Name the four temperaments that have been recognized by psychologists.

II. Can you assign to any of your friends or acquaintances characteristic temperamental differences? Do you know persons who are generally hopeful and light hearted; others who are "moody" and depressed; others who are prone to anger, and still others who are not easily moved, who "take life as it comes"? Are these moods and temperaments due largely to external circumstances, as far as your observation goes, or are they principally caused by the way in which the individual looks at life and feels toward it? 


\section{CHAPTER VI}

\section{THE PRACTICAL SIGNIFICANCE OF THE}

\section{AFFECTIVE LIFE}

THE importance of the affective life to behavior has been pointed out in the preceding chapter. In the following pages this relation will be more definitely considered and further amplified. As has already been said, the great service of feeling is that it stamps with approval or disapproval any act of the individual, and thus tends to confirm and perpetuate such an act, or to prevent its repetition. Thus certain modes of behavior are finally considered desirable or the opposite, according to their pleasurable or unpleasant results.

Affection and Attention. - The affective coloring makes it possible to hold a remote end of action in the mind in the face of immediate inclination. An end of action that had no feeling value could never dominate an individual, and hence sustained attention would be impossible in such cases, and behavior would be reduced to the level of instinct and habit.

I should not have remained at my desk when I heard the music of the circus parade, had not the end that I was working toward been tinged with a strong desire to complete my task. The child in school will not steadfastly pursue a distasteful lesson, 
except under the influence of some end that he wishes to gain, either in the shape of securing a reward or avoiding a punishment. The matter of feeling or affection is, therefore, just as important in active as in passive attention; but in active attention the affective coloring attaches to the idea of the end, while in passive attention it attaches to the immediate activity.

It should not be inferred, however, because remote ends of action are held in attention through the pleasurable affective tone accompanying them, that the pleasure as such is the end of the action. Generally the person does not consider definitely whether the attainment of a desired end will bring pleasure or its opposite. The pleasure is not the purpose of the activity; it is merely the accompaniment of activities that on the whole are desirable.

The boy who is holding in his mind the proposed ball game at the close of school, is not thinking of the pleasure that he is to experience, but of the details of the game. He gets pleasure in imagining these, it is true, but his thoughts are centered in the activity, and are not rehearsing the pleasure as such. It is true that if he did not get pleasure out of the game, he would not continue to play it or to think about it; the activity would not occupy his attention to the exclusion of his studies, nor engage his interests in any way, but this does not mean that he is thinking of the pleasure when his mind is on the game.

The Importance of Insuring Pleasurable Outcomes. This distinction between pleasure as the conscious end of action and pleasure as the accompaniment of desirable ends or actions is important from a practical standpoint. Acts that are to be repeated, ends that are 
to be achieved, and behavior that is to be confirmed, should be made as pleasurable in their consequences as possible, but little should be said about the pleasure itself. The function of the pleasurable experience is so to emphasize the end of action that it will stand out clear in consciousness. When this takes place, the behavior will inevitably move in the right direction and achieve the desired result. On the other hand, if the pleasure of the activity is emphasized as something distinct from the activity, the result is likely to be undesirable. The experiences of the individual and the race emphasize the fact that pleasure as an end of action when definitely set up and recognized is a veritable willo'-the-wisp. A striking illustration of this fact is found in later Greek civilization among the Epicureans. The aim of this school was to do nothing except for the pleasure that could be obtained from it. In the end many found that a life conducted on this principle defeated the very object that it sought, and instead of attaining the greatest pleasure in life, the Epicureans ended in seeking the easiest method of escaping from life through a painless suicide. It is a fact of common experience that the seeker after pleasure soon becomes sated, blasé, and despondent.

Pleasure Accompanies Instinctive and Habitual Activities. - Since pleasure attends those acts that result satisfactorily, that place the individual in desirable relations to his environment, it might be inferred that 
no act could be pleasurable until its results had finally indicated its desirability. This is, however, not strictly so. All instinctive activities, all inborn tendencies, and, in general, all habitual activities are pleasurable, as far as they have any conscious accompaniment; to inhibit these activities causes definite unpleasantness, and when they are "blocked" by external forces, an emotional storm may ensue.

It is to be remembered in this connection, however, that these impulses, as far as they are inborn or instinctive, have come down through generations of inheritance to the present time because on the whole they have proved themselves useful to the race and hence have survived. Therefore it would be in accord with the principle previously set forth to find their expression pleasurable and their prevention unpleasant. Habits, in a similar way, represent the forms of behavior that have been valuable in individual development; and their pleasant affective coloring is also clearly justified.

Play, curiosity, imitation, and many other inborn tendencies to be discussed later are agreeable in their expression apart from any result secured. Some of these can with difficulty be repressed even when in individual instances the outcome is disastrous and hence unpleasant. For example, the migratory instinct that in one of its forms is called "spring fever" and which impels the individual to seek a change of environment, is with some persons so strong that the most unpleasant consequences are ineffectual in checking it. Some cases of persistent truancy can thus be explained. 
The Practical Significance of the Emotions. - While the practical value of the simpler feelings is quite obvious, the usefulness of the emotions is not so easily demonstrated. Indeed, because of the turmoil in which they place the individual and the havoc that they work in the train of thoughts, it was held for a long time that emotions were always undesirable and a mark of weakness. It is, however, reasonable to suppose that the emotions possess some positive value; otherwise they would long since have been eliminated in the sifting of the evolutionary process, - for nothing that is harmful can permanently survive, and even something that is merely useless is likely to be eliminated. The emotions, however, are among the most fundamental and persistent parts of our mental inheritance. How, then, can their survival be explained?

If we were to identify the emotions with intensified feeling, it would not be difficult to show their value as incentives or inhibitions to action. Under the dominance of rage the person would be more likely to attack and destroy his enemy, and when possessed by fear he would more readily run away and thus save himself from destruction. But, as we have already seen, emotion cannot be considered as a pure state of feeling of great intensity; there must be added to the mental complex that constitutes the emotion, certain ideas, certain impulses to action, and above all the impossibility of consistent and useful behavior in the presence of a difficulty that cannot 
be adequately met and immediatsiy overcome. Surely in themselves abortive behavior and confusion in the thought processes cannot be considered as in any way useful. Yet these are invariable and essential characteristhis of the emotional experience. Without this "blocking" of adjustment, with its accompanying confusion of ideas, emotions woulu be bereft of their chief characteristics. All that wculd be left would be a feeling of greater or less iniensity and an idea of the object calling forth this feeling; but such a mental state would not constitute a completed emotion.

The Value of the Emotior must be Sought in its Outcome. - It is evident that if emotions have some value (and it seems impossible to hold that they do not in the light of their antiquity and prevalence in both human and animal life), this value cannot reside in the emotional expressions as such, but in something that results as a consequence of this emotional expression. The attempt has been made by various writers to show how such expression may have incidental values sufficiently great to account for the appearance and continuance of certain kinds of behavior that manifest themselves under emotional stress.

Among such incidental values may be mentioned the fear that comes to the fighter when his adversary shows evidences of rage, and thus strikes terror to the heart, or when the attitude of misery and despair calls forth the sympathy of the onlooker and in consequence aid. 
Now it is evident that the mere rage as such renders the person less able to fight than if he possessed a cool head, while the emotion of despair in itself hinders its possessor from meeting the situation in any useful way. It is because of the effect on others, and because of their subsequent behavior in consequence of this effect, that such emotional expressions possess a value for the individual manifesting them. Attempts have been made to show how all varieties of emotional expression have some sort of utility, - even frowning, trembling, and other apparently unmeaning or harmful forms of behavior. We cannot here go into the details of this discussion, but must turn to a consideration of the most important service that the emotions render in bringing into existence useful forms of behavior.

Emotions Induce New Modes of Behavior. - The great value of the emotional experience lies in the fact that through the turmoil it causes, there are made possible new modes of behavior and new trains of ideas, resulting in new activities. It often takes nothing short of a mental cataclysm or "shock" to wipe out old and harmful habits of conduct and to set up new and useful actions. During the period when the will seems paralyzed, when thoughts are confused and action vacillating and uncertain, the old and harmful habits that have dulled the mind and mechanized behavior are at least temporarily obliterated, and the opportunity is thus offered for a new start and the gradual formation of a new set of 
habits and new attitudes of the mind. Emotion may then be looked upon from the physical standpoint as a means for blocking old paths of discharge in the nervous system, and opening up new paths which may to advantage be utilized in the future; while on the mental side it may be considered of service in casting out old, stale, and relatively harmful sets of ideas that have centered around certain forms of behavior, thus affording the opportunity for a fresh start and for the establishment of another set of ideas.

An example of the function of an emotional experience in preparing the way for a new set of adjustments is to be found in the religious emotion as it manifests itself in the various phenomena of "conversion." The old self with its evil habits and base ideas is adjusted to certain typical situations, and for these situations the behavior may or may not be relatively satisfactory. The mere feeling of unsatisfactoriness and discontent with the old life is not, however, sufficient to bring about a change in the established modes of conduct that have grown up through years of experience. The individual does not get away from the old self so easily. He must be plunged into fears and doubts, he must experience hopelessness and despair, he must be thrilled with the agonies of a lost soul, before a change comes about and he is freed from the former life and given the opportunity to start anew. All this unrest, this doubt and hesitancy in action, this confusion of thought and this waste of nervous energy, is, considered in itself, bad; it is valuable only because it may lead to a new point of view in regard to life and a new and better method of coping with its problems. The religious emotion considered in and for itself is a disorganizing experience; it brings about a temporary chaos; but if from this travail of the soul there be born a better life, then the emotion has a value. 
Nations, like individuals, sometimes need a complete upheaval in order to bring about a newer and better adjustment. Great political reforms have frequently been achieved by slow and deliberate processes; but on other occasions rational reform has seemed impossible, and only a radical catastrophe has brought about a better state of things. This is particularly true of such an event as the French Revolution, which, in spite of its excesses, seems now to have been necessary in order that France might work out her emancipation. The revolution in itself was bad; its results were, however, good. Perhaps even a clearer example of this necessity for violence is furnished by the American Civil War.

The Theory of Consequences Holds for All Emotions. What is true of the religious emotion is true of all other genuinely emotional experiences, whether they be high or low. Fear, anger, jealousy, contempt, joy, grief, thrills of religious awe, moral grandeur, æsthetic appreciation, and humorous incongruity are all in the last analysis related to some incomplete and unsatisfactory mode of adjustment, and all have a value in their consequences, resulting in better adjustments to the objects calling forth these emotions.

Even a just appreciation of the ludicrous and trivial in conduct, an appreciation that has immense practical significance, is conditioned on a temporary blocking of the ordinary channels of thought and typical modes of behavior. As Professor Angell has well said: "The joke is par excellence the typical stimulus provocative of disorganizing tendencies in our coördinations. We listen to the skillful raconteur, our minds following step by step the evolution of the epic, and then, presto! the 
unexpected occurs; our minds react to the shock. with an appreciation of the anomalies of the situation. The motor discharge in laughter announces the relief of the energy pent up momentarily by the unforeseen $d \dot{e}-$ nouement, and the total experience constitutes our feeling of the funny, the odd, or the amusing."

Often a tense situation is saved by a flash of wit. Sir Walter Raleigh, when he was led to execution, felt of the ax and remarked, "It is a sharp medicine, but a cure for all ills." The solemnity of the ceremonies attending the signing of the Declaration of Independence was relieved by Franklin's famous pun, "We must all hang together," remarked one of the signers. "Yes, - or separately," replied Franklin.

In school management, serious crises may often be averted by the ready wit of the teacher. The following story is told of Sir William Thomson (now Lord Kelvin), the famous professor of physics at the University of Glasgow. He placed upon the blackboard of a lecture room, "Professor Thomson will meet his classes here to-day." A wag erased the letter $c$, and when the professor mounted the platform at the beginning of the lecture hour, he read these words, "Professor Thomson will meet his 'lasses' here to-day." The great physicist quickly turned the laugh in the other direction by erasing the letter $l$ from the word "lasses."

The Affective Element in Teaching. - One of the most important problems that arise in connection with education concerns the value that should be attached to the affective life, in both its more simple and its more complex forms.

Until recently there has been a tendency to give feeling but a small place in formal education. The emphasis was placed on mere intelligence, particularly 
on mere knowledge. We know, however, that facts as such have no value in the control of conduct. It is only when they have some worth, when they appear valuable to the individual, that they lead to action. There must be a glow of feeling, a desire, some form of approval, a prejudice, that attaches itself to the mere fact and gives it a sanction. Even when the fact itself has no immediate practical significance, its value in reference to other facts that are being taught, must be shown. A date in history, as a mere date, has little use, but when its connection with events in which the pupil has an interest is shown, the date becomes significant, it has worth, there is an actual feeling that is attached to it, and it thus becomes of service in further learning. When we come to the larger facts that relate to good government, social integrity, moral uprightness, and the like, mere facts should never be presented. A simple knowledge of the machinery of our government does not make better citizens; the nature of the effects of alcohol and narcotics may be learned by the child and have no further effect than to satisfy his curiosity; the poverty and degradation of the slums may excite only a morbid interest. The parent in the home, the teacher in the school, and the leader in the social life should all see to it that those whom they would teach are not given mere information, but that in addition to the knowledge imparted there is awakened a genuine feeling that may lead to desired action. 
It is because of the failure to recognize the operation of this factor that it is so difficult to effect reforms in human society through a mere change in the curriculum of the public schools. Those unacquainted with the difficulties under which the teacher does his work often wonder why by teaching certain facts and principles we cannot make all pupils healthy, temperate, humane, chaste, and law-abiding. It is evident, however, that, basic to the principle must be the desire, the feeling of worth, the ideal. We must not only instruct pupils in the facts and laws of physiology and hygiene; we must also imbue them with a strong and effective desire to lead moral lives. A man might know the facts and laws and still fail to apply them. Knowledge is at best only a means to an end; and if we are to insure its application to the needs of life, we must see to it that our pupils are inspired with aims, with ambitions, with purposes that are consistent with the rights of others. The high school graduate might use his knowledge of chemistry to manufacture dynamite for an infernal machine; his knowledge of physics to arrange the batteries that would explode it; his knowledge of geography to reach the scene of his crime. Knowledge as such is a quite impersonal thing; it may work for evil just as readily as for good; and if the school concerns itseif with knowledge alone, if it neglects the aims and ends toward the attainment of which knowledge should be used as a means, it fulfills only one half of its duty, - and by far the less important half.

The Emotional Element in Teaching. - The relation of the emotions to the problem of teaching is not so easily determined. Some would insist that there is small place for the emotions in life, and consequently no place in the school; that the teacher should never show emotion and that the pupil should never experience it. We have seen, however, that emotion has a value in that it enables the individual and the community to break 
away from an habitual mode of behavior of a low order, and substitute for it modes of behavior of a higher order. It makes possible a renaissance, a re-birth. The religious revival that sweeps the community often upsets the equilibrium of the community life. Women neglect their household duties and men slight their business; there is much purposeless activity, a waste of energy that in itself is bad. Yet if the revival leads later on to a better attitude in the community life, to a more valuable form of behavior on the part of the individuals in the community, it has served a useful purpose. If it ends in mere excitement, in a religious and moral dissipation, it is not to be justified.

What is true of the larger life in the community as a whole is equally true of the smaller life in the home and in the school. The child should be stirred to emotional excitement only when new attitudes and new varieties of conduct are demanded that cannot be secured in less radical ways. The boy who cannot be impressed with the desirability of right actions by ordinary means should be made to fear, the pupil who will not stand up for his own rights must be touched with the spirit of rage, if the proper acts of self-protection are to be set up. So it is with the higher emotions. Often the comprehension of a moral situation cannot be brought home to the individual until he experiences, either actually or in imagination, the struggle between good and evil impulses, the pangs of remorse, and the exultation of a 
moral victory. It is the chief function of art, particularly of literature, in the poem, the story, and the drama, to bring home the great moral truths, by presenting vividly to the imagination situations filled with emotion, and causing the pupil to re-live these experiences in imagination. In this way he may readjust himself on a higher level, through an emotional experience that attaches itself to an imagined rather than to an actual situation.

The æsthetic emotion has likewise an important place in education. Artistic appreciation is seldom secured by mere formal instruction in the history and principles of literary composition, of painting, of sculpture and architecture. There should be a time when the intellectual attitude that such an interpretation demands should give way to an actual emotional thrill.

The emotion that comes in the moment when a comic situation is comprehended, is of distinct value in awakening dull wits and sluggish minds. These are too "matterof-course" and should be touched at times with the humorous and ideal aspects of life. The school has too frequently considered all forms of humor dangerous to the seriousness of formal instruction and has written over its portals, "Abandon mirth all ye who enter here."

The Emotional Element in Religious Education. The teaching of religion is one of the most serious problems that confront the world to-day. It is now generally held in America that formal instruction in dogmatic 
theology should find no place in the school, and such instruction is probably less common than formerly in the homes. Even in the church it seems to be losing its former important position. What is to take its place? Surely not the Bible as literature, in which the stories of the Old Testament are put on an equal basis with the classic myths and the tales of the Norse heroes. The essence of true religion does not lie in dogmas, creeds, and observances; neither is it to be replaced by the pleasures of fancy or the delights of literary appreciation. An appreciation of the grandeur of the Psalms cannot be made an effective substitute for the thrill of reverential awe that the individual experiences in the presence of the God of the Psalms. A knowledge of the self-sacrifice and love of Christ can never serve as a substitute for the emotion of reverence when the individual bows in humility before the Man of Sorrows.

True religious attitudes can be induced and kept alive only by occasional religious emotions. Reverence, awe, a feeling of the insignificance of the individual in the presence of the overmastering power of the universe, these have still an important place in human life. That the young person may realize them and fashion his behavior accordingly, he must experience their emotional thrill.

The Moods and their Use in Education. - We have said in an earlier part of our discussion that an emotion tends to pass over into a permanent mood. Since these 
moods, unlike the emotion, do not have the quality of stirring the individual up, since they permit clear thinking and definite action, they are valuable in themselves and not merely in their results, provided that they are worthy. A proper attitude of fear in regard to the really dangerous, a feeling of resentment toward improper conduct on the part of others, a sympathetic understanding of the worth of a moral situation, a sense of reverence for the higher things of life : all these and many others are desirable moods, and the emotions in which they originate have thus a justification.

Should the Teacher Show Emotion?-We have seen that the emotion has a certain value, apart from its function in making possible new adjustments in the organism, in that its expression often has an effect on the individual toward whom it is directed. An exhibition of rage may excite fear; dejection and sorrow may arouse pity; indignation may engender a sense of remorse. It is therefore not true that the parent and the teacher should show no emotion in dealing with children. The child who is punished should not only realize that wrongdoing is unpleasant. He should feel that it is wrong. But if he is being treated as a morally irresponsible being, if the punishment is administered from the sole standpoint of its consequences in improving his conduct, it loses much of its significance. 


\section{Questions AND EXERCiSes}

I. In anticipating a desired activity (a vacation trip, a "party," a feast) what does your mind "dwell upon" - do you "think" about the feelings that you will experience, or do you imagine yourself going through with the activities? In other words, is the end that you have in mind the pleasure, or is the pleasure merely the accompaniment of the images that pass through your mind?

2. What useful purposes do the emotions serve? Can you find examples in your own experience where your life has been transformed in some measure by an emotional "shock" which perhaps at the time only confused you and rendered your conduct ineffective?

3. How would you explain the efficiency of religious "revivals"?

4. In what way may an appreciation of the ludicrous, the comic, and the "funny" serve a useful purpose in life?

5. What is the relation of emotion and feeling to moral education? If we are to "teach" temperance in the schools in a way that will be successful in promoting temperance, what must be done in addition to imparting "knowledge" ?

6. What subjects in the curriculum are best suited to appeal to the feelings and the emotions?

7. What are some of the great moral truths that may be enforced by the study of Macbeth, the Idylls of the King, the Vision of Sir Launfal? Should the pupil experience in imagination the emotions that are here portrayed? 


\section{PART II \\ MECHANICAL MODES OF BEHAVIOR}

\section{CHAPTER VII}

\section{THE NERVOUS SYSTEM AS THE ORGAN OF BEHAVIOR}

IN the previous chapters behavior has been discussed principally from the standpoint of the states of consciousness that go with it, although we have spoken from time to time of certain reflex, instinctive, and habitual activities. In these activities, consciousness is either entirely absent, or, if present, it seems to have no directive value. The types of behavior that do not require consciousness for their execution must now be considered, - those forms of conduct that occur in a machine-like way and take place with mechanical regularity when the proper conditions are present to bring them about.

A piece of dirt blows into my eye and I immediately shut the lid. It is true that I know that a particle is in my eye and that the lid is shut fast. This knowledge does not make me close the lid, however. Consciousness accompanies the activity, but does not direct it. As long as the particle remains lodged in my eye the lid will continue to close from time to time, even in spite of my best efforts to keep it open. Again there are times when I wink 
my eye and do not know that I am doing it. It is quite evident in this latter instance that the act of winking goes on without conscious control, for there is no consciousness present to direct it. It is, however, equally true in the former case that consciousness does nothing in directing the act of winking. Its presence does not account for the behavior; the winking in both instances is an "involuntary" act.

The Nervous System and Behavior. - Behavior that is not directed by consciousness is to be understood as being entirely controlled by the nervous system and as the direct result of activities going on within this system. To understand these activities it will therefore be necessary to consider briefly some of the most essential facts in regard to the brain and the spinal cord. The way in which the nervous system acts may best be understood if we review some of the steps in its development from the lowest forms of animal life up to man.

The Simplest Type of Behavior. - In the amœba there is no nervous system. This single-celled bit of living matter or "protoplasm" is without any organs whatsoever, yet it takes nourishment, moves about, and reproduces itself, although there is no specialized mechanism for executing these activities. Any part can temporarily serve as a mouth or a stomach; movement is accomplished through a change of form; and reproduction consists merely in the animal's breaking in two and thus duplicating itself.

The amœba not only executes the acts described above; it also responds to stimulation of various kinds. 
It changes its behavior when affected by lights of different colors, and yet it has no eye to see; it responds to changes in temperature and to electric shock, and yet there are no organs for receiving these excitations. Further than this, there are no muscles whose activity can bring about these changes in behavior. And, finally,
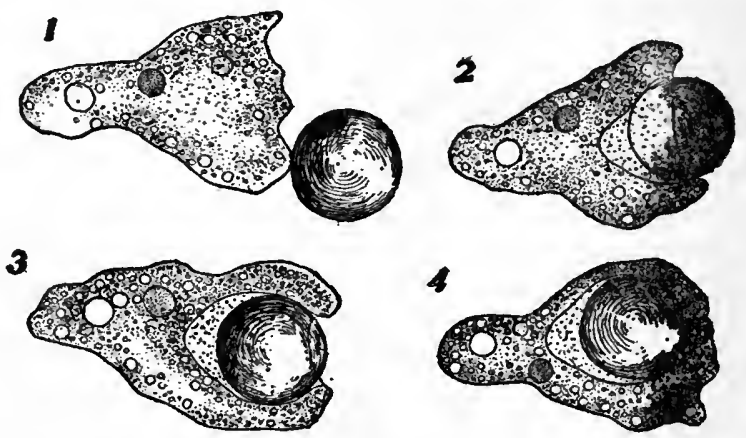

Fig. 4. - Food-taking reaction of the amœba. The numbers illustrate the four stages of the activity. In No. I the food is external to the substance of the amceba ; in No. 4 it is completely surrounded. (From Jennings, "The Behavior of Lower Organisms," Fig. 18.)

there is no specialized device by which the excitation, after it has been received, can be conducted from the point of its reception to some other part of the organism at which an appropriate response to this excitation is made.

Complex Behavior Requires Complicated Structures. The more highly organized animals, however, possess sets of specialized cells (different "tissues" making up different "organs"); and each of these sets of cells performs a specific function. Among these specialized "tissues" are devices for receiving the excitations that 
come from the world outside, for conducting these excitations from the point where they are received, and finally for transferring them to a muscle which by its activity produces a response or movement.

In the case of the chick, for example, rays of light from bits of food, grains of sand, and the like fall upon the eye. The stimulation is carried from the eye along the nerves of sight to a central portion of the nervous system, and here the excitation is transferred to nerves leading to certain muscles. The stimulation at length reaches these muscles, which are then set in action, with the result that the chick pecks at the bits of food and the grains before it. The chick has (r) a relatively intricate nervous system with sense organs, such as the eye and the ear, each of which is particularly adapted to receive a special type of stimulation; and (2) various muscles that are affected by the stimulation when it has been carried to them through the nervous system. By their activity these muscles set up certain appropriate forms of behavior.

The Simplest Form of Nervous System. - The nervous mechanism in its most simple form serves to join a sense organ with a muscle or set of muscles. The whole is a unit, the various parts acting together. Stimulation is received and transferred to the appropriate place for the necessary action to take place. The neryous system may then be considered as a device for turning the excitations received from the external world into 
appropriate responses. The amœba is capable in a very simple way of responding to such excitations, although it possesses no nervous system. As behavior becomes complicated in the higher forms of animal life, a nervous system puts in its appearance along with other specialized sets of cells. Complicated behavior and a complicated nervous system go together; where the one exists, the other is surely to be found.

We may be aided in understanding the workings of the nervous system and the manner in which it has developed by thinking of it after the analogy of a telephone system. Perhaps telephones are first installed when the town is small, and the instruments are correspondingly few. The connections that can be made are therefore few in number. As the town grows, the number of instruments correspondingly increases and the possible number of connections multiplies. When the town has reached the proportions of a large city, there are many thousand instruments, and an almost limitless number of connections is possible. Also the system of one city may be brought in connection through "long distance" with the systems of other cities, and one subscriber may thus be put in touch with millions of others. In this way parts remotely separated can be brought into almost instant communication.

If we carry our analogy of the telephone system still further, we shall see that, while it is possible for an almost infinite number of connections to be made, in fact, such a number is never made. Each subscriber has a limited number of persons whom he ordinarily "calls up," and only in rare instances and under unusual conditions does he call up others; further, there are certain lines that are more often used than are others.

The nervous system may be thought of in like manner. It has various centers, corresponding to the various telephone exchanges in the various districts of one city and to the exchanges in 
various cities, all capable of acting when the necessity arises, thus joining all parts together in a unit.

\section{"Preferred"} Paths of Conduction. - In the nervous system, then, all sorts of com binations theoretically may be made, but all are not actually made. There are certain preferred or usual paths for the conduction of nervous energy throughout the nervous system, just as there are certain customary connections within a tele- System," Fig. 655, after Cajal.)

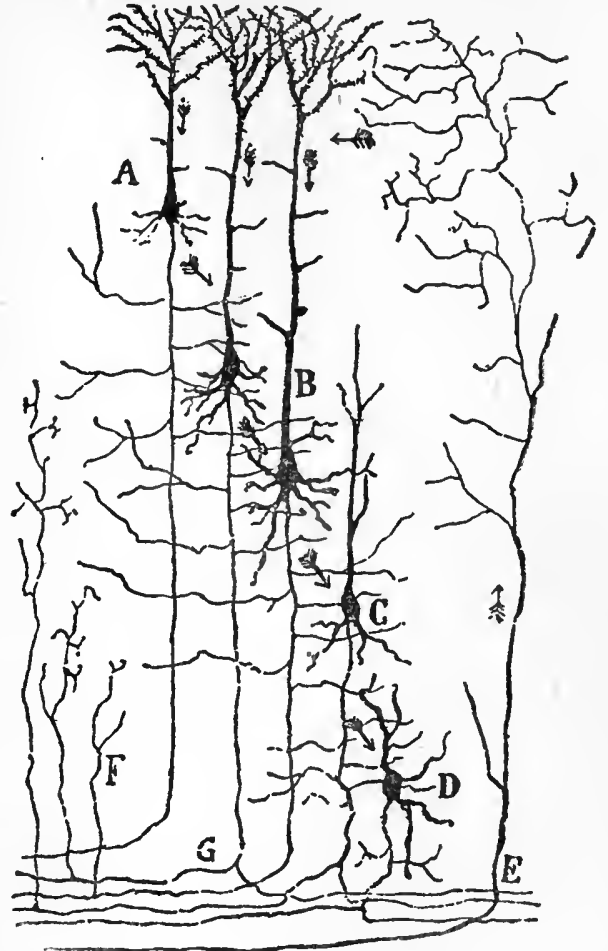

FIG. 5. - This figure shows the intricacy of the connections between neurones in the cortex. The thick cell bodies with their processes, the axones and dendrites, are to be observed. (From Barker, "Nervous phone system. Some of these paths of nervous conduction are already in existence in the organism at birth, while others are developed during the life of the organism. The former are inherited, while some of the latter are the result of experience. 
The Neurone. - The most essential part of the nervous system consists of elements technically known as "neurones." Each neurone is separated from all the others; that is, no two neurones are actually joined together in the sense that one grows into another.

The typical neurone has a central portion, known as the "cell body," and from this grow out two different "processes," the one a long threadlike growth, called the "axone" and the other a shorter branching extension that looks something like a tree or thick shrub, and for this reason is given the name of "dendrite." The axone likewise ends in a number of branches, known as the "end-brush."

The Synapse. - As has previously been said, no two neurones grow together. The connection is made at the point where the end-brush of the axone interlaces with the branches of the dendrite. This point of contact is called the "synapse." The ease with which the nervous excitation passes from one neurone to another at the synapse decides what path it shall take. It follows the path of least resistance. If the resistance is great, then the flow of energy is checked in that particular direction and must find other ways of discharge.

The ease with which the transmission is made from one neurone to another depends either upon inherited conditions, or upon conditions that develop during the life of the individual. In either case we find, as has already been said, preferred paths of conduction; that is, paths 
along which the excitation tends to flow under ordinary conditions.

There are, however, times, as, for example, in the case of emotional stress, when the old channels of discharge are no longer adequate, and new paths are formed. The more often the new paths are traversed, the less becomes the resistance at the synapses, and the more likely are the excitations to follow these new paths.

The flow of nervous excitation is supposed to be in one direction, and that only. The dendrite receives the excitation and transmits it toward the cell body, while the axone carries the outgoing excitation.

Classes of Neurones. - There are three classes of neurones: those that receive a stimulation from a sense organ and conduct it inward are called "sensory" neurones; those that convey a stimulation outward toward a muscle are known as the "motor" neurones; the third class of neurones connect the sensory and motor neurones and are called for this reason "associating" neurones. These three kinds of neurones are not essentially different in structure, although the sensory neurones are so constructed as to "pick up" different kinds of excitation, such as stimuli of light, sound, pressure, temperature, and smell. However, the way in which they act depends largely upon their position in the nervous system. Those that are connected with the organs of sensation are of necessity the ones that receive the ingoing excitation, while those that end in the muscles are the parts in the chain that are directly respon- 
sible for movement. The neurones higher up serve as bridges between the incoming and the outgoing excitations. It must be remembered that this connection between sensory excitation and motor response is the condition of all experience; that sensation is incomplete without response; and that the nervous system tends always to act in this sensori-motor way. We shall see later the significance of this fact in our experience and its importance in all learning.

The Central Nervous System. - In the higher animals and in man, by far a larger part of these neurones are to be found in the "central nervous system," which comprises the brain and the spinal cord. Outside of the central nervous system are to be found collections of nervous elements which together make up what is known as the "sympathetic nervous system."

In man and the higher animals the general appearance of the central nervous system is practically the same. At the top of the cord there is a budding out into the "medulla," and above this the great mass of nervous substance contained within the skull and called collectively the brain. This has many different parts, but only a few of the most important can be mentioned here. The larger part of the brain consists of the "cerebrum," divided into "hemispheres," and showing a corrugated surface, with folds and fissures. At the back and below the cerebrum is a smaller mass of nervous substance that is given the name of the "cerebellum," or little brain. 

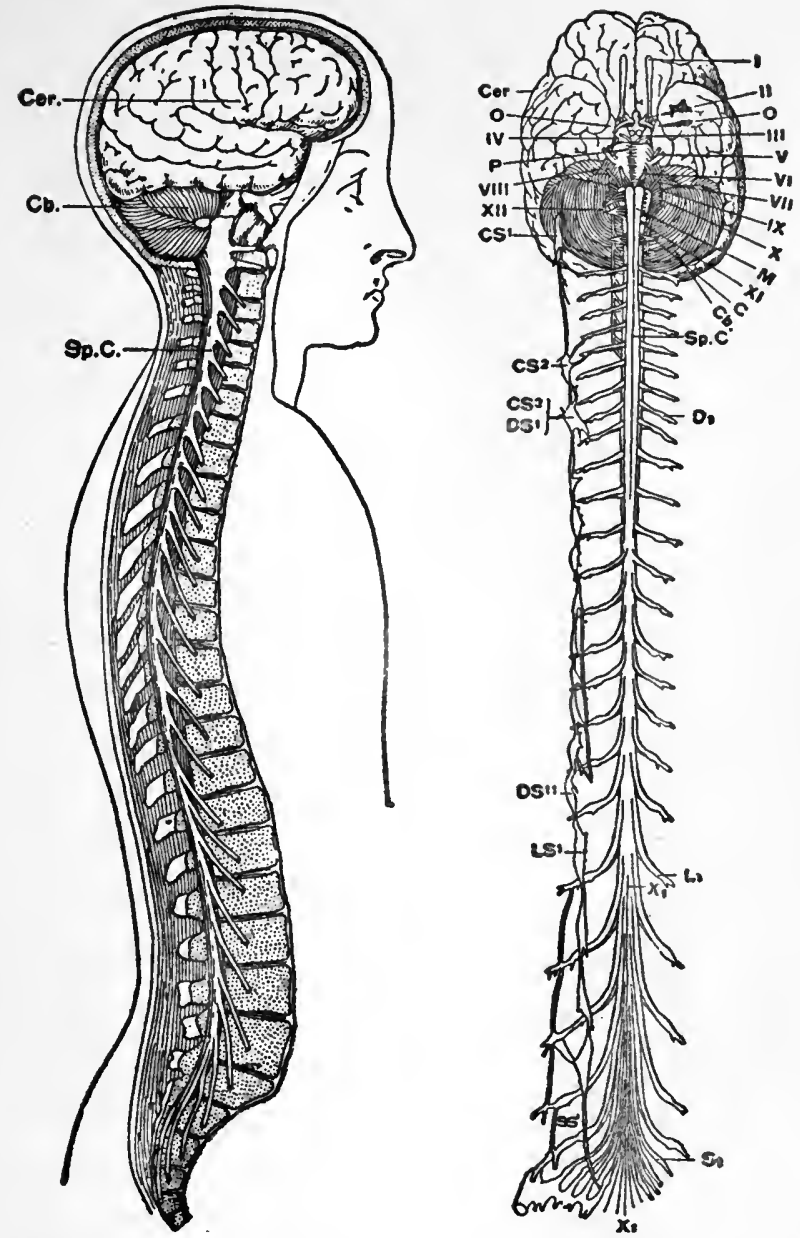

Fig. 6. - Complete view of nervous system. On the left the nervous system is seen in relation to the body; on the right it is represented as removed from the body and viewed from the front. Cer., the cerebrum ; $C b$., the cerebellum ; $S p . C$., the spinal cord. The Roman numerals from $I$ to $X I I$ inclusive in the righthand figure indicate the twelve pairs of "cranial nerves," nerves not passing through the spinal cord, but entering the brain directly. Below are to be seen the roots of the "spinal nerves" and attached to these at one side, the left, is shown the cord of the sympathetic nervous system; on the other side, the right, this cord has been removed. The letter $M$ indicates the medulla, the budding out of the spinal cord at the top. (From Angell, "Psychology," Figs. I2 and 13.) 
Below the cerebrum at the base of the brain and still included within the skull cavity are other masses of nervous substance that make up the "lower ganglia."

Within this central nervous system are to be found about eleven thousand million separate neurones, apparently mingled together in the greatest confusion, but nevertheless under normal conditions working in perfect harmony and leading to behavior that is definite and well-ordered. The confusion, then, is apparent, not real. This wonderful organization that produces harmony among so great a number of parts is due, as has already been pointed out, to two facts: (I) in the intricate windings of the nervous elements there are certain definite paths that are inborn; and (2) many other such paths are gradually opened up after the individual has passed beyond the period of embryonic or prenatal development and has entered upon life as a separate organism.

The Functions of the Central Nervous System. The Cord. - The various parts of the nervous system show a certain degree of specialization; that is, they do not all perform exactly the same kind of work.

The spinal cord is the great channel of communication between lower centers and those higher up. There are ascending and descending paths of conduction. Excitations arising from the sense organs in the skin and various internal structures are conveyed to the brain, where these excitations are related to certain specific sensations 
and where in turn excitations may be sent out to various muscles. If the cord is seriously injured, these sensations are no longer possible, and the activity of those muscles lying below the point of injury ceases; in other words, paralysis results. It is as if the wires in a part of the telephone system had been cut, so that no communication could be received at the central office and no messages could be sent out.

However, there are nerves that enter the brain at its base, known as the "cranial nerves," and these do not pass through the cord. Hence such nerves would be unaffected by an injury to the cord, and these could still carry the ingoing excitations and send out the response to the muscles with which they are connected just as if nothing had happened. So an individual with an injured cord might not be aware of a touch on the hand or the prick of a pin on the leg, might be unable to move his limbs, and still be able to see and hear and move the muscles of his eyes and face in the usual way.

The cord not only conveys excitations to centers lying higher up; it not only carries excitations from the higher motor centers to various muscles; it can act to a degree independently of these higher centers. It can immediately transmit a sensory impulse to a motor neurone or a number of these, and behavior can result without the brain taking any part in this behavior. In other words, there are "associating" neurones in the cord itself. This transmission may be between neurones at the same level in the cord, or between a neurone at one level and a neurone at another lying higher up, or still again between 
a neurone lying on one side of the cord and a neurone lying on the opposite side. The most simple instance of transfer is when the discharge passes from one neurone to another at the same level and on the same side of the cord, thus involving the activity of but two neurones. Usually the relation is much more complex than this. Between the top of the cord and the cell bodies lying near the surface of the cerebrum, and constituting the "cortex," there are to be found transfers of a much more elaborate and complex character, but still essentially like the more simple transfers lower down.

(2) The Cerebral Cortex. - The most intricate of these transfers or "coördinations" is in the cerebral cortex itself, the most highly organized portion of all the nervous structure, and the last to develop in the race and in the individual. The cortex is the outer structure or "bark" of the cerebrum. It is made up of a vast number of cell bodies of neurones. The axones of these cortical neurones form a large part of the internal "white" matter of the cerebrum.

Certain parts of the cerebral cortex are chiefly concerned in the reception of sensory excitations that arise in the external world, while others direct the proper response of the muscles. The former are known as "sensory areas" and the latter as " motor areas."

The sensory areas that are marked out with considerable definiteness are concerned with sight and hearing. The motor region in the cortex not only sends out 

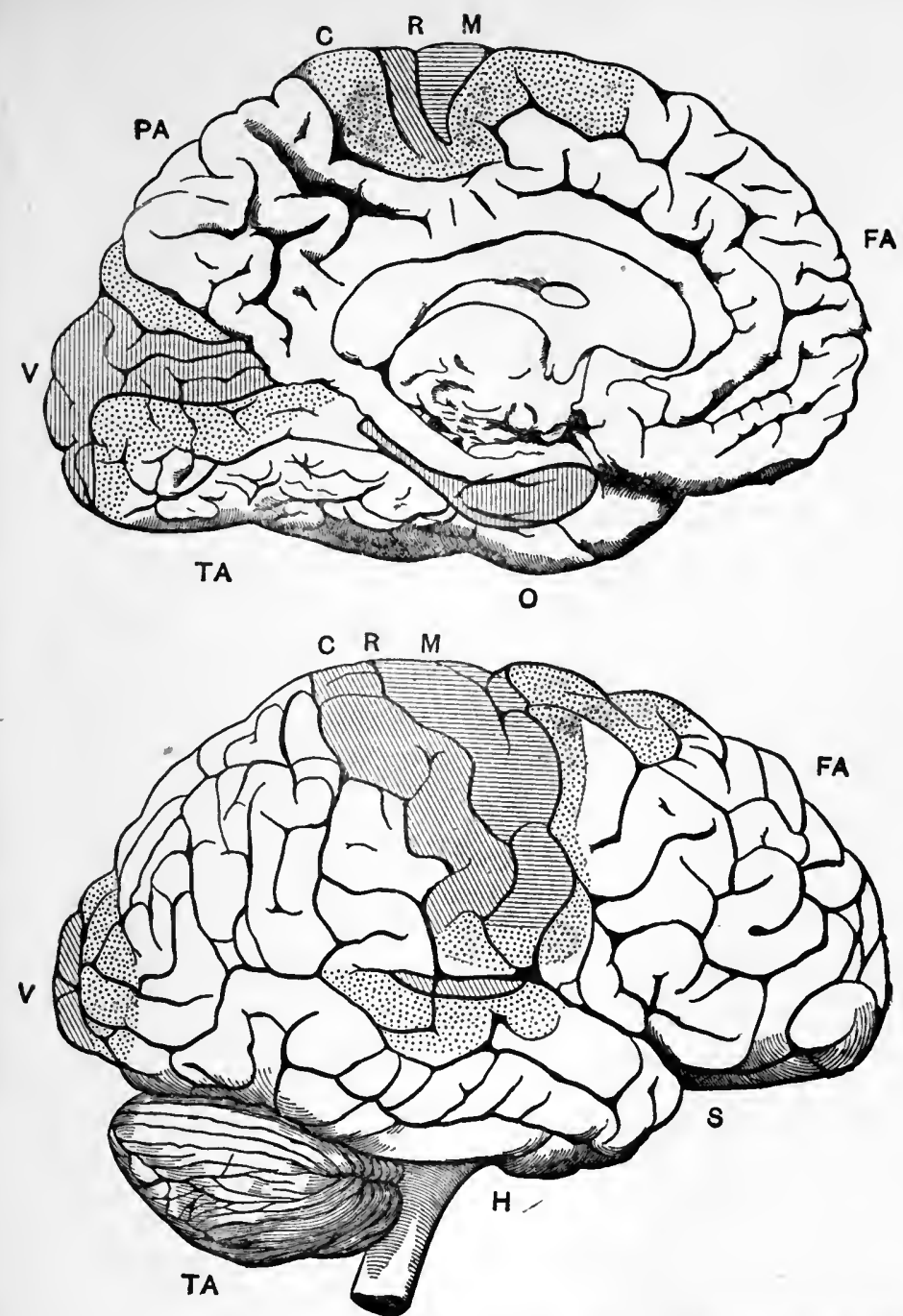

Fig. 7. - Localization of function in the cerebral cortex. The upper figure shows the mesial surface of the left hemisphere of the brain; the lower, the outer surface of the right hemisphere. The motor areas are indicated by horizontal shading; the sensory areas, by vertical shading; the association areas remain unshaded. The areas containing dots are either partially sensory or motor in their function, or doubtful. The auditory area lies above $H ; V$ marks the visual area; $M$ is above the motor area; $F A$ marks the frontal, $P A$ the parietal, and $T A$ the temporal association areas. (From Pillsbury, "Essentials of Psychology," Fig. 7.) 
impulses to the muscles, but it also receives excitations due to the activity of these muscles, and thus we become conscious of the activity of these muscles, although we may not see the movements that are made. For this reason we can walk or write with our eyes closed.

Certain parts of the cortex do not seem to have any definite sensory or motor areas, and it is believed that these parts of the cerebrum are chiefly concerned in connecting other parts. These regions are, for this reason, known as the "association areas," and they are supposed to be intimately connected with the higher thought processes.

Consciousness Correlated with Cortical Activity. Whether consciousness is connected with all of the activities of the nervous system or not is a question not easy to answer, but it is clear that the more developed forms of consciousness are in some way related to the activities of the cerebral cortex. In man these higher activities take on such importance, and the consciousness accompanying them is so complex, that all more simple and rudimentary forms of consciousness are necessarily obscured.

In the blazing light of day no one would suspect that the stars were sending forth their light. This is so slight that it means nothing in addition to the brilliancy of the sun. So it is with those weaker forms of consciousness that may perchance attend the activities of the lower brain and the cord. If they do exist they cannot be recognized, since they contribute so little to the total light of consciousness. Whether they are present or not, they appear to 
have nothing whatever to do in controlling the behavior connected with these parts of the nervous system whose activities may be thought of as entirely automatic and without conscious control.

Inhibition and Facilitation. - Up to this point we have considered the nervous system as a means for receiving excitations and for transferring them into action. While this is the general purpose of nervous activity, it does not follow in every instance that excitation immediately issues in action. In the lower centers it happens that, under normal conditions, stimulation and positive response are joined in invariable sequence. The higher centers, however, not only facilitate response; at times they check response. Here we observe the phenomena of "inhibition" and control that characterize the higher intellectual activities. It is a well-known fact that yielding to every impulse, distraction, and whim is an indication of a weak or undeveloped mind. Deliberation and decision mean that there must be a check on hasty and uncontrolled behavior. The lower centers, if left to themselves, respond to their customary excitations in definite and unvarying ways. They may act to a purpose, but in a quite irrational way. The cortical neurones exercise a control over the activities of the lower lying neurones and serve to check their activity when the necessity arises. 


\section{Definitions and Explanation of Terms Used}

Involuntary action. - Behavior not controlled by consciousness.

Sense organ. - A special device, such as the eye and the ear, that receives stimulation from the external world.

Preferred paths of conduction. - Definitely worn channels in the nervous system along which excitations flow in much the same manner as a stream follows a river bed. While these channels are assumed to exist, they cannot be seen even with the most powerful microscope.

Neurone. - A single element of nervous substance of which the entire nervous system is composed. There are about eleven thousand million neurones in the nervous system of the human adult.

Cell body. - The central portion of the neurone.

Process. - An outgrowth from the cell body of the neurone.

Axone. - One of the two processes of a neurone; a long, threadlike growth, sometimes several feet long, constituting, with its white covering (the "medullary sheath "), the typical nerve fiber.

Dendrite. - The other process of a neurone, shorter and resembling in appearance a thick shrub or tree; hence its name.

End-brush. - The branching termination of an axone. Symapse. - The point of contact between two neu- 
rones. There is no actual joining, but the end-brush of the axone interweaves with the branches of the dendrite of another neurone.

Sensory, motor, and associating neurones. - Neurones receiving the stimulation from an end organ are called sensory; those conveying the stimulation to the muscles, motor; and those connecting these, associating neurones.

Sensori-motor activity. - No excitation is complete without some form of response. All stimulation tends to express itself in movement.

Central nervous system. - This includes the brain, with all its various parts (cerebrum, cerebellum, lower ganglia, and other parts), and the spinal cord with the medulla growing out at the top. Outside of the central nervous system are collections of nervous elements, or ganglia, comprising the sympathetic nervous system.

Cerebrum. - The name given to the upper mass of the brain. In all higher animals, and particularly in man, this composes the larger part of the nervous substance within the skull cavity. It is divided into equal hemispheres.

Cerebellum. - The "little brain," below and at the back of the cerebrum.

Cranial nerves. - Twelve pairs of nerves enter the brain without first passing through the cord. They have to do chiefly with the senses of sight, hearing, taste, and smell and with certain movements connected with the face and eyes. 
Cerebral cortex. - The cerebrum is covered with a layer of nerve cells known as the "cortex," or covering. In all high animals this is the most important part of the nervous system, as far as its connection with consciousness is concerned.

Areas of localization of the cortex.-Different parts of the cortex are connected with various sensations and with various kinds of behavior. Sensory areas, related to sight, hearing, and touch, have been definitely mapped out. A motor area, that sends out impulses to various muscles and also receives excitations coming from these muscles when in activity, has likewise been located. Motor neurones are found in smaller numbers in certain other portions of the cortex. There are also association areas in the front and at the sides of the cortex, and these seem to have something to do in relation to the higher intellectual activities.

Inhibition. - An activity of the higher centers in the nervous system that checks, represses, and holds in control some of the activities of lower centers.

\section{QUESTIONS AND EXERCISES}

I. In what different ways does the amœba's behavior resemble that of the more highly organized animals? What differences in behavior between the two forms?

2. What specialized sets of cells in the higher animals are concerned with locomotion? With digestion? With respiration?

3. What is the nervous system, as a specialized set of cells, concerned with? 
4. Describe a typical neurone, naming its three parts. How are the excitations transferred from neurone to neurone? What is meant by the "synapse"?

5. Name the three classes of neurones. The sense organs might be termed the "end stations" of sensory neurones. Name the sense organs, and state the kind of information that each "picks up."

6. What is the function of the motor neurones? What is the function of the associating neurones?

7. What do you understand by the term "central nervous system"? What are its chief divisions, and what is the function of each?

8. What is meant by the cortex of the cerebrum, and of what is it chiefly composed? What reasons can you give for believing that the cerebral cortex is the part of the brain that is chiefly concerned with "conscious" activities - sensation, perception, memory, thought, etc. ?

9. What areas of the cortex are probably concerned with sight? With hearing? With sensations of movement? In what part are the cell bodies of motor neurones most frequent?

Io. What is meant by inhibition? How does the cortex exercise inhibition on the movements otherwise controlled by the spinal cord? 


\section{CHAPTER VIII}

\section{REFLEX AND INSTINCTIVE BEHAVIOR}

WE have now sufficiently described the structure and activity of the nervous system to discuss somewhat in detail the nature of the various types of behavior that are to be considered as directed entirely by nervous activity and are not to be looked upon as under the control of consciousness.

Reflex Behavior. - In Chapter I we spoke of reflex behavior and gave as an example of this the action of the eye when light of different degrees of intensity affects that organ. When the illumination is intense, the size of the pupil is small; when it is weak, the pupil grows larger. In this case the excitation, due to the light acting upon the eye, is carried along sensory nerves to certain centers where it is directly carried over or "reflected" to motor neurones that send their discharge to the muscles which control the size of the pupil. In this case, stimulation results directly in a definite response. There is no intervention of consciousness in any way, and the whole activity is the result of a certain definite inherited arrangement in the eye itself. The course of the nervous stimulation and discharge is fixed during the period before birth and is fully marked out at birth. Another reflex 
activity that has been discussed is that of winking. Here, as in the case of the reflex mechanism of the pupil of the eye, the activity is due to the fact that there is an inherited path between the excitation and the response to this excitation. Numerous other examples of reflex activity might be cited, such as coughing, sneezing, swallowing, and sucking. They are all to be explained in the same way, - namely, in terms of inherited paths of preferred conduction between stimulation and response. The ease with which the stimulation traverses the nervous system from its beginning in the sense organs to its end in the muscles is conditioned largely on the openness of certain of these paths at the synapses. When the discharge of nervous energy is facilitated at these points of contact between the neurones, then the whole process is direct and certain, and the activity is "reflected " from the sensory to the motor neurones without difficulty.

Instinctive Behavior. - Besides the simple reflex activities, such as those that have been enumerated above, there are reflexes of a much more complicated nature. When several simple reflexes act together to bring about a certain form of desirable behavior, the result is called "instinctive activity." In the first chapter, a typical form was briefly discussed,- namely, the tendency of human beings and animals to draw away from an unpleasant or dangerous object. In such a form of behavior a number of reflexes are involved, all working together to bring about the desired end. None of them, however, 
are controlled by consciousness or dependent upon experience. In Chapter II, other instincts, such as play, imitation, and curiosity, were briefly touched on.

Characteristics of Instinctive Behavior. - In all of these the fundamental characteristics of instinctive activities are to be noticed: (I) They are all directed toward some end that is useful. (2) They are all made up of various simple reflex activities. (3) They are all outside of voluntary direction. (4) None of them have been learned, and all must be thought of as depending upon inherited paths of conduction in the nervous system.

One of the most complicated of instincts in animals, and one often cited, is that of nest building among birds. The bird does not learn to build its nest; it is not aware of the reason that exists for building it; but is moved by an impulse that it does not comprehend to go about the construction of the home for its young, of whose coming it has no knowledge. The bird is conscious of its actions to an extent, but this consciousness must be thought of as the accompaniment rather than as the cause of the instinctive behavior. In the nest-building activity of the bird, and probably in all such activities, whether manifested by animals or human beings, there is a certain amount of feeling that accompanies the instinct. Thus there is a close relation between instinct on the one hand and feeling and emotion on the other hand.

The Adaptive Instincts. - Attention has already been called to the tendency of the little child to imitate 
what he sees others doing. He does not know why he imitates; he simply sees a movement and copies it, finding pleasure in the mere act of copying. Once he has imitated successfully, he is likely to repeat spontaneously that which he first imitated, - again not because he recognizes that this repetition will perfect the movement, but simply for the pleasure that the repetition gives. Moreover, he will take to pieces the mechanical toy that he is playing with, not because he recognizes that he may learn something that will be of benefit to him later, but for the pure delight of finding out how it works, - of satisfying his curiosity.

These are general tendencies that are native or inborn, and it is clear that they are very useful in adapting the child to the world into which he is born. Through imitation he acquires very quickly the type of behavior that those about him employ. He does not have to learn this behavior laboriously and slowly as the race learned it ; rather, he leaps at once, as it were, upon the shoulders of the generations that have preceded. It took thousands of years for our language to assume its present form, but through imitation the child learns to use this language in a few years. Our remote ancestors did not eat with forks; indeed, the art of eating with the fork has been developed within the last few centuries; but the child to-day is born into a world of forks, and through imitation he quickly learns an art which the race acquired only after a long period of development. Our great-grand- 
fathers made fire with flint, steel, and tinder. They learned this art by imitating those about them. We have lost the art now - or rather we have let it die - because other and better means of making fire have been developed; but it is through imitation that these improved means are passed on to the next generation.

Similarly, the instinct of curiosity leads the child to pry into the world about him, - to find out all he can about his surroundings. This coöperates with the instinct of imitation in adapting him to the life that he must live, - for some of the gains that man has made have been crystallized in utensils, implements, machines, and other devices, as well as in definite actions and adjustments. Acquaintance with the latter is gained by imitation, but the prying instinct of the child enables him to gain some knowledge of the former far in advance of any immediate need for using them. And besides this, there is the great world of natural objects some of which he must know and recognize, and here, too, the prying instinct is of great service.

Play has also been referred to as an adaptive instinct. The delight that the child takes in activity simply for the sake of activity gives him a control over his muscles. He learns how to make different movements, and how to put different elements of movement together to make new combinations, - to " coördinate " movements, as the process is called.

These adaptive instincts are emphasized at this point 
because they are especially important to human education, - they are the instinctive bases upon which the teacher and the parent must build. They are also mentioned first because they clearly illustrate the important features already referred to of all instinctive activities. But other instincts are also important to education, and also illustrate these characteristic features.

The Individualistic Instincts. - A very significant group is made up of the individualistic instincts. This name is given because the activities make for the preservation and welfare of the individual and often come into conflict with the welfare of others. Prominent among these are the fighting instinct, the predatory instinct, and the selfassertive instinct. The fighting instinct is represented by the inborn tendency to seek physical combat with those who threaten one's welfare, invade one's rights, appropriate or destroy one's property. The predatory instinct impels one to appropriate or destroy the property of others. The self-assertive instinct leads to display, domineering, and other activities which, under primitive conditions, tended to excite in others the instinct of selfabasement and the act of subjugation.

These instincts, also, have their affective and emotional accompaniments. The activity of fighting is accompanied by the feeling of resentment, by the "lust of combat." If the instinct is " blocked" or if it cannot be adequately expressed, it gives rise to a pronounced emotion of anger, which may even take the more violent 
form of rage or frenzy. The expression of the predatory instinct is normally accompanied by the feeling of vindictiveness; if the expression is blocked, it may give rise to the emotion of hate. The self-assertive instinct is characterized by the feelings of pride, vanity, and arrogance; but if the expression is futile, - if one's pride is not respected, or if one's vanity excites only contempt, - then the emotions of shame and humiliation may supervene.

The Sex and Parental Instincts. - The sex and parental instincts are, next to the instinct of self-protection, the most fundamental and imperious in the human organism. Indeed, the parental instinct may negate all others, and impel the individual to sacrifice even life itself for the sake of the offspring. The sex instinct is the basis of conjugal love; the parental instinct, of parental love. Blocking the expression of the sex instinct may arouse the emotion of sex jealousy; while inability adequately to protect the young gives rise to the most intense form of the emotion of grief.

The Social Instincts. - A fourth class of instincts is given the designation, "social," and is represented by the tendency to compete with others, - the instinct of rivalry; by the tendency to congregate in groups, the gregarious instinct; by the tendency to coöperate with others, - the coöperative instinct; and by the tendency to aid others who are weaker or who are in distress, - the altruistic instinct. The affective and emotional states associated with these instincts are 
clearly marked. Rivalry is represented on the affective side by the feeling of emulation; lacking adequate satisfaction, it arouses the emotions of envy and jealousy. The gregarious instinct is at the basis of the important feeling of sociability, - the delight in human companionship. Where this instinct cannot be gratified, where the individual is removed from his kinsmen, his friends, and all those with whom he has been accustomed to ally himself, - one of the most acute emotional states may arise, - that yearning for human companionship with which the lonely castaway on the desert isle eats out his heart, or the more common but scarcely less acute "homesickness" that we have all experienced. The instinct of coöperation arises relatively late in individual development, as it also developed late in the evolution of the race. It is at the basis of one of the most important of the affective complexes, the feeling of loyalty; and one of the most terrible of all emotions, - and yet one from which some of the deepest lessons of life have emerged, - may supervene if loyalty fails. This is the emotion of remorse, and its terrors, viewed as possibilities or anticipated in imagination, form the basis of the ideal that lies at the very foundation of effective social life, - the ideal of duty. Still later in development, both individually and racially, the instinct of altruism appears. The feelings of friendly solicitude for the welfare of others and of delight in promoting this welfare are the normal accompaniments of this instinct. When adequate 
expression fails, - when aid cannot be rendered, the emotions of pity and sympathy or the more intense emotion of grief may be aroused.

Religious and Esthetic Instincts. - Certain strong instinctive tendencies lie at the basis of the religious life, and while it is impossible to say just what these instincts are, there can be no doubt of their existence. We are justified, then, in speaking, somewhat metaphorically, of the religious instincts. As these express themselves in later life, they are manifested in a turning away from this world and in seeking in another a consolation that cannot be found in life as we know it. The religious attitude is one of the subjugation of the self in the presence of the overmastering power that is its object. It expresses itself in feelings of reverence, humility, and veneration. When the object that it seeks is far removed, mysterious, and incomprehensible, - when all religious ceremonies become inadequate and approach to the divine power difficult, - then appears the emotion of awe. The individual falls prostrate before the transcendent deity that is beyond his comprehension and whose glory and majesty pass all understanding.

The asthetic instincts in their cruder aspects appear at an early period in the history of civilization. The choral dance, the song, and the chant are at basis expressions of the instinct of rhythm. The expression of this tendency fills the being with a feeling of harmony, and in its intense form it gives rise to the emotion of ecstasy. Another phase 
of æsthetic development is closely connected with the attitude of contemplation. Theindividual forgets himself ashe stands before the beautiful object, lost in feelings of admiration. As he recognizes in the art product the expression of an ideal that struggles to realize itself in the materials that embody it, but which at the best imperfectly realize this ideal, he is swept by the emotion of rapture.

Closely related to the æsthetic instinct is the appreciation of the comic. There seems to be an innate tendency in human beings to note incongruities in the speech and behavior of their fellows, to regard all novel experiences that do not excite fear as something out of place and ludicrous. When such situations arise suddenly and their outcome is unforeseen, the emotion of astonishment possesses the individual.

The social, religious, and æsthetic ideals and attitudes, while based upon primitive instinctive tendencies, are profoundly modified by experience. Hence it is difficult to determine just what instincts underlie them. For this reason, some writers separate them from the less complicated and clearly innate tendencies, and term them sentiments.

Summary. - The relation between the primitive instincts and the affective states of feeling and emotion is so complicated and yet so important that the following table is inserted in the way of summary of the preceding sections. It will be noted that the instincts are grouped, with reference to the function that they fulfill, into six classes. Under each class the more important specific 
instincts are listed. Following the name of each specific instinctive tendency is a statement (r) of its characteristic expression; (2) of the feelings that either precede or accompany its normal expression; and (3) of the emotions that are commonly aroused when the normal instinctive expression is for any reason " blocked" or prevented.

It should be understood that the "blocking" of a desire or impulse, which, as we have seen, gives rise to an emotional experience, does not necessarily mean that it cannot in any way be expressed. It simply means that the possible expression is, for one reason or another, inadequate. Thus the individual, in working out an instinctive tendency, may get beyond the possibilities of further effective expression. The emotion of wonder arises, for example, when our curiosity is not gratified; our prying and exploring fail to satisfy. On the other hand, when we are impelled to imitate the activity of some one else, we may be balked by our inability to execute the same movement in an effective way. Then arises the emotion of vexation, with the usual accompaniment of all emo- tions - mental confusion, intense feeling, ineffective movements.

It should also be said with reference to the following table that there are certain feelings which attach to several instincts: for example, pride may go with the expression of the combative instinct and with the expression of the self-assertive instinct; admiration is common to the imitative and the æsthetic instincts; desire, in a certain sense, is common to all of the instincts in which the effective movement is toward the object that arouses the instinctive activity, while dislike or aversion is common to all of the instincts in which the effective movement is away from the object. For some of the instincts (repetition and constructiveness, for example), words which designate the accompanying feelings do not exist, although there can be no doubt in either case that the adequate expression of the instinctive tendency gives rise to a pleasant affective "tone." 


\begin{tabular}{|c|c|c|c|}
\hline NAME OP INSTENCT & $\begin{array}{l}\text { Physical } \\
\text { EXPRESSION }\end{array}$ & $\begin{array}{l}\text { NORMAL FEELING } \\
\text { ACCOMPANYING } \\
\text { ADEQUATE } \\
\text { EXPRESSION }\end{array}$ & $\begin{array}{l}\text { EMOTION AROUSED } \\
\text { BY "BLOCKING" } \\
\text { OF ADEQDATE } \\
\text { EXPRESSION }\end{array}$ \\
\hline \multicolumn{4}{|l|}{ Adaptive } \\
\hline $\begin{array}{l}\text { Imitation } \\
\text { Repetition }\end{array}$ & $\begin{array}{l}\text { Copying acts of } \\
\text { others } \\
\text { Repeating one's } \\
\text { own move- } \\
\text { ments }\end{array}$ & Admiration & Vexation \\
\hline Play & $\begin{array}{l}\text { Spontaneous ac- } \\
\text { tivity }\end{array}$ & Exhilaration & $\begin{array}{l}\text { Hysterical ec- } \\
\text { stasy }\end{array}$ \\
\hline Inquisitiveness & $\begin{array}{ll}\text { Prying, } & \text { explor- } \\
\text { ing, } & \text { taking } \\
\text { apart } & \end{array}$ & Curiosity & Wonder \\
\hline Constructiveness & Putting together & $\begin{array}{l}\text { Pleasure of con- } \\
\text { struction }\end{array}$ & $\begin{array}{l}\text { Perplexity, ela- } \\
\text { tion }\end{array}$ \\
\hline Migration & $\begin{array}{c}\text { Seeking new sur- } \\
\text { roundings }\end{array}$ & $\begin{array}{l}\text { Novelty, "Wan- } \\
\text { derlust" }\end{array}$ & \\
\hline Acquisitiveness & $\begin{array}{l}\text { Collecting, } \\
\text { hoarding }\end{array}$ & Desire & Greed, avarice \\
\hline \multicolumn{4}{|c|}{$\begin{array}{l}\text { Individualistic } \\
\text { (a) Self-Protective }\end{array}$} \\
\hline Combative & Fighting & Resentment & $\begin{array}{l}\text { Anger, wrath, } \\
\text { frenzy }\end{array}$ \\
\hline \multicolumn{4}{|l|}{ Retractive } \\
\hline $\begin{array}{l}\text { (I) Shrinking } \\
\text { (2) Flight }\end{array}$ & $\begin{array}{l}\text { Hiding } \\
\text { Flight }\end{array}$ & $\begin{array}{l}\text { Timidity } \\
\text { Fear }\end{array}$ & $\begin{array}{l}\text { Terror } \\
\text { Despair }\end{array}$ \\
\hline $\begin{array}{l}\text { Repulsive } \\
\text { (b) Self-assertive }\end{array}$ & Thrusting away & Dislike, dread & Disgust \\
\hline (c) Antisocral & $\begin{array}{l}\text { Strutting, preen- } \\
\text { ing, domineer- } \\
\text { ing }\end{array}$ & $\begin{array}{l}\text { Arrogance, su- } \\
\text { periority, pride, } \\
\text { vanity }\end{array}$ & $\begin{array}{l}\text { Shame, humilia- } \\
\text { tion }\end{array}$ \\
\hline $\begin{array}{l}\text { Teasing and } \\
\text { Bullying }\end{array}$ & Torture, insult & Contempt & \\
\hline Predatory & $\begin{array}{l}\text { Stealing, de- } \\
\text { stroying }\end{array}$ & Vindictiveness & Hate \\
\hline
\end{tabular}




\begin{tabular}{|c|c|c|c|}
\hline NAME OP IMSTENCT & $\begin{array}{l}\text { Physical } \\
\text { Expression }\end{array}$ & $\begin{array}{l}\text { NORMAL FEELING } \\
\text { ACCOMPANYINO } \\
\text { ADEQUATE } \\
\text { EXPRESSION }\end{array}$ & $\begin{array}{l}\text { EMOTION AROUSED } \\
\text { BY "BLOCKING" } \\
\text { OF ADEQUATI } \\
\text { EXPRESSION }\end{array}$ \\
\hline Shyness & $\begin{array}{l}\text { Withdrawal, } \\
\text { seeking soli- } \\
\text { tude }\end{array}$ & Self-distrust & Fright \\
\hline \multicolumn{4}{|c|}{ Sex and Parental } \\
\hline Sex & Mating & Conjugal love & $\begin{array}{l}\text { Passion, sex } \\
\text { jealousy }\end{array}$ \\
\hline $\begin{array}{l}\text { Protection of } \\
\text { young }\end{array}$ & $\begin{array}{l}\text { Guarding, } \\
\text { shielding }\end{array}$ & Parental love & $\begin{array}{l}\text { Self-renuncia- } \\
\text { tion, grief }\end{array}$ \\
\hline \multicolumn{4}{|l|}{ Social } \\
\hline Rivalry & $\begin{array}{l}\text { Competitive } \\
\text { acts }\end{array}$ & Emulation & Jealousy, envy \\
\hline Gregarious & $\begin{array}{l}\text { Congregating in } \\
\text { groups }\end{array}$ & $\begin{array}{l}\text { Sociability, kin- } \\
\text { ship }\end{array}$ & $\begin{array}{l}\text { Homesickness, } \\
\text { yearning for } \\
\text { companionship }\end{array}$ \\
\hline Coöperative & $\begin{array}{c}\text { Working to- } \\
\text { gether }\end{array}$ & Loyalty & Remorse \\
\hline Altruistic & Helping others & $\begin{array}{l}\text { Friendliness, } \\
\text { solicitude }\end{array}$ & $\begin{array}{l}\text { Sympathy, pity, } \\
\text { grief }\end{array}$ \\
\hline \multicolumn{4}{|l|}{ Religious } \\
\hline Self-abasement & Subjugation & $\begin{array}{l}\text { Reverence, hu- } \\
\text { mility, vener- } \\
\text { ation }\end{array}$ & Awe \\
\hline \multirow{3}{*}{$\begin{array}{l}\text { Esthetic } \\
\text { Rhythmic }\end{array}$} & & & \\
\hline & $\begin{array}{l}\text { Dancing, song, } \\
\text { chant }\end{array}$ & Harmony & Ecstasy \\
\hline & Contemplation & Admiration & Rapture \\
\hline
\end{tabular}

\section{Definitions and Explanation of Terms Used}

Reflex activity. - This consists in its most simple form of an excitation that is mechanically carried over, or " reflected," from a sensory to a motor neurone. Consciousness may or may not be present. In either case it performs no service in directing the behavior. 
Instinctive activity. - This consists of a complex series of reflex activities working together harmoniously to bring about a valuable form of behavior. Consciousness, while present, does not exercise control over such activities.

Innate. - Something born with the individual; distinguished from that which is acquired. An innate tendency may be present at birth, or it may put in its appearance later. However, if it is innate, it is not gained through experience.

\section{QUESTIONS AND EXERCISES}

r. Define reflex behavior. How is it distinguished from instinctive behavior? Illustrate both.

2. Name the four important characteristics of instinctive behavior.

3. Why are play, curiosity, imitation, inquisitiveness, and constructiveness called "adaptive" instincts?

4. Name the principal individualistic instincts, and show the relation of each to self-preservation.

5. What instincts are included in the class called "social"? Can you give illustrations of social instincts in animals below man?

6. What instinct may explain certain cases of truancy?

7. Note the behavior of a child (from three to seven years old) for a period of half an hour. What activities can you find that are probably due to instinctive tendencies, and to what instincts are they due?

8. Analyze one of your dominant motives or ambitions back to a fundamental basis. Can you find a "core" of instinct? What emotions are aroused when the realization of the motive seems hopeless? 


\section{CHAPTER IX}

\section{THE VALUE OF THE HUMAN INSTINCTS}

Two questions of educational importance arise in connection with instinct: (I) of what service are these primitive tendencies to behavior? what instincts must education try to confirm and sanction? and (2) how shall education go about to change the instinctive tendencies that are not valuable in their primitive form? The first of these questions will be answered in this chapter; the second will form the theme of Chapter X.

The Value of the Adaptive Instincts. - We have already discussed somewhat in detail three of the most important of the adaptive instincts (namely, imitation, play, and curiosity) and have shown, particularly in regard to play, its value in preparing the individual with a set of acts and a stock of experiences that will be of service to him later on in life. What is true of these two instincts is likewise true of the other adaptive instincts. The squirrel collects nuts for the coming winter, although it does not need them at present and although it has no knowledge of its future needs. A similar instinct prompts the bee to gather honey, although the insect has no idea that it will be of use at some future time. In a 
like manner, the human being prepares for a future that he cannot foresee. The collecting and hoarding instinct in the child has not in civilized communities so direct a value as it has in the cases of the animals above cited; nevertheless, by means of making these collections the child may learn much that will be useful to him later on in his experience. Like the play instinct, the collecting instinct may be used by the teacher as a means of indirect instruction. The collection of stamps and coins, for example, may awaken an interest in and give a certain acquaintance with foreign countries and thus serve as a valuable aid in the study of geography and history ; the gathering and preserving of various flowers and insects may be of help in nature study, and so on.

The constructive instinct is clearly of great value to the individual, and may be made of service in education. It in part explains the interest that most pupils show in manual training, and in cooking, sewing, and other domestic arts.

Repetition likewise has great educational significance. Through the tendency to repeat, it becomes possible for the child to establish those forms of behavior that are the most beneficial, and it is of no small service when intentionally utilized by the teacher as a means of imparting knowledge and of forming useful habits. Since repetition is important as a means of learning, it is indeed fortunate that there is a natural tendency on the part of the child to repeat. Here a sound educational method and a 
predisposition on the part of the learner work together to bring about the desired result.

The Value of the Individualistic Instincts. - The instincts of combativeness, retraction, and flight have less value in present-day civilization than they possessed in the past. Among animals and primitive peoples the fear of the unknown, of the dark, of certain animals such as insects and reptiles, of objects with fetid odors, was very important in protecting the individual against the ever present dangers that lurked in the forest and the cave, that threatened life in the ambush of the enemy, the lair of the beast, and the very air that one breathed. In these earlier days the fearless must soon have perished. Combativeness and pugnacity, too, had their place in the hut and the cabin, the forest and jungle. A calm attitude, a lack of emotion, a calculating coolness, belong more to modern society than they did to the savagery of the past. Further, when there were few recognized laws and no means of enforcing them, existence depended largely on the ability and the will to fight. Combativeness was an essential in the struggle to survive, and the fighting instinct was indispensable.

While the usefulness of combativeness, retraction, and flight in the primitive stages of stress and struggle must be recognized, it is held by many that these crass impulses are no longer valuable and should have no place in the modern world. To an extent this assumption is right. There are many fears that humanity should have 
outgrown, and these should be banished from the mind of the child as soon as possible; certainly they should never be fostered, as they sometimes are by unwise parents and negligent nurses. Superstitious dread, irrational terrors, and the like must be removed. It is wrong to tell the child that the "bogey-man" will catch him, or that a tiger is lurking in the dark ready to devour him. Such fears as these fill the mind with dread and accomplish no lasting good. However, it must be remembered that there are rational fears, and that due caution is extremely valuable in the affairs of life. The problem here is to change the reference of fear, - to detach it from the objects that naturally arouse it, - and to attach it to other objects. This is the problem of the next chapter, however, and need not detain us at this point.

The distinctly anti-social instincts have little in their favor under present-day conditions. Teasing and bullying, which are common practices among boys, may serve to keep the young upstart in his proper place and to make the eccentric and peculiar child conform to the group; in so far, this instinct is social rather than the opposite; so, too, mild forms of fagging and hazing may result beneficially, but on the whole this spirit is dangerous to the school and community life, and if tolerated at all, should be held strictly within bounds.

The predatory instinct combined with the gregarious instinct leads boys to form gangs and commit all sorts of offenses against property. In some of its expressions it 
is not necessarily an indication of moral delinquency and should not be regarded too seriously, yet it may lead to the most unhappy consequences if given free scope. This is one of the instincts that should be repressed as far as possible. The highwayman and the viking belong to the past. They are out of place in modern life.

The spirit of adventure, which is allied both to the predatory instinct and to the instinct of migration, expresses itself not always in deeds of disorder and violence. It sometimes leads the young person to leave home and "seek his fortune" in the great world outside of his home environment. This impulse to rove served a very useful purpose in the earlier development of society, but it is a dangerous tendency in a boy of the school age, and sometimes ends in grave results.

The Value of the Social Instincts. - The social instincts are of the greatest importance and form 'the clearest examples of instincts that education must foster and confirm. The desire for companionship is common to all normal human beings and even manifests itself, often in a very marked manner, in the "herding instincts" of the lower animals. Children at a very early age seek the companionship of other children. One of the greatest misfortunes that can befall a child is to be left entirely or even largely in the society of adults. The lonely child deprived of actual playmates, not infrequently creates imaginary companions with whom he plays in fancy, and thus in a way attempts to make up 
in this unreal manner for the vital lack of actual associates. The young person and the adult, like the child, are social beings, and bereft of society, they are generally wretched. There is no punishment so severe as that of solitary confinement.

The instinct of coöperation has been a powerful force in building up the community life. The history of civilization has been that of the gradual expansion of sympathy and understanding among ever widening groups. From the family it has extended to the tribe and then to the state and nation. The present century promises to carry it beyond the confines of national barriers and to see a real federation of mankind, based upon a mutual comprehension and a common feeling.

Rivalry is to be classed as an instinct of a social nature, since through it a large amount of social progress has been brought about. Competition has sometimes been thought of as something essentially base and unworthy. It is maintained by some that it is this spirit that fills our reformatories and prisons. This point of view is so radical that it carries with it its own refutation. Competition is not bad in itself; like everything else it may become an evil if carried to an extreme. If abnormally strong tendencies to rivalry have filled our penal institutions, it is equally true that abnormally weak tendencies to compete have filled our almshouses. Competition among human beings does not necessarily nor generally mean a bitter hand-to-hand struggle for existence, in 
which the weak are ruthlessly pushed aside and left to perish. It means rather a more or less conscious attempt on the part of the individual to achieve certain ends that have been set up as social ideals. Of necessity it is true that in the striving for these ends some will outstrip others in the race; some will arrive at the goal, or at least get reasonably near it, while others will be left far behind; and the force of rivalry in life depends upon this primitive factor. The instinct of rivalry, like the fighting instinct, must be modified if it is to be thoroughly serviceable.

The Value of the Religious Instincts. - Much has been said and written in recent years in regard to the innate tendency in the large majority of human beings to turn their attention toward the supernatural and to seek in another world a consolation that this cannot afford. The religious instinct is extremely complex and manifests itself under various forms. There can, however, be little doubt that there is a fundamental instinctive attitude of the normal human being toward the universe that may be called religious. The definite form that this instinct takes is largely the result of his surroundings, and of the specific form of religious education to which he is subjected. The fundamental tendency, however, must be considered as innate and in no sense acquired, although the specific expression that the religious attitude takes is not the result of inheritance. It is due rather to the prevailing social ideals that the individual quite unconsciously appropriates and to the 
kind of religious teaching the child may have received in the home and the school. One of the most important problems that the school is called upon to solve at the present time is the extent and kind of religious instruction that should be provided. In the United States dogmatic instruction in any form of religious belief cannot be given to the children in the public schools. Theinstruction must be indirect in its nature; nevertheless it should be sufficiently vital to appeal to those deep-lying tendencies in human experience that relate themselves to another world. The religious instinct is not decaying, as some would have us to believe. Specific forms of religious belief, together with certain kinds of religious practices, have been brought into question. But there is as strong a faith as ever in those fundamental experiences which men call religious. The religious instinct is still vital, and there is no reason to believe that in the advance of modern society the necessity for a supreme being has been put aside. The religious instinct is basal to human progress and happiness. It cannot be regarded as a relic of the superstition of our uncultured ancestors.

\section{QUESTIONS AND EXERCISES}

I. What instinctive tendencies can education employ in furthering its own ends? What tendencies should be confirmed by education? What tendencies should be modified?

2. In what ways may the school employ the instinct of play? The instinct of imitation?

3. Give illustrations of the useful and harmful employment of the instinct of rivalry. 
4. It has been suggested that the school should stimulate rivalry between groups rather than between individuals. How may this be accomplished ? What instinct would be appealed to in group rivalry?

5. What reasons can you give for considering the religious attitude as based fundamentally upon instinct?

6. At what time in the life of the individual is it likely to most definitely show itself ? Do you make any distinction between the religious attitude of the child and that of the youth and adult? 


\section{CHAPTER $\mathrm{X}$}

\section{HOW INSTINCTIVE BEHAVIOR MAY BE CHANGED}

THE ability profoundly to change inherited behavior through experience is the most important human characteristic. It is this factor that lifts man above the brute, for while the lower animals may modify instinctive tendencies within certain limits, these limits are narrowly circumscribed. Furthermore, the lower animals do not have to modify their instincts profoundly in order to live the life of their species. But man in order to be man must get beyond instinct. The behavior that is distinctively human is that kind that has been changed to suit the stage of development that the race has reached.

All Education Must Begin with Instinct. - But education must always start with instinct, and-however far above the primitive plane it may carry the individual - it must rest in the last analysis upon instinctive tendencies. In the last chapter, it was shown that certain instincts, even in a relatively unmodified form, have a utility in civilized human life. Some of these (the adaptive instincts of play, curiosity, imitation, repetition, and constructiveness) lead the individual to modify his be- 
havior for himself, - that is, without the aid of a guide or teacher. The task of education here is to give these adaptive tendencies a chance to operate in a helpful way,to set desirable "copies" for imitation; to provide space and companionship and leaders for healthful plays; to give curiosity something to pry into and explore that will yield valuable knowledge; to give the constructive instinct objects to work upon.

Beyond these instincts that are useful in their original form, however, are a large number of others that must be changed or transformed. The present chapter will discuss the various ways in which desirable changes may be effected.

The Modification of Instinct. - (a) The Attachment of Another Feeling with its Appropriate Response to an Object that Naturally Arouses an Undesirable Instinct. This is the simplest method of modifying an instinct, and is in fact the only one that can be effectively employed in the training of animals and in the earliest stages of the child's education. The most common form that this method takes is that of physical punishment. The efficiency of physical punishment lies in the fact that the feeling of fear and the movement of retraction or flight are associated with an object that would naturally arouse another feeling and another movement. Thus the child must learn to repress his acquisitive instinct. Nature tells him to appropriate the object that pleases him; but civilized society is possible only when men respect 
the property rights of others. We simply cannot in this world appropriate every object that pleases us. We must learn to repress - to " inhibit" - this tendency, and to learn this thoroughly means beginning very early in life to distinguish between the objects that we may take and those that we must leave. Thus when the child appropriates a forbidden object, the careful parent sees to it that the act results unpleasantly. In the course of time, - perhaps even after the first disastrous experience, - the object that originally stimulated the desire for possession now stimulates the instinct of withdrawal or retraction, and the feeling of fear.

This may be clearly observed in children during the second year of life. Some objects the child will touch and play with freely. In his attitude toward others you will often note an initial reaching movement; then the hand falls back, and perhaps the child withdraws from the neighborhood of the object. In the course of time, the actual advance and withdrawal cease. Inhibition has become a habit with reference to this particular forbidden object; the temptation is no longer felt; the instinctive tendency has been effectively modified.

This conquering of instinct probably requires no memory image of the first disastrous experience. No judgment is necessary; the child does not say to himself, "I took this object before, and was punished; now I will leave it alone." The unpleasant affection immediately colors the perception of the object, just as, before correction, a pleasant affection was a part of the immediate perception. 
The reader may find examples of this immediate fusion of the unpleasant experience with its object by recalling the way in which he looks upon some article of food which, through over-indulgence, or for some other reason, has caused nausea. For some time afterward, one does not like to see the article in question, for the unpleasant affective coloring is immediately fused with the perception.

The Significance of the Unpleasant in Moral Training. - It is difficult to overestimate, in connection with the problem of moral training, the importance of this fundamental method of modifying instinct. Moral culture consists primarily in shifting the emphasis which nature has placed upon certain acts and activities. We no longer need to fear the dark; the feelings of disgust and repulsion no longer need attach to certain objects that were dangerous in primitive life ; but we do need to fear evil, and we $d o$ need to attach to certain tendencies that may have been very important in primitive life the feeling of disgust that will lead us to thrust them out of our presence. Aristotle, centuries ago, suggested that the primary problem of moral culture is to lead the individual to love the good and to hate the bad. Love and hate imply feelings and emotions that originally attach to certain instincts. Education faces the problem of detaching these feelings from the objects that originally stimulated them, and attaching them (with their appropriate responses) to other and often vastly different objects.

This suggests the importance of thus modifying undesirable instincts very early in the child's life. Unless unsocial tendencies 
bring unpleasant consequences, they are bound to become confirmed, and the difficulty of eliminating them is increased tenfold. The years of early childhood in the home, and the first five or six years of the child's school life, are fundamentally significant in this connection. One cannot solve all of the problems of moral education in the preadolescent period, but if the basis is properly laid at this time, the later problems will be greatly simplified. The child who has had a proper training in these formative years will evince a strong prejudice against lying, theft, laziness, disobedience, and physical uncleanliness. He may not know why these things are wrong, but he will feel that they are wrong, and this is the fundamental and important factor; for conduct is at basis a matter of feeling, and those in whom forbidden activities arouse disgust and abhorrence may be safely trusted to pass through the later emotional and moral crises in comparative safety.

\section{The Doctrine of Natural Punishments. - A great} many misleading statements have been made by writers upon the subject of child discipline. Some have maintained that "nature" will look after the necessary corrections, - will associate unpleasant consequences with wrong acts and pleasant consequences with right acts. Leave the child to the operation of the environment about him, these theorists maintain, and he will acquire the kinds of acts that are valuable, and discard those that are useless. One form of this doctrine is known as the theory of " natural punishments" and was elaborated in a very ingenious way by Herbert Spencer, with whose name it is commonly associated. The doctrine has many points to commend it, for it is true that the child, in adjusting himself to the world about him, 
will learn to inhibit many instinctive tendencies that do not "fit in" with present-day conditions. This method of learning, however, should not be depended upon alone. It is really a process of trial and error, and like all such processes is cumbrous and uneconomical. Conscious correction by parent and teacher proceeds upon the basis of intelligence and foresight, and saves the child from undergoing too many painful experiences by seeing to it that the pain comes at the proper time.

The natural method of punishing the child for careless use of matches would be a painful burn. But the careful parent will spare the little child this experience by associating the handling of matches at an irresponsible age with an unpleasant consequence sufficiently strong to inhibit the tendency, but far from being so painful and dangerous as an actual burn.

Pleasure vs. Unpleasantness in Learning. - Still other educational writers (and not a few parents and teachers) believe that the child may learn the necessary inhibitions of life without experiencing unpleasant consequences. These people would place the emphasis upon the positive rather than upon the negative side; they would always reward the good rather than punish the evil. Again, there is much to be said for this point of view, and one would be foolish, indeed, to withhold the pleasure that ought to attach to right doing. But the doctrine has certain limitations and dangers that need to be held very clearly in mind : - 
(I) In the first place, the fear of the unpleasant and the disagreeable is probably a more effective stimulus than the liking and desire for the pleasant. This is true in animal psychology, as has been abundantly demonstrated. There is no doubt that it also holds with children and, indeed, with adults. This does not mean, however, that the two should not work together, or that the pleasant sanctions should not always be used when it is clear that they will be effective.

(2) Another reason for not entirely discarding the unpleasant lies in the fact that the kinds of behavior that are most significant and important in social life are the farthest removed from instinct; consequently it is difficult always to find naturally or instinctively pleasant objects with which to associate these socially-important activities. The finest things in life are its generosities, its sacrifices, its renunciations, its achievements that have come after persistent effort and struggle, - and all of these things - these greatest "goods" of life have but a restricted instinctive sanction. Sacrifice, for example, is instinctive or natural only in connection with the protection and care of offspring, and even then in a pronounced form only in the mother. Achievement has an instinctive basis in the powerful instincts of combativeness and rivalry, but persistent effort, - effort continued for a long time against tremendous odds, and in the face of contrary desires that are keen and imperative, - is an art that strikes against the most funda- 
mental instincts. The greatest triumphs of humanity have come largely through the pain economy. The highest ideal that man has yet conceived is represented by the agony of the cross. Struggle and suffering, the will to do the things which are not pleasant and agreeable, the ability to throw instinctive desire and immediate pleasure to the four winds, - these have been the forces which, working through the long centuries of human history, have lifted mankind, notch by notch, to its present level. And there is no reason to believe that factors demanding less of the individual could ever have accomplished, or will ever accomplish, a similar triumph.

The Modification of Instinct. - (b) The Attachment of Another Response to an Object and to the Feeling that the Object instinctively Arouses. - This is also one of the simpler methods of modifying an instinctive tendency. The combative instinct furnishes a good example. It is naturally aroused only by some gross invasion of one's own physical " rights," and it is naturally expressed only by actual physical combat. If I ruthlessly take from the little child the object which he has appropriated and in which he finds pleasure, he will strike, kick, bite, look ferocious, and emit, not the cry of pain, but the cry of rage. This is the normal expression of the fighting instinct aroused by a normal stimulus. Primitive man similarly responds to a similar situation. Civilized life, however, compels another mode of response. If my neighbor steals my horse, I cannot well keep from re- 
senting the act keenly; it would not be well for social life that feelings of resentment should be repressed when personal rights are invaded, for this would encourage an exploitation of the decent and law-abiding by the lawless. On the other hand, while I feel the resentment, I must not express that resentment in the primitive fashion. I must seek satisfaction, not with my fists, my teeth, and my nails, but through a due and proper process of law. Thus civilized society, while sanctioning the attachment of a primitive feeling to a primitive stimulus demands an entirely different response.

Educationally, this method is important in connection with most of the individualistic instincts, with some of the adaptive instincts, and especially with the sex instincts. It is right that rivalry should stimulate the feeling of emulation, for in this way progress is assured through many members of the group. One individual achieves an advance over his fellows, and his fellows struggle to catch up with him. This is "good," for it tends to advance the entire group. But rivalry can' easily be expressed in ways which are " natural " enough but which are, nevertheless, quite inconsistent with social welfare. It is " natural" to take an unfair advantage; primitive man had no standards of honor in combat. Civilized man has established such standards, - standards that have been wrought out of the race experience through centuries of struggle and suffering. The child must be taught to live in accordance with their 
dictates. He must be made to feel that cheating, de ception, "hitting below the belt," tale-bearing, and "knocking" are dishonorable and forbidden means of expressing his instinct of rivalry. $\mathrm{He}$ must learn to "play the game" fairly and squarely and to prefer honorable defeat to a dishonorable victory; and he must generalize these standards of conduct beyond the athletic situation, and apply them to every situation in which he competes with his fellows.

It is for this reason that supervision of the games and plays of childhood is imperative; for these activities, unsupervised, are likely to confirm and sanction underhanded means of winning. It is true that the cheat will be detected, and it is true that under certain conditions a much more effective punishment will be meted out to him by his fellows than the cleverest supervisor could devise. But these conditions do not always govern the situation. If the cheat happens to have the qualities of leadership, he will infect with his virus a goodly following among his companions; and the evil, which is bad enough when individually expressed, runs riot through the entire social group. It has been found that unsupervised playgrounds in our large cities are veritable hotbeds of vice, and the same may be true of unsupervised recesses and noon intermissions in the school. Where large numbers of children congregate, the welfare of society demands that a responsible adult be present, with full authority to check in the bud the first expression of a dangerous tendency.

The Modification of Instinct. (c) The Detachment of a Feeling from its Natural Object and Response, and its Attachment to Other Objects and Responses. - Much more difficult than either of the methods of modifying instincts discussed above is the method which attempts to lift a 
strong feeling bodily out of the instinct to which it naturally belongs and to fasten it firmly to another object and to an entirely different response. This process is sometimes called the sublimation of the instinct, and its importance lies in the possibility of thus enlisting in the service of an important social ideal the powerful force that the native feeling represents and the energy that it may set free.

This is what has happened, for example, when we "stand up for what is right," "fight for a principle," " make war on evil," and do other strenuous deeds which we can adequately describe only by employing a militant metaphor. The " cause" for which we "fight " becomes in effect a part of our own personality. We have appropriated it; it is ours. Hence the feelings and emotions that naturally go with the fighting instinct come to attach to the cause that we have made our own if this cause is invaded, questioned, or made light of by others. But while the feeling of resentment is aroused by the invasion of our cause, the primitive method of expressing this feeling must not be permitted to operate. On the side of response as well as upon the side of the object or stimulus, there must be a modification.

A very good illustration of an effective attempt to "sublimate" a primitive instinct is to be found in the success of the Salvation Army. Here we see a military organization with innumerable suggestions of actual physical combat enlisted in the service of the most peaceable of ideals. The Boy Scout movement (as it has been developed in America) makes a similar use of the feelings 
connected with several of the primitive instincts, attaching them to other objects and insuring responses that are only symbolic of the actual primitive responses.

In general it may be concluded that these concrete and tangible factors that hark back in a symbolic way to an older instinct will be of inestimable service in enlisting in a worthy cause the feeling originally attaching to the instinct. Fortunately for us, nature did not draw fine distinctions, and when she associated feelings and emotions with instinctive activities, it was usually by very superficial bonds. These were sufficient for her purposes, and the very superficiality serves us a useful turn now that civilized life has compelled a reconstruction of so many of our native tendencies.

The Relation of Attention to the Modification of Instincts. - We have discussed three general methods of modifying instinctive tendencies. In all of these, the principles that were developed in the chapter on attention are important. It will be remembered that "passive" attention was at that time termed instinctive; attention is naturally given to those stimuli that "fit in "with instinctive or inborn tendencies. On the other hand, "active" attention means attending by effort to something that is not attractive, that does not " fit in " with an immediate instinctive need. The early stages of active attention always represent a modification of instinctive behavior; it is only because we can give active or effortful attention that we can get above 
instinct and climb to the plane of civilized life. In the chapter on Attention, we emphasized the importance of holding in mind the remote end as a means of overcoming the tendency to follow immediate desire. In the chapter on Feeling it was pointed out that the only way in which the idea of a remote end can be made effective over behavior is to endow it with a feeling that will conquer the feeling attached to the immediate tendency. In other words, we really place the gratification of the desire in the future and work steadfastly toward that instead of following the behest of immediate desire.

Ideals in Relation to Instincts. - This attachment of a strong feeling to the idea of an end to be attained turns the idea into an ideal. The ideal may be closely related to an instinct, as when the boy who does not like to sell newspapers - who fears the taunts of his competitors, or the rude refusals of those whom he approaches as customers - conquers his shyness by the ideal of earning money, - of gratifying his instinct of acquisition. Another ideal that works close to the instinctive level is represented by the boy who dislikes arithmetic, but who works at his problems in spite of his distaste for them, because when he finishes them, he may gratify his constructive instinct at the manual-training bench.

It is through this pushing forward of the instinct this delayed gratification - that the first steps are taken away from primitive passive attention, and the first step is made toward active attention and the conquest 
of immediate desire. But education must not content itself with conquests that reach no further than this. It must start with these, but it must soon get beyond them. Other ideas, unconnected with instincts, must be endowed with feeling and thus given strength to overcome immediate tendencies. The boy must come in time to work steadfastly at a given problem or a given task, even if a primitive desire is not to be gratified either immediately or in the future. In other words, the most effective ideal that man has ever conceived is the one that is farthest removed from the primitive sanctions. It is the ideal of Duty, and the individual who does not form an effective ideal of duty in his early life will find it hard to adjust himself satisfactorily to a world that gives its richest rewards only to those who are able to hold themselves in leash through the storm and stress of struggle and temptation. It is only when a man works from motives of duty that one can depend upon him without question. Though this ideal be strong, he may fail to carry his message and bring back an answer, but this failure will be due simply and solely to the limitations of his nature. But when a man has lived through his early life accustomed to shirk tasks that are distasteful or for which he can see no gain to himself, he is certain not to be dependable. He may carry the message and bring back the answer if he wants to or if the reward is clear and tangible; but in the important crises, he will fail. It is one of the serious defects of 
HOW INSTINCTIVE BEHAVIOR MAY BE CHANGED I63

modern educational theory that it has been blind to * this principle.

\section{Definitions and Explanation of Terms Used}

Modification of instincts. - Changing the character of "an instinctive activity by (I) attaching another feeling and its appropriate response to an object that naturally arouses an undesirable instinct; (2) attaching another response to an object and the feeling that it naturally arouses; or (3) detaching a feeling from its natural object and response, and attaching it to other objects and responses.

Sublimation of instinct. - Modification of the third type described above.

Doctrine of natural punishments. - The theory that the unguided experience of the child will lead to the essential modification of instinctive tendencies.

Ideal. - An idea surcharged with feeling, and thus made an effective end or goal of conduct.

\section{QUESTIONS AND EXERCISES}

I. What is meant by the statement: "Man, in order to be man, must get beyond instinct."

2. Describe and illustrate the three ways of modifying instinct. Illustrate the following terms used in the discussion: "Object arousing instinctive activity"; "Feeling normally accompanying instinct"; "Response."

3. Find in your own experience instances of the modification of instinctive tendencies through the discipline of unpleasant consequences. Did the "memory" of the consequences thereafter 
"fuse" immediately with the object or situation, or did the painful experience have to be recalled explicitly in order to inhibit the tendency?

4. What is meant by the doctrine of natural punishments? With whose name is the doctrine associated? State some cases in which it may be wise to leave the discipline of the child to "natural consequences." What are the limitations of this doctrine?

5. From your own experience, what type of incentives would you judge to be the more powerful, - those involving fear of unpleasant consequences, or those involving hope of reward?

6. What standards of honor is it essential to develop in order to counteract the dangers involved in competition?

7. Name some forms of competition that may be permitted in school work. Under what circumstances is such competition likely to become dangerous?

8. What is meant by "sublimating" an instinct? In what ways may the energy generated by the strong "fighting" and "property" instincts be turned into desirable channels?

9. In what way does active attention mean a conquest of instinct? Define the term "ideal." Name the ideals that have been particularly important in the development of the race. Show how these have represented a conquest over instinct or "nature." (These ideals are typically represented by the various virtues: honesty, charity, forgiveness, chastity, temperance, industry, duty, etc.). 


\section{CHAPTER XI}

\section{HABITUAL BEHAVIOR AND THE LAW OF HABIT-BULDING}

IN the last three chapters, two types of behavior that occur without the direction of consciousness have been discussed, - namely, reflex behavior and instinctive behavior. It was pointed out that inherited connections in the nervous system condition these two types of behavior. The present chapter will be concerned with another class of automatic or mechanical responses, - habits.

Habit Contrasted with Instinctive Behavior. - Habit resembles instinctive behavior in two important particulars. In the first place, it is not controlled by consciousness, and is to be looked upon as due to paths of preferred conduction in a chain of sensory and motor neurones. In the second place, like instinct it often has important conscious accompaniments, especially of an affective character.

The important difference between habit and instinct lies in a difference of origin. This difference is best expressed by saying that habits are acquired, while instincts are innate or inherited. The connections between neurones which give rise to habits are made during the lifetime of 
the individual and through his own experience in reacting to the world about him. The connections between neurones that give rise to instincts are either born with the individual or, if they appear after birth, they are due to tendencies which are inborn. Instincts, then, are fairly constant with all members of the same species, varying only in intensity; habits, on the other hand, vary in kind with different individuals. The animal that depends chiefly upon instinct is suited only to a narrow range of life; it must live in the environment for which its instincts fit it. The animal that has the power to modify instincts and to form habits can adapt itself to varying or changing environments.

The Affective Element in Habit: the "Propensity." The intimate relation between instinctive behavior and feeling or affection has already been emphasized. Since habits have so many resemblances to instincts, it is not surprising to find that the expression of a habit, like the expression of an instinct, is frequently accompanied by a pleasurable affective tone. A complex habit, indeed, becomes pleasurable as it becomes automatic. The difficult feats of skill which are acquired through a period of intense and often disagreeable effort come to be sources of enjoyment; just "going through the movement" is often a pure delight.

The fascination which games of skill possess for the initiated illustrates this principle. The beginner finds the complicated movements involved in playing golf, tennis, or billiards difficult to 
master; he becomes discouraged and is often tempted to give up the task and seek his recreation in something else. But gradually, as the art is acquired, the unpleasant factors are eliminated; and when the activities have become fairly automatic and mechanical, a real pleasure attaches to them. The same transition from a stage of unpleasantness to pleasantness and even fascination is to be observed in the growth of almost every habit. The cold morning bath is ordinarily not only unpleasant but highly disagreeable to the beginner; but continued practice makes it a thoroughly gratifying exercise. The novice at the piano looks upon the weary hours of practice as the last word in drudgery; but once the technique is mastered, - once the adjustments have become automatic, - playing becomes a source of pleasure.

This affective "propensity" of habits is most clearly recognized, however, when the customary expression or activity is interfered with. Our routine is broken up; the stimulus that ordinarily "sets off" a series of movements is prevented from doing so; and we feel irritated, ill at ease, out of harmony with our surroundings. Indeed, if the break is sudden and unexpected, - if an unlookedfor situation comes between the stimulus and the habitual response, - a period of emotional excitement may ensue, precisely as it does when a strong instinctive tendency is suddenly "blocked."

The Importance of Habit-formation. - In one sense, the whole process of education culminates in the formation of useful habits, - in the acquisition by the individual of certain forms of behavior which will adapt or adjust him to the life which he is to lead. As will be pointed out later, however, education in the school 
and home cannot form all of the useful habits that the individual will need, for the conditions of life are continually changing, and neither the teacher nor the parent can predict with certainty just what habits will be needed in the mature life of the individual. Hence, while all education may culminate in habit, it does not follow that school education does nothing but form habits. A very important part of its duty is to prepare the child to form habits for himself when he needs them, - to furnish him with conscious guides to behavior which will permit him to meet new situations, - as well as to fix permanent and rigid habits which will control his conduct in the unchanging situations. It is with the latter problem, however, that the present chapter is especially concerned.

The Law of Habit-formation. - The process of habitforming in education may be stated under three heads : (I) focalization of consciousness upon the combination of movements to be made automatic; (2) attentive repetition of this behavior; (3) permitting no exceptions to occur until the habit has been established.

(I) Focalization. - This really means gaining a clear idea of the way in which the different muscles must work together in order to form the habit. Very frequently the teacher gives a demonstration of the appropriate movements, making certain that the pupils repeat the movements in the same way, and thus get the "feel" of the new adjustment. 
The "Montessori" method of primary education employs some" ingenious devices for insuring effective focalization. When the child is learning to write, for example, he is given blocks upon which are pasted letters cut from a fine-grained sandpaper. With the tip of the finger the child is taught to trace the letters as they are written. He follows the sandpapered lines with the finger, the slight "tickle" of the paper proving an effective incentive impelling him to repeat the movement until the proper coördination of the muscles has been mastered.

Habits may also be initiated by the process of " trial and error" described in Chapter II. The individual "blunders" about in trying to solve a situation, and finally " hits upon" the fortunate combination of movements that will meet his purpose. This successful method stands out from the others simply because it is successful. He repeats it readily and the habit may be quickly established. In general, however, this method is of only slight importance in education. As will be shown later, it is essential to economy of habit-formation to begin with the most effective and economical adjustment and not to run the risk of permitting inadequate habits to be formed. It has been said that fully two thirds of the drill work of the teacher in the elementary school is given over to the breaking of inadequate habits that the child has been permitted to form. "One way to reduce this waste in education is to see to it that the right habits are formed first.

(2) Attentive Repetition. - No habit can be formed without repetition. The combination of movements 
constituting the habit must be repeated over and over again until the neurones are permanently connected. Furthermore, mere repetition, if not ineffective, is at least uneconomical. Attention must be given to the repetitions. Among the lower animals, it is often impossible to secure such attention, and for this reason the habits that can be formed are very simple in their nature and a longer time must be spent in their acquisition. Drill is necessary in learning, but it should never be lifeless, mechanical drill. The learner must be conscious of his failures, of his inadequacies, but it is even more important that his successful efforts should be recognized and commended.

The necessity for securing attention to the repetitions involved in habit-formation is recognized by skillful teachers in the invention of devices which will insure the pupils' interest in the work, and relieve the monotony which is otherwise inevitable A device is a means of varying the work in some of its non-essential or superficial details, while, at the same time, the fundamental adjustments or movements are preserved. Thus, in making automatic the associations represented by the "tables" in arithmetic, different types of problems are introduced; the difference, however, is in the details; the fundamental relations of the numbers are still preserved.

Spelling, as a habit-building process, consists in making automatic the sequence of letters in words. In English spelling, these sequences must in many cases be mastered literally by "main strength," for there are very few rules that will aid one. The spelling of each word, then, becomes as it were a separate habit, and the problem in teaching spelling is first to focalize the form effectively, and then to insure attentive repetition until the proper order of the letters has become " second nature." Devices for sus- 
taining attention are particularly important here, and one of the most effective of these devices is the spelling match. Here the strong instinct of rivalry is brought into the service of habit-formation, impelling the individual to repeat attentively that he may later make a good record either for his own advancement over others or for the honor of his "side."

In general, "marks" and "grades" may be looked upon as devices for impelling the pupil to give the necessary effort to his work when the intrinsic and immediate interest in it has died away.

(3) Permitting no Exceptions. - In establishing a new habit, especially when it opposes, as it often does, an old habit that must be uprooted, or when it opposes a strong instinct, it is essential that no exception to the desired behavior be permitted, and especially that there be no relapse to the older habit or to the instinctive response. While this principle is important in all phases of habit-formation, it has been emphasized most frequently in connection with the so-called "moral" habits. The reformed drunkard must not allow himself to take even " one glass" ; for, if a return to the older habit is initiated, it will be harder than ever to break loose from its shackles.

One of the most important applications of this principle in education is to undertake only a few habit-building processes of the same sort at the same time. In spelling, for example, it is well to take up only two or three new words at a time, to focalize these adequately, and to keep recurring to them until they are thoroughly mastered. In correcting inadequate or ungrammatical 
habits of speech it is also essential to proceed systematically, one error at a time, keeping the correct form constantly before the pupils, and seeing to it that it is used in place of the incorrect form.

The Importance of Initiative or "Motivation" in Habit-formation. - The law of habit-formation, which is involved in the three principles discussed above, should be applied with a full knowledge of certain general characteristics of the habit-building process and of the conditions under which habits are economically established. The first of these more general conditions is illustrated in all three of the principles just discussed. The attitude which one takes toward the habit to be formed is a fundamental factor in the efficiency of the habit-forming process. If one is imbued with a strong desire to master the new habit, it is clear that one will focalize it more carefully, repeat it more attentively, and avoid exceptions more zealously than if there is no particular interest in its formation, - hence the importance of insuring in the pupil a strong motive for thoroughly mastering the new adjustment.

This may be accomplished in several ways, each of which, however, is more easily described than applied. It is sometimes possible to show the pupil the need for the new adjustment, and thus provide him with what is called a "natural" motive for making it automatic. If the pupil realizes, for example, that perfecting his speech forms will enable him to communicate more ef- 
fectively, he will have a natural motive for the study and repetition essential to this end. If he can see that an absolutely automatic mastery of the addition and multiplication tables will save time and money in his business relationships, he will have a natural motive for undergoing patiently and persistently the necessary drill.

Motives May be Closely Related to the Child's Life and Interests. - It is obvious, however, that these natural motives which relate directly to the life-activity for which the special training in question prepares, can be used only occasionally in the lower schools, for the reason that the pupil cannot always appreciate and understand theultimate value of the material that he is asked to learn. It becomes necessary, then, to introduce other types of motive, similar to the devices referred to above. The practice approved at the present time by most educators is to emphasize, as far as possible, motives that relate clearly and closely to the child's own immediate interests and childish needs. Thus the teacher who wishes to emphasize the importance of serious work in language may interest his pupils in a correspondence club formed in coöperation with another school. Or a school exhibition or entertainment may be planned, and the pupils asked to write the invitations to their parents and other members of the community. They may even work out, write, and learn the speaking parts of a drama. The importance of the arithmetic drills may be im- 
pressed by showing how essential is accurate and clear-cut number work to good results in manual training.

In any case, it is essential to stimulate the "will to do," and the teacher who can successfully attain this end is pretty certain to accomplish good results in the habit studies.

The Importance of the Right Start. - The economy of initiating the desired habit in its simplest and most economical form has already been referred to. Many teachers in the departmental work of the high school or the college prefer that, in the special subjects which they teach, the students who come to them should have had no previous training. This attitude is an implicit recognition of the dangers that the wrong start involves. A great deal of the criticism that the schools meet from business men who employ public-school graduates is due to the fact that - along with the valuable habits that the school has implanted - certain very undesirable modes of behavior have been permitted to become habitual. Sometimes these are represented by clumsy and uneconomical methods of writing and computation; more frequently it is the moral habits that are defective. The boy has not been " disciplined " into habits of obedience, promptness, industry, and respect for those in authority; and his bad habits must be uprooted before he can do his work properly.

The Phenomenon of Interference in Habit-formation.

- When habits that are in the process of formation con- 
flict in certain of their elements, it is necessary that these be continued until they are firmly established; otherwise they will mutually destroy one another. This fact of "interference" has long been recognized, and recently an attempt has been made by actual experiment to find out more precisely just how this interference operates. It has been found that, at the outset of the process of forming two conflicting habits, the learning of either is not so rapid as if it were being mastered alone. After the lapse of some time, however, both are as firmly established as if they had not been in conflict at the outset, and in the aggregate no time is lost because of the original interference.

The learning of two foreign languages during the same period of time is a case in point At the outset there is a danger of confusing the vocabularies and idioms, but if the practice in both is continued, an effective mastery will be attained. The person who has learned both French and German until he can speak either fluently does not confuse the two tongues. For each he has a definite set of habitual associations, represented in the nervous system by separate sets of connected neurones. The practical significance of these principles may be formulated as follows: Never begin the mastery of two conflicting types of behavior unless both can be continued long enough to become permanently established habits.

\section{The "Practice Curve" and its "Plateaus." - At} the outset of forming a new habit, the rate of learning is rapid. It then progresses more slowly, and there are periods of no improvement, and sometimes periods of relapse when the learning goes back to an earlier and 
less perfect stage. If the learner persist in his effort, these periods of no progress may give place to periods of rapid growth. Periods of growth thus commonly alternate with stationary periods, giving rise to what is technically known as the "practice curve." What is pictured in this curve is the growth of the habit from its earliest beginning to a point where it has reached a fairly perfect form. The initial growth is very rapid; the later growth is relatively slow; and the curve gradually "flattens out," representing the plane of maximal effciency in the habit. The places in the curve representing the intermediate periods of no growth, or of actual loss in progress previously made, are known as "plateaus."

The Significance of Plateaus in Habit-formation. The periods when growth is slow and halting or, indeed, non-existent, are critical for the learner, since he is likely at such times to become confused and discouraged, and to give up entirely the discipline that is essential to further growth.

In practically all subjects involving habit-formation, the initial stages are interesting first on account of their novelty, and secondly on account oi the relative ease with which some skill - trifling in amount and yet gratifying to the learner - may be attained. There comes a period, however, when difficulties increase, and progress is greatly retarded. The pupil who has found it rather easy to work out manual training projects in- 
volving only the simplest operations comes to a project which requires the making of nicely fitting joints. $\mathrm{He}$ must now climb to a higher plane of skill, and the difficulty of making this advance stands out sharp and clear against the relative ease of his early conquests. The student of telegraphy may have little trouble in "sending" ten or fifteen words a minute, but to increase his speed to the point where he can send twenty or thirty seems to take much more than double the time and effort required for the simpler achievement. The young teacher may quickly reach the point where her supervisor will grade her instruction and discipline as " B," but years of strenuous and persistent work may be necessary before the grade month after month is recorded as "A plus."

The Treatment of Habit on the "Plateau" Stage. It is a matter of controversy among psychologists whether these plateaus of growth are really essential in the practice curve, or whether they may not be avoided if proper precautions are taken. In other words, if the teacher did his work perfectly, would not these halting places in the progress of pupils disappear, and would not the curve of growth be represented by a steady upward sweep, with no "flattened" places, and no periods of actual relapse?

This question cannot be answered at the present time, but it should be insisted that the teacher may take certain steps to render these plateaus less disastrous than they would be otherwise. In the first place, the pupil 
may be encouraged to persevere, even if he has reached a plateau of growth. Or, if the conditions warrant such a course, he may be encouraged to drop his task for a while and to come back to it later, for frequently lack of progress is due to fatigue, and a rest will restore the capacity for growth to its original efficiency. Again the teacher may see to it that the learning proceeds by carefully graded steps; that the learner does not attempt a new set of habits or a new type of skill until he is ready for it.

It is important in this connection that the types of skill with which the school deals should be analyzed into their component habit-elements, in order that these elements may be mastered systematically. One point of excellence in the "Montessori" methods lies in the fact that the complex habits, such as those involved in writing, have been carefully analyzed, the simpler habit-elements dissected out, as it were, and the means devised for insuring that the pupil masters each element in order, - the simpler before the more complex.

Finally, the teacher may see to it that one of the chief factors in success has a chance to operate, - namely, self-confidence in one's ability to do the work, to solve the problem, to master the skill. There is some danger here that the child may come to depend too much upon praise and adulation, and to become discouraged if praise is not forthcoming when he thinks that it should be. But between excessive praise which would lead to this result and the absence of all commendation, which deadens every one save the genius, there is a happy 
medium which the intelligent teacher will quickly recognize.

The Importance of Intense Effort. - In forming a new habit, the learner should, at times, put forth the greatest effort of which he is capable. It often happens that, in these periods of unusual effort, a higher degree of efficiency is reached than could possibly be attained otherwise; and when this level is once reached, it gives the learner confidence to persevere until he can maintain it permanently.

The distinction between the expert and the mediocre workman is often found in the ability of the former to reach this level of maximal efficiency and to maintain himself upon this level. The difference between the poorly paid office stenographer and the successful court reporter is a difference between these two levels of perfection. It is the circumstance of a little greater accuracy and a little greater rapidity that makes one person an expert and another a drudge.

The practice of the schools to devote certain brief periods each day to intensely concentrated, "rapid-fire" drills in arithmetic and other subjects is to be commended from the point of view provided by this principle. It is the intense effort that educates.

\section{Rapidity vs. Accuracy in Habit-formation. - It is} a fact of common observation that "Haste makes waste." There is a point in every stage of learning beyond which the rapidity with which the work is done will be the source of many errors. While it is desirable to "speed up " the learning occasionally, it would be unfortunate to continue this excessive speed at the ex- 
pense of accuracy in performance. Continued errors and unskillful methods of work soon become permanently fixed, and then a high grade of attainment is impossible. The learner should be encouraged to keep to as high a level of rapidity as is consistent with accurate results, but should not be urged to work so rapidly that the results will be inferior.

Slow learning does not necessarily mean that the work is being done in a careful manner. Many pupils learn slowly largely because they are indolent and inattentive. These should be stimulated to do more rapid work. Their slowness in no way promotes efficiency. In the ideal school, where each teacher will have only as many pupils as he can teach effectively, it will be possible to study each pupil as an individual to determine the conditions under which he can work best.

The Specific Character of Habits. - Habits are specific. They consist in doing certain definite activities in certain definite ways. The term "general habit" has been a source of confusion in educational theory; and while there is some justification for employing the word in connection with habitual attitudes of mind and body, it will promote clear thinking to confine the word " habit" to the specific responses to specific situations or stimuli.

The specific character of habits might be inferred from the physical basis which has been assumed for these modes of behavior, that is, the formation of preferred paths of conduction among definite groups of neurones. This implies that the excitation must move in one direction, and only one. When there is a possibility of the excitation taking various courses; then the habit has not been completely established; and hesitation and conscious direction 
must intervene. A fully established habit is one in which the path between stimulation and response is fixed, and in which the resulting behavior is definite and certain.

The "Transfer" of Habits. - Upon the question of the possibility of transferring a specific habit from the situation in which it has been formed to another situation, there has been a great deal of controversy which has led in recent years to careful experiments. Much work still needs to be done in this field before we may confidently lay down general laws, but, pending thoroughly valid conclusions, certain hypotheses for the guidance of practice may be drawn from the facts now at our command.

(I) Transfer through "Identical Elements." - In the first place, it has been shown by experiment that habits built up as responses to certain situations may "spread " as habits to other situations if the latter have numerous or significant points of identity with the former. By the spread of habits " as habits," we mean that the response in the new situation is thoroughly automatic and mechanical; the individual does not have consciously to lift the old habit out of its old setting and apply it to the new situation.

Let us suppose that the child has formed in connection with his school life the specific habits of prompt and regular attendance. He goes to school "on time" and he goes each day. He does not "think" about these things, but when the time comes for going to school, he picks up his books and starts off. It is needless to say that these habits of promptness and regularity would be most 
valuable to him in his later life, but will they "spread" to out-of school situations? It is probable that in most cases they will, for the school situation is a "work" situation, a "duty" situation, and the employment which the pupil enters later is also likely to appeal to him as possessing these characteristics. The two situations present points of identity, and the habits common to one are likely to become common to the other. If the school should lack these characteristics, the habits would tend to remain specific to the school situation.

Too much reliance must not be placed, however, on the chance that situations will possess points of identity. The experiments that have been made show that a very slight change in the situation may serve to prevent a useful habit from "spreading." Nevertheless, it is well to make the school situation resemble the situations that are to be met in later life in all possible and legitimate ways. In general, the more closely school resembles actual life conditions, the more likely it will be that the valuable habits to the building of which the school devotes so much of its energy will be really important factors in the pupil's later life.

(2) Transfer through "Ideals of Procedure" and "Concepts of Method." It is much more essential in insuring the "spread" of useful habits to develop in the pupil an appreciation of the importance and value of the habits and a definite idea of looking about him to see when and how these habits may be employed in new situations. It was pointed out that habits tend to "spread" as habits (that is, on the mechanical or automatic level) 
only when situations possess points of identity. But it is always possible to transfer a habit from one field to another through a conscious process. Here the activity is no longer mechanical and automatic; it has been raised into the clear light of consciousness, and the great importance of consciousness, as has already been pointed out, lies in the fact that it enables us to meet new situations. From one point of view, the function of consciousness is to select from our stock of specific habits, a new combination of responses that will enable us to meet the new situation effectively.

Thus, while habits of promptness and regularity of work may be transferred on the automatic level from the school situations to the situations of later life, it would be folly for the teacher to depend upon this chance when he can make the "spread" much more certain by developing ideals which will impel the pupil to be prompt and regular in every situation which he may meet. In the former case, the transfer is limited to the automatic level; in the latter case, it operates consciously and explicitly; the individual has made promptness and regularity ideals, - he has endowed them with the affective force which insures their control over conduct. Beyond this, he has an idea of what promptness and regularity mean and how to achieve these virtues. In other words, he has a definite concept of the desirable method of procedure.

In order, then, that a habit may have "general" value, it must be one that can in whole or in part be evoked by many situations; or it must be one from which certain ideals of procedure may be derived and applied to many different forms of behavior. 
This limitation of the activity of specific habits has far-reaching consequences in education. Because the pupil habitually attends to his work in nature study, it is not to be inferred that he will necessarily give an equal measure of attention to the lesson in history. He is more likely to give attention to all of the school subjects, if he is led to recognize the value of forming these specific habits of attending. He may be orderly and neat in his written work in English and still hand in disorderly papers in arithmetic and geography. Indeed, he is likely to do this unless neatness is insisted upon in all subjects or unless neatness has been made a general ideal. The child may as a matter of habit be obedient when his father is present, and quite the reverse when left with his mother. He may keep strict order under one teacher and be the center of disturbance in the next class. Obedience to constituted authority is the general ideal that must be developed here; otherwise the habits of obedience formed in one situation will be of negligible value in other situations.

The Limitations of Habit. - While it is desirable that the individual should be equipped with as many useful habits as possible, no human life should be given entirely over to the sway of habit. The person who has all or most of his activities reduced to the plane of unvarying routine is simply and purely a machine. To grow means to have fresh interests, to meet new problems, to put old responses together in new ways, - in short, to build new habits. One of the ideals that the mature individual should cherish is the ideal of growth, and this should impel him assiduously to seek for means through which action may be improved. With advancing years, the temptation becomes stronger and stronger to rest content with the progress already made. What 
has been aptly termed the "plasticity of youth" is lost. New modes of behavior are acquired slowly and with increasingly distasteful effort. To "keep young" means to fight against this natural tendency to crystallize one's life in the inflexible forms of routine behavior.

While "drill" is an indispensable method of education, the teacher who devotes all of his time to this process will fail really to educate his pupils. Beyond and above the specific habits that are to be built up (and which must never be neglected) are the facts and principles to be impressed, the ideals, standards, tastes, and "points of view" to be engendered. It is these that will prepare the child for the new and varying situations of life, while habit-building looks after the unchanging or constant situations. It is particularly through knowledge upon the one hand and ideals upon the other that the pupil is prepared to form for himself new habits that will fit new circumstances in his life.

The Importance of Teaching Pupils how to Form Habits. - The preceding discussion leads to a final topic in connection with habit-building. Not only is it essential that pupils be led to form useful habits; it is of prime importance that they be given a mastery of the method of habit-formation. Out of the specific disciplines of spelling and penmanship, learning the tables and memorizing selections from literature, coming to school regularly and promptly, obeying those in authority and respecting the rights and feelings of others, - 
out of these the great lesson of self-discipline should gradually emerge. The child who leaves the elementary school should know how to go about it to form a habit for himself; he should understand the importance of adequate focalization, attentive repetition, and the avoidance of exceptions, - although he need not know these names; and above all, he should appreciate the significance of attacking a habit-building task aggressively and persisting in it unremittingly. The most successful teachers are those who make these great lessons of life shine out clear and strong through the seemingly trivial and paltry details of the day's work.

\section{Definitions and Explanation of Terms Used}

Propensity. - The affective "tone" which often accompanies the expression of a well-developed habit.

Focalization. - The process of gaining a clear idea of the way in which different elements go together to form a desired-habit.

Practice curve. - A diagrammatic representation of the growth of a new combination of responses into a perfected habit. The curve rises rapidly at first, and then tends to "flatten out" until, when the habit has reached a maximum of efficiency, the line is horizontal.

Plateau. - Flat places or depressions in the practice curve before the final flattening has been attained. Plateaus indicate that growth has stopped for the time 
being, or (if the curve is depressed) that the learner has gone back to a less efficient stage.

Concept of method, Ideals of procedure.-These are agencies involved in the "transfer " of specific habits from the fields in which they have been formed to other fields.

\section{Questions AND Exercises}

r. Define habit and contrast it with reflex and instinctive behavior. In what way does the formation of habits promote economy in behavior?

2. Name some of the important specific habits that education must impart. (Remember that a specific habit is a specific or particular response to a specific or particular stimulus or situation).

3. In what different ways may adequate "focalization" be encouraged?

4. What is meant by attentive repetition, and what is its signifcance to the process of habit-formation? What steps may the teacher take to insure that the pupil is attentive to the necessary repetitions?

5. Why is it important to start the formation of any desirable specific habit with a demonstration of the simplest and most effective movements? Note in the work of a teacher the effort that is spent in breaking up undesirable habits. Compare with the time and effort spent in the positive process of building desirable habits from-the start.

6. Why are "exceptions" unfortunate in habit-formation?

7. What is meant by "interference" in habit-formation. Illustrate. How may its evil effects be avoided?

8. Define and illustrate the term "plateau" as this is used in describing the progress of growth in a habit. What should be the attitude of the teacher with regard to these plateaus?

9. What is the relation between accuracy and rapidity of movement in forming a habit? 
Io. The best way to study the laws of habit-formation is to form a habit and watch the process. Select a simple adjustment, such as taking a new route on your way to school; doing a certain type of work at a definite time, - for example, studying each evening from seven to eight, or going through with calisthenic exercises each morning and evening; learning a new game involving motor adjustments, - tennis, golf, handball, - or a new movement or "play" in a game. Note ( $\mathrm{I}$ ) the importance of strong initiative or motive; (2) the temptation to exceptions and their influence if permitted; (3) how long it takes the adjustments to become "automatic" - to take care of themselves with a minimum of attention; (4) the growth of the "propensity," - when do you begin to feel a delight in the activity, and when does deprivation of the opportunity to exercise the habit cause an unpleasant feeling; (5) the phenomena of interference; (6) the phenomena of plateaus.

II. After the habit has been well established, try the process of habit-breaking. Select some undesirable habit that has been formed: biting the nails; mispronouncing certain words (correct one at a time and watch the process); using certain undesirable or ungrammatical forms of speech. Note in this case the "cues" that have heretofore, perhaps without coming into clear consciousness, "set off" the undesirable activity. Can you break the habit by avoiding the cues? What is the influence of exceptions upon the process of habit-breaking? How many "inhibitions" or "repressions" are necessary before the desire to follow the habitual mode of behavior is no longer felt?

I2. Under what conditions may specific habits, built up as responses to specific situations, be transferred to other situations?

13. Make a list of the school subjects that have as their primary purpose the building of habits. Make a list of those that should leave with the pupil knowledge (ideas and principles) or ideals rather than specific habits. What specific habits are necessary to the successful study of history, geography, physiology? (In this connection, consider the phases of these subjects that should be memorized - lists of dates, boundaries, etc.) 


\section{PART III}

\section{CONSCIOUSLY CONTROLLED MODES OF BEHAVIOR}

\section{CHAPTER XII \\ SENSATION AND BEHAVIOR}

IN the preceding chapters, consciousness has been referred to as an important factor in controlling behavior. Instinctive behavior and habitual behavior, as we have seen, may be largely independent of conscious direction; but we have also seen that, if instincts are to be changed or redirected, or if specific habits are to be applied to situations different from those in which they have been formed, consciousness must control the processes of redirection or transference. We may reverse this statement and say that whenever consciousness is present, there is some aspect of the total behavior that is not completely mechanical.

The Elements of Consciousness. - Reference has already been made to the elements of consciousness. If any state of consciousness be analyzed by what is called the process of introspection ("looking in " or 
observing one's own consciousness), at least two types of elementary processes are recognized,-affection and sensation. In Chapters V and VI, affection was discussed with reference to the simpler and more complex forms in which it appears, - namely, feeling and emotion. The importance of affection lies in the fact that it gives value to our conscious experiences : the two affective qualities, "pleasantness" and "unpleasantness" have been, throughout the development of mind, the signs or symptoms of what is beneficial or detrimental to the organism.

Sensation, on the other hand, informs the organism of the world in which it lives, and of the condition of its own body. It is through sensation that we become aware of situations demanding a response.

The Organs of Sensation. - The external world manifests itself to us through physical stimuli that set up excitations in the "sense organs." These organs are primarily " differentiated" or "specialized" ends of sensory neurones. Each sense organ "picks up" a special type of physical stimulation and ordinarily responds to no other type of stimulation. Thus the eye "picks up" the vibrations of the ether that are known as light waves ; the ear responds to the vibrations that are known as sound waves; the taste buds on the tongue respond in a characteristic way to different solutions that find their way into the mouth; the organs of smell respond char-

1 The number of elements is still a matter of dispute among psychologists. Some recognize the "image" as an element. 
acteristically to different gases that are inhaled through the nose; the pressure and temperature sense organs report the weight and temperature of objects in contact with the skin; and so on.

Definition of Sensation. - The stimulus thus " picked up " by the sense organ is transformed into an excitation of the nerve substance, and this excitation travels up the sensory nerve. It may be deflected to a motor neurone at some point below the cortex of the cerebrum; if this is the case, the sensory impression may never become a matter of consciousness, and the behavior is thoroughly mechanical, - either reflex or habitual, accordingly as the pathway between the sensory and the motor neurone is inborn or acquired. If, however, the sensory impression does reach the cortex of the large brain, it will probably give rise to a definite sensory experience. This consciousness which is correlated with the stimulation of a sense organ is termed a sensation.

"Pure" Sensation an Abstraction. - Pure sensations, however, do not exist in any developed form of consciousness. What we ordinarily call sensation is something more. The mere sensation has been given a meaning and then it is a perception. This book that $\mathrm{I}$ see is not a mere visual object that has color and form. It means something to me; I recognize it as a book; in other words, I perceive it. That patch of red that falls upon my eye is more than a simple sensation of redness, for I recognize it as red, and this recognition makes of it 
a perception. So, too, the bell that $I$ hear is not pure sound, but sound interpreted to mean bell. Thus it is with all of my sensory experiences; I invariably interpret them in the light of my past experience, and this interpretation is perception.

Sensation Incomplete without Response. - It is important to understand how this interpretation of sensation takes place. Conscious experience is not, as some have supposed, made up by the addition of various sensory experiences, one after the other. Mere sensation could never give meaning to any object of experience. The sensory stimulus must express itself in some form of action before a perception can be set up. Now, this is just what we should expect to be the case, since we have held throughout to the point of view that consciousness is of service to the individual only in so far as it influences conduct. All sensory experiences tend to find expression in movement. This is what has already been termed in an earlier chapter the "sensori-motor" character of experience.

But while this interpretation of experience is necessary, there must always be at the basis of our mental life either sensation or feeling; otherwise there would be no conscious conditions to set up behavior. It is necessary therefore to inquire somewhat more fully into the nature of the sensory experiences that lie at the basis of consciousness. Sensation comes to us through several different avenues. The chief of these are the eye, the ear, 
the nose, the mouth, the skin, and the muscles. Sensations also arise from the internal organs.

The Attributes of Sensation. - All sensations have certain attributes; that is, features that invariably characterize them and without which the sensations cannot exist. These, as commonly given, are intensity, duration, quality, and clearness.

No sensation can arise without possessing some degree of intensity. A light, for example, may be very dim or extremely bright, a sound just barely audible, or distressingly loud, a taste may be faintly or excessively bitter, but in any case there must be some degree of brightness, or loudness, or bitterness.

Likewise a sensation must exist for a certain interval of time to be actually present as an element of consciousness. This may be but a small part of a second, or it may be much longer ; in any case, however, the sensation must occupy a measurable amount of time.

Again, every sensation must have some quality that distinguishes it from other sensations. For example, the sensation quality makes us aware whether the present object of consciousness is a light or a sound. There are, of course, as many different sensory qualities as there are different kinds of elementary sensations.

When we say that every sensation has a degree of clearness, we mean that it is more or less definitely attended to. It is the amount of attention that determines the clearness of the sensation. A noise, 
though faint, may be clear, if we attend to it, while a very bright light may be scarcely perceived, if our mind is on something else. Intensity and clearness do not necessarily go together. However, it is true that originally the intense experiences are the ones that attract attention, and it is further to be remembered that by holding an experience in mind we seem to add to its intensity and also to increase its duration. A very faint noise is no longer heard when our attention relaxes, and, on the other hand, it seems to grow in strength when we attend to it.

Classes of Sensations. (a) Visual Sensations.One of the most important of our sensory experiences is that of vision. The visual sensation is due to light waves in the external world acting upon the sensitive parts of the eye. Differences in intensity in visual sensations are known as brightness differences ; differences in quality include color differences and differences in shades of gray, ranging from white to black. The brightness has to do with the amount of luminosity in the sensation. For example, when I turn down the lights in my study, the brightness is decreased. It is brighter on a sunny than on a cloudy day; brightness decreases as the twilight grows, and so on.

All visual sensations must have some degree of brightness, but color may be absent. For example, the various shades of gray are bright, but they do not possess color. On the other hand, all colors have some degree 
of brightness. A red with no brightness could not be seen. Decrease the luminosity of any color, and it finally will vanish.

The Color Qualities. - Color qualities are numerous. It is estimated that there are about 30,000 different color sensations that can be distinguished. There are, however, but nine actually different colors, or hues. These are red, orange, yellow, yellow-green, green, bluegreen, blue, violet, and purple. All of these except purple are found in the solar spectrum, and form the colors of the rainbow. Out of these nine colors, four are called "elementary," for in them no other more simple hues can be detected. Red, yellow, green, and blue are these four colors. Red is just red, and nothing more. Orange, however, contains both red and yellow, yellowgreen and blue-green are both compounds, while violet and purple contain both blue and red. By mixing hues in various ways and adding also various amounts of gray, the 30,000 different colors can be produced.

When a hue has all of the color possible in it, it is said to be fully saturated. A red that is just as red as it can be, a blue that has all of the quality of blueness possible, are such saturated colors. The saturation of a color is decreased by mixing it with some shade of gray. The light grays produce tints and the dark grays, shades.

Contrast and Adaptation. - Certain colors antagonize, or contrast with others. For example, red and blue-green form such a contrast. Two such colors when prop- 
erly mixed produce a shade of gray. These colors mutually destroy each other and leave nothing but a gray of a certain brightness. Such antagonizing colors are called complementary. For every color there is another complementary color. Two complementary colors when brought close together produce a marked contrasting effect, each color enhancing the other. For example, yellow appears more yellow and blue more blue when these two colors are placed side by side.

The eye easily becomes adapted to both color and brightness. If you put on a pair of blue glasses, for a while the entire landscape appears blue, but this effect wears away, and after a time you are not aware of it. The landscape again appears quite normal. We ordinarily notice adaptation most strikingly when we come from the bright sunlight into a room with drawn shades. At first we can hardly grope our way around, for our eyes are adapted to the sunlight. After a while they become adapted to the darkened room, and then objects in it are distinctly visible.

Other sense organs besides the eye show this ability to adapt themselves to various forms of stimulation. It is a well-known. fact that after a time odors lose their strength, and that sensations of warmth and cold tend to become neutral. We do not notice the pressure of our clothing, candy becomes less sweet after we have eaten a quantity, and a lemon that at first is so sour that we make a wry face when we suck it loses some of its disagreeable quality.

After-Images. - Another interesting fact in regard to color sensation is found in after-images. If you look 
steadily at a patch of saturated color for about thirty seconds and then close your eyes, or look away at a gray background, you will see a similar patch of the complementary color; a yellow patch giving an indigo, and a green patch a purple, for example. These after-images are called negative because they appear in the color that contrasts with the object originally gazed at. There are also after-images that are positive, - that is, of the same kind as the original object. These are best seen in connection with colorless objects. If you look at a very bright light for an instant and then suddenly close the eyes, or look at a dark background, the original light seems to continue for some seconds, though you are no longer looking at it. The trail to a rocket, or to a shooting star, is a positive after-image. There is no actual trail ; it is merely " in the eye." These positive afterimages often appear at night when you are walking on a street ablaze with electric signs. Not infrequently, as you turn your gaze away from the actual objects themselves, you may see these signs written in letters of fire on the dark sky. Sometimes, too, these letters appear dark, rather than bright. This is because you have gazed so long at the letters that you get the negative after-image.

The Color Zones of the Retina. - If you look directly at an object, you will see it accurately in its proper color ; if, however, you see the color at one side, it tends to lose its quality. Red and green are seen in their true colors 
only a short distance from the center of vision, while blue and yellow are clearly observed much farther to the side. On the extreme edge of the eye all colors appear gray. The margin of the eye seems to have little ability to see color.

This interesting fact may be shown as follows: Shut the left eye and gaze with the right at a dot marked on the wall, or better still, on a large sheet of gray paper. Have an assistant bring a small piece of colored paper attached to a stick slowly toward the dot from right to left. With your gaze steadily fixed on the dot, you will first see the colored paper as a gray object and only later in its true color. If it is blue or yellow, you will detect the color sooner than if it is red or green. Purple paper will first seem colorless, then blue, and finally in its true color. This is due to the fact that the blue in the paper can be seen sooner than the red portion of the mixture. Likewise in an orange mixture the yellow component will first appear.

Perception of Form Involves other than Visual Sensations. - It should be remembered that the eye sees not only colors and grays of various degrees of brightness, including white and black, but also form. Likewise it observes the position of objects in space. It distinguishes right from left, up from down, and near from far. We are not obliged actually to touch objects to know where they are in space.

Without making actual measurements, we judge that a certain building is a mile away; that a tree is one hundred feet tall; that this stick is a yard long. The judgment of distances and positions in space is not due, however, to simple sensations, but to perceptions that have gradually been built up in our experience. We 
know the meaning of a mile only after. we have had experience in walking, or the significance of a yard after we have used objects of that or a similar extent. In other words, our behavior in relation to these positions in space makes up the perception.

(b) Auditory Sensation. - We have seen that the qualities of visual sensation differ in two fundamental ways, - namely, in sensations of colored and of colorless light (white, gray, and black). We find a somewhat similar difference in regard to sensations furnished by the ear. A sound may be either a noise or a tone. Noise is generally less pleasant than tone.

Tonal Sensations and their Characteristics. - Tones lie at the basis of music. Their qualitative attribute is known as pitch, or tone quality, i.e., the tone is high or low. The intensive attribute is known as intensity, that is, the tone is loud or soft. The timbre of a tone is due to the instrument which sets it up. The same musical note sounds different when it is produced by a violin than it does when it comes from a pipe organ. Consonant tones unite with one another, as for example the $\mathrm{C}$ and $\mathrm{G}$ on the piano; tones like $\mathrm{C}$ and $\mathrm{C}$ are harsh and disagreeable. Such tones are dissonant. When consonant tones are sounded together, they blend, or fuse. This can be shown by striking the various chords on the piano. It is difficult, even for the experienced ear, to pick out all of the simple tones that make up some of these fusions.

All sound is caused by vibrations of the air particles. 
Irregular vibrations produce noise and regular vibrations tone. These vibrations are carried to the ear drum and then conveyed through what is known as the middle ear to the inner ear, where the sense organs of hearing are to be found. These are affected by the stimulation, and this is carried on up the auditory nerve to the cortex, and we become conscious of the sound.

The inner ear contains not only the sense organs of hearing, but also of equilibrium. Through this sense we can tell something of the position of our bodies, though we may not be able to see. The diver knows through this sense how to come to the surface of the water. If it is injured, or lacking, he may be unable to tell in what direction to go, and consequently he may drown.

(c) Taste or Gustatory Sensation. - The sense organs of taste are to be found on the tongue and the soft palate. Substances in liquid form, or that can be dissolved in the mouth, excite these sense organs. There are but four tastes, - sweet, bitter, sour, and salt. All other socalled tastes are really odors. If the sense of smell is cut off by stopping the nostrils with cotton, strong coffee and weak quinine will taste alike, vinegar and lemon juice are merely sour, and so on. We know that it is the common practice to hold the nose when taking some disagreeable medicine. Then it does not "taste so bad." As a matter of fact, the smell is the disagreeable part of the sensation.

(d) Olfactory Sensations. - The sense organs of smell are to be found in the upper portion of the nose. These 
are stimulated by substances in the form of a gas. There are many kinds of odors, but no exact classification has been made of them. There are odors of fruits, of camphor and spice, of flowers, of musk, of onions and garlic, of burning tobacco, coffee and toast, of cheese, of opium, and of decaying animal matter. Some psychologists have tried to put all possible odors in one or another of these classes, but such an arrangement is not very satisfactory. One reason why our knowledge of odors is so extremely limited is doubtless due to the fact that the sense of smell has but slight practical use in directing our behavior, and for this reason has been but little observed. The practical value of smell is much greater in many of the animals below man than it is in the human race.

(e) Dermal Sensations. - In the skin are to be found various sense organs that are affected by stimulations of three different kinds and are connected with the sensations of pressure, temperature, and pain.

There are no other sensations that come from the skin except these three. Such experiences as wetness, dryness, sharpness, smoothness, and roughness are merely compounds or fusions of these three fundamental sensations, often with added sensations of movement. Wetness is, for example, a blending of the temperature sensation with pressure. This is clearly shown when you hold your hand before a pipe discharging cool compressed air. The air rushes out and strikes the hand with a 
strong impact. This pressure sensation combined with that of coolness results in a sensation similar to that caused by holding the hand under a faucet of running water. There are also other sensory experiences coming from the skin, like itch and tickle. These are likewise fusions.

It is an interesting fact that the points of origin of the various skin sensations are not equally distributed over it, but are located in small spots. If a blunt-pointed piece of cold metal, or a leadpencil not too finely sharpened, be moved over the back of the hand, for example, there will be found small areas, scarcely more than points, at which a distinctly cold sensation will flash forth, but there will be larger spaces between these points which do not respond to the cold stimulation. If the metal point is warmed and moved over the same portion of the skin, similar but not identical points responding to the warm stimulation will be found. If the skin is tapped with a horsehair, pressure spots can be located. Pain spots are also found by using a stiff hair, pointed at the end and pressed down on various parts of the skin. There are some parts of the body that are extremely sensitive to pain, while others are incapable of sensing the prick of a needle.

(f) Kincesthetic Sensations. - Sensory nerves run from the muscles, the tendons, and the joints, and sensations arise at these points, - the " muscular" sensations from muscles, "strain" sensations from tendons, and "articular" sensations from joints. These sensations, although not commonly attended to, are extremely important in the behavior of the individual. Without them accurate movement would be impossible. We can write with our eyes closed and walk about without no- 
ticing every step that we take. The ability to improve our behavior, - to make it more accurate and efficient, is due largely to these motor or kincesthetic sensations. They inform us immediately of the way in which we are acting in the situation before us.

(g) Organic Sensations. - There is still one further group of sensations. These are called the organic. They arise in connection with the activities of the internal organs. Hunger, thirst, nausea, and sensations arising from breathing and the circulation of the blood are examples of organic sensations. These sometimes play an important part in our emotional experiences, as we have already seen. They have also a good deal to do with our so-called "self-feelings." Because they are so thoroughly fused with other parts of consciousness, however, they are difficult to analyze, and comparatively little is known about them.

The Significance of Sensory Defects. - Since all of our experiences come originally through the avenue of one or more of the senses described above, it follows that any attempt to educate the individual will be useless unless these senses are actively working. The person who has lost his eyesight or who is deaf will be badly handicapped in his learning. A few individuals who have lost the two important senses of sight and hearing have with great labor been educated through the channels of the dermal and also of the motor sensations. Such persons evidently need very special treatment, and 
their education must be for the most part individual. As far as the public school is concerned, a more serious problem arises than that of educating those who cannot see or hear. This comes in connection with those pupils who are not actually blind or deaf, but whose vision is faulty and whose hearing is poor. This dullness of sensation often prevents such children from understanding the ordinary school instruction, and they are looked upon not infrequently as backward or even feeble-minded. There are a few simple tests that can be used in a rough way to discover these lacks, and they should be applied to find out as far as possible whether any of the pupils in the school are suffering under serious handicaps in their learning. Investigations have shown that eye defects are extremely common among school children and that deafness is also an important factor in retarding the pupils.

Color Blindness and Tonal Deafness. - There are also some individuals who, while they may be able to see clearly, are color blind. They cannot distinguish certain colors. To most color-blind persons both red and green appear as gray, although blue and yellow are rightly sensed. There are also a few individuals who may be described as "tone-deaf." Their hearing in the ordinary sense of the word may be good, but their ability to distinguish tones is very slight.

The Place of "Sense Training" in Education. - An important question arises in the education of the child 
in the kindergarten and the primary grades as to the place of "sense training." It is generally agreed that a certain amount of this is not only beneficial but necessary. Children should be taught to distinguish colors and to discriminate between various shades of gray; they should be able to tell by simple touch and with closed eyes the difference between silk, velvet, satin, cotton, and other fabrics; they should have practice in recognizing various pitches that they hear sounded and in picking out the separate tones in a chord struck on the piano; they should be able to tell with fair accuracy the weight of different objects by lifting them; to estimate length, breadth, and area without measuring the objects, and so on. In fact there is not one of the important senses that cannot through special training be made more effective as an avenue of learning. During the preadolescent period, children may be easily interested in exercises of this sort, as the success of the Montessori methods has proved. 'Of course, such exercises are not merely an education in sensation. They involve perception, discrimination, and judgment.

\section{Definitions and Explanation of Terms Used}

Introspection. - Observing the mental processes as they go on in one's consciousness.

Sensation. - Those processes of consciousness that arise in connection with the stimulation of a sense organ and the transmission of this stimulation to neurones 
lying in the cerebral cortex. In adult experience there are no pure sensations, but rather sensations interpreted; that is, perceptions. This interpretation of sensation is the result of the activities that take place in response to the stimulation connected with the sensation.

Attributes of sensation. - An attribute of a sensation is any aspect of the sensation that is necessary for the sensation's existence.

Intensity. - This is one of the attributes of sensation. Every sensation must have a certain degree of strength, or intensity. A light of zero intensity would be complete darkness.

Duration. - A second attribute of sensation. A sensation that did not last for a certain length of time, no matter how brief, would not be a sensation.

Quality. - The attribute of a sensation that gives it a particular name ; that distinguishes it from other sensations. Sight is thus distinguished from hearing, pressure, taste, smell, and so on.

Clearness. - This is the fourth attribute of sensation. Every sensation must have a certain degree of clearness; that is, it must be more or less in the center of attention. It may be just barely perceived or it may be given undivided attention, as the case may be.

Brightness. - The brightness of a visual sensation is its luminosity. Sensations of color possess some degree of brightness, though brightness may be present without color, as in the case of white and the various grays. 
Hue. - The hue of a color distinguishes it from other colors. The principal hues are red, yellow, green, and blue. These are called primary colors because they are not made up of other colors, as are orange (red and yellow), violet (blue and red), and so on. All of the hues are to be found in the rainbow or solar spectrum with the exception of purple.

Saturation. - When a hue has in it all the color possible, - when red cannot be more red, or a blue more blue, - it is said to be completely saturated. The saturation may be made less by adding white or gray. White and light grays added to colors give tints and the dark grays give shades.

Complementary colors. - Every color has an antagonistic color that is its exact opposite. If these two colors are mixed in proper proportions, they neutralize each other and give a gray. Thus red and a bluish green and orange and blue are such complementary colors. These colors when not mixed, but placed side by side, form color contrasts. A strip of orange paper placed beside a strip of blue paper produces such a contrast. The edge of the blue near the orange looks more blue and the edge of the orange near the blue seems a richer orange than when these two colors are not so contrasted. Dark and light grays also form contrasts.

Visual adaptation. - When the eye gazes at one color for some time, the color seems to lose its richness. If you look at the landscape through a piece of yellow glass, 
it at first seems very yellow, but after a little time this effect gradually wears away until it is scarcely to be noticed. The eye is adapted not only to color but to brightness. On coming out of a dark room everything at first seems unusually bright, but the effect wears off. If you go into a dark room, at first you can see nothing, but after a short time objects become dimly visible because the eye has become adapted to the darkness. Other senses beside vision show similar capacity for adaptation. Smells fade out, tastes lose their intensity, and touch and temperature sensations are scarcely noticed after they have been present for some time.

After-images. - If an object is gazed at for a certain length of time, it may seem to be present after it has been actually removed. If it appears in the same color and intensity, it is called a positive after-image; if it appears in the opposite color and intensity, it is called a negative after-image. There are after-images of some of the other senses as well as of vision, as, for example, of touch and temperature.

Noise and tone. - Sensations of sound are either noise or tone. The best examples of tones are to be found in sounding bells, tuning forks, and musical instruments. Noises are rumbling, grating, hissing, and so on. In most noises there is some tone, and vice versa.

Pitch. - All tones, and perhaps all sounds, have a certain pitch; that is, they are high or low.

Timbre. - Every tone possesses a certain character- 
istic that gives an idea of the nature of the instrument producing it. The same note sounds different when struck on a piano than when played on a flute or an organ.

Consonance and dissonance. - When several tones blend harmoniously they are consonant; when they do not so blend, but produce a jarring effect, they are dissonant. When they blend so that the various component tones run together and are not easily recognized, they are said to be fused. There are fusions of this sort in all of the senses.

Sense of equilibrium. - This informs us of the position of our bodies in space without the aid of vision. The sense organ of equilibrium is in the inner ear.

Kincesthetic sensations. - Sensations that give us information in regard to the movements of the various parts of the body, including the organs of speech, locomotion, manipulation, etc.

Organic sensations. - These arise from the activity of the various internal organs of our bodies. They come from the beating of the heart and the tension of the blood vessels, from the activities of stomach and intestines (in digestion), and so on. They generally blend together, giving us a massive sensation of our "personality."

Color blindness. - This is a defect in vision that prevents the person afflicted from seeing certain colors (usually red and green) as they really are. These colors are confused with each other and with gray. 


\section{QUESTIONS AND EXERCISES}

I. Distinguish between affection and sensation as elements of consciousness. State the function of each with reference to behavior.

2. What is meant by the term "sense organ"?

3. Make a list of the sensations that you experience during an interval of two minutes. What sense organs are active in furnishing these sensations?

4. Name and illustrate the four attributes of sensation.

5. What is the distinction between brightness and color in visual sensations? What is meant by the "saturation" of a color? If a "spectrum chart" is available, make a list of the colors $(a)$ in the order of their saturation; $(b)$ in the order of their brightness.

6. What is meant by "complementary" colors? Name the complement of each color on the spectrum. (If a "color mixer" is available, it is an interesting exercise to demonstrate the laws of color mixture. Disks of colored paper, representing all of the primary hues, should be provided. By making a slit along a radius of each disk, two disks may be placed together upon the mixer in such a way that the colors may be combined in any desired proportion. The mixing is accomplished by rapidly rotating the disks; this, it will be understood, is not an objective mixing of the pigments; the rapid rotation prevents the two colors from being seen separately, and the combination or fusion, which is different from either of the original colors, really takes place in the retinæ of the eyes.)

7. Fix upon a sheet of white paper a one-inch square of red or blue; place the sheet about twelve inches from the eye; look at it for one minute (holding the hand over one eye); then replace the sheet with another which shows only a white surface. The negative after-image will be clearly projected against the second sheet.

8. The color zones of the retina may be mapped upon a 
blackboard. The base of the board should not be more than twenty-four inches from the floor. The person whose color zones are to be mapped should be seated so that the eyes will be four feet from the board. Upon the board at the level of the observer's eyes, make a "fixation" mark (a small Greek cross with arms an inch long and an inch wide may be marked in with white crayon); and through this fixation point draw with white crayon light radiating lines; at least eight lines (including the vertical and horizontal axes) should be drawn. Disks of red, green, yellow, and blue cardboard one and one half inches in diameter should be prepared and attached to light wooden wands. The observer is seated in a comfortable position, and yet in such a way that the head is immovable. One eye should be blindfolded, and the other should fixate the Greek cross. The experimenter than takes the blue disk, holding it from him by the wand, and passes it along one of the lines from the periphery toward the center. At first the observer (still keeping his eye upon the fixation point) will see no color whatsoever in the disk, but, as the experimenter moves it slowly toward the center, a point will be reached where the color is clearly perceived. When this point is reached, the observer says, "Now," and the experimenter marks the point on the line. Then, starting from the center, he moves the disk outward, the observer still keeping his eye upon the fixation point. When the color is no longer seen, the signal is given, and the experimenter marks the point. This will not always be identical with the point found on the first test, and it is well to take as the final limit of the color vision, a point halfway between the two points so determined. The remaining lines are traversed in the same way, and then the middle points upon all of the lines are connected, preferably with crayon of the same color as that of the disk used in the experiment. The zones for the other colors may then be determined in the same way.

9. What are some of the differences between tones and noises? With what differences in the physical stimuli are these conscious differences correlated? 
ro. What are the four qualities of taste sensations? To what sensations are many of the experiences commonly spoken of as tastes due? What taste sensations do you get from coffee? From lemonade? From butter?

II. What three types of sensations are furnished by the skin? Move a lead pencil (not sharply pointed) lightly and slowly over the skin and locate the "cold spots" on the back of the hand. What parts of the skin seem to be most numerously supplied with pressure sense organs?

I2. From what sense organs do we receive sensations of movement? It has been said that, of all the kinds of sensation, those informing us of the movements of the body are the last that we could get along without. Can you justify this statement?

I3. What is included under the term "organic sensations"? Why is so little known about this group of sensations?

14. What sensations are particularly important in the work of education, and why? What are some of the more common sensory defects?

I5. What is meant by "sense training," and what is its place in education? 


\section{CHAPTER XIII}

\section{PERCEPTION AND BEHAVIOR}

IN discussing sensation in the preceding chapter, it was said that all sensory experiences in the mature or adult consciousness are something more than sensations. In a word, they are sensations plus meaning. This meaning given to the sensation makes it a perception. Further, the meaning is gained through action. It is because we behave in certain ways in reference to certain sensations that they have gained the meaning that they have for us, - that they have become perceptions.

This book that I see before me has a meaning as a book in terms of what I can do with it, not simply in terms of its appearance to the eye. It is a book because I can handle it, turn its pages and read its contents. Similarly, the bell that $I$ hear has a meaning in so far as my behavior has some relation to it. If $\mathrm{I}$ recognize it as a dinner bell, the sensation means that I respond in some way to the sound, either actually or in imagination. Conduct, either by myself or by some one else, either actually executed or merely pictured in the mind, gives the whole meaning that the sound has as dinner bell. If I perceive the sound as some other kind of a bell, then the meaning that $I$ give is to be analyzed in terms of another kind of behavior. The fire bell means a certain form of behavior, the car bell another, and the telephone bell a third. Further, the fire bell means one kind of behavior for the fireman, another kind for the crowd in the street; the car bell calls forth one kind of action from the motorman, another from the passenger, another from the 
driver of a near-by wagon; the telephone bell signifies a certain sort of conduct for the owner of the 'phone and another sort for the person in the next apartment who happens to hear it.

Meanings come from Adjustment. - Meanings are made and changed in terms of behavior, and of behavior alone. We perceive objects only in so far as they are directly or indirectly recognized as influencing actions. An object that could not call forth any kind of activity in reference to it would be no object at all. This point of view is of the greatest importance in the field of education. Following this principle, one may say that all learning finally consists in doing. Not only is the educated man equipped through his education to act properly, but also he has gained this education by acting. The process of learning is not a passive process in which a certain amount of information is poured into the pupil. The child must in some way act in reference to the facts that are presented to him before he really learns anything.

In recent years this principle of activity on the part of the child in connection with his learning has been generally recognized. In the kindergarten and in the primary grades the child is required to perform various acts in reference to the objects that form the materials of his instruction. He gets a certain meaning for the word "ball" when he pronounces it, or writes it, or draws the object that it represents; another meaning when he handles the ball itself, throws it, and rolls it about. A yard means something to the child that actually measures it off on the floor of the schoolroom; the pupil perceives that two pints make a quart when he fills up the quart pitcher from a pint measure; number work acquires a new meaning when the arithmetical processes are employed in actual 
situations, as, for example, in the school bank. In connection with every subject of the school curriculum some form of conduct is necessary for substantial learning. Examples need hardly be multiplied to enforce this important principle.

Meanings are Individual. - Since various objects and situations mean different things to different persons, in so far as they have behaved differently toward these objects and situations, it is evident that this difference in meaning must always be taken into consideration. This is a fact that has long been known, but not sufficiently regarded. We are likely to think that a situation which means one thing for us means the same for everybody else, - a source of trouble when we are dealing with others. It is particularly fatal for the teacher to assume that the child attaches the same meaning to objects and events that the adult attaches to them. The child's experience has been extremely limited, and the meanings that the most common things possess are often fragmentary, inadequate, and obscure. It becomes the business of the teacher, therefore, and of all others who are dealing with children or adults in a practical way, to discover the meanings that the ordinary situations in life possess for those who are to be taught. It is fatal to assume that the same thing, the same word, the same act, the same event, have the same meaning for all.

A number of investigations have been conducted in regard to the meanings that common objects possess for the child at the beginning of his school life; and the results have clearly shown that very little can be assumed as to what the child actually knows, 
even about the most simple things. It is particularly true that the city child has a very inadequate perception of the scenes and events that belong to country life, and it is useless to talk to him about these unless they have acquired for him some definite meaning. It is also true that the country child has a very imperfect comprehension of many of the things that are familiar to the city child. It would be a great advantage if the city child could spend some time in the country and if the country child could visit the city. However, since this is often impossible, the teacher must rely on a large amount of illustrative material in dealing with those things with which the child has had little or no acquaintance. Charts, models, lantern slides, and stereoscopic views are important aids in instruction if properly used. It is probable that in the years to come the moving picture will be employed more and more as a means of making things remote from the child's experience really vital factors in his daily life.

Objective Teaching in Developing Meanings. - It follows from the fact that perceptions arise through active experience with the objects to which they are attached that this experience should be as direct as possible. The mistake should not be made of attempting to explain what can be at once perceived. More facts can be learned in regard to the nature of various wild animals by a half day's visit to the zoölogical gardens than by months of explanation. This does not mean that the child or adult should not be guided in forming proper perceptions and that the mere presentation of the object is sufficient, but it does mean that a large amount of elaborate explanation and discussion is often worse than a waste of time.

In the past teachers have overestimated the importance of explanation and elaboration in the instruction of children. They 
have often explained the obvious, only to confuse the child. It is more important to perceive that a thing is so than to attempt to explain why it is so. In elementary instruction the object to be studied should be presented to the child, and he should be guided to discover the more important facts concerning it by the means of a few straightforward and direct questions. Those things that he cannot perceive by this means are too difficult for him to comprehend by more elaborate and abstract methods. Explanation will only add to his confusion and uncertainty.

Apperception. - The term "apperception" is one that is often used in psychology, especially in its application to education. Apperception and perception are not essentially different. In either case the present experience is given its meaning in terms of the past behavior in regard to similar experiences. It is true that as we advance in life we build up a number of different attitudes in regard to the typical situations that confront us, and these attitudes may be considered as habitual tendencies to behave in certain definite ways in the presence of these situations. These habitual attitudes constitute the "apperceptive bases" for interpreting new experiences. It is a fact of everyday experience that the business man, the professional man, the artist, the teacher, the farmer, have different points of view that must be considered in dealing with these different groups. What will strongly influence one group will have no effect on another. The politician in particular recognizes this, and in his appeals to the electorate he fashions his course accordingly. The most successful candidate for 
office is generally he who appeals to a few fundamental apperceptive bases that are shared by a majority of the people. It is he that "feels the public pulse." The person who is "remote from the masses" is he who either cannot comprehend their point of view, or if he does comprehend it, has no sympathy for it.

No more important educational principle has ever been formulated than that which reads, "Bring the instruction down to the apperception of the pupil." His knowledge of facts, his prejudices, his point of view must be understood, if his range of information is to be widened and his conduct influenced. It is particularly important that the teacher does not "go over the heads" of his pupils; it is equally important for the teacher not to arouse the antagonism of those under him, by disregarding their ideals and prejudices. The teacher in a new locality should be extremely careful not to praise unduly the locality from which he comes. He must have a regard for "local pride," if he expects to get a sympathetic hearing. Nothing is more disastrous than to get out of touch with one's pupils at the start.

True and False Perceptions. - Since perception interprets sensations, gives them a meaning, it follows that this meaning may be correct or incorrect and that the perception may be true or false. In regard to pure sensation, the question of its truth or falsity could never arise. It is an immediate fact and as such cannot be doubted. If I have a sensation of redness, it can be neither true nor false; it simply is; it merely exists, and this existence is a fact of consciousness that cannot be questioned. When, however, I perceive the redness as the cover of a book, I may be right or wrong; the ob- 
ject may be what I perceive it to be, or it may not be. Even the redness as such may be wrongly interpreted. I have a sensation of redness, but as soon as I assume that this redness belongs to some external object, then there is the possibility of an error. As sensation it exists, but as a red object perceived, it may or may not be there in the world outside of me. It may, for example, be merely an after-image and wholly "in my eye." When I call it red, I thereby imply that it is an object that will be experienced as red by others and by myself at different times; in other words, that it is something that has a reality beyond my immediate sensation.

Behavior the Criterion of True and False. - When we ask how the true and the false perception may be distinguished, our fundamental principle of behavior becomes of immediate service. We can find out only by our conduct and the conduct of others whether or not our perception is correct. If the perception that I have will "work" in my subsequent behavior, then I may be reasonably sure that it is true; if it will not "work," then I am obliged to consider it false.

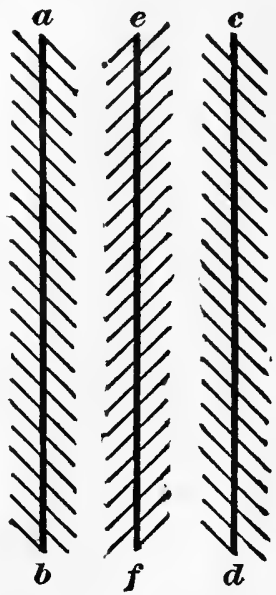

Frg. 8. - The Zöllner Illusion. (From Calkins, "A First Book in Psychology," Fig. 25.)

A few illustrations will serve to make this point clear. In the accompanying illustration known as the Zöllner figure (Fig. 8), 
the heavy black lines do not appear to be parallel. That is my immediate perception of this figure. However, if I examine it further, I will find, on measuring the distance between the black lines, that it is the same at all points, and that my original perception does not agree with my subsequent experience in regard to these lines. Another example of this same fact is found in the false perception in regard to the area of the two accompanying figures from Wundt (Fig. 9). The area of the upper figure appears to be much smaller than the area of the lower. However, if the position of these two figures is reversed, it will be found
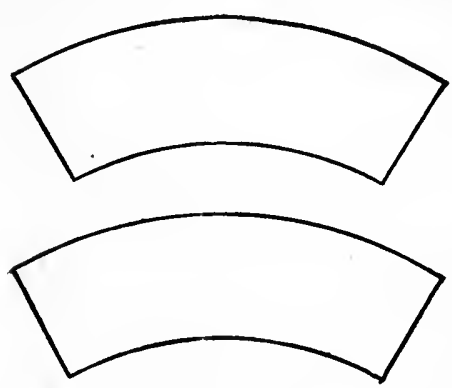

Frc. 9. - Illusion in comparative area of two figures, after Wundt. (From Titchener, "Experimental Psychology," Vol. I, Pt. I, Fig. 48 B.) that their size seems also to be reversed, the figure occupying the lower position always appearing to be the larger. Now, if I place one figure upon the other, they will appear to be exactly the same. Numerous illustrations of false perceptions of this type could be given.

One of the most striking instances of a false perception to be found in literature is that of the "air-drawn" dagger in Macbeth. It appeared to the overwrought brain of Macbeth as a substantial reality, but it would not stand the test of actually being grasped. In other words Macbeth could not behave toward it as he could toward a real dagger. He could not make the perception "work out" in his conduct. This is the only way by which we may distinguish reality from unreality.

The true perception may then be defined as a sensory experience that will "work" consistently in behavior. The false perception fails at certain points to do this. The hills on the horizon in the clear sky are perceived as near at hand. I decide to walk to them; but $I$ find it a long journey. My perception of the distance was 
wrong, and my subsequent test of walking to them was not in agreement with my original idea as to their distance. A person is afflicted with a mental disease; he hears voices plotting his destruction, and believes that he is followed by ruthless enemies. His behavior is influenced by these beliefs ; it is no longer in harmony with that of the community, and he becomes dangerous to himself and to his fellows. So we judge as to the truth or falsity of our own ideas and the ideas of others by an appeal to conduct. This is the final, the only ultimate test.

Illusions and Hallucinations. - There are two kinds of false perceptions, illusions and hallucinations. The Zöllner and the Wundt figures, previously referred to, are illustrations of the former, and the air-drawn dagger of Macbeth of the latter. Both the illusion and the hallucination agree in the one essential particular, namely, that they will not work out consistently in behavior, but they differ, in that an illusion is quite normal, while an hallucination is abnormal. I can prove in my own conduct that the palm trees and the pool of water that $I$ see over the burning sands of the desert are not really there as I perceive them to be, for when I journey to the spot, I find no shade to protect me, no water to cool my thirst, and no verdure to rest the dazzled eyes. My companions, too, have had the same experience as I. The illusion is entirely normal.

With the hallucination, however, this is not true. Macbeth alone saw the dagger; he might even have stretched forth his hand and felt its hilt, but others would not have had the same experience. His behavior 
would not then agree with that of the normal individual. The person who hears voices plotting his own destruction has generally no test by which he can discover that they are unreal, but others do not hear them. If all persons heard these voices, and if on subsequent tests it was found that the actions of all could be based on the perception of these voices, then we should conclude that they were real.

Classification of Illusions. - There are two kinds of illusions. The first kind arises from the fact that certain conditions that ordinarily exist are in the particular instance not present, and yet no allowance is made for the change. Mention has already been made of the hills that on a clear day seem near at hand, when in reality they are far away. This illusion is due to the fact that ordinarily objects at a distance are seen in a haze and are indistinct in outline, while objects that have a clear outline are near at hand. However, it happens in the particular instance under consideration that the atmospheric conditions are different from what they are generally, but I make no allowance for the unusual clearness of the air, and I perceive the hills as near, when in truth they are many miles away. We get the exact reverse of this illusion when we perceive objects in a fog as remote and as unusually large. Our subsequent behavior, however, shows them to be small and near at hand.

An illusion of the second type arises when we are 
strongly expecting something to happen, when our minds are set in a certain direction. I am looking for a friend, and I seem to see him many times before he actually comes; I am listening for the toll of the lighthouse bell, as I strain my eyes through the fog and turn my head to catch its faintest tone. So I seem to hear it now and again, though in reality it is miles away. Illusions of this second type depend less on actually existing objective conditions than do those of the first type, and they approach in kind those false perceptions that have been given the name of hallucinations. When the idea in the mind becomes unduly powerful, then the individual is likely to have distinctly abnormal states of consciousness and to become the victim of a genuine hallucination. We may remember that eventful journey of Ichabod Crane from the house of the Van Tassels through the gloomy darkness of Sleepy Hollow. Dejected and filled with fear, the mind of the unhappy pedagogue was set in just the right direction to get the fearsome experiences that came to him in the appearance of the headless horseman. He perceived falsely, he acted foolishly. If he had not been expecting ghosts, he might not have seen them. If his mind had been perfectly normal and his courage that of the average man, he would probably have detected the sham, and hence not have fled ingloriously. This illustration of a false perception is one taken from the border line between an illusion of the second type and an hallucination. 
Hallucinations as Symptoms of Mental Disease. Since our discussions do not lead us into the field of abnormal psychology, we need not consider the practical significance of hallucinations. We need merely to say in passing that they are often important symptoms in determining the nature of mental diseases. In the case of illusions, however, particularly those of the second type, it is a somewhat different matter. Children, most often of the primary-school age, get false notions in regard to reality, because they are unduly expectant, because they think that certain things are likely to happen, and because they are prone to believe in manifest absurdities. Often these false expectations are due to unwise suggestions that they get from their companions. They believe that there are dangers hidden in the dark because they have been told so, or because the conduct of others has led them to believe so. Little children quickly take up these ideas and weave them into realities that may result in harmful consequences. Adults must be particularly careful to suggest in no way those ideas that will work out injuriously in the behavior of the children under their charge. The mind of the child is highly imaginative and extremely impressionable. A word of caution should be said, however, at this point in regard to imagination and the danger of confusing it with false perception. Imagination, as will be shown in the following chapter, is neither deceptive nor false in its own nature; and although a too vivid imagination may 
pass over into an illusion or hallucination, it does not generally do so. As will be pointed out, imagination gives to us a world of reality not inferior to that opened up to us by perception.

\section{Definitions and Explanation of Terms Used}

Apperception, like perception, is the interpretation of the present experience in terms of our past behavior. We generally speak of apperception, however, when we mean a highly organized form of perception. Our apperceptions are general attitudes toward a large number of experiences. The business man has one attitude toward the world of commerce, the lawyer another, the teacher another. We must know the fundamental attitudes of those with whom we deal, if we are to be successful in our dealings with them.

False perceptions are perceptions that will not work out in our behavior. The immediate experience of the object will not agree with our future experiences.

Illusion. - An illusion is a normal false perception; all normal persons under similar objective conditions will experience the same illusions.

Hallucination is an abnormal false perception. Only the person who is the victim of the hallucination experiences it. 


\section{QUESTIONS AND EXercises}

I. Distinguish by example between a sensation and a perception. What essential factor is represented by a perception that differentiates it from a mere group of sensations?

2. What is the relation of response or behavior to the formation of perceptions? Illustrate.

3. Give examples which show that the same object means different things to different people. Give examples showing how the meanings of objects have varied in the course of your own experience.

4. What is the significance of the term "apperception"? Refer to the examples called for in Question 3, and show that the differences in meanings depend primarily upon differences in attitude or adjustment.

5. What is the criterion or standard by which we judge a perception to be a "true" or a "false" report of conditions in the world about us?

6. Distinguish between illusions and hallucinations. What are the two principal sources of illusions?

7. Illustrate from your own experience how an illusion may arise because of unusual objective conditions. Have you ever experienced an illusion due to excessive expectancy on your part ?

8. Dream experiences furnish striking illustrations of hallucinations. Describe some of your dream hallucinations. 


\section{CHAPTER XIV}

\section{IMAGINATION AND BEHAVIOR}

At the conclusion of the preceding chapter the fact was emphasized that imagination is not to be identified with false perception. This warning is necessary, since not only in general usage, but also in psychology, imagination is often confused with illusion and hallucination. The mental image, however, is no more real nor unreal than is the percept; and, as will be shown later, the truth or falsity of imagination is to be tested by exactly the same standard as is the truth or falsity of perception, i.e., by the criterion of behavior. When I look at the table at which I am writing, I have sensations of color, of pressure, of strain. These are interpreted, and I perceive the table. I shut my eyes and recall the table in imagination. The object of my consciousness is not a table at the moment present to my senses; it is rather the mental image of the table. I am not only conscious of the mental image of the table, but I am further aware that the immediate object of my consciousness is not then and there present to my senses. The mental image has with it a certain quality that distinguishes it from the concrete object of perception that is directly present to the senses. 
It is an interesting exercise to analyze the difference between the percept, the visual after-imagc, and the mental image. If you observe, for example, a red disk on a gray background, you will have before you an object of direct sensory experience; you will perceive the red"disk and the background to which it is attached; if you gaze at this object for a certain length of time under proper conditions and then look away, you will get a negative after-image of the disk, which will differ in certain particulars from an object of direct sensory experience, but which in most particulars will be sufficiently like an object actually present to the senses to be easily confused with such an object. If now you recall in imagination the red disk with its background, you will probably find that it is less vivid than either the object itself or the after-image. The color of the after-image may seem faded, but there is still a color that is of a distinct sensory character; but the imagined red is hardly red at all, or any other color. It is not, for example, a pink nor a brown. Further, the objective disk has a distinct outline, the after-image is less distinct, but still generally fairly definite, while the mental image is hazy and without clear and permanent outline. It is much more difficult, too, to hold the mental image in attention than it is either the after-image or the actual object. Under these conditions it is a simple matter for me to tell whether the object before me is to be classed as a percept, an illusion (as is the after-image), or, finally, as an object of my imagination.

Definition of Imagination. - In the light of the above considerations, imagination may be defined as the consciousness of an object of sensory experience with the additional consciousness that this object is not immediately present to the senses. In other words, in a true state of imagination we are always aware that the object of which we are conscious is not present at the time and in the place that we imagine it to be. I recall the face of a friend, his 
voice, his manner of walking, and so on, but I do not have the impression of his actual sensory presence. I know that I am imagining. If $I$ had the definite experience of his actual sensory presence, $\dot{I}$ should have either a true or a false perception, as the case might be, but not a mental image. It is important that we make this distinction, for unless we do, we shall continually confuse imagination with illusion and hallucination, and as a result we shall consider the mental image as something unreal, and imagination as a dangerous and misleading activity of the mind.

Truth and Falsity of Imagination. - Imagination, then, is not to be considered as something essentially deceptive. Its truth or falsity is to be tested in exactly the same way that the truth or falsity of perception is to be tested, - namely, by actual experience with the object of my imagination.

I imagine how my friend that I knew in the college days of long ago will appear, when $\mathrm{I}$ once again see him at the approaching class reunion. Is my image of him true, or is it false? This question I can answer only after I have again met him and found out by the test of experience whether we can behave toward each other as we did in the old-time days. If I find him not essentially changed, if I can talk with him in the same familiar way, if we still have the same interests and ideas, then. I have pictured him substantially as he is, although I may not have added enough gray hair to my mental representation, nor a sufficient number of pounds to his physique. He is the same, I say, for he acts the same toward me, and I find that $I$ can act the same toward him. I had a true image of my friend. But another friend has grown pompous and 
dignified, as the years have gone by. He talks only of his pro. fession and is remote and distant. How different he is from the fellow that used to lead the class cheering and who scorned excessive dignity and self-importance! My image had pictured him as of old, but I find that the picture does not agree with my later experience. I cannot behave toward him as I did in our college days, for he has changed his behavior toward me. My mental picture of him was false. It failed to fit the case.

An inventor plans a piece of intricate machinery that he hopes will revolutionize industrial conditions and bring him fame and fortune. Has he a true image? It all depends on whether his machine will do what he thinks it will. The image as such is not unreal, because it is an image; the future will decide whether it is practical or not; whether it will work. If it can be made to fit actual conditions, then it is real; if not, then it must be classed as an unreality.

Reproductive and Productive Imagination. - Imagination is termed productive when it recombines former perceptions in new ways; when it merely revives a former perception or a number of such perceptions, without essential change, it is termed reproductive.

I recall the appearance of the desk at which I have been sitting, the face of a friend, or the voice of a singer at the opera. These are acts of the reproductive imagination. There is nothing new added; there is merely the revival of a past experience. On the other hand, I imagine the landscape of the planet Mars, and I do not reproduce what I have already experienced; I put together in new ways bits of landscape that $I$ have seen in actual life, or in pictures, and this recombination gives me something unlike anything I have ever seen. All 
works of art, all the ideas of great inventors, all the schemes of political parties and the projects of men of affairs rest in the last analysis on the ability to recombine in new ways elements drawn from past experience. These creations may be real or unreal; it all depends on whether they can be actually made to work in everyday experience. It can thus be seen that to stamp imagination as such as unreal would be to stamp most that is essential in human life as unreal. Without reproductive imagination the past would be gone beyond recall, and without productive imagination not a plan could be formed for the future; not an ideal could be made to stand forth as a reality; indeed, there would be nothing but the present, and that would be without significance or importance, since it could not be compared with the past, nor related to the future.

It must be remembered that, while productive imagination is creative in the sense that it calls to the mind something never actually experienced in the form that the imagination presents it, the elements which enter into this creation are themselves not mere mental products. They have formed a part of past experience. The wildest imaginings, the most impossible fancies of the mentally deranged, all have had some rererence to previous experience. Nothing comes into the mind in the first instance except through direct sensory experience. It may be worked over and recombined, but nothing absolutely new is added.

Kinds of Mental Imagery. - It is generally held by psychologists that there are as many kinds of imagination as there are various kinds of sensation. Thus, it is said 
that there are images of sight, hearing, touch, temperature, pain, taste, smell, movement (of the muscles, joints, and tendons), and of the sensations coming from the internal organs. It seems quite certain that we have visual images of brightness, color, and form and also images of tones and noises, although the visual images are the most common of all. It has been doubted by some psychologists whether we have any genuine images belonging to the other senses. What we often think is a motor image, or an organic image may actually be a faint sensation. For example, when I think of bowing my head or of raising my arm, the motor image that seems to be aroused may in reality consist of sensations set up when I quite unconsciously start to make the movement which I do not carry out.

It is possible for the individual to gain some idea of the kind of mental imagery that he possesses by looking into his own mind and asking himself questions like the following:-

Call to mind a rose. Can you see its color? Can you hear the rustle of the tissue paper in which it is wrapped, as in imagination you remove it from the box in which it has been placed? Can you smell its fragrance? Imagine taking one of the petals in your mouth. Can you taste it? Touch the rose. Can you feel its softness? Now your hand clasps the stem. Does the thorn prick you? Can you feel the coolness of the leaves and their moisture? Imagine that you are running. What is the mental picture that you get? Do you get the sensations that come from the muscles of the legs, from the joints and the tendons? Do you actually seem to be out of breath with the effort? Can you recall the beating of your heart, the dryness in your throat, and the nausea that comes from your overexertion? 
These and other similar questions may reveal to you the extent to which you may actually recall through imagination the concrete experiences that you are attempting to revive. While there are great differences among individuals, you will probably discover that most of your mental images are hazy and weak and that they resemble only in a very general way the sensations that they represent.

Concrete and Symbolic Imagery. - Images are not only classified according to the sensations to which they correspond, but they are also considered as either concrete or symbolic in so far as they bring to mind an actual object or merely the symbol of such an object. If there comes to mind the idea chair, I may see a mental picture of the chair, or I may see the word " chair" as if it were written, or hear the word spoken, or think of speaking it myself. In the first instance I have a concrete image, but in the three later instances symbolic images. The word "chair" is a symbol of the actual object.

Again, when there comes to me the thought of infinity, I may have a visual image of the deep blue sky and stars shining forth from the depths of unending space, or I may see before me the mathematical character $\propto$, that stands for infinity. It is clear that in the former case my image is concrete, in the latter symbolic.

Many of the symbolic images that we use in our thinking are "motor," that is, they are images (or vague sensations) of movements of the vocal organs, or of the hands, arms, and other parts of the body employed in making gestures. I. may think " no," for example, as a 
sensation in my throat that would arise if I actually spoke the word; I may represent this idea as a shaking of the head or again as a gesture in which I wave away or repel something that I do not wish. It is probable that these motor ideas constitute an important part of our thinking.

In early life we think much more in concrete imagery than we do later. This concrete imagery, too, is largely visual in its character. The adult, however, often loses the power of bringing to mind images having the vivid character that they possess for children. A part of this loss in vividness is due to education. In this there is both an advantage and a disadvantage. We should find it quite impossible to think out an intricate problem in concrete terms; we are obliged to use symbols, otherwise we could make no progress. To hold the child to the concrete indefinitely would mean that the higher mental processes would never be developed. On the other hand, the ability to appreciate the various forms of art, to decide on definite kinds of conduct, to comprehend human nature, - in a word, to enter into life in all its richness and fullness, - is based on the power to experience in imagination the actual situations that the world offers. Too often the literary masterpiece that the child is reading is merely a jumble of words. He studies his lesson in history, but again the word-symbol does not reveal to his mind's eye the actual events; he is instructed in the forms of right conduct, but too often the instruction becomes a set of mere platitudes. It has been a fault of the schools to substitute the printed word for the vital fact for which it stands; this has resulted in a verbal cram that is worse than worthless; it is often positively injurious. The teacher should always aim to make a part of his instruction concrete; he should see to it that the pupil never loses the power that he originally possesses of reviving in a vivid manner his past experiences and of reconstructing these through productive imagination into something that is actual, that is aglow with reality and pulsating with life. 
Imaginal Types. - It was thought at one time by psychologists that different individuals possessed different types of imagery; that, for example, one person thought principally in visual terms, another in auditory, and another in motor. It is true that individuals of unusual talent have possessed remarkably vivid imagery in some special field. Great painters have had the ability to see in their mind scenes and faces with almost the richness and definiteness of objective experiences; gifted musicians have heard in imagination long musical compositions played. It is also true that disease has sometimes taken away from the patient his power to think in a certain kind of imagery. For example, he may be unable to recall how a word looks when printed; he may no longer be able to picture the face of a friend, or to revive the image of the street on which he lives.

These are, however, exceptional cases. As a rule the great majority of persons think in various kinds of imagery on various occasions, and they are not predisposed to one type alone. It is quite possible through special training to strengthen a type that is weak. As a rule it is an advantage to think in as many kinds of imagery as possible, and the schools should employ the visual, auditory, and motor imagery, both concrete and symbolic, in their various forms.

The Educational Value of Imagination. - One of the most important practical problems that arise in connection with imagination relates to the value and danger 
of productive imagination in the early years of childhood. The child is prone through imagination to create a world of his own, to people it with all sorts of unrealities, and to treat it as objective. This seems to be a defect at the first glance; yet productive imagination greatly enriches the mind of the child; it extends his experiences beyond the narrow barriers of his home life. In play he lives through all sorts of stimulating experiences. $\mathrm{He}$ is thus provided with a world that is rich and varied, a world in which he as truly lives as he does in the world that the adult knows as the only actuality. It is important that the child have the advantages that this imaginary world is capable of giving him. On the other hand, however, it is dangerous to stimulate his fancies to the point where he cannot distinguish between what his imagination creates and what confronts him as hard, cold fact.

In deciding how far the child may safely be allowed to go in his construction of an imaginary world, there is one safe principle on which we may base our decision. This is the fundamental principle of behavior. We must ask ourselves what are the results in the life of the child, as he lives it day by day. Do his imaginary companions help him by appealing to them to solve his little problems or do they keep him from the normal companionship of actual playmates? $\mathrm{He}$ is made to believe in Santa Claus. Does this belief give him an idea of generosity and kindness that actually makes him a better child, 
or the opposite? Does the stork myth offer to him a satisfactory explanation of the origin of life, or should the child be told the simple biological facts? These are questions that must be solved largely in each individual case as it arises. It may be said in general, however, that those children who are unimaginative need to be stimulated, while those whose fancies are excessive should be held in check.

In considering the extent to which the child's imagination may be allowed to have free scope and even be stimulated, the following important facts should be kept in mind :-

(I) The Child does not Confuse the Real with the Fancied. - The normal child is usually capable of distinguishing between fact and fancy. In his play he imagines with great vividness that the stick that he bestrides is a prancing steed, yet he does not go so far as to confuse it with his father's horse. Toward the perceived horse he acts quite differently than he does toward the imagined horse. His conduct shows that he makes the essential distinction that is necessary to guide his behavior. The girl that is playing "house" does not attempt to eat the mud pies that she imagines to be like her mother's pastry. If the imagined object and the perceived object were treated as identical, then the behavior of the child would be such that he could not get on in the practical world to which he must conform. 
(2) The Imaginary World a Privilege of Childhood. The vivid character of the childish imagination tends to become less as he advances in years, and hence he naturally outgrows those fancies that in adult life would be absurd and injurious, but which in childhood are quite rational and helpful. His belief in supernatural beings, for example, is something that is on the whole helpful to him at an early age. He is too young to understand the materialistic conceptions in regard to the nature of things that form the basis of the adult's view of life. It does not harm the child to believe in fairies, gnomes, and elves. It would be a serious matter if the adult held to such conceptions. When this crude supernaturalism that the child naturally manifests in his earlier years tends to be outgrown, as it does at about the eighth or ninth year, it should no longer be insisted on. When the child is capable of understanding a new order of things, he should be instructed in that new order according to his ability to comprehend it. This applies particularly to religious education. All honest questions of the child concerning the supernatural elements in the Bible story should be honestly and fearlessly answered. However, the adult view should not be forced on the immature mind of the boy or girl until it can be understood and properly related to life.

What is true of the child in this particular is equally true of inferior and undeveloped races. They should not be instructed in those things that they cannot understand. It is necessary to remember always that what is the crudest superstition for an 
advanced age or a developed civilization may be the most simple truth for a lower stage of intelligence and development.

(3) The World of Fancy must be Limited. - A child may be encouraged in vivid fancy in one direction, and be held to the strictest account in another. For example, he may be allowed to people his imaginary world with all sorts of peculiar animals, but he must be held to strict account in regard to those that form the materials for his instruction in his course in nature study. There are many things that from the start he must know definitely and accurately, and here fancy can have no place.

In the moral instruction of the child it is essential that his imagination be kept from calling up those actions that are undesirable. If he is not likely to do a certain thing, it is folly to impress it on his attention and allow him to experience it in imagination. The fact that he is told that it is not a desirable kind of behavior does not change the fact that he should not imagine this kind of behavior at all.

(4) Imaginary Achievement must not Replace Real Achievement. - It is important that the child should not believe that what he has created in fancy is already an accomplished fact. There are many persons who have never succeeded in the world's struggle for the simple reason that they never could effectively distinguish between what they pictured to themselves as achieved and what they had actually accomplished. There are not a few of life's failures who have earned millions of dollars " in their minds" ; who in fancy have been social 
reformers and leaders of men; who have written books, invented flying machines, and become captains of industry, through the mere thinking that these things were accomplished; in a word, who never could quite distinguish between the thought and the deed.

\section{Definitions and Explanation of Terms Used}

Imagination. - The consciousness of an object of sensory experience with the additional consciousness that this object is not immediately present to the senses. This object of imagination is termed the mental image in distinction from the percept.

Productive and reproductive imagination. - The former recombines the elements of past experiences in new ways, the latter reinstates them without essential change. My image of a centaur is productive; my image of a horse that I have seen is reproductive. Productive imagination that creates objects that are not capable of realization in life as we know it is called fancy. The mythological characters of the Greek religion, the imaginings of little children that create fairies and goblins, are examples of such fancies.

Concrete and symbolic imagery. - The former reproduces an object of sensory experience, the latter brings to mind the word or some other symbol that stands for the object. The mental image of a horse is concrete, of the word "horse" symbolic.

Types of imagery. - There are said to be as many 
types of imagery as there are different sensations. Thus we speak of the visual (sight), the auditory (hearing), the motor (movement), the dermal (touch, temperature, and pain), the gustatory (taste), the olfactory (smell), and the organic (breathing, circulation, digestion, etc.) types. We also speak of the concrete and symbolic types.

\section{QuEstions AND EXercises}

I. Define imagination, and give examples showing the difference between perception, false perception, and imagination.

2. Distinguish by example between productive and reproductive imagination.

3. In what way may productive imagination aid us in behavior?

4. Test yourself with regard to your ability to form images in different fields of sensation: Recall the image of the house in which you live; compare the vividness of the imaged colors, and the accuracy of imaged forms and distances with the vividness and accuracy of the corresponding perceptions. Can you imagine a familiar tune played upon the piano? Compare the image with the perception, noting the points of similarity and difference. Try to image the odor of coffee; of tar; of camphor; of kerosene or gasolene. How would you compare your ability to form images in this field with your ability to image sights and sounds? Try to image tastes, pains, and movements, and make similar comparisons.

5. Illustrate the difference between concrete and symbolic imagery. From the preceding exercise you have probably found it very difficult to image accurately or vividly smells, tastes, pains, movements, and perhaps sounds; by the use of symbols, however, you can adequately describe experiences involving these sense departments. Recall a disagreeable journey that you have taken: what details are present in actual concrete imagery, and what details do you reconstruct by means of symbols? Do you 
actually reëxperience the feelings of fatigue? Do you actually resmell the disagreeable odors?

6. In what way should the imaginative life of children be regarded from the point of view of education? Have you known unfortunate results to follow from children's belief in fairies? In Santa Claus? In your own childhood, did you confuse the real with the fancied?

7. Can you recall instances of children's doubts in regard to the world of myth and fancy in which they formerly may have had implicit faith? When such doubts arise how should they be met? 


\section{CHAPTER XV}

\section{MEMORY AND BEHAVIOR}

The Wider Use of the Term "Memory." - The term "memory" in its widest signification is used to mean the retention of any experience in such a way that it changes behavior. This change in behavior is taken to be the fundamental test as to whether an individual remembers or not. If the individual learns through experience, if he is capable of education in the widest sense of the word, then he remembers ; if no such learning is possible, then there is no evidence of memory. Memory in this sense of the word is to be found in practically all animal life, probably even in its simplest form, the amœba. It becomes more and more evident as we go up the scale.

If a tuning fork is sounded near a spider, it drops from its web to the ground. If this same animal is tested day after day with the sounding fork, it finally responds to the stimulation no longer, but remains undisturbed in its web. It has learned to ignore the fork; in a sense it remembers its former experiences and acts accordingly. A more striking example of this sort of memory is found in the hermit crab, which usually avoids the darker parts of the aquarium in which it is placed, but which can be attracted into the shadow if food is put here. In seeking the food, the crab will go around a wire screen placed in its way; at length 
the presence of the screen alone is sufficient to cause the crab to move toward it and around it, although the food is no longer there. All vertebrates show through their behavior marked evidences of memory. Fishes, frogs, and turtles have been taught to find their way about simple mazes; cats, dogs, and monkeys readily learn to open puzzle boxes. Indeed, all animals that have been observed in their free activities, or that have been tested experimentally, have given evidence to a greater or less degree that their behavior can be changed through experience.

The Narrower Use of the Term "Memory." - As the term "memory" is more commonly used, it means more than the persistence of an experience in such a way that it produces a change in subsequent behavior. It generally signifies not only the retention of this past experience, but the definite conscious recall of this experience and the recognition that it does belong to the past and not to the present. It is clear that many of the events in our past which have an influence on our present behavior are not remembered in this latter sense of the term. Often they have been entirely "forgotten"; we do not recall that we have ever experienced them; yet they remain and make a profound difference in our conduct.

This fact is strikingly illustrated in certain abnormal conditions. An individual who is aftlicted with "hysteria " may, for example, continually refuse to take water when offered in a glass. There is no clear reason for this peculiar behavior, but it is finally learned that the patient at one time in her experience was shocked and disgusted on discovering that she had put to her lips a glass that had recently been drunk out of by the house dog. She had 
entirely forgotten this unpleasant event, yet quite unknown to her, it persisted and worked itself out in her behavior years after it had faded from mind.

Recollection. - When an event is recalled as belonging to the past, it is said to be recollected. This recollection may be very definite, or quite hazy, as the case may be. In the latter instance there is little more than the mere impression of familiarity, of " having been there before," that accompanies mere recognition. On the other hand, the past experience may be recalled in great detail and all the circumstances connected with it brought back. The different degrees of recollection are often experienced by the individual who in later life returns to the scenes of his boyhood. There are many objects that he recognizes only in the sense that they do not seem entirely strange; there are others that are dimly outlined through the haze of the years; while still others are recollected in minute detail.

Recall and Recognition.-Recollection is the culmination of conscious memory. It is preceded by recall and recognition. Usually recall implies recognition and a certain degree of recollection, but not always. I may recall an event without recognizing that it has been a part of my past experience, and I may recognize something that I have been unable to recall. That is, I know it when it is presented, although I was not able to bring it into my consciousness unassisted. As an example of recall without recognition may be cited the coming to 
mind of an expression, or the executing of an act, which has formed part of an earlier experience, but which may seem quite spontaneous and original. We sometimes use the language of a text that we have studied in school, or an apt phrase that we long ago committed to memory, and think that we have just invented it.

While as a rule recall is accompanied by recognition, recognition often takes place without recall. We are constantly recognizing objects and experiences as they are presented to us, although we could not recall them in any real sense. I have forgotten the name of the man I was introduced to yesterday, but when a friend asks me, "Was it Thomas?" I at once recognize that this is the correct name.

Impression and Association. - In order that any act of conscious memory may take place, it is necessary that the remembered experience shall first be impressed and then associated with other experiences. Without impression the experience could not be retained and without association it could not be recalled. If we think of memory from the standpoint of the activity of the nervous system, we may consider the impression as the stamping in of the original experience. This is supposed to produce some sort of a trace or change in the nervous substance, a memory "scar" as it has sometimes been called, that tends to persist indefinitely. If the nervous substance were like the sands of the seashore, experience could easily write its characters upon its surface, but these 
would soon be obliterated; on the other hand, if it were like the granite rock, experience could only with great difficulty cut its markings into its unyielding substance, although these when once cut would remain. The nervous system that is effective must be at the same time plastic and retentive. There are individual differences in this respect; age and disease also tend to modify the character of the nervous system in such a way as to make it less capable of receiving and retaining impressions.

However retentive the nervous system may be, this is not enough to insure a good memory. Only through association are experiences raised to the surface of consciousness. They remain hidden in the depths of the unconscious until they are brought up through their connection with something in consciousness. If we consider association in its relation to the nervous system, we may say that the ease with which any event is recalled depends upon the connection of the neurones that are concerned in this event with others that are related to the consciousness of the moment. If they are disconnected, if the discharge is blocked at the synapses, then memory is impossible. Forgetfulness in its more common forms may be considered as due to a temporary or permanent interruption of these connections.

This point of view is seemingly substantiated by what we know of loss of memory through disease or accident. It is possible that a blow on the head may cause a person to lose all memories of the events immediately preceding the accident. It is to be supposed 
that the neurones involved in these events have become disassociated from the rest of the nervous system rather than that they have been themselves injured or destroyed, and that, consequently, they have been split off in their activities. That such is the case is indicated by the fact that these lost memories may be subsequently restored. We notice a similar condition when we are very tired. We find it then extremely difficult to recall the name of a friend, or an event, although we have no difficulty in bringing it back to consciousness the next morning. The night's rest has restored the nervous sytem, and the "blocking" disappears.

It was long ago pointed out by James that little can be done to improve one's retentivity, since this seems to be a matter of the nervous substance as such and to be beyond the control of educative influences. On the other hand, there are various means of impressing the event or fact to be remembered upon the mind, and also of forming the proper associations, in order to make it possible to recall the fact or event when desired.

A fact may be impressed by frequent repetition and by making . it so vivid as to arouse the interest and secure the attention. Going over the same thing again and again is a favorite device that, despite criticism from some quarters, still forms one of the chief methods of instruction in the schools. In recent years the factor of vividness in presentation has been given an emphasis that it long had deserved, but which it had not always been accorded. As we have said on a previous page, mere repetition is of little advantage if that which is repeated is not attended to. The forming of proper associations is one of the most important problems that faces the teacher. The materials must be so organized that they may be easily recalled when they are needed. Obviously it would be a waste of time to learn the important dates 
in history if they were not related in such a way that they could be used in their proper connections. This matter will be discussed more fully in the next chapter.

The Tests of Memory. (a) The Method of Retained Members. - There are various tests of memory. The common test and one almost exclusively used in the schools is that of ability to recall the parts of what has already been learned. This recall may be a verbatim reinstatement, as in the case of rote memory, or it may be recall in terms of the sense or meaning of what has been learned. The test of my memory for a poem that $I$ have studied is how much of it I can repeat word for word, but the test of my memory of a history lesson is how many of the important ideas I can reproduce. To repeat the language of the text may be no indication that I really know what I have been studying. Obviously, as the person becomes more mature, mere rote memory for most things is less important than memory for the sense or significance of what he has studied.

(b) The Saving Method. - I may test my memory for a poem that I learned to the point where I could repeat it word for word, not by trying to reproduce it, but by seeing how long it takes me to learn it again. To-day I may not recall a word of it, although a week ago I thought I had mastered it. But when I relearn it, I find that it takes me just half as long to commit as it did on the first occasion. Hence I may say in a very real sense that $I$ have but half forgotten it. It is true that a great many things that we 
have learned in the years gone by now seem entirely vanished from our minds. That they are not completely lost, the test of relearning will prove.

(c) The Method of Right Associates. - As we have just pointed out, we recall experiences through their association with others. Hence a valid test for memory is to find out on presenting one of the facts associated with another whether the second can be recalled. For example, a pupil is learning a GermanEnglish vocabulary. His memory may be tested by asking him to repeat it word for word, or by finding how long it will take him to relearn it when it is partly forgotten, or by presenting the English words one by one and asking him to give their foreign equivalents.

(d) The Method of Recognition. - Another test for memory consists in recognizing the object to be remembered when it is presented. The boy who is sent into the workshop knows his tools if he can use them; the pupil remembers his language lesson if he recognizes the meaning of words when he meets them. At one time it was believed that the child had really mastered his studies when he was capable of giving a set of definitions and rules. The real test, however, is not that he remembers a collection of words ingeniously framed by an adult, but that he knows how to use in a concrete instance the principles hidden behind these definitions; in other words, that he recognizes in the particular example before him something that he has previously studied. 
It was not so long ago that the idea prevailed that there was virtue in memorizing such unintelligible statements as the following: "An abstract noun is the name of a quality, action, or condition of a person or a thing, apart from the person or thing itself." The teacher felt that the pupil had mastered fractions when he knew all of the rules that the arithmetic contained in regard to this intricate subject, or that he had an actual knowledge of geography if he could bound all of the states in the Union, give their capitals, and recite their chief products. To-day it is generally realized that, while this verbal cram may be valuable if it has been preceded by an intelligent study of meanings, it is worthless when used alone. A verbatim test of memory is not the real test of knowledge. More and more the fundamental importance of recognition is being appreciated, and recognition means in the last analysis merely the knowledge of what to do, of how to behave, in regard to any object or situation when it is presented. Other tests for memory that are valuable are after all valuable only in so far as they assume that when the individual has recalled something, he then recognizes it; is able to do something with the material thus recalled.

(e) The Method of Reconstruction. - Closely associated with recall as a test for memory is reconstruction. This latter test consists in putting into its original arrangement materials that have been presented in a certain order and then rearranged. This memory for order and arrangement is often more important than the memory for the objects to be arranged.

This is illustrated in the work of the school when, for example, the pupil is given an outline map and is told to put in their proper places cities, mountains, rivers, etc., that have previously been studied in a complete map. Memory for order is also important in such a subject as history. The pupil may know the names of all of the presidents of the United States, but it may be equally 
important to know the order of the separate administrations. Indeed for certain purposes, he may be given the names and then asked to arrange them properly.

Retentiveness. - It is to be kept in mind that the measure of memory, tested by any of the methods above discussed, is not only what is the present efficiency of the memory, but also how long this efficiency will continue. I may, for example, be able to repeat a poem by heart to-day, but do $I$ know it well enough to recite it without mistake a month hence? I may have mastered a new stroke in tennis, but if I do not play again for a week, shall I be able to execute it then? Quite obviously, if I have just learned the poem so that I can repeat it, much will be gone at the end of the month; if I have to-day acquired for the first time the new stroke, I may be quite unable to make it next week. In other words the test for permanent memory is not only what I know now, but also how long I have known it. If I learned a poem a year ago and can repeat it to-day without an error, I shall probably be able to repeat it correctly a month hence. If I mastered the stroke in tennis last season and can now execute it perfectly, the probability is that I shall never forget it.

It has long been recognized that cramming is ordinarily a bad method of study. The pupil may, in a brief space of time, acquire a superficial mastery of subject matter. On examination day he may seem to know as much about the subject as another pupil who has mastered his lessons thoroughly and faithfully day by day. As an actual fact his "knowledge" is not permanent, and 
the examination test is therefore a false one. For this reason it is wise to give tests at times when pupils are not expecting them. If they know that this is the practice of the teacher, they are more likely to have their knowledge in a form in which they are prepared to give it forth.

The Laws of Forgetting. - To understand the facts of memory it is equally essential to understand the facts of forgetting. It has been definitely determined that we forget what we have learned very rapidly at first and then much more slowly. If we are studying something in which there is little meaning, in which we rely on impression very largely and on association but slightly, a large amount of the material learned will have faded from our minds in the first few hours after we have stopped the learning. What remains after this leaves us much more slowly. In memorizing something that has meaning, we find that we forget it less rapidly, although the fact still remains that the rate of forgetting is more rapid at first than it is later on. It has been found that if the subject studied is to be remembered for any length of time without a large loss in the first few hours, it is necessary to study it beyond the point of merely mastering it. In other words, if the person wishes to retain what he is learning, he must go over it again and again, even after he is convinced that he has memorized it.

Faulty Observation Leads to Defective Memory. Much of the supposed inability to remember is really 
lack of original observation of that to be remembered. It is therefore a fault of attention, and not an actual memory defect. Improving one's methods of observation is therefore one of the most important factors in securing a "good memory." This fact may be strikingly illustrated by showing a person a colored picture representing some simple scene, asking him to look at it for a brief period, perhaps a minute, and then later asking him to describe the picture. It will be found that certain of the details - some of these seemingly the most obvious - are passed over entirely, simply because of the fact that he paid no attention to them when the picture was before him.

Distortion and Confusion in Memory. - One of the greatest dangers in a poor memory is not the simple forgetting of certain details of an experience, but the falsification of these details. In other words the person believes that he remembers something that either did not take place, or occurred quite otherwise than in the way in which he remembers it. There are many ways in which this falsification may arise. One of these is by confusing the details of one experience with those of a similar experience. I saw a friend a week ago at the seaside. At that time he showed me a business letter that interested me. The next day I visited him in his office in the city. Some time later I "remember" that he showed me the business letter at his office.

A similar error in memory involves a confusion of vari- 
ous parts of the same experience. I am called to the court to tell of a quarrel that I witnessed on the streets some months ago. I testify in good faith that one of those engaged in the disturbance called another harsh names. In reality it was a third person who was principally responsible.

It often happens that a person does not actually remember certain details of an experience and quite unconsciously fills these in from what he supposes would generally be true. In other words he unwittingly makes the experience that he is recalling like other experiences of a similar nature. In the colored picture that he observes there is, for example, a cradle of a brilliant bluegreen color. He does not look at it carefully, but when later asked the color, he is absolutely sure that it is a brownish red, because most of the cradles that he has seen are of that color.

One of the common sources of mistakes in memory arises through talking about an event that you have witnessed, or through reading about it. What others say to you, or what you see in the papers, finally becomes confused with your own experience. There are many things in our past lives that we cannot tell whether we have actually observed or whether we have been told about them. When we talk with others, they not only tell us definite things, but they also suggest incidents that we afterward develop until they seem to have.been actual experiences. For these reasons it is extremely 
difficult to get reliable witnesses to an occurrence that has excited great public interest. These witnesses have talked the matter over so many times with the officers of the law, the lawyers, the newspaper reporters, and their friends that the occurrences that they originally witnessed are mingled with a mass of "hearsay" details that they are not able to distinguish from their own experiences.

Suggestion as a Factor in Distorting Memory. - If a person is questioned in regard to an experience, he is more likely to falsify some of its details than if he is allowed to give his own version of it unassisted. If the questioner so puts his query as to suggest a certain answer, the person examined has a tendency to reply with the answer sought. For example, the police detective may say to the suspect whom he is grilling, "Did you not have a quarrel with the murdered man?" If he repeats this question time and time again, the prisoner may answer, "Yes," through the force of the suggestion, although no quarrel has actually taken place. Here lies one of the great objections to the so-called "third degree" methods. Questions that are much more mildly suggestive than the example given above act in very subtle ways to lead the memory into error, particularly in the case of children, who tend to answer all questions in the way in which they think the questioner wishes them to answer.

Factors Conditioning Accurate Memory. - The accu- 
racy of memory is greater for certain details of an experi ence than it is for others. Actions, especially those of persons, are likely to be observed carefully and remembered with approximate exactness. Objects at rest, and their relations in space, are less likely to be observed, but when attended to, are kept in mind well. On the other hand, the qualities of things, particularly their color, seem to be but poorly observed and remembered. Very little dependence can be placed on a person's memory for color.

The accuracy of memory depends much on the person's disposition. Some individuals have a tendency to elaborate their memories until what they "recall" resembles but little the original occurrence. There are many children and not a few adults that like to "show off " and tell " big stories," which at first they may recognize as inaccurate, but which after several repetitions they actually believe themselves.

Accuracy also depends on age. In spite of the common belief that children have exceptionally good memories, it has been clearly shown that they remember less and are more likely to give a false report of what they do recall than adults. Memory seems to be more accurate and extensive from the time of maturity on to old age, when it often rapidly declines.

We are more likely to remember pleasant than unpleasant experiences. Except under unusual conditions, we do not dwell on the sorrows of the past. This is not 
because we have not had them impressed originally with great force. Indeed, it is a rule that we attend more to the unpleasant than the pleasant. Our failure to remember them is due to the fact that we refuse to associate and recall these unpleasant experiences. It is, indeed, fortunate for us that we can thus ignore the unpleasant and disagreeable features of our experience when they can no longer be of value in directing our behavior.

The Function of Forgetting. - While the falsification of memory is always undesirable, forgetting, in many instances, serves a very useful purpose. We cannot and should not remember every detail of an occurrence. The recall of every element of an experience is seldom required. We cannot keep our minds burdened with the unessentials. It is as necessary to know what to forget as what to remember. Obviously we should forget only those things that are not important for the purpose we have in mind, and we should remember the important details. This will be discussed more at length in the following chapter.

The Improvement of Memory. - The question of the improvement of memory is an important one. In the first place it should be remembered that an "all around" memory training is impossible. It has been well said that we do not have "memory," but "memories"; that is, we remember some things well and others badly. Indeed, the very fact that my 
mind is impressed with certain details may mean that I do not attend to others, and hence they are not likely to be stamped on my mind so that they can later be recalled. If I am interested in learning certain formulæ in mathematics, I may entirely forget the engagement that I made with a friend. Usually, persons who are "forgetful" forget certain things only and remember others very well. We call them forgetful simply because they do not keep in mind those matters that we consider important. Memory cannot then be strengthened as we would strengthen a muscle, merely by exercising it in committing any sort of material. If I exercise it by learning poetry and improve it in that direction, this does not of necessity mean that my memory has been strengthened for learning the moves in chess.

The best way to improve the memory is to improve our methods of memorizing. In the first place, we must train ourselves to more accurate observation of what we wish to recall. We must learn the value of holding our attention to what we are memorizing. In the second place, we must accustom ourselves to form helpful associations, so that recall will become easier. Finally, there are certain technical methods of memorizing that are superior to others. These will be discussed in Chapter XVII. 


\section{Definitions and Explanation of Terms Used}

Memory. - In the most fundamental sense of the term, memory signifies the retention of any experience in such a way that it modifies subsequent behavior; in the narrower and more common use of the term, it signifies the conscious recall of any fact or event, with the added consciousness that this fact or event belongs to our personal experience.

Retention. - The holding of an impression so that it may subsequently be recalled.

Recall. - The revival in consciousness of a past experience.

Recognition. - This term signifies that the present fact or event is known; that is, it does not seem strange; we know how to behave in relation to it; it is accompanied by a " feeling of familiarity."

Recollection. - The fact or event that I recognize is revived in recollection with the circumstances that originally accompanied it. I not only recognize the boy that I see on the street to-day, but I recall in greater or less detail the events connected with my meeting him on a previous occasion. I may recall an event and not recognize it as a part of my past experience. I may not be able to recall an event that I recognize as familiar when it is again presented. I may both recall and recognize without recollecting. Recollection always implies recognition, but recognition may not develop into recollection. 
Impression. - This term signifies the "stamping in " of the original experience in such a way that it persists for an appreciable period of time.

Association. - This term signifies the connection of the impressed experiences with other experiences in such a way that one tends to recall the other.

Rote memory. - This term signifies "learning by heart," or "word for word."

Methods of testing memory. - The most common method is to find out how much of that which has been once learned can be reproduced. This is technically termed the "Method of Retained Members." A second method is to find out how long it will take to relearn something that has once been learned and later in part or wholly "forgotten." The amount of time saved in the relearning over the first learning indicates the amount remembered. This is technically known as the "Saving Method." If I save half the time in the relearning, then my memory at the beginning of the relearning was just fifty per cent of what it was originally. A third method of testing memory is termed the "Method of Right Associates." In this test one of the facts or events associated with a second fact or event is presented, and the test is, Can the person recall this associated fact or event? A fourth test is termed the "Method of Recognition." When an object is presented, my memory is measured by the amount of familiarity that this object has for me. Do I know what the object is 
when I see it; am I able to use it; do I know how to behave in relation to it? The fifth test is the "Method of Reconstruction." Can the person who is thus tested put back into the original order parts that are no longer in this order?

Rate of forgetting. - This signifies the rapidity with which we lose from memory that which we have learned. The rate is very rapid during the first few hours; then it becomes less and less rapid.

Falsification of memory. - We often think that we remember facts and events that do not actually belong to the experience that we recollect. Falsification often arises because we confuse the parts of two separate experiences; again it is due to the tendency to think that what ordinarily happens has happened on the occasion that we are now recalling, although in this particular instance the customary did not take place. Another source of falsification is "suggestion." Some one implies by a question or a statement that the facts are thus and so, and we then tend to take up this implication and consider it as true. Hearsay is also a common source of falsification. We confuse what we are told, or what we read about, with what we have actually experienced. The tendency to tell " big stories," to add to and embellish what we have witnessed, is also a common source of falsification. Finally, inaccurate observation as well as the fading of the original impression makes all of these various errors of memory possible. 


\section{Questions AND Exercises}

I. Define memory as the term is used in the narrower psychological sense. Compare memory with perception, false perception, and imagination, giving examples.

2. Distinguish between recognition and recollection.

3. Distinguish between impression and association.

4. Describe three important methods of testing memory, and show how each may be employed in the work of teaching.

5. What are some of the dangers of the "cramming" method of learning? Under what conditions may "cramming" be an effective method of learning?

6. Why is it essential to learn beyond the point where the material may be recalled without error?

7. What factors are likely to cause a distortion of memory, and how may this distortion be avoided?

8. Secure a colored picture of fair size (for example, fifteen by twelve inches). This should depict some simple scene and contain a reasonable number of details (too many will cause confusion). Show this picture to adults and children, allowing them to observe it for one minute. First ask the observer to describe what he has seen; then ask questions, some of them misleading. Note the source and character of the errors. 


\section{CHAPTER XVI}

\section{ASSOCIATION AND BEHAVIOR}

IN the preceding chapter the importance of association in the recall of an experience was emphasized. The present chapter will consider in detail the nature of association and the manner in which it operates.

"Simultaneous" and "Successive" Association. Psychologists generally divide associations into two classes, and to these they give the names respectively of simultaneous and successive associations. In simultaneous associations the various elements do not follow one another; there is no conscious lapse of time between the appearance of the first element and the others. All seem to spring up in consciousness at once. I hear the "honk" of an automobile horn, and instantly there comes to my mind a picture of the machine itself with its driver and occupants.

When we speak of associations, however, we more often think of successive associations in which the elements associated stand out clear and distinct in our consciousness. It is these successive associations that we can study in their formation, since there are definite stages in the apperance of the various ideas that thus group themselves together. Further, we can control in some 
measure the manner in which they are formed and thus control the memory processes which depend on these associations.

The Primary Laws of Association. - The first "laws of association" go back many centuries to the Greek philosopher and scientist Aristotle, who pointed out that experiences were associated either by contiguity in space or in time, or by similarity (including contrast). These are seemingly very simple in their nature. Two objects are experienced together, or one event follows closely on another. When I recall the first object, or event, I tend to recall the second. These two instances illustrate the principle of contiguity. I hear the deep note of the whistle on the steamship that is making out to sea, and I at once think of a cry of distress because of the similarity of the sound. The word "black" brings to my mind "white," because of the contrast involved.

These so-called laws of association, however, are of no great value. They simply tell me how certain objects are arranged through association in my consciousness, but they give very little insight into the actual means by which associations may be formed and controlled.

An attempt has been made to explain the formation of associations through contiguity by picturing what happens in the nervous system when various neurones are stimulated together or in immediate succession. It is held that under such circumstances these neurones tend to become linked together at their synapses in such a way that the stimulation of the first tends in the future to cause the stimulation of the second. For example, the 
neurones involved when I see the flagman at the railroad crossing associate themselves with the neurones involved when I see the tracks. They act either together or in immediate succession (contiguity either in space or in time), and hence they become connected in such a way that when the "flagman" neurones are stimulated (either when I see or think of the flagman) then the "track" neurones are set into activity, and there comes to my mind the image of the tracks, although they are not actually present to my senses. This explanation, whether it is correct or not, is of no practical significance. I can in no way directly control the activity of my neurones, and hence am unable to control my associations through a knowledge of how the neurones may act. Further than this, while the physiological explanation above discussed may serve to explain associations by contiguity, it is powerless to explain associations by similarity or contrast. We must seek for a more fundamental law of association than those already discussed, if we are to get at a principle that will be of use in understanding and directing our associative processes.

The fundamental principle of association appears when we ask ourselves the conditions under which we judge an object to be similar to another or to contrast with it. We may think that this judgment is made because of the essential likeness of certain experiences and unlikeness of others, a likeness that is inherent in these experiences themselves and which any one may find to exist in them. This is not so, however. The likeness or the difference is something that $I$ read into these experiences, and whether I find likeness or difference, whether this likeness or this difference is in certain aspects of the experience or in others, depends upon the point of view, the idea that $I$ have in my mind when I 
make such comparisons. This point of view may be a definitely conscious matter, or it may be obscure and difficult to recognize, but in any case when I associate experiences according to this law of similarity and contrast, I do so because of the mental attitude, either clearly conscious or merely present as a vague tendency, that turns my thoughts in one direction rather than in another.

Why is it, for example, that in the gathering twilight of the November evening, as I see the full moon just appearing above the horizon, I am reminded of a football? Surely there is little likeness between the two objects that would impress the ordinary observer. The reason, however, is quite apparent. I am returning from a football game, and my mind is full of the contest. My thoughts are on football; my mind is, for the time being, centered in the sport. So the round moon suggests a round football. On another occasion I again see the full moon, and this time it brings to mind the glowing lights at the entrance of the theater that I visited recently. Why do I find this new similarity? Merely because I am thinking of the play that I have witnessed and I have the "theater attitude."

Mental Attitude or "Purpose" Determines Associations. - Why do I sometimes find resemblances between objects and again differences? This is also a matter of what is in my mind. If I am looking for differences, black will always suggest white, but if I am making comparisons based on similarity, black will call up such a thought as velvet, night, coal, and so on. When these attitudes are very definite in my consciousness, they may be termed purpose, and we may also think of the more obscure "points of view" as indefinite and partly con- 
scious purposes. It is what I am aiming at, either clearly or indefinitely, that decides how my associations of similarity and difference shall be formed.

I may be aiming to prove that political upheavals are dangerous, and I will then with definitely conscious intent look about for historical examples to prove my contention. That is why I see a similarity between present-day conditions and those that preceded the French Revolution. Here my associations follow a very definite purpose. Again, I may be a prejudiced partisan, and although I am not aware of it, my "prejudice" (really a scarcely recognized purpose) leads me to discover in the candidate of my particular faction resemblances to Abraham Lincoln, and in his opponent for office a likeness to Benedict Arnold. I will not admit to myself that I am thus prejudiced, but as a matter of fact it is my "point of view" that discovers these likenesses and differences. In reality, neither man is a hero nor a villain.

It is a fact which reveals itself on careful analysis that not only the associations of similarity and contrast are formed under the direction of purpose, but those of contiguity as well. It is quite clear that many of the objects that are brought together in space and in time are not associated. This is partly to be explained by the fact that all are not equally well impressed on my attention, and I do not recall one member of a pair when the other is presented because of the fact that the former was never really stamped on my mind. There are, however, many instances when this lack of recall is not due to original lack of observation, but rather to the fact that the two experiences do not naturally belong together in terms of my mental attitude. 
As an example of this the following illustration may serve: I sometimes see the flagman at the crossing, but I also often see him in another part of the town of an evening when I am returning from my office. He has done his day's work, and in the warm weather is generally sitting on his front porch as I pass by his home. According to the law of contiguity, when I think of the flagman I can equally well recall the railroad crossing or his home. As a matter of fact, to-day I associate him with the crossing, for as I call him to mind I am thinking also of a shipment of machinery that $I$ am to send to a customer in a distant city. My mind is on the railroad, and I quite naturally think of the flagman in his capacity as an employee of the railroad. I may say that the purpose of my entire thought at this time is connected with freight facilities. When I recall the flagman and think of his home, I am considering how his ward will vote at the coming city elections, and my purpose (or attitude) is quite different from what it was when I was thinking about shipping a carload of machinery. In this second instance I call to mind the flagman as a citizen, and I therefore recall his home rather than the railroad crossing.

So it is with all of our conscious associative processes that are at all elaborate. The way in which they are linked together is finally decided, not by a mere objective circumstance, but by the trend of our minds at the time at which they are recalled. It is only under conditions of the most trivial and disorganized thinking that our associations are dependent on external circumstances to decide in which way they shall be formed.

Secondary Laws of Association. - Beside the laws of association discussed above, several others have been formulated that sometimes have been described as the secondary laws of association. Some of these are not so much laws of association as they are laws of impression. Among these the laws of frequency and of vividness have been briefly discussed in the preceding chapter. The 
former refers to the simple fact that the more often experiences are presented together, the more likely they are to be recalled together. This is due to the circumstance that they have become impressed on consciousness through repetition. This form of association may further be explained from the standpoint of the nervous system by supposing that as experiences are repeated again and again the connections between the neurones involved become more and more firmly established.

I tend to recall vivid experiences, such as the football rush that $I$ took part in as a freshman, the day on which $I$ received promotion in the office where I was working, and so on. Vivid experiences are held in mind in part because the vividness stamps them in and in part because they are connected with ideas and purposes that give them interest and significance. Other secondary laws of association are the laws of primacy and recency.

The principle of primacy asserts that those experiences that come first in a series of related experiences are more likely to be recalled than those that come later. I remember the first day of my visit at the home of my friend better than those that followed. I shall never forget the port at which I landed on my first visit to Europe, although many of the other cities that $I$ visited later are now very indistinct in my memory.

So it is with recent events. The last class that I attended as a senior in college has left an impression on my mind that has never faded out. I can remember no 
other so distinctly; indeed for most of them I have no memory at all. Primacy and recency are two laws that in the last analysis are special forms of vividness. The first and last things stand out because they are emphasized by the position in which they are placed, and because they thus arouse the attention and become vivid.

These four laws, then, are really reduced to two,the law of frequency, or repetition, and the law of vividness, or interest. These laws relate both to impression and to association. In so far as they concern association, however, they will be found to be merely variations of the law of purpose, or attitude.

\section{Mental Attitude or "Purpose" Explains Secondary} Laws. - Things that are often repeated are thereby stamped more and more upon consciousness. That can be readily seen. But why are they recalled together? Largely because they fit together in accordance with the general trend of my thinking.

In the city in which I live, the fire gong rings the "no-school signal" on stormy days; invariably the no-school signal is accompanied by a holiday for the children. These two events always go together, and the children and the teachers learn to associate them, so that when the signal is heard, it at once connects itself with a holiday. The children are "thinking school" and the teachers are "thinking school." School forms the main purpose of their thought and actions, - they are in the "school" attitude. I know equally well that the signal means no school, but I seldom associate the fire gong with the school, because I am not thinking of school, I am thinking of business. 
In the early hours of night the crescent moon, except on rare occasions, is seen in the western sky. These two conditions go together and have been repeated time after time. That probably the majority of people do not join them together was shown to me on one occasion by the fact that when the moon was partly eclipsed at an early hour of night and appeared as a crescent in the eastern sky, no one to whom I spoke about the event the next morning had noticed anything unusual. They were not aware the moon was eclipsed; they thought merely that it was the "new" moon. They must have observed the relation between the new moon and the western sky time and time again, but they were not thinking about astronomical facts and so this relationship failed to associate itself in their minds.

The principle of vividness is in a large measure to be explained as due to the predominating purpose, trend, or attitude of the mind. Vividness is not necessarily something external. Bright lights, loud noises, sharp pains, are more likely to attract attention than weak sensations of the same character. Yet, to Paul Revere, waiting to carry his message of the approach of the British soldiers, the dim glow of the lanterns from the belfry across the river was more vivid than the lightning's flash would have been. The lantern signal signified something, - it fitted into the purpose that brought him to the shore on that eventful evening; his mind was bent on giving the alarm, and with this the signal accorded.

The shipwrecked sailor hears above the roar of the waves, as they surge around the fated ship, the faint cry of the rescuers on the beach, for this cry fits into his thoughts; it means chance of 
rescue and hope of life. The victim of the accident, lying on his cot in the hospital, is conscious of the sharp pain in his lacerated hand, but in the focus of his attention is the dull ache that he feels in his side. The latter is more vivid, for it means more in terms of his injury and his chances of recovery, and his "mind is on" this.

Emotional Congruity and Association. - There is still another so-called law of association that has been termed by James congruity of emotional tone. This signifies that those objects and events are associated that agree with the prevailing mood of the individual who makes the associations. If I am sorrowful, then I think of winter landscapes, barren deserts, lost friends, and so on. If I am glad, I think of June days, bountiful harvests, and merry companions. The person who is of a gloomy disposition is always recalling his misfortunes, but his optimistic friend remembers only the cheerful experiences. The congruity of emotional tone is much the same in our affective life as are purpose, trend, meaning, and attitude in our intellectual life. Our thought processes may be controlled either by the purpose that we set before ourselves, or by the tastes, feelings, and prejudices that sway us.

The various conditions of association as described above are often strikingly illustrated by the associations formed by the insane and mentally defective. Certain patients are unable to associate ordinary things and events because the fundamental ability to receive and hold impressions has been lost. An alcoholic patient, for example, can remember nothing about the events of the day, simply because they have never been stamped upon his conscious- 
ness. Another person is quite capable of receiving and holding impressions, but he cannot bring these together in a well-ordered whole. We say that he does not think clearly, simply because there is no controlling purpose, no fundamental feeling, that organizes his fleeting thoughts. $\mathrm{He}$ is incapable of holding himself down to any one line of association. He chatters on in a random fashion, with his mind now on one thing, now on another. Some one says "day" in his hearing, and his thoughts go on as follows: "Night; yes it was a dark night. Don't you like the night better than the day? The day is a 'daisy.' Did you ever pick buttercups? Oh, the butter here is bad; I am going to complain to Dr. M- when I see him." (An attendant rattles his keys.) "What a bunch of keys. If I had them I would unlock every door in this ward. Then the patients would get out. But we must have patience, for it is a virtue, you know." So the unfortunate individual wanders on, each succeeding idea determined by something quite trivial, such as the sound of the preceding word or some external happening that turns the attention in its direction.

In contrast to this there is another patient who has one controlling thought, a "fixed idea," as it is sometimes termed. All his associations group themselves around this idea. He cannot get away from it. It forms the main purpose of his insane consciousness. Perhaps he believes that some one is trying to annoy him. Every thought centers around this delusion; every event suggests it to him.

A third person is afraid of everything. His mood is one of constant terror. There is no definite idea that dominates his consciousness in this instance, but his emotional attitude leads to all sorts of associations in terms of this mood. He fears, simply because he is in a fearful state, not because he has anything specific to fear.

We see all these types of association illustrated in normal individuals in a less intensive form. 
Certain persons are spoken of as "thick." Nothing makes an impression on them; they seem to observe but little, and consequently to recall but little. They are never on the alert, never keen-witted. There are others who think in a random fashion. Their thoughts go helter-skelter, and they seem to have little purpose in their thinking. They just "ramble on and get nowhere." Then there are others who get a "notion into their heads and simply can't get it out." They do not progress mentally, because their thinking always revolves around one idea. They are radical in thought; they are "cranks" in behavior. Finally, there are those who let their emotions unduly control their associations. The person who is of a sullen mood is always turning his attention to those experiences that arouse his anger; the person that is over sympathetic lets his mind run along sentimental channels. An exaggeration, an intensification, of any of these types would carry the individual over into the "insane" class.

Summary. - There are, then, three ways in which our associative processes may be formed and controlled. In the first place we must so fix the various facts and events to be associated that they shall have a relative permanency. This can be done by making these facts and events vivid, and by repetition. Here we have the two fundamental principles of drill and interest. Arouse interest, secure attention, repeat. This has already been discussed in the chapter on Habit.

The second and most important method of establishing associations is by the control of the thought through some idea or purpose that leads it in a definite direction. Here we have the principle of organization that is so important in all learning. The associations must not be left to the mercy of trivial and external circumstances; 
they must be controlled from within by some idea. This idea in a sense selects the others that are to keep it company. It must be remembered that such ideas are in the direction of the interests of the individual, and they form the parts of consciousness that are attentive; hence, as we have already said, vividness itself means purpose, and is to be considered not only as a means for fixing the facts to be associated, but also of joining them together and directing the course that they shall take. So the second rule for association will read, - Organize the material to be associated according to your ideal interests. By the term "ideal" is signified that the interests which control your associations shall stand out before you as ends to be secured, as purposes to be realized, as goals to be attained. The interests should not be immediate and trivial, such as distract the attention of the dog that is trying to open a puzzle box, or that lead the feebleminded and insane to ramble on with no consecutive ideas to guide their associations.

The third manner in which the associative processes may be controlled is through the feelings as they work themselves out in some dominant mental attitude of the individual. These attitudes may be thought of as very dimly recognized ideas or purposes that are rich in feeling. They are really prejudices of the affective rather than of the intellectual type. We meet them on all sides. They decide how a person thinks and acts in politics, in religion, and in his more general social relationships. They are 
among the most subtle and powerful forces that control our lives. Here the rule reads, - Form wholesome and rational prejudices; cultivate desirable attitudes of mind.

Educational Corollaries. - These three rules for the formation and direction of proper associations are well illustrated in school procedure. The principles of repetition and interest have already been discussed and need no further comment here. The principle of purpose and the principle of prejudice, however, need further amplification.

The teacher should never give a lesson to the class, should never conduct a recitation, without some definite plan. There should be a fundamental idea controlling the entire topic or set of topics. All material that is not connected with this idea should be excluded. The material excluded may be important in other connections, but unless it is related to the topic under consideration it has no place in the lesson. The subject may be American history and the topic to be developed the manners and customs of the New England colonists. Emphasize everything that relates to these particular facts, - the habits of work and recreation; the customs in dress, in travel, in worship; customary articles of food and how they were prepared, served, and eaten. More important still, insist that the pupils make a selection themselves with these definite points in view. Encourage them to find a number of essential topics in what they are studying, teach them to make outlines of the 
leading facts, - in a word, accustom them to organize their own associative processes.

Not only will the original learning be much more valuable if the material is organized, but the recall will be greatly aided. In an organized body of knowledge there is the central idea around which are arranged subsidiary ideas and the facts that illustrate and explain these ideas. Each fact tends to lead up to the central idea, and through it to other facts that relate to this idea. The facts are thus all bound together, and the recall of one leads naturally to the recall of the others.

The Importance of "Prejudices." - We cannot, however, "think out" definitely all of the associations that enter into our consciousness. Much must always be left to those more fundamental attitudes that we have called prejudices. Here the idea that is at the basis of the prejudice is generally quite obscure. Sometimes it is not recognized by ourselves or by others. We refuse for a moment to consider certain kinds of action because we have been made to "feel " that they are essentially wrong. We do not have an "open mind" in these respects, and we are "illiberal " in regard to the suggested conduct. We have no sympathy for the person that indulges in this kind of behavior, for we cannot understand him.

It can at once be seen that these prejudices are either bad or good only in so far as they influence behavior beneficially, or the reverse. It would be a misfortune to have an open mind in regard to stealing; it would be foolish to attempt rationally to consider the possible 
desirability of murder. On the other hand, we should never shut our minds through prejudice to the consideration of some of the great social and economic problems that are up for discussion before the forum of public opinion to-day.

In forming the right kind of prejudices the teacher, scarcely less than the parent, has a great influence and a great responsibility. There are some questions that should be treated as forever settled; some topics that cannot be debated. There are, for example, certain "excuses" that children offer for improper conduct that cannot be tolerated; there are certain basic ideas that in every community should always be stamped with disapproval. Those matters, however, that warrant debate should never be dogmatically decided. The educated person is he who has an open mind for many things, and at the same time a stock of firm prejudices that decide his behavior in a large number of instances. Such a person alone is efficient.

\section{Definitions and Explanation of Terms Used}

Simultaneous and successive associations. - In simultaneous associations all of the elements joined together are present in a single moment of consciousness. In successive associations the parts associated follow one another in a temporal sequence.

Laws of association. - The so-called Primary Laws are those of Contiguity in Space and Time and of 
Similarity (including Contrast). Objects and events that are together in space, or that succeed each other in time, are likely to be associated; also objects and events that are alike, or that are set over in opposition, the one against the other. The so-called Secondary Laws are those of Primacy, Recency, Frequency, and Vividness. To these is sometimes added a fifth law, Congruity of Emotional Tone. By vividness is understood that quality in an object or event that arouses the attention. This may be due to some quality that is objectively striking, such as a loud noise or a bright light; or, as is more often the case, it may be the result of the interest that the experience possesses for the individual who finds it vivid. Primacy and recency are special cases of vividness. The first things and the last things tend to arouse the attention because of their position in relation to other events. Experiences that are frequently repeated tend to become firmly impressed, and hence are more likely to be recalled. Experiences are congruous in emotional tone when they tend to arouse the same or similar feelings. For this reason they are likely to be associated.

Purpose. - We ordinarily mean by purpose a goal which we hold before the mind and strive to attain. It becomes the end of our thought and conduct. In the present discussion the term "purpose" has been used to signify not only the definite conscious intention which controls our mental processes and determines our actions, but 
also those less definitely recognized ends, desires, and interests that we find on examination to be present in all of our mental life and which decide the direction which our thoughts shall take and the manner in which our associations are formed. In this wider sense of the term, purpose is the fundamental law that explains the arrangement and the grouping of our thoughts.

Fixed idea. - This is an idea that forces itself on attention. The person who is controlled by a fixed idea cannot banish it from his mind for any length of time. All his associations center around it and are to be explained by its presence in consciousness.

Deliusion. - This is a belief that is quite unwarranted, but which cannot be banished from the mind of the person who is a victim of it.

Organization. - This term signifies the arrangement of our thinking according to some fundamental principle. All subjects of instruction should be organized around a few important points in such a way that all of the various facts bear a definite relation to these points. In this way the whole will have a significance, and the various parts will be more easily kept in mind.

\section{Questions AND Exercises}

I. Distinguish by example between simultaneous and successive association.

2. Give examples of association by contiguity and similarity. If the value of association lies in its power to bring past experience into consciousness to help us in solving present situations, why 
is it fortunate that the associations between similar experiences have been emphasized in the development of mind? Can you give a similar reason for the emphasis of experiences happening in close connection with one another (contiguity)?

3. Illustrate what is meant by the statement, "Mental attitude or "purpose' determines associations." Find examples in your own experience showing that the same object suggests different associations when the purposes or problems that you have in mind differ.

4. State the secondary laws of association and give an illustration showing the operation of each. Of these four laws, which are the most important in the work of education?

5 . In what way does attitude or purpose condition the operation of these secondary laws?

6. Describe the three methods by which the associative processes may be formed and controlled. Show how each of these methods may be employed in teaching.

7. What is the influence of prejudices upon behavior? Name some prejudices that should, in your opinion, be encouraged. Name some that should, if possible, be broken down. 


\section{CHAPTER XVII \\ ECONOMY IN LEARNING}

SINCE all advanced stages of learning are based on memory and association, it is evident that correct methods of learning depend on the manner in which impressions are received and joined together. It is not a matter of indifference how we learn. Many investigations have been made in recent years to determine the most advantageous methods of learning, and it has been shown that it is possible to save both time and energy by the use of economical devices in memorizing and in associating the materials of study. The most important of these economical methods will be discussed in the present chapter.

Learning by Wholes vs. Learning by Parts. - It is a common practice for a person who is committing a piece of poetry or a paragraph of prose to learn it bit by bit. In the case of the poem, he studies the first stanza until he can repeat it without the aid of the book; then he studies the second stanza in the same way, then the third, and so on, until he has finished the task. In the case of the prose selection, he follows a similar method, learning a few sentences at a time. This method of learning has been technically called the Part 
Method because the learner commits to memory piecemeal.

It has been conclusively shown that in general this is a wasteful method of memorizing, and that it is a saving to learn by the Whole Method. When this latter method is employed, the poem, or the prose selection, is studied from beginning to end each time until the task is completed.

The advantage of the Whole over the Part Method is to be explained largely by the fact that, in studying any thing that has meaning, correct associations are formed only when each part studied is connected with that next following. In the case of the Part Method, however, the last line of the stanza of poetry, for example, is not connected with the first line of the stanza next following, as it should be according to the sense, but it is joined with the first line of the same stanza. Thus it is quite possible when learning by the Part Method for the student to have no knowledge of the meaning of the selection as a whole. He may be able, moreover, to repeat each part learned with absolute correctness and yet not be able to join the parts together, nor to remember the order in which they come.

Disadvantages of the Whole Method. - There are two disadvantages that are connected with the Whole Method, however, which must be taken into consideration and which make certain modifications in procedure necessary. In the first place, this way of learning is likely to discourage the immature pupil. He studies the selection over again and again, and perhaps cannot then repeat a single line correctly. It seems as if he were making no advance, and he becomes disheartened. The 
remedy for this obvious difficulty is to habituate him from the start to the Whole Method, to show him that in the end it is easier than the Part Method, and that it accomplishes more satisfactory results.

In the second place, it almost invariably happens that certain portions of the material that is being studied are more difficult than are others. As a result, the easier portions are learned long before the more difficult, and yet if the Whole Method is strictly followed, these parts that have been learned must be studied together with those that are harder. For this reason, it is desirable to study the whole selection until the easier parts are mastered; then to spend some time in mastering the more difficult portions; and finally to fix the entire selection in mind by the Whole Method.

The Best Length for Learning Periods. - Another important question as to the best method of learning may be stated as follows: "If you had two hours that you could devote to the study of a certain lesson, would it be more advantageous to spend this entire time at one sitting, or would it be better to divide the time spent into several; four, for example, allowing thirty minutes for each period of study?" When the question is put in this way it may be difficult to give an answer for each individual case. The thirty-minute period will undoubtedly be more advantageous for young children, and probably for mature students that " settle down " to their tasks with little loss of time; for those, however, 
who spend ten or fifteen minutes in "warming up " for their work, short intervals of study are distinctly disadvantageous. In general, however, for a task extending over a long period of time, it is better to divide the learning into various study periods. For example, it is probably desirable to have in the lower grades two periods for number work daily rather than one. In the high school it is usually more advantageous to extend a study over the whole year with shorter periods than to crowd it into one semester with long periods. There is no doubt that the extended course is decidedly better than the one that is given in half the time, although the same number of hours may be devoted to the course in each instance.

The reason for the superiority of the work that is extended over a considerable period lies chiefly in the fact that this added time gives the material learned an opportunity to be fixed in mind through wide associations. The longer it is present as a part of the mental content, the greater is the opportunity for establishing many associations that relate it to other material that is being learned and to that which has already been mastered.

The Importance of Recall in Learning. - In committing a task to memory the learner often turns away from the book that is before him to see how much he is able to recall. This practice is justified by sound psychological principles. It has been found by actual tests in the laboratory that recall is a great aid in learning, and that it should be practised even more than is at present the custom. The attempt should be made to recall not only at the end of the learning, but at frequent 
intervals during the study period. Many a pupil believes that he has mastered his lesson when he really knows very little about it. His ignorance arises because he has not taken the trouble to discover by means of attempted recall just where his strength and his weakness lie. It is well to spend a certain amount of time at the completion of each task in reviewing what has been studied and in determining exactly what portions need to be more accurately mastered.

Recall is valuable for two reasons. In the first place, as has already been said, it shows the learner where the weak places in his task are, and in the second place active recall tends to establish firm associations and make a permanent impression. It is a great economy in learning to use the spare intervals, periods too brief for systematic study, in recalling what has previously been studied. The utilization of these odds and ends of time makes an important total in the aggregate.

The Value of the Recitation. - The value of the recitation is closely related to that of recall. One of the chief functions of the recitation period is not to discover how much the pupil knows and to assign to him marks, but to show him where his knowledge is weak and his understanding slight. It is further advantageous as a means of emphasizing the important facts and in forming the correct associations. In other words, by means of the recitation the teacher aids the pupil to recall those things that are necessary for him to fix permanently in mind. Hence, during the recitation the pupil should be encouraged to recall and restate the lesson in large 
units or "topics." A " pumping " recitation has but small value.

Interference in Learning. - Impressions and associations formed at various times tend to interfere with one another. If $I$ have just finished learning one selection of poetry and at once start to commit another, there is danger of confusing the two selections. This fact of interference has already been discussed in a preceding chapter in another connection. It is to be remembered that the chance for interference is greater in proportion to the incompleteness of the learning. If I have committed the poem so that I can readily remember it and permanently retain it, then my learning of other selections subsequently will not interfere with my retention of the poem first learned. On the other hand if I have just barely mastered the poem, it can easily become confused with what I subsequently study.

Again the possibility of interference is greater in proportion to the closeness of the periods of learning the first and the second (or interfering) selection. I am more likely to confuse two poems when I study one directly after the other, than if there is a time interval between. For this reason it is always well to leave a brief time that is unoccupied between successive periods of study. This gives the opportunity for the fixing of the materials just learned.

Finally, interference is directly proportional to the similarity of the materials. I am more likely to con- 
fuse two dates in history than I am a date in history and a formula in mathematics. For this reason subjects that are alike should not be studied one directly after the other.

Interference seems to be due to two chief causes. In the first place a certain length of time seems to be required in order that the memory impressions shall become established. This is irrespective of the associative connections into which they enter. In the second place, it is easily seen that since effective recall is largely a matter of proper associative connection, it is necessary that the correct associations be perfectly free to form themselves without entering into competition with other associations that are in the process of formation. The greater the meaning of what is being learned, the greater is the possibility of forming 'wrong associations, or of breaking up those associations that have just been formed.

The Value of Thorough Learning. - If the material that is being learned is to be retained for any length of time, it is desirable to study it longer than is necessary simply to reproduce it. That which is just barely learned is rapidly forgotten, but that which is firmly fixed in the mind fades much more slowly from memory. It is therefore economical to learn what one is committing to memory beyond the stage of mastery that may seem sufficient at the time of learning.

Rote Learning vs. Rational Learning.-- Most of our learning does not consist in committing to memory verbatim the materials of study. It is rather learning by the "sense," or "meaning." It is necessary in this case to determine what should be held in mind and what may be skimmed over and forgotten. It must also 
be remembered that rote memory is never to be justified in itself, but only in so far as it can later be used in connection with something that has meaning. If I commit dates in history, lists of rulers of Europe, and presidents of the United States; if I learn to name the principal bones of the body and the counties in the state in which I live, this knowledge has value only in so far as it relates itself to something that has real significance. Dates in history are useful because they mark off important epochs and help us to keep in mind momentous events. Presidents and monarchs have no importance as mere names; they are valuable only in so far as their relation to their time and their connection with the events of their day are significant. The names of the bones of the body are worthless bits of mental furniture unless their use is known. The counties of a state are of no importance to the learner unless he sees their connection with the economic and political conditions of the state. There is no learning that is valuable which does not immediately or ultimately connect itself with conduct or behavior; and rote memory, if considered for itself alone, is a waste of time. More and more as the child advances in the grades should the emphasis be placed upon significant learning and upon the conditions that are fundamental to it.

The Value of Mnemonic Devices. - It has been found by experiment that it is from eight to ten times as easy to commit to memory significant material as material without meaning. It is therefore desirable whenever possible 
to introduce meaning into what is being studied. This necessity has resulted in the use of various tricks in learning and in the elaboration of so-called "mnemonic methods" of aiding the memory. The often advertised methods of "improving memory" are generally of this character. What is learned is held in mind by artificially devised associations, - as, for example, by arranging a list of names in such a way that their initial letters will spell a word or phrase. The fault with such methods of learning lies in the fact that the associations thus formed are not of real significance and that they must often be unlearned before the significant associations can be established. For this reason mnemonic devices should be employed with great caution and only when all other methods fail.

"The Warming up" Per:od in Learning. - It is a fact of common observation that much time is often lost by the learner in starting upon his task. It may take him from five minutes to half an hour to "warm up " to his work. Indeed, some persons habitually "dally" along, and never get thoroughly engrossed with the task at hand. Such individuals find their attention easily distracted, and they let their minds wander away from their studies at the slightest pretext. Efficient learning is largely a matter of concentrated attention. It therefore follows that the person who can readily adapt his attention, who can plunge at once into his work, has a decided advantage over the person whose adaptability is less. 
This adaptability is partly a matter of individual make-up, but largely the result of the formation of correct habits and ideals of work. It is improvable to a high degree.

The Most Favorable Rate of Learning. - The question of the rapidity of learning is important from the standpoint of mental economy and efficiency. Is it well to go over the material with deliberation or with haste? This depends upon at least three things: (I) the general disposition or type of the learner, (2) the nature of the material, and (3) the stage to which the learning has progressed.

In the first place, there are certain individuals that naturally learn more rapidly than do others. This rapidity may be due either to carelessness or to the mental alertness of the learner. If the rapidity is the result of carelessness, then the learner should form the habit of studying more deliberately; if, on the other hand, this rapidity is due to superior intelligence, then it should be encouraged. The rapid learner is not of necessity the rapid forgetter. Slowness may be due to stupidity as well as to care and accuracy.

In the second place, the learning should be more rapid with material that is easy to master than with difficult material. The difficulty depends on several factors. If the subject that is being studied is unfamiliar, progress should not be so rapid as if it were well known; simple narration or description is not so difficult to master as exposition. 
In the third place, the rate of learning should not be the same at the beginning of the acquisition as later on. At first the learner must proceed slowly in order that he may familiarize himself with the material before him; later he can learn more rapidly. It has been shown by experiment that the tendency of the learner is to go slowly at first and then more rapidly, - to increase the "tempo," as it is technically termed.

A General Rule for Learning. - The various facts concerning economical learning discussed in this chapter may be summarized in a general rule as follows:-

(r). All material, no matter what its nature, should be gone over carefully and slowly several times until it is clearly understood, and then the rate of learning may be increased in accordance with the character of the material and the type of the learner.

(2) The material should be studied by the Whole Method until the easier parts are mastered; then the attention should be given to the more difficult parts one by one; and finally the whole should be studied until it is well fixed in mind.

(3) The study should not end with the first successful attempt to reproduce what has been learned, but it should continue for some time after this point has been reached.

(4) During, and immediately after, the learning, recall should be practiced and the weak parts in the learning discovered and strengthened. It is well also at spare 
intervals to recall to mind what has been previously studied.

(5) If the material to be learned is of considerable length, it is economical not to attempt to master it at one sitting, but to divide the study into several sittings. This is particularly important for children.

(6) Care should be taken that immediately after one study period another subject should not be taken up. An interval of from five to ten minutes should be left free, and during this time that which has just been learned may with great advantage be recalled.

(7) Whenever it is possible, the learning should be in terms of the sense or meaning of the material, since learning by rote without regard for meaning is very slow and difficult.

(8) It is highly important that the learner habituate himself to begin at once with his task. In other words, he should facilitate the adaptation of his attention in all ways possible.

It is important for the teacher to train himself and his pupils in economical methods of learning. It is as essential to know how to study as to acquire knowledge itself. The teacher is not to rest content with requiring that his pupils master the lesson; he should inquire into their methods of study; find out the time that is consumed and the conditions under which the work is done. He should from the outset show his pupils how to study. He should observe them at study and take pains to correct individual faults. Study periods in school should be as important as recitation periods. The teacher who has charge of such a period should not consider that his duty is done when he sees that order 
and quiet are observed. It is desirable that there be more study periods in the school hours, even if these are secured at the expense of cutting down some of the recitation periods. The conditions of study at home are often far from ideal, and here incorrect methods of learning may be established and never outgrown.

It is important that some of the study periods be supervised by the teacher with the specific aim of teaching pupils how to study. He should have no other class, no personal work that he is trying to perform. This may be readily accomplished in the secondary school. In the elementary school, however, it is often the custom to have one class at work at their desks while another class is reciting. Thus it happens that the entire time of the teacher is taken up with the recitation. It would be greatly to the advantage of both teacher and pupil if during certain study periods the teacher could give his entire attention to this phase of the school work.

\section{Definitions and Explanation of Terms Used}

Whole method. - This term signifies the learning of memory material by going over it again and again until it is mastered. It is contrasted with the Part Method in which the material is mastered "piecemeal."

Recall. - The term is used in this chapter to signify the practice of attempting to bring back to mind that which is being learned, in order that mistakes may be noted and the progress that is being made discovered.

Mnemonic methods of learning. - This signifies the use of artificial devices to give meaning to memory material when no such meaning exists. As a rule mnemonic aids in learning are dangerous.

Adaptability of attention. - By this is meant the ease with which the learner concentrates his attention upon 
something new. Some individuals spend a long time in " warming up" to their work. In such cases they adapt their attention slowly; others have readily adaptable attention. The adaptability of attention may be improved by continued effort under guidance of an ideal.

Tempo of learning. - This relates to the rate of learning. Some individuals go over the material rapidly, and others slowly. There are not only these individual differences, but also differences arising from the nature of the material and the point in the progress of the learning.

\section{Questions AND Exercises}

I. Contrast the "whole" and "part" methods of learning, and state under what conditions each may profitably be employed. (The reader would do well to test the relative merits of each of these methods for himself. Two poems of equal length, equal difficulty, and equal interest should be chosen. One should be learned either line by line or stanza by stanza; the other should be learned by rereading and reciting it as a whole until it is mastered. Note carefully the number of repetitions required in each case, and the amount of time spent upon the learning. It is also well to try the same experiment with prose selections.)

2. In connection with the tests suggested above, the question of the best time-interval for learning may also be investigated. In comparing two methods, of course, the intervals given to repetition should be equal, but when the learning of the two poems has been completed by practicing, say, through a number of ten-minute periods, try two other poems with thirty-minute periods.

3. The importance of recall may be tested by learning two selections of the same length, difficulty, and interest, reading one repeatedly until it has been thoroughly mastered, and reading the other to the point where it can be partly recited, then continuing 
by recitation, referring to the printed page only when it is necessary to "refresh the memory." Note carefully the time consumed and the number of repetitions essential to mastery. Needless to say, the time intervals and the general method of procedure (that is, by "parts" or "wholes" as the case may be) should remain constant in the two tests that are to be compared.

4. What is meant by "interference" in learning? Compare with interference in habit-building (see Chapter XI). What other resemblances can you detect between habit-building and memorizing?

5. The significance of meaning and organization to learning may be clearly seen by comparing the learning of a series of "nonsense syllables" with the learning of the same number of syllables forming a group of meaningful words. The result is so obvious, however, that one does not need the experiment to be convinced of the value of organizing materials into meaningful units.

6. What is meant by "mnemonic devices"? In your own experience have you found such devices to be useful? If so, can you explain the secret of their utility?

7. Note, in the tests suggested above, the length of the "warming up" period. Does it vary in your own learning, and under what conditions? What means do you employ (if any) to shorten the period?

8. In your own learning, have you noted whether the rate or tempo of repetition is a variable factor? (This may again be tested by experiments similar to those discussed above. Again it should be insisted that, in testing one of these factors, all others must remain constant.)

9. What steps may the teacher take to improve methods of learning among his pupils? 


\section{CHAPTER XVIII}

\section{BEHAVIOR AND THE HIGHER THOUGHT PROCESSES}

IN the earlier chapters, the fact has often been emphasized that a large part of our behavior is under the control of instinct and habit: definite situations give rise to responses that are more or less mechanical in their nature. There are, however, occasions when new situations are presented that cannot be met in habitual or instinctive ways. The old modes of conduct are no longer adequate, and something that differs both from instinct and from habit must supervene if the difficulty is to be solved.

The Thought Crisis. - It is under these conditions of inadequate adjustment that a "thought crisis" arises. If the situation is so unusual that we cannot solve it by instinct or habit, - if our customary behavior is "blocked," and no new modes that are practicable present themselves, - we may be seized and overcome by emotion. If, however, the new situation presents a suggestion of possible solution, - if it seems that a satisfactory solution is possible, - we begin to think clearly and definitely, we "reason out" how to accomplish the end that we seek. While under the sway of 
emotion our thoughts are confused, our feelings intense, and our attention fluctuating; under the guidance of reason our ideas become clear, our feelings are subdued, and our attention is fixed successively upon the single elements of the situation that apparently lead to the goal of our endeavor.

The incidents of the sailing trip described in Chapter I serve to illustrate the development of the thought crises under the stress of a new and unexpected situation. The sailing of the boat was largely a matter of habit until the ledge of rocks came into view. Then it was that a difficulty was presented demanding intelligent action. But an emotion came first. When it seemed as though the boat must dash upon the reef, a wave of fear swept over me. I did not know how to act. In vain my mind ran over one aspect of the situation and then another. I could not think clearly; I felt helpless; and my attention, undirected by reason, focused one point and then another in a confused and haphazard fashion. But this confusion was only momentary. Out of it the idea of "heading the boat up" quickly emerged. Instantly my thoughts became clear; my intense feelings subsided; I had a definite purpose that controlled both my thinking and my doing. But this in turn gave place to another wave of emotion when I found that, after all, I could not sail around the reef by heading into the wind. Again the intense feeling of helplessness overcame me; again the ideas became confused, and attention flitted from point to point. But once more, a clear idea of a means of escape dispelled the confusion. Again the flow of thought clarified, and the despair that had seized me faded away. I worked rapidly, but steadily and persistently. There was nothing haphazard, nothing meaningless, in either thought or deed. Out went the sail until it hung flapping and limp in the wind. The boat "lost head," was caught by the wind and the tide, and thus drifted out of danger. The difficulty had been solved, not by falling back upon 
habit or instinct, not by a lucky chance, but by "thinking out" the problem.

\section{Real Thinking Always Involves a Real Difficulty. -} Intelligent thinking never arises except under the stress of some difficulty ; it never appears unless a problem is to be solved, unless a new set of conditions is to be dealt with. This is the first and unvarying condition of thought. Nature indulges in no luxuries, and when there is no need for thought, intelligently directed behavior disappears. When, however, one is compelled to think, the ideas that come into consciousness assemble themselves around the problem that one is facing. These ideas "flow on," so to say, toward the end that one is seeking. In other words, the sequences of perceptions and images are, in clear thinking, always going somewhere; they are not moving in a haphazard manner as in states of emotion, idle fancy, or " day dreaming." This is the second condition of rational thought.

Thinking Always Involves Past Experience Revived as "Meaning." - Another condition of " thinking" is found in the fact that it always goes beyond what is immediately present in sensation. A succession of pure sensations (or their reproduction in uncontrolled images) would not constitute a thought process. Ideas and meanings must be employed; sensations must be interpreted in the light of past experience ; and more than this, the meaning must be related to the problem in hand. Conscious processes that have a meaning unrelated to 
the problem are likewise incapable of playing a useful part in one's thinking.

This important fact may be illustrated as follows: When I heard the band playing on the occasion of the circus parade; when I caught a glimpse of the procession passing my window; when I saw the crowd assemble on the street, and my son rush out of doors to join it; these sights and sounds were more than pure sensations. They possessed a significance, a meaning, and yet I rigorously rejected them, thrust them out of my consciousness, because their meaning did not "fit in" with the problem that I was then facing. I turned to my desk and once more took up the task that I had set before me. As I became more and more deeply engrossed in my work, the sensory impressions coming in from the outside world became correspondingly dim. I vaguely "knew" that I was sitting at my desk, that I had a pen in my hand, and that a sheet of paper lay before me; but these sensory data did not enter into my thoughts, not because their meaning was unrelated to my problem, but rather because to me at that time they were devoid of meaning. Indeed, they were as near to what we have termed "pure" sensations as it is possible to approximate in states of normal consciousness.

When we say that certain conscious processes are excluded from the onflowing current of thought, then we signify either that they have no meaning to us for the time being (that they are pure sensations, or pure images); or that their meaning in no way fits in with the meaning of the processes that are then occupying our minds (that their meaning has no relation to our problem). Usually these two aspects of meaning are closely related, since we ordinarily give a meaning to a sensory experience in so far as we attend to it, and we usually 
attend to those sensations that do have significance for us in terms of our present problem.

Passive attention, it is true, often attaches itself to objects that have no significance for our thinking, - no relation to our present problem. We must let the flash of lightning into our consciousness; we must give it a meaning (that is, recognize it), although it may have nothing whatsoever to do with the general trend of our thought. However, since it has no place in the assembly of conscious processes, it quickly loses its meaning and is lost to consciousness. On the other hand, those experiences that do have a place rapidly grow in meaning as they are attended to and brought into the clear light of consciousness.

Meanings Vary with the Problem in Hand. - Meaning, while it appears in its most marked form in states of consciousness that are known as the rational processes, is never absent in a consciousness that possesses any degree of complexity or significance. The red flag that I see is more than a mere red object. It means to me danger when I see it displayed at the railroad crossing. Later I see a similar flag over a shop door, and now it means to me that an auction is in progress. Again, I see a red flag carried by a band of men and women who are parading through the streets, and this time the flag means to me Socialism. In any case, the state of consciousness goes beyond the immediate and direct sensations informing me of the object and extends to what the object signifies.

All objects of my experience, then, whether present to the senses, or merely imagined, signify something be- 
yond the objects themselves. The table that is before me means an object to write on, because it stands in my study, and I am accustomed to sit at it when I am writing. The table in the dining room means an object to eat from, because this is its customary use.

Meaning is Fundamentally Determined by Use or Behavior. - This again suggests the important principle already referred to in the chapter on Perception, namely, that "meaning" fundamentally resides in the use of the object that is given a meaning. This fact is strikingly illustrated in the definitions of little children. A horse is "to ride"; candy is "to eat"; a knife is " to cut with"; etc. Only in later childhood are objects defined in terms of their qualities, and these in their last analysis stand for or represent some kind of behavior in reference to the object. If nothing could be done with it, - if it had no use, no reference to our lives and our needs, - it would have no meaning.

This is as we should expect it to be, from the principle that we have held to in our previous discussions, namely, that consciousness is useful because it helps in directing our behavior. The mere sensory experience acquires significance only through the acts that accompany it. Identity of meaning consists in an identity of behavior, and a difference in meaning consists in a difference of behavior. Two objects mean the same thing when the behavior that they call up is identical ; different things, when the accompanying behavior is different. 
Thus it happens that a single object may mean different things to different persons, simply because they behave toward it differently; further, this same object may mean different things to the same person at different times, because his behavior on these different occasions may vary.

The fact that meaning at first attaches itself to the behavior that is called forth by an object that possesses this meaning, and later to some quality that resides in the object, may be illustrated by the following example:-

When the boy sees a pond of ice, or calls it up in imagination, he at once "thinks of it" as a surface to be skated on. This is its meaning to him. An adult may have in mind, in seeing the ice or in imagining it, not the activity of skating, but the quality of smoothness. Here the meaning is represented by a quality rather than by a definite act. But if the significance of smoothness is analyzed, it will be found to reside in some such activity as skating or sliding which is made possible by smoothness.

\section{Why Meanings Attach to Qualities as Well as to Acts.} - Accurate thinking requires that meanings should attach to qualities as well as to acts because ( $I$ ) these qualities are less cumbersome to deal with in our thinking; (2) they are more definite; and (3) they are more easily represented in consciousness than are the activities that they symbolize. Our thinking would move on in a most uncertain and laborious way if we were obliged to call to mind in any detail the various kinds of behavior that center around an object of consciousness. As thought becomes more and more refined and exact, the qualities that represent behavior and thus give meaning 
to their objects become less and less rich in movementdetails, and farther removed from concrete experience.

The Development of Symbols that Stand for Qualities. - But the process of condensation goes even farther than this. As acquaintance with the world of objects continues, even the qualities become less and less explicit in thinking, and a mere word or other " symbol" comes to stand for them, and in turn for the types of behavior that they represent. A pond of ice is no longer definitely adjusted to with certain movements typical of skating or sliding. It may no longer even be "visualized " or imagined in visual terms when we think of it. The very word "ice" carries with it all the essential meanings. And yet if we analyzed our meaning of this word, we should find that it would lead first to definite images of the appearance of the ice (its qualities) and ultimately to the movements which these qualities imply.

The Value of Thinking in Symbols. - In order to think accurately and rapidly, it is necessary to think in symbols, - to think in abstract rather than in concrete terms. But if this thinking is to have final value, we must always be able to translate these symbols into the behavior for which they stand.

A helpful analogy may be drawn between the use of symbols and the use of money in the commercial world. Symbols words, diagrams, formulæ - are the common denominators of experience, just as coins are the common denominators of value in the business world Money stands for values, represents values; but in itself it need have no value. It must, however, always 
be capable of being turned into objects or processes that possess intrinsic worth, - bread, clothing, building-materials, labor. Likewise the symbol may be quite unlike the object for which it stands: the word "horse" when written or printed does not look like a horse; when spoken, the sound is not like any sound that the horse makes; there is here no sensory resemblance between the symbol and the object symbolized. We simply understand that this is to mean what the object "horse" means; but to use the word effectively in our thinking or in communicating with others, we must be capable of translating the word into its basic meaning.

\section{Conceptual and Perceptual Attitudes. - When I rec-} ognize an object - for example, a pencil - and know what to do with it, I find that my knowledge of the pencil is based upon my experience either with this particular pencil, or with other pencils. I know how to behave in regard to the particular object, for the simple reason that I have previously behaved toward the same object or toward similar objects in a certain way. A conceptual attitude implies that I behave toward various objects of a class in a similar way; while a perceptual attitude implies that I behave toward a definite, particular object in a typical manner.

There is in my study a particular chair that has the "trick" of falling over if I lean too heavily against the back. I have learned this fact through several unpleasant experiences, and now I conduct myself in reference to this fact when I am seated in the chair. This particular chair means this particular form of behavior with reference to it, and my attitude toward it is a perceptual attitude, for I behave toward no other chair in just the same way. Toward the majority of chairs, I have the conceptual attitude; that is, I behave toward one just as I do toward the rest. I know how to 
use the various chairs, not because I know anything about these chairs in particular, but rather because $I$ have a general idea of how to behave toward all chairs.

The Economy of Conceptual Behavior: The Judgment. - It is evident that the conceptual type of behavior is more economical than the perceptual type, since the former extends its meanings over a much wider field of experience than does the latter. It is therefore highly important that rational thought make use of the conceptual mode of thinking, as, indeed, it does to a very large extent.

Conceptual thinking expresses itself most clearly in what is termed the judgment. The judgment identifies the particular object of thought with the type to which it belongs, and this identification gives us the cue to the appropriate behavior. We say, for example, that the round, yellow object lying on the shelf is an orange. This classifies the particular object with reference to similar objects that we have met in our past experience. We consequently know what to do with this item of present experience. Our behavior is suggested by the class into which the object is placed; or, to use the technical term, our conduct is indicated by the general concept under which the particular is subsumed.

Reasoning and the Syllogism. - Thinking culminates in reasoning. In reasoning, the various judgments that concern a single phase of human experience are joined together in such a way that they lead to a conclusion. 
The most common example of a rational process is to be found in what is technically known as the syllogism. Here we have a statement called the major premise, another known as the minor premise, both leading to a conclusion that is "deduced" from the two premises. For example, we make the judgment, "All honest men tell the truth"; and we follow this statement by a second, "John Smith is an honest man"; this brings us to the conclusion, "John Smith tells the truth." We call this process deduction, because we start from some general principle and arrive at a particular conclusion.

- Reasoning often takes the opposite direction, however. We observe that, day after day, the sun rises in the east. From these particulars we arrive at the conclusion that the sun always rises in the east. This method of procedure from the particular to the general is termed induction.

Both Induction and Deduction Characterize Thinking. - Ordinarily both induction and deduction are employed in solving a problem by the rational method. It is only on exceptional occasions that either method is used alone. From observing a number of facts, we conclude that a certain general principle applies; then we seek, from the suggestions given by this general principle, to find more facts that will confirm it.

Inductive Teaching. - Successful teachers frequently employ what is known as the "inductive development lesson" to impart a general principle, a rule, or a defini- 
tion. It is the purpose of this lesson to lead the pupils to see, in a number of particular instances, the operation of a general truth which holds for all of the cases studied. In a sense, the pupils " rediscover" the principle for themselves, although it should be remembered that this " rediscovery" is only partial ; in other words, the materials are so presented that the principle comes out in a clear and unequivocal fashion.

The different phases of the inductive development lesson have been termed the "formal steps." They are five in number: (I) the preparation, culminating in the statement of the aim; (2) the presentation; (3) the comparison and abstraction; (4) the generalization; and (5) the application.

(I) The preparation is the introductory step, and aims to adjust the pupil to the problem of the lesson. This is usually accomplished by reviewing the knowledge that he already possesses bearing upon the problem. If, for example, the aim of the lesson is to develop the principle that cities are likely to grow up at the termini of trade routes, or where transshipment of goods is necessary, the step of preparation would briefly recall to the pupils' minds what they have already learned about trade routes; the names and location of cities that owe their growth to this law; and similar data. This work is largely informal and conversational in character, and should lead naturally to the statement of the problem in concrete terms; for example, "To-day we shall try to find out why these cities have grown up at these points."

(2) In the step of presentation, new facts are given and illustrated with reference to the problem in hand. In the example already cited, the important facts are those that have to do with the necessity for transshipment. These may be presented by pictures showing the typical commercial activities of such cities as New York, Buffalo, Duluth, New Orleans, and Baltimore. 
The differences between rail, river, canal, and ocean transporta. tion would be clearly and forcibly brought out, with the emphasis upon the need of docks, elevators, and warehouses; the necessity for employing large numbers of men in loading and unloading; the probability that many of the men employed on the railroads, the canal boats, and the ocean-going ships would make their homes at these termini; the need of stores, banks, and other business houses to provide for this population; and, finally, the advantage that is offered by a "center" of this sort for manufacturing establishments that may take advantage of the possibility of shipping goods over various routes.

(3) The step of comparison and abstraction is frequently fused with the step of presentation, but it is always well to bear in mind the importance of making comparisons and of finding out the points that are common to the facts presented. As the lesson on the growth of cities proceeds, every fact presented should be related to the problem in hand: "Why will the necessity for transshipment bring people to the point of transshipment?" "Why will the presence of laborers, railroad men, and sailors mean that stores and banks will develop?" "Why are manufacturing industries likely to grow up in a city of this sort?" The points of similarity between the different cities studied are also emphasized.

(4) In the step of generalization, the essential conclusion revealed by the study of particulars is formulated in a rule, general principle, or definition.

(5) The step of application carries the generalization, principle, or rule back to other concrete cases which it may "cover" or explain. Thus the principle that cities tend to develop at the termini of trade routes may be inductively derived from a study of a few particular instances, and then employed to explain other instances. Where it fails satisfactorily to account for the growth, another problem is raised which may in turn lead to another inductive lesson.

From the example given, it is clear that the "inductive" lesson is not exclusively inductive. The step of 
application, indeed, represents almost a purely deductive procedure, - passing from the general principle to particular instances. There are other stages of deduction interwoven throughout the inductive process. This alternation of induction and deduction is usual throughout all constructive thinking.

A very good example of this alternation may be found in the detection of crime. The procedure here illustrates actual "reasoning" rather more clearly than does a school lesson, for the latter ordinarily deals with problems that have already been solved, and only a few of the essential stages in the process of original discovery are repeated with the pupils. (It should be remembered that this process in school work is justified, not because the various rules and principles are really sanctioned by the few particulars that can be presented, but rather because the method is effective in fixing the principle in the minds of pupils.)

To take an illustration from the field of crime-detection: A murder has been committed. The room of the victim is found in disorder, and the body of the murdered man lies at the side of the bed. The first step is to get a clear idea of the details of the case. For this reason the room is minutely examined, and every detail that may have a bearing upon the case is noted and recorded. This procedure corresponds roughly to the step of presentation described above. Next, through a process of comparison, abstraction, and generalization, the 
conclusion is reached that $X$ committed the crime. This conclusion "covers" and explains the particular facts, but is an "assumption" or "hypothesis" that must be tested by finding out how it fits into other facts that have been neglected for the time being, such as the whereabouts of the accused at the time of the murder, the motive that he may have had, and the like. This stage is roughly analogous to the step of application.

Here, as in the example from teaching, there are interwoven threads of induction and deduction. In the first place, before the significant facts can be intelligently observed and collected, there must be some point of view, some criterion, some "theory," that will guide in their collection. Not every detail or incident is important, and the point of view or theory decides what shall be accepted and what rejected. Thus a general principle operates from the very outset, and initiates a deductive procedure. Finally, after all of the facts have been collected and (it may be) an entirely different conclusion reached, it is essential to test this conclusion with reference to all of the available data. This again is a deductive procedure.

Educational Corollaries. - In the light of the preceding discussion, certain suggestions with regard to the place of reasoning in the process of education may be indicated:-

(1) The Pupil should be Confronted with Actual Problems. - Since thinking comes only when a problem 
is presented or a situation faced, only when a "crisis " in our behavior arises, it follows that, to stimulate thought, we should confront the pupil with actual problems. Wherever possible, the materials of instruction should be brought forward to solve problems which the pupil recognizes as such. Assimilated in this way, facts and principles take on a significance and meaning which they would otherwise lack. Unfortunately, not all of the knowledge that must be imparted can be presented in answer to a definite problem arising in the pupil's own life; but the teacher will find that effort spent in searching out possible points of contact between the lives of the pupils and the materials of instruction will pay large dividends in interest, enthusiasm, effective learning, and accurate retention.

This process is technically known as "motivating" the work of instruction, and is similar to the process of motivating the habitbuilding disciplines. Very frequently, however, the term is used in too narrow a significance. While it is well to employ in vitalizing instruction the pupils' interest in games, in out-of-door activities such as garden-making and school-excursions, in manual-training work, and in dramatics, it should also be remembered that the older type of school work provided many opportunities for real and engrossing problem-interests. Eighth-grade children may, for example, be curious to know the causes that led to the Civil War. This interest forms a real and effective problem or "situation" from which a valuable exercise in reasoning may result. In the light of this interest, a list of facts may be presented and the pupils asked to select from these any that seem to be significant as causes of the War. Animated discussions will follow as to why 
certain events were significant and other events insignificant. Under the guidance of the teacher, the relations between cause and effect will be emphasized in an effective way, and the real cause may be formulated in a summary or conclusion.

In this connection, it is clear that presenting facts with reference to a problem is one way of organizing these facts. Teaching which continually emphasizes this procedure will inevitably impress the pupil with the value of knowledge in solving problems, and with the importance of organizing knowledge with reference to unifying purposes.

The "assignment" of lessons is particularly important from this point of view. In a skillful assignment, the material to be studied is definitely and explicitly related to some problem or purpose. Generally the new material leads on from a point that the pupils have already reached, and, in many cases, problems have already arisen in their minds which can be solved only by the material of the new lesson. The expert teacher is always very careful in making assignments to make these problems explicit, and to show in what way the new lesson will help to solve them.

(2) The Development of "Meanings" is Fundamental to Effective Reasoning: the Importance of Actual Adjustments. - Since rational thought involves the employment of meanings, it is essential that the pupil be well supplied with a stock of meanings if he is to think effectively. In other words, he must have his " resources," - his "stock in trade," — as well as a problem to solve. Since meaning is, in the last analysis, to be reduced to behavior or conduct, it follows that the factor of doing, 
of making actual adjustments to actual situations, is an important element in teaching the pupil how to think. The words that form the vehicles of meanings must be capable of being worked back into actual adjustment; otherwise their employment in education is but the most barren type of formalism.

It is at this point that the emphasis that has been placed in recent years upon manual training and other types of teaching involving actual motor responses finds a large part of its justification. These activities are important, not only because they "fit for life," but also because they give significance and meaning to the more abstract processes that the school properly emphasizes. All of the "laboratory" subjects, such as physics, chemistry, botany, zoölogy, physiography, and physiology, make a prominent use of this factor. In the study of literature, the temperate employment of the dramatic tendency has been found to add a most valuable element in understanding and appreciation.

But it should not be supposed that effective response need always involve actual movements of the body, actual motor adjustments to external situations. The factor of doing is sometimes adequately represented by imagined adjustments. Even the older formal education, with its exclusive emphasis upon words, was often effective because, with many of the pupils, the words suggested motor responses which were carried out imaginatively. The problem of education in giving the pupil a usable capital of meanings is to make certain that words will operate in this way, and that the pupil will live in imagination, if not actually, the events and conditions which the words describe. In short, successful education should enable the pupil to think out his problems when necessary without the employment of actual objective situations. But, in order to attain this end, it must emphasize the objective situations in its earlier stages, and proceed very gradually from the concrete to the "abstract." 


\section{(3) General Meanings or Concepts are the Most Impor-} tant Resources for Thinking. - The concept, as has been said, stands for a "type-reaction" that includes a large number of particular cases. It, therefore, becomes the "cue" to a large number of acts and covers a wide range of behavior. It is obviously of the greatest importance from the standpoint of mental economy to reduce experience to the form of general concepts and principles, and thus to provide the "resources" of thinking. The conceptual attitude is the essential attitude of intelligent human beings.

One of the oldest and most important principles of teaching is the "Law of Concept-building." This is usually stated as follows : "Proceed from the concrete to the abstract; from the particular to the general ; from cases to principles." Thus in developing the meaning of any important term (such as "noun," "adjective," "verb," "adverb," and "preposition," in grammar; "commerce," "water shed," "river basin," "coastal plain," etc., in geography; "digestion," "respiration," "locomotion," in physiology ; "contagion," "infection," etc., in hygiene; "representative government," "electoral college," "democracy," "bill," "law," "act," etc., in civics) the teacher first brings the pupils face to face with concrete cases illustrating these terms just as clearly as possible, presenting them, if feasible, in connection with definite problems. After the pupils have become familiar with the concrete cases, the "definition" of the term may be formulated and learned. In some cases, the definition may be given first and then illustrated by a wealth of concrete details. The order of procedure will depend upon circumstances, and no dogmatic rule can be laid down for governing this phase of the teaching; the illustration of the definition is the important thing, and for this the teacher can afford to spend a great deal of careful planning. 
In general, illustrations should be selected upon the basis of the clearness with which they body forth the principle or the definition that the teacher wishes to impart. Many illustrations miscarry because they suggest irrelevant factors, - lead the pupil off "on the wrong track" and consequently obscure rather than illuminate the point at issue. Again, the point may be so enmeshed in details that the pupil "cannot see the woods for the trees."

Illustrations, wherever possible, should be objective. The school museum is important in this connection, especially in providing specimens of various commodities of commerce in different stages of manufacture. In many cases, definitions can be richly illustrated by school excursions to near-by points of interest. A visit to the freight depot, for example, may be made to illustrate very effectively the meaning of the word "commerce."

Objective illustration, as has been said in another connection, may be profitably supplemented by the use of pictures, diagrams, and charts; and there are, of course, many phases of instruction that can be illustrated only through these means. The stereoscope, the projection lantern, and the reflectoscope offer opportunities for helping imagination to construct and react to situations that the pupil could never have an opportunity actually to face. The moving picture will doubtless be utilized in the schools of the next generation, and even now it is possible to arrange with local moving-picture theaters for the presentation of films in the school; and manufacturers of films are beginning to provide for this extension of their activities.

In connection with the use of pictures, as has already been pointed out, it is essential to keep clear in mind the purpose of the work. As an educative agency, the picture must be something more than merely entertaining. It must illustrate a definition or a general principle, and the teacher must see to it that the pupils pass from the perceptual to the conceptual attitude.

(4) The Tentative Hypothesis: its Value and its Dangers. - It has been pointed out that inductive 
reasoning works from particulars toward a general conclusion which will cover the particulars studied and which is generalized to cover other similar particulars. It is, however, impossible in most cases to test the generalization with reference to all of the particulars which it is supposed to cover. When a generalization is suggested by a study of a few concrete cases, it is known as a "tentative hypothesis," and if it is found valid when applied to a large number of cases, it becomes a "law."

It is fundamentally important in education to emphasize the distinction between " tentative hypothesis" and "laws." The hypothesis is, of course, a necessary and valuable step in reasoning. It forms the "clew" upon which further reasoning proceeds. The danger that confronts the reasoner is that he will take the hypothesis as a permanent principle, and then shut his mind to the facts that it fails to fit.

There are two points at which the danger of confusing an hypothesis with a law needs to be guarded against with especial zeal. One is represented by the investigations that are made to establish some belief in which the investigator is deeply and emotionally interested. In a case of this sort, he is likely to find what he is looking for, and to be blind to anything on the other side. $\mathrm{He}$ may be quite unconscious that his bias is thus defeating the purposes of his investigation; hence it is essential that he should consciously "lean" a little to the other side, in order to counteract the deeplying attitude that unconsciously tends toward the desired result.

In the second place, it is always well to place the burden of evidence upon any hypothesis that tends to open the lines of least resistance, intellectually or morally. It is sometimes said, for 
example, that a "strict" bringing-up defeats its own purposes, leading to an evil life rather than to a good life. The example of clergymen's sons is often cited in this connection. If a boy who has been brought up in the family of a clergyman "goes wrong," this single fact is likely to be extended or generalized to cover all such cases. As a matter of fact, there is no evidence to show that the rule is general, and much evidence that points to the permanent influence of a home discipline that is administered with reasonable rigor. Discipline of the latter type is the line of greatest resistance, consequently the burden of proof should be placed upon the theory that speaks against it. The same principle holds with matters of school government; a proposed policy that is based upon "soft" and "easy" methods should certainly be looked upon as a tentative hypothesis, not necessarily to be rejected, for it may involve a helpful reform; but rather to be tested carefully under controlled conditions and within a restricted area until its influence can be accurately determined.

The Problem of "Training Reasoning." - The foregoing summary would be incomplete without a reference to the possibility of developing " reasoning power." This question, like that of the "transfer" of specific habits, has been disputed very vigorously among educators during the last two decades. The following hypotheses may form tentative suggestions for practice pending a final decision:-

(I) The pupil may be profitably instructed in methods of reasoning. He may be taught by numerous examples the necessity of extended and unprejudiced observation, of careful comparison and abstraction, and of cautious generalization. He may be shown over and over again the danger of drawing hasty conclusions, of leaving out 
of consideration factors that must influence his judgment, and of depending without question upon the "hearsay" evidence of others. He may be taught the value of approaching his problems in the rational attitude, of analyzing them into their elements, and of searching in his experience and in the records of race experience for some practicable solution. If he is led over and over again to take these steps, to go through with the rational processes himself, and if, moreover, he is thoroughly impressed with their value - with the fact that they "get results" - there is every reason to believe that his mind will be "trained" somewhat as the older adovcates of the "doctrine of formal discipline" contended. $\mathrm{He}$ will gradually formulate an ideal of rational procedure.

(2) In this connection, also, it is possible to give the pupil a command of what may be called the ideal " schemata " of reasoning. He may learn to arrange his propositions in a logical order so that the connection of one with another will be clearly revealed. In other words, he may be taught, through innumerable illustrations and exercises, to organize in a logical fashion, his facts, principles, hypotheses, conclusions, and proofs.

The courses in geometry are often effective in attaining this result. The pupil sees the advantage of arranging arguments in a certain, definite order, passing gradually from step to step until the conclusion is reached or the principle established. Well-organized work in 
English grammar and especially in the grammar of the more highly inflected languages, such as Latin or German, may contribute toward the same end, - provided that the teacher is skillful enough to make clear to his pupils the advantage of close organization.

(3) The high school pupil may come to appreciate the worth of the rational attitude as contrasted with the emotional attitude or the attitude of " trial and error." He may be shown through the study of physics, chemistry, and biology, and perhaps through the study of industrial history, that careful, serious, persistent, and patient thinking has made possible the great triumphs of science, and the comforts and amenities of life that have resulted from these achievements. The lives of men like Morse, Stephenson, Fulton, and the Wrights are full of inspiration to the normal adolescent, and these lives illustrate at every point the triumph of reason over the obstacles that nature has placed in the way of human progress.

(4) Whatever may be the case with regard to the methods of rational thinking, there can be no doubt that the reasoning "capacity" depends as much upon "resources" as upon "method," and here education has a clear and undisputed field. It can and must supply the pupil with the concepts, the facts, and the principles that have been garnered and winnowed through the long course of human experience, and which constitute the materials with which reasoning works. In other words, it can and must pass on to each generation as much of 
the accurate knowledge that has been accumulated as the child can readily assimilate. In this way, possibilities of rational thinking are opened up, and, if the teacher does his best to demonstrate to the child the rational methods of using this knowledge and to give him an appreciation of the value of using knowledge rationally, he may be fairly confident that something has been done to "train the reasoning powers."

\section{Definitrons and Explanation of Terms Used}

Thinking. - A complex mental process which may take place when instinct and habit are inadequate in directing behavior. In the process of thought past experience is consciously brought to bear upon a present situation. The process of thought differs from an emotion in that it involves a steady onflow of ideas and perceptions, and clearness of ideas rather than affective intensity.

Meaning. - The essential form in which past experience operates in the process of thinking. As was pointed out in the chapter on Perception, the "meaning" of a group of sensory impressions is determined by the adjustments or responses that have been made to these impressions in the course of experience. The qualities represented by the sensory ingredients in a perception or an idea, however, gradually come to stand for or represent these adjustments or responses ; and the qualities may in turn be replaced by symbols which bear no sensory re- 
semblance whatsoever to the original perceptions, but to which the appropriate meanings may be attached. Thus meaning is, at basis, a "cue" which suggests a certain adjustment.

Conceptual attitudes. - These are often termed concepts. A concept or a conceptual attitude is a general meaning; that is, a "cue" for a type of conduct that holds good for a number of different objects or situations.

Judgment. - The simplest process of thought, consisting in identifying a perception or an idea under a more general meaning, and thus suggesting the type of conduct that is appropriate.

Judgment, like all thought-processes, arises only in a " crisis" which compels the individual to hesitate before acting; in this period of hesitation, the situation is analyzed, and the analysis suggests the concept with which it is to be identified or otherwise related.

Reasoning. - A more complicated process of thinking which involves passing from one judgment to another, and finally reaching a conclusion.

Inductive reasoning. - That form of reasoning which proceeds from particular judgments to one that is more general.

Deductive reasoning. - That form which proceeds from a general judgment to a statement of one or more of the particular judgments which it " covers."

Inductive teaching. - The type of teaching that leads the pupil from particular judgments to a general con- 
clusion. The inductive development lesson leads the pupil gradually to see in the particular judgments the operation of a general truth and to formulate this general judgment.

Tentative hypothesis. - A judgment based upon an inspection of a relatively few particulars, and inferred to cover all particulars of the same class.

\section{Questions AND EXERCISES}

I. Find in your own experience an example of a "thought crisis." What difficulty did the crisis present? Did you formulate the difficulty in words? Was there a tendency at first or at any time during the process of solving the difficulty to give way to emotion? If so, contrast the emotional experience with the thought experience. Can you subscribe to the statement that thinking involves clear ideas and a coherent onflowing of mental processes, while an emotion involves unstable attention and mental confusion, combined with great affective intensity?

2. In solving the difficulty through a process of thinking, indicate the points at which your past experience was revived as an aid in making a new adjustment. Was past experience revived in perceptual terms or in conceptual terms? Did you formulate in words a definite judgment as the "conclusion" was reached? If so, what was the nature of the judgment, - did you identify a part of the new situation under a general term or symbol which suggested a "type" adjustment?

3. Distinguish (by an example from your own experience) between judgment and reasoning. What is meant by inductive reasoning? By deductive reasoning? Give an illustration of a course of reasoning that is chiefly inductive, and point out the places where deductive processes appear.

4. What is the value of symbols in thinking. What do you have in consciousness as you read the following words: home, pavement, horse, bicycle, floor, swift, smooth, charity, walk? 
Describe as accurately as possible the mental processes that constitute your consciousness as you read, and get the "meaning" of the following sentences: "With a light heart, she left the house and tripped down the steps." "He 'remained at the key in spite of the accident." "The boiler exploded and the man was killed; he was a stationary engineer." "We felt the jar." (Note the changes that take place in your consciousness as the interpretations of the words vary.)

5. Prepare a number of problems that might be presented to an eighth-grade class when the formation of the Federal Constitution is being studied. How would you introduce, in such a way that a "problem" would be present, a lesson in English grammar involving the working out of a definition of the adverb ? Suggest for a sixth-grade lesson an assignment on the industries of New England which will present a problem or a series of problems to be solved by the pupils.

6. What steps would you take in teaching geography to show the pupils the value of rational thinking instead of rote learning?

7. Can you definitely describe any way in which your study of geometry has helped you in reasoning in other fields? In what ways, if any, has the study of English grammar helped you in reasoning in other fields? 


\section{APPENDIX}

\section{SUGGESTED COLLATERAL READINGS}

Chapter I, Consciousness and Conduct

JAMEs, Talks on Psychology and Life's Ideals, Chapters II, III, IV, and V.

- Psychology, Briefer Course, Chapters XI and XXIII.

KIRKPATrick, Genetic Psychology, Chapter VII.

O'ShEA, Education as Adjustment, Chapter V.

Royce, Outlines of Psychology, Chapter IV.

Chapter II, Behavior and Learning

Colvin, The Learning Process, Chapter I.

KIRKPatricK, Genetic Psychology, Chapters III and V.

WASHBURN, The Animal Mind, Chapters X and XI.

Chapter III, Unlearned Behavior

Groos, The Play of Man, Part III.

Haxt, Aspects of Child Life and Education, pages 84-I4I.

-, Youth, Chapter VI.

\section{Chapter IV, Attention and Behavior}

Angeld, Psychology, Chapter IV.

BAGLEY, Classroom Management, Chapters IX, X, XI, and XII.

Calrins, A First Book in Psychology, Chapter VI.

JAMres, Psychology, Briefer Course, Chapter XIII.

-, Talks on Psychology and Life's Ideals, Chapters X and XI.

PILlsbury, Essentials of Psychology, Chapter V.

Royce, Outlines of Psychology, Chapter XI. . 
Seashore, Elementary Experiments in Psychology, Chapter XIII. Titchener, An Outline of Psychology, Chapter VI.

Chapter V, Behavior and the Feelings, and Chapter VI, The Practical Significance of the Affective Life Angell, Psychology, Chapters XIII, XIV, XVIII, and XIX. Calkins, A First Book in Psychology, Chapter XI. James, Psychology, Briefer Course, Chapter XXIV. Pillsbury, Essentials of Psychology, Chapters XI and XII. Royce, Outlines of Psychology, Chapter VII. TItchener, An Outline of Psychology, Chapters V, IX, and XIII.

Chapter ViI, The Nervous System as the Organ of BEHAVIOR

Angell, Psychology, Chapter II.

JAMES, Psychology, Briefer Course, Chapters VII and VIII.

JuDd, Psychology, Chapters II and III.

PIllsbury, Essentials of Psychology, Chapter II.

Thorndike, Elements of Psychology; Chapters IX and X.

Chapter VIII, Rerlex and Instinctive Behavior; Chapter IX, The Value of the Human Instincts, and Chapter $\mathrm{X}$, How Instinctive Behavior may be Changed Angell, Psychology, Chapters XV, XVI, and XVII. HaLL, Aspects of Child Life and Education, pages 205-239. James, Psychology, Briefer Course, Chapter XXV.

, Talks on Psychology and Life's Ideals, Chapter VI. MacDougall, Social Psychology, Chapters II, III, and IV. Marshall, Instinct and Reason, Chapters IV, V, and VI. Prldsbury, Essentials of Psychology, Chapter X.

Chapter XI, Habitual Behavior and the Law of Habit BUILDING

Angell, Psychology, Chapter III.

Bagley, The Educative Process, Chapter VII. 
JAMEs, Psychology, Briefer Course, Chapter X.

JudD, Psychology, Chapter VIII.

Royce, Outlines of Psychology, Chapter VIII.

SwIrT, Mind in the Making, Chapter VI.

\section{Chapter XiI, Sensation and Behavior}

Angell, Psychology, Chapter V.

Calkins, A First Book in Psychology, Chapter III.

JaMes, Psychology, Briefer Course, Chapters II, III, IV, V, and VI.

JUDD, Psychology, Chapter V.

Pillsbury, Essentials of Psychology, Chapter IV.

Royce, Outlines of Psychology, Chapter V.

SEASHORE, Elementary Experiments in Psychology, Chapters I, II, and III.

Titchener, An Outline of Psychology, Chapters II and III.

\section{Chapter XiII, Perception and Behavior}

ANgell, Psychology, Chapter VI.

HaLl, Aspects of Child Life and Education, pages i-52.

JaMes, Psychology, Briefer Course, Chapter XX.

- Talks on Psychology and Life's Ideals, Chapter XIV.

JASTROW, Fact and Fable in Psychology, pages 275-295.

PIIISBury, Essentials of Psychology, Chapter VII.

SeASHore, Elementary Experiments in Psychology, Chapters XII and XIV.

\section{Chapter XIV, Imagination and Behavior}

Angeli, Psychology, Chapter VIII.

Calkins, A First Book in Psychology, Chapter II.

Colvin, The Learning Process, Chapters VII and VIII.

James, Psychology, Briefer Course, Chapter XIX.

Royce, Outlines of Psychology, Chapter VI.

SEASHORE, Elementary Experiments in Psychology, Chapter IX. 
Chapter XV, Memory and Behavior

ANGeld, Psychology, Chapter IX.

Colvin, The Learning Process, Chapter IX.

JaMEs, Psychology, Briefer Course, Chapter XVIII.

- - Talks on Psychology and Life's Ideals, Chapter XII.

SEASHORE, Elementary Experiments in Psychology, Chapter XI.

Titchener, An Outline of Psychology, Chapter XI.

\section{Chapter XVI, Association and Behavior}

Angeil, Psychology, Chapter VIII.

Bagley, The Educative Process, Chapter XI.

Colvin, The Learning Process, Chapter $\mathrm{X}$.

James, Psychology, Briefer Course, Chapter XVI.

Pillsbury, Essentials of Psychology, Chapter VI.

SEASHORE, Elementary Experiments in Psychology, Chapter X.

\section{Chapter XVII, Economy in Learning}

Calkins, A First Book in Psychology, Chapter VII, pages II 5-I23.

Colvin, The Learning Process, Chapter XI.

MCMurry, How to Study, Chapter VII.

PILLsbury, Essentials of Psychology, Chapter VII.

WATT, Economy and Training of Memory.

Chapter XVIII, Behavior and the Higher Thotght

Processes

Angell, Psychology, Chapters X, XI, and XII.

BAgLey, The Educative Process, Chapters VIII, IX and X.

Colvin, The Learning Process, Chapters XX, XXI, and XXII.

Dewey, How We Think.

JAMES, Psychology, Briefer Course, Chapter XXII.

PILLsBury, Essentials of Psychology, Chapter IX. 


\section{INDEX}

Abstraction, step of, 310.

Accuracy, in habit formation, 179.

Active attention, definition of, 68 ; in modifying instincts, 160 .

Adaptation, visual, 195 f., 207.

Adaptive instincts, I 28 ff., 149 f.; value of, $140 \mathrm{ff}$.

Adjustment, control of, $16 \mathrm{f.}$; definition of, I9.

Adventure, spirit of, 144 .

Esthetic emotions, function of, 102; instinctive basis of, $\mathrm{I}_{34} \mathrm{f}$.

Affection, as conscious element, $7,73 \mathrm{f}$., Igo; significance of, $89 \mathrm{f}$.; in teaching, 98 ; and attention, $89 \mathrm{f}_{\text {. ; }}$ and behavior, $72 \mathrm{ff.}$; and efficiency, 75; and instinct, $132 \mathrm{f}$; and habit, 166 ; and moral culture, 153 .

After-images, I96 f., 208, 228.

Aim, statement of, 309 .

Altruistic instincts, $\mathrm{I}_{22}$.

Amoba, structure of, I07 $\mathrm{f}$.

ANGeII, J. R., 97, II5.

Anger, 77 ; instinctive basis of, $\mathrm{I} 3 \mathrm{I}$; in learning, ror.

Animal psychology, 26, 27, 32, 45, 60, 243.

Animals, learning in, 26 f., 32, 45 ; behavior of, 32, IO9, $343 \mathrm{f}$; ; attention of, 60 .

Anit-social instincts, I43.

Apperception, 225; and perception, 217 ; and habit, 213.

Application, step of, 3I I.

ARISTOTLE, I52.

Arithmetic, teaching of, I7O.

Arrogance, feeling of, 132 .

Articular sensations, 202.

Assignment, of lessons, 3 I4.

Associating neurones, II 3 ; definition of, 123 ; in cord, II7.

Association, 13, 246 ff., 26I, 264 ff.; laws of, $265 \mathrm{ff}$., $279 \mathrm{f}$.; areas of, in cortex, 120; simultaneous, 264; successive, 264 .
Attention, definition of, 54, 68; function of, 54; kinds of, 55 ff.; span of, $65 \mathrm{f.}$; active, $5 \mathrm{I}, 60$; passive, 55 fi.; secondary passive, 6I f.; adaptability of, 295; in thought process, 302 ; rhythms of, $6 \mathrm{r}$.; as influencing changes in consciousness, $6 \mathrm{f}$; ; and fatigue, 64 ; and behavior, 53 fi.; fluctuations of, 69 ; and emotions, 8o; and affection, 89 f.; and instincts, $160 \mathrm{f}$; ; in habit formation, $\mathrm{r} 6 \mathrm{~g} \mathrm{f}$.

Attitudes, 306, 317, 323; bodily, in attention, 67 f.; habitual, 180; of contemplation, 134; religious, IO3.

Attributes of sensations, $193 \mathrm{f}$.

Auditory sensations, I99 $\mathrm{f}$.

Axone, II2; definition of, 122.

BARKER, L. F., III.

Behavior, I2I; definition of, I9; guidance of, I6 f.; habitual, I65 ff.; instinctive, I 27 ff.; reflex, I 26 f.; modification of, $26 \mathrm{ff}$.; unlearned, 37 ; and affection, 72 ff.; and association, $264 \mathrm{ff.}$; and attention, 53, $66 \mathrm{f}$.; and consciousness, $\mathbf{I}$ ff.; and emotion, 8o, 95, f.; and feelings, $72 \mathrm{ff}$.; and illusions, 2I9 f.; and imagination, $227 \mathrm{ff}$; and judgment, 307; and meaning, 303; and memory, $243 \mathrm{ff}$.; and reasoning, $307 \mathrm{ff}$; and thought processes, $298 \mathrm{ff}$.; of animals, 32,45 , 109, $243 \mathrm{f}$.

Biographical materials, in teaching, 321.

Blocking, of habitual behavior, I67; of instincts, I3I, 136; of synapse, $247 \mathrm{f}$.

Boy Scout movement, 159.

Brain, II4.

Brightness, of visual sensations, 206; qualities, $\mathrm{I} 94 \mathrm{f}$. 
CaJal, R., i II.

Calkins, Mary E., 2 Ig.

Cell body, i 12.

Central nervous system, I14 ff., 123 ; functions of, I 6 ff.

Cerebrum, II4, II5, II8, Ir9; definition of, 123.

Cerebellum, definition of, 123.

Child, imagination in, 235 ff.; memory in, 257.

Circular activity, 30.

Clearness, as attribute of sensations, I $93 \mathrm{f.,} 206$.

Collecting instinct, 140.

Color blindness, 204, 209.

Color contrast, 207.

Color qualities, $194 \mathrm{f}$.

Color zones, of retina, $197 \mathrm{f}$.

Combative instincts, 112, I56 f.

Comic, instinctive appreciation of, r35.

Companionship, instinctive desire for, 144.

Comparison, step of, 310.

Competition, instinctive basis of, 145 .

Complementary colors, 196, 207.

Composition, teaching of, 173 .

Concept, 13, 306, 323; of method in habit-building, 183,187 ; building of, 3 r 6 .

Concepts, as resources, $3 \mathrm{I} 6 \mathrm{f}$.

Conclusion, in syllogism, 309 .

Concrete imagery, 240.

Conduct, and consciousness, $x$ ff.; and the feelings, $90 \mathrm{ff}$.

Conduction, paths of, III, I16, I22, 127.

Consciousness, definition of, I ff.; and memory, 244; elements of, I 88 ff.; and behavior, $189 \mathrm{ff}$; nature of, 19 ; function of, 2 ; and cortical activety, I20; and habit, $165 \mathrm{f}$.; and instinct, Io6 f.; and learning, 24 ff.; selective function of, 54 .

Consequences, theory of, in child discipline, 153; in emotions, 97.

Consonance, 209.

Constructive instincts, I4I.

Contiguity, in association, $265,279 \mathrm{f}$.

Contrast, in association, 280 ; visual, I95 $\mathrm{f}$.

Cqnversion, psychology of, 96 .
Coöperative instinct, 132,145 .

Cortex, cerebral, I18, 119, 124; and consciousness, 120.

Cortical localization, I 24.

"Cramming" in memorizing, 252.

Cranial nerves, I I 5, I I7, 123.

Crisis, of thought, 17 f., 313, 323; definition of, 20.

Curiosity, 92, 129; definition of, 5r ; nature of, 48 .

Deduction, 308.

Deductive reasoning, 323 .

Defectives, attention in, 67 .

Definitions, development of, 316 .

Delusion, definition of, 28r.

Dendrite, definition, 122.

Dermal sensations, $20 \mathrm{r}$.

Development lesson, inductive, $300 \mathrm{ff}$.

Devices, nature of, I 70 .

Discipline, Spencer's doctrine of, 153 .

Dissonance, 209.

Distortion, in memory, 254.

Drill, in education, $169 \mathrm{f}$.

Duration, of learning periods, 285 f.; of sensations, 193, 206.

Duty, ideal of, 162 .

Ear, 190.

Economy, in learning, $283 \mathrm{ff}$. ; of conceptual behavior, 307 .

Ecstasy, emotion of, 134 .

Educability, as symptom of memory, 243.

Education, moral, 152, 153; and instincts, $149 \mathrm{ff}$; through drill, I6g $\mathrm{f}$.

Efficiency, and feeling, 75 .

Effort, in habit-building, 179.

Elements, of consciousness, $189 \mathrm{f}$.

Emotion, definition of, 84, 86.

Emotional congruity, in association, $273,280$.

Emotions, and behavior, 80; and instincts, 78, 128; as complex feelings, 76 ; characteristics of, 77 ; functions of, 96 ; in teaching, 100 ff.; of anger, 13I ; practical significance of, $93 \mathrm{ff}$.; value of, $94 \mathrm{f}$.

Emulation, 145 ; instincts of, 133 .

Envy, instinctive basis of, 133 .

Equilibrium, sensations of, 200, 20 .

Exceptions, in habit-building, $17 \mathrm{r}$. 
Experience, and learning, 25 f.; as determining paths of conduction, III; conditions of, II4; nature of, I9; religious, 96.

Eye, I9o; adaptation of, I95 $\mathrm{f}$.

Facilitation, 127; nature of, 121 .

Facts, function of, in behavior, I99.

Fatigue, 65, 69; in habit-building, 178 ; and attention, 64 .

Fear, 77, 142 f.; in learning, Ior.

Feeling, as an ingredient of consciousness, 7 ; in instinctive behavior, 128 , I32, I60; and behavior, 72 ff.; and habits, I66; significance of, $89 \mathrm{ff}$.

Fighting instinct, 131, I59.

Fixed ideas, 28r.

Fluctuation of attention, 69 .

Focalization, definition of, 186 ; in habit-bui'ding, 168 .

Foreign language teaching, 175 .

Forgetting, function of, 258 ; laws of, 253 ; rate of, 262.

Form, perception of, 198 .

Formal discipline, $180 \mathrm{ff} ., 259,3 \mathrm{Ig} \mathrm{ff}$.

Formal steps, of recitation, $300 \mathrm{ff}$.

FrankLin, B., 98.

"Free ideas," in learning, 31 f.; definition of, 35 .

Frequency, in association, 280; in recall, 269.

Generalization, step of, 3 ro.

Geography, teaching of, $300 \mathrm{ff}$.

"Good," criterion of, 75 .

Grades, 171 .

Gregarious instinct, 132 .

Grief, emotions of, 132 .

Groos, K., 4 r.

Gustatory sensations, 200 .

Habit, $8 \mathrm{f}$., I5I ; and affection, gr f.; and apperception, 217 ; and instincts, I6 5 f.; limitations of, 184 .

Habit-building, I85 f.; significance of, in education, $167 \mathrm{f}$; ; law of, $168 \mathrm{ff}$.

Habits, instinctive repetition in formation of, I4I; adaptive nature of, I66; nature of, I65 ff.; specific character of, 180 ; transference of, I8r.

HALI, G. S., 42, 43.
Hallucinations, 22 I f., 225.

Hate, emotions of, 132 .

Hearing, sensations of, $199 \mathrm{f}$.

Hemispheres, cerebral, I14, II5.

History, teaching of, $25 \mathrm{I}, 313 \mathrm{f}$.

"Homesickness," instinctive basis of, 133.

Humiliation, instinctive basis of, $\mathbf{I 3 2}$.

Hypothesis, 31 2, 317, 324.

Hysteria, 244.

Idea, and ideal, 165.

Ideal, definition of, 163 .

Ideals, nature of, I6I; as agencies in transfer of training, I82 $\mathrm{f}$.

Ideas, "free," in learning, 31 f., 35 .

Identical elements, in transference of habits, I8I.

Illusions, 55; and hallucinations, 221 ; classes of, $222 \mathrm{f}$.; visual, $2 \mathrm{Ig}$ f.

Illustration, in teaching, 317 .

Image, 228; as conscious element, I 90 .

Imagery, 23 I f.; types of, 235 ; concrete, 233; symbolic, 233.

Images, and meanings, 301 ; after, 196, 208.

Imaginal types, 235 .

Imagination, I2 ; definition, 218,240 ; function of, 229; and behavior, $227 \mathrm{ff}$.; and learning, 315 ; educational value of, $235 \mathrm{f}$.; and emotions, 83 ; limits of, 236 .

Impression, as factor in memory, 246 f., $26 \mathrm{I}, 268$.

Incentive, definition of, 69 ; nature of, 60.

Individualistic instincts, I3 I f.; value of, 142 .

Induction, 308.

Inductive reasoning, 323 .

Inductive teaching, $308 \mathrm{ff}$., 323 .

Inhibition, definition of, 124 ; nature of, 121; of instinctive behavior, 151.

Initiative, 37, 42, 92, 129 ; definition of, 35 ; nature of, 29 ; in habitbuilding, II 2 .

Instinctive behavior, $9 \mathrm{f.,} \mathrm{26,} 37 \mathrm{ff}$; definition of, 139; character of, 128 .

Instincts, adaptive, r $28 \mathrm{ff}$.; æsthetic, $134 \mathrm{f}$; ; individualistic, $13 \mathrm{I}$ f., $\mathrm{I43}_{4}$; modification of, $149 \mathrm{ff}$.; nest build- 
ing, I28; parental, 132; religious, I34 f., I46 f.; sex, I32; social, I32, $144 \mathrm{f}$.; sublimation of, I59; table of, 137 ; value of, 140 ; and affection, $9 x \mathrm{f}$.; and attention, $56 \mathrm{f}$.; and education, I49 ff.; and emotion, 78, 1 28; and feeling, 128; and habits, I $65 \mathrm{f}$.

Intelligence, function of, 28 .

Intensity, as attribute of sensations, I93, 206.

Interest, as influencing conscious changes, $6 \mathrm{f}$.

Interference, in habit-building, I74 f.; in memory, $288 \mathrm{f}$.

Introspection, definition of, 205 .

Involuntary action, I 22.

Involuntary attention, $55 \mathrm{ff}$.

JAMES, W., 79, 248, 273.

Jealousy, instinctive basis of, 132, 133 . JENnings, H. S., 108.

Judgment, $\mathrm{r}_{3} \mathrm{f}$., 307 ; definition of, 323 .

Kinæsthetic sensations, $202 \mathrm{f}$.

Knowledge, and morality, 100, 153 .

Laboratory, function of, 315.

Labyrinth, in animal experiments, 27.

LANGE, C., 79.

Language, training in, 171 .

Law, definition of, 318 .

Learning, 24 ff., 27, 30, 33, 39, I 29 ; and attention, $59 \mathrm{f.}$; and imagination, 315 ; in animals, $26 \mathrm{f}$, 32, 45 ; definition of, 35 ; economy in, 283 fi.; length of periods of, $285 \mathrm{f}$.; rate of, 292 ; rules for, $293 \mathrm{ff}$; through trial and error, 32 ; through curiosity, 49; through play, 4I ff.

Lesson, assignment of, 314 ; inductive development, $3 \circ 9 \mathrm{ff}$.

Localization, cortical, 124.

Loyalty, instinctive basis of, 133 .

Major premise, in reasoning, 308 .

Marks, as incentives, I $7 \mathrm{I}$.

Maze, in animal experiments, 27.

Meaning, I I, 289, 294, 313; definition of, 322 ; as conscious element, I9o $n$.

Meanings, and adjustment, 214; and affection, 7 ; and attention, 66; and association, 272; and perception, 2I 3 ; and thought processes, $300 \mathrm{ff}$.; as individual, 215 ; development of, $314 \mathrm{f}$; variations in, $302 \mathrm{f}$; and behavior, 303; and symbols, 305; and qualities, $304 \mathrm{f}$.

Medulla, I I4.

Memorizing, methods of, $283 \mathrm{ff}$.

Memory, 12 f.; definition of, 260 ; distortion of, $254 \mathrm{f}$.; falsification of, 262 ; improvement of, $256 \mathrm{f}$., $258 \mathrm{f}$.; loss of, 247 ; tests of, 249 ff., 261 ; and behavior, $243 \mathrm{ff}$.

Mental imagery, $23 \mathrm{I}$.

Migratory instincts, 92.

Mind, as synonymous with consciousness, $I$.

Minor premise, in reasoning, 308 .

Mnemonic devices, $290 \mathrm{ff}$., 295.

Montessori method, 169.

Mood, nature of, $84 \mathrm{f}$; definition of, 86.

Moods, educational significance of, I03 $\mathrm{f}$.

Moral education, I52, $174,185 \mathrm{f}$.

Morality, and knowledge, $1 \infty 0$.

Motivation, in habit-building, I72; in higher thought processes, $3 \times 3$.

Motive, definition of, 69; nature of, 60.

Motives, "natural," 172.

Motor areas, II8, I I9.

Motor neurones, II3, I27; definition of, 123.

Muscular sensations, $202 \mathrm{f}$.

Museum, educational use of, 47 .

Needs, as determining behavior, 37 .

Nerves, cranial, Ix5, Ix7, 123 ; spinal, I 5 , 117 .

Nervous system, as organ of behavior, I06 f.; plasticity of, 247 ; structure of, $108 \mathrm{ff}$.

Neurone, definition of, 122 ; nature of, II 2.

Neurones, functions of, I 21 ; classes of, II3 f.; in cortex, 118 .

Noise, sensations of, $199,208$.

Objective teaching, $216,3 \times 7$.

Observation, and memory, $253 \mathrm{f}$.

Olfactory sensations, $200 \mathrm{f}$. 
Organic sensations, 203, 209.

Organism, definition of, 19.

Organization, in higher thought processes, 275, 281, 314 .

Organs of sensations, 190.

Pain, 74, 201 ; and learning, 60.

Parental instincts, 132.

"Part" method in memorizing, $283 \mathrm{f}$., 295.

Passive attention, $55 \mathrm{f}$.; definition of, 68; laws of, $56 \mathrm{f:}$; significance of, $57 \mathrm{f} . ;$ and instincts, 160 ; and higher thought processes, 302 .

Perception, 11, 15, 19I, 206; of form, 198; and behavior, 213 ff.; and imagination, 227.

Perceptions, true and false, $218 \mathrm{ff}$.

Pictures, in teaching, 47, 317.

Pitch, as tonal quality, 208.

Pity, emotion of, 134 .

Plateau, in habit-building, 175 ff., 187.

Play, 92, 130; as instinctive, 40; definition of, 50; limitations of, $44 \mathrm{f}$.; organization of, $46 \mathrm{f}$.; supervision of, 158 ; theories of, $4 \mathrm{I} f$; ; value of, $4 \mathrm{r}$.

Playgrounds, 158.

Pleasantness, $90 \mathrm{ff} ., \mathrm{r} 5 \mathrm{r}$; as affective quality, 74 ; function of, 74 ; in learning, 154.

Practice curve, in habit-building, $175 \mathrm{f}$., 186.

Predatory instinct, 131; use of, $143 \mathrm{f}$.

Prejudice, 268, 278 f.; in reasoning, 308.

Preparation, step of, 309 .

Presentation, step of, 309 .

Pressure, sensations of, 201 .

Pride, feeling of, 132.

Primacy, as law of association, 280.

Problem, 18; importance of, in higher thought processes, 312.

Productive imagination, 230, 240.

Promptness, habits of, $18 \mathrm{I}$ f.

Propensity, of habits, 166, 186.

Psychology, definition of, I f.; problem of, $18 \mathrm{f}$; of animals, 26, 27, 32, $45,60,243$; of conversion, 96 ; of play, 40, 50.

Pugnacity, instincts of, 142.

Punishment, I 53.
"Pure" sensation, rgr.

Purpose, 5 f., 54, 280.

Puzzle box, in animal experiments, 32.

Quality, as attribute of sensations, 193 , 206; and meaning, $304 \mathrm{f}$.

Rage, emotion of, 132 .

Rapidity, in learning, 179, 292, 293, 296.

Rapture, emotion of, 135 .

Reading, imagery in, 234.

Reasoning, $14 \mathrm{f}$; ; and behavior, 307 ff.; definition of, 323; training of, $3 \mathrm{Ig}$ ff.

Recall, 244, 293, 295; and recognition, 245; importance of, in memorizing, $286 \mathrm{f}$.

Recency, in association, 280 .

Recitation, function of, $287 \mathrm{f}$.

Recognition, 244, 260; and recall, 245; method of, in testing memory, 250.

Recollection, 245, 260.

Reconstruction, method of, in testing memory, 251 .

Reflex behavior, 9, I 26 f., I 28, I38.

Religious education, 147; emotional element in, $102 \mathrm{f}$; ; imagination in, 238.

Religious experience, 96 ; instinctive basis of, $134 \mathrm{f}$., $146 \mathrm{f}$.

Remorse, emotion of, $\mathrm{r} 33$.

Repetition, instinctive, 30 , I 29, I4I ; and attention, 58; and memory, 248 ; and habit, 169 f.

Reproductive imagination, 230, 240.

Resentment, instinctive basis of, 156 .

Resources, concepts as, 316, 321 .

Retained members, as method of testing memory, 249 .

Retention, 260.

Retentivity, 246 f., $252 \mathrm{f}$.

Retina, zones of, $197 \mathrm{f}$.

Retraction, instincts of, 136,142 .

Reverence, instinctive basis of, 134 .

Rhythm, and attention, 58 f., 61 f.; instinctive basis of, 134 .

Right associates, as method of testing memory, 250.

Rivalry, instinctive basis of, 132, 145 .

Rote learning, 26r, $289 \mathrm{f}$. 
Saturation, of color sensations, I95, 207. Saving method, in testing memory, 249. Secondary passive attention, 6r, 69 .

Self-assertive instincts, 131 .

Self-consciousness, 203.

Sensation, Io f., I5; and behavior, r $89 \mathrm{ff}$.; and perception, 213 ; definition of, 19I, 205; as conscious element, I $89 \mathrm{ff}$.; attributes of, $193 \mathrm{f}$.

Sensations, organs of, I90; auditory, I99 f.; classes of, I94 ff.; dermal, $20 \mathrm{I}$ f.; gustatory, $200 \mathrm{f}$.; kinæsthetic, 202 ; olfactory, $200 \mathrm{f}$.; organic, 79, 203, 209; visual, $194 \mathrm{ff}$.

Sense organ, definition of, I22.

Sense training, $204 \mathrm{f}$.

Sensori-motor activity, I I4, I23, 192.

Sensory areas, I 18 , I 19.

Sensory defects, $203 \mathrm{f}$.

Sensory neurones, II3, I 23.

Sentiments, nature of, 135 .

Sex instincts, 132 .

Shame, feeling of, 132 .

Similarity, in association, 265, 280.

Simultaneous associations, 279.

Situation, I8, 24; definition of, 20; as arousing emotions, 77,82 .

Smell, sensations of, $200 \mathrm{f}$.

Sociability, instinctive basis of, 133 .

Social instincts, $132,144$.

Spelling, teaching of, r $70 \mathrm{f}$.

SPENCER, H., I 53.

Spinal cord, I I $4 \mathrm{f}$.; functions of, I I $6 \mathrm{f}$.

Stereoscope, educational use of, 47 .

Strain, sensations of, 202.

Study, methods of, $253 \mathrm{f}$.; periods, 294.

Subjugation, instincts of, 134 .

Sublimation, of instincts, 159.

Successive associations, 279 .

Suggestion, as distorting memory, 256 .

Syllogism, $307 \mathrm{f}$.

Symbolic imagery, 233, 240.

Symbolic thinking, $305 \mathrm{f}$.

Symbols, and meanings, 305 .

Sympathetic nervous system, II4.

Sympathy, emotion of, 134 .

Synapse, I27; definition of, I22; nature of, II 2 ; blocking of, $247 \mathrm{f}$.; and association, 247 .

Tardiness, I8I f.

Taste, sensations of, 200 .
Teaching, affective element in, $98 \mathrm{ff}$.; assignment in, 314; emotional element in, I00 ff., ro4; illustration in, 317; inductive, $308 \mathrm{ff}$; objective, 2 I6; through biographical materials, 321 .

Temperament, nature of, 85 ; definition of, 86.

Temperature, sensations of, 201.

Tests, of memory, $249 \mathrm{ff} ., 26 \mathrm{I}$.

Thinking, definition of, 322 .

Thomson, W., 98.

ThorNDIKE, E. L., 32.

Thought, and behavior, $298 \mathrm{ff}$.; confusion of, in emotions, $8 \mathrm{I}, 94$.

Thought crisis, I7 f., 20, 313, 323 .

Timbre, definition of, 288 .

Titchener, E. B., 220.

Tonal deafness, 204.

Tonal sensations, I 99 .

Tone, definition of, 208.

Training, of imagination, 235; of senses, $204 \mathrm{f}$.; of reasoning, $319 \mathrm{ff}$.

Truancy, 92.

Transference, of habits, $18 \mathrm{I}$.

Trial and ërror, $26 \mathrm{ff} ., 34,35,169,321$.

Unpleasantness, 74, I5I, I54 f.; in moral education, 152 .

Value, and affection, 7 ; and attention, 55 ; and emotions, 94 ; of consciousness, 20; of instincts, $140 \mathrm{ff}$; of imagination, $235 \mathrm{ff}$.

Vanity, feeling, of, 132 .

Veneration, instinctive basis of, 134 .

Vexation, emotions of, 136.

Visual defects, $203 \mathrm{f}$.

Visual sensations, $194 \mathrm{ff}$.

Vividness, as factor in recall, 269.

"Warming up" period, 64, $29 \mathrm{If}$.

Washburv, Margaret F., 27, 32.

"Whole" method of memorizing, 293, $295,283 \mathrm{f}$.

"Will to do," I74.

Work, definition of, $5 \mathrm{I}$; conditions of effective, $64 \mathrm{f}$.

WUNDT, W., 220.

YERKES, R. M 27.

Zöllner illusion, 219 . 
THE following pages contain advertisements of a few of the Macmillan books on kindred subjects. 



\title{
The American High School
}

\author{
By JOHN FRANKLIN BROWN, Pн.D.
}

Formerly Professor in Education and Inspector of High Schools for the State University of Iowa. New York, Igog.

Cloth, 12mo, 462 pages, $\$ 1.40$

The experience of the last fifty years has both revealed the special nat ure of the problems of the secondary school, and developed a considerable body of knowledge concerning them which every high school teacher should possess. This information the author has collected and presented here in a very direct, practical way. While the facts and principles contained in the book apply to bigh schools generally, the circumstances and needs of the smaller schools have veen kept particularly in mind.

The volunie is designed to supply systematic information concerning the work and the problems of the high school, which every teacher and administrator should possess. Among the topics treated are: the origin and function of the high school; its organization and management; the program of studies; material equipment; the nature and special needs of the high school pupil; the qualifications of the teacher; the class exercise; social life; the school and the community; and current problems of special interest. The treatment is practical throughout both in the statement of problems and in the suggestion of a proper method of procedure under given conditions. A well-selected bibliography of some five hundred titles furnishes a guide for further study and is an exceedingly valuable feature of the work.

History Teacher's Magazine. - “This book deserves wide reading for many reasons. It is encouraging in spirit, but fearless in criticism, which is everywhere constructive; its style is simple and direct throughout, thus adapting itself to the attention of parents and school boards as well as the profession; it deals with questions vital to both large and small schools; its bibliographies and illustrative material in the appendices are pilots on a vast sea; and a careful reading will result in a greatly increased faith in the present high value and the boundless future possibilities which the author cherishes in such large measure for the American high school."

\section{THE MACMILLAN COMPANY}




\section{BY WILLIAM CHANDLER BAGLEY}

Director of the School of Education, University of Illinois

\section{Craftsmanship in Teaching}

$$
\text { Cloth, 12mo, } 247 \text { pages, } \$ 1.25
$$

Readers of "The Educative Process" and "Classroom Management" by Director W. C. Bagley of the University of Illinois will welcome the author's new book on "Craftsmanship in Teaching." The book is made up of a series of addresses given before educational gatherings, the subject of the first one giving the book its name. In these addresses the personality of the author is more in evidence than is possible in his more systematic work, but the same sane, scientific point of view is apparent throughout.

\section{Classroom Management}

$$
\text { Cloth, xvii }+332 \text { pages, } \$ 1.25
$$

This book considers the problems that are consequent upon the massing of children together for purposes of instruction and training. It aims to discover how the unit-group of the school system - the "class " - can be most effectively handled. The topics commonly included in treatises upon school management receive adequate attention; the first day of school; the mechanizing of routine; the daily programme; discipline and punishment; absence and tardiness, etc.

\section{The Educative Process}

Cloth, $x i x+358$ pages, $\$ 1.25$

The book aims to prevent a waste of energy on the part of the young teacher by setting forth a systematic and comprehensive view of the task that is to be accomplished by the school, with the working principles for the attainment of the end. The best idea for the author's plan of treatment can be had from his division of the book. Part I discusses the function of education and of the school in biological and sociological terms. Part II continues the same topic from the psychological standpoint. Part III deals with the functioning of experience in its relation to the educative process. Part IV treats of the relation of education to the three periods of child-development: the transitional, the formative, the adolescent. Part $\mathrm{V}$ considers educational values and the necessity of ideals in the educative process, and Part VI concludes with the technique of teaching.

\section{THE MACMILLAN COMPANY}




\section{A Brief Course in the Teaching Process}

\section{By GEORGE DRAYTON STRAYER}

Professor of Educational Administration, Teachers College, Columbia University

Cloth, I2mo, xiv + 315 pages, \$1.25

This new book by Professor Strayer.meets the great and very real need for a teacher's professional book of "Theory and Practice," which, though full of meat, can be read in those "marginal minutes" which are all that a very large number of teachers have for reading.

Professor Strayer has had in mind not so much the specialist as (I) the young teacher, who needs to get much help in a short time;

(2) the teacher with limited training to whom every schoolroom problem is mountainous, and (3) the overworked teacher who desires to keep abreast of the world in her profession, but has not time to wade through morasses of display stock of pedagogical "wisdom." For example: The Chapter on "Study" offers more in a few pages than some entire books of hundreds of pages devoted to the topic.

The ever troublesome questions of inductive and deductive teaching are made clear as crystal in two brief chapters. Teachers who have studied whole books on these topics only to be befogged will be surprised at their simplicity as given here.

\section{The Learning Process}

\section{By STEPHEN SHELDON COLVIN, Ph.D}

Professor of Psychology at the University of Illinois

$$
\text { Cloth, I2mo, } x x y+336 \text { pages, } \$ 1.25
$$

In the multitude of books on psychology here is at last one that meet the teacher's needs; truly a rara avis among books.

It is not sensational, and it does not make large claims to originality, but it is scholarly. It gives the latest contributions to the subject, and in so far as is possible in a book, aids the teacher by making clear the processes of the learning mind, and showing how to take advantage of them.

\section{THE MACMILLAN COMPANY Publisbers




\section{NEW BOOKS FOR TEACHERS}

Aspinwall - Outlines of the History of Education

$$
x v i+195 \text { pages } \$ .80
$$

Graves - Great Educators of Three Centuries

$$
\text { viii }+289 \text { pages } \quad \text { I.IO }
$$

- Peter Ramus

$$
\text { ix }+226 \text { pages }
$$

Gregory - Better Schools

$$
x+283 \text { pages } \quad \mathbf{I} 25
$$

Howerth - Art of Education

$$
\text { rvi }+237 \text { pages } \quad 1.00
$$

KING - Social Aspects of Education

$$
\mathbf{x v}+425 \text { pages } \quad 1.60
$$

McVannel - Outline of a Course in the Philosophy of Education

$$
\text { ix }+207 \text { pages } \quad .90
$$

PERRY - Outlines of School Administration

$$
\text { viii }+425 \text { pages } \quad \text { r.40 }
$$

SAchs - American Secondary School

$$
\text { xviii }+295 \text { pages I.ro }
$$

Schultze - Teaching of Mathematics

$$
x x+370 \text { pages } \quad \mathbf{1 . 2 5}
$$

Smith - All the Children of All the People

viii +346 pages $\quad 1.50$

Soldan - The Century and the School

$$
\text { vii }+206 \text { pages } \quad 1.25
$$

TAYLOR - The Principles and Method of Teaching Reading xiii +238 pages

\section{THE MACMILLAN COMPANY}

Publishers

CHICAgO
64-66 Fifth Avenue

New York 




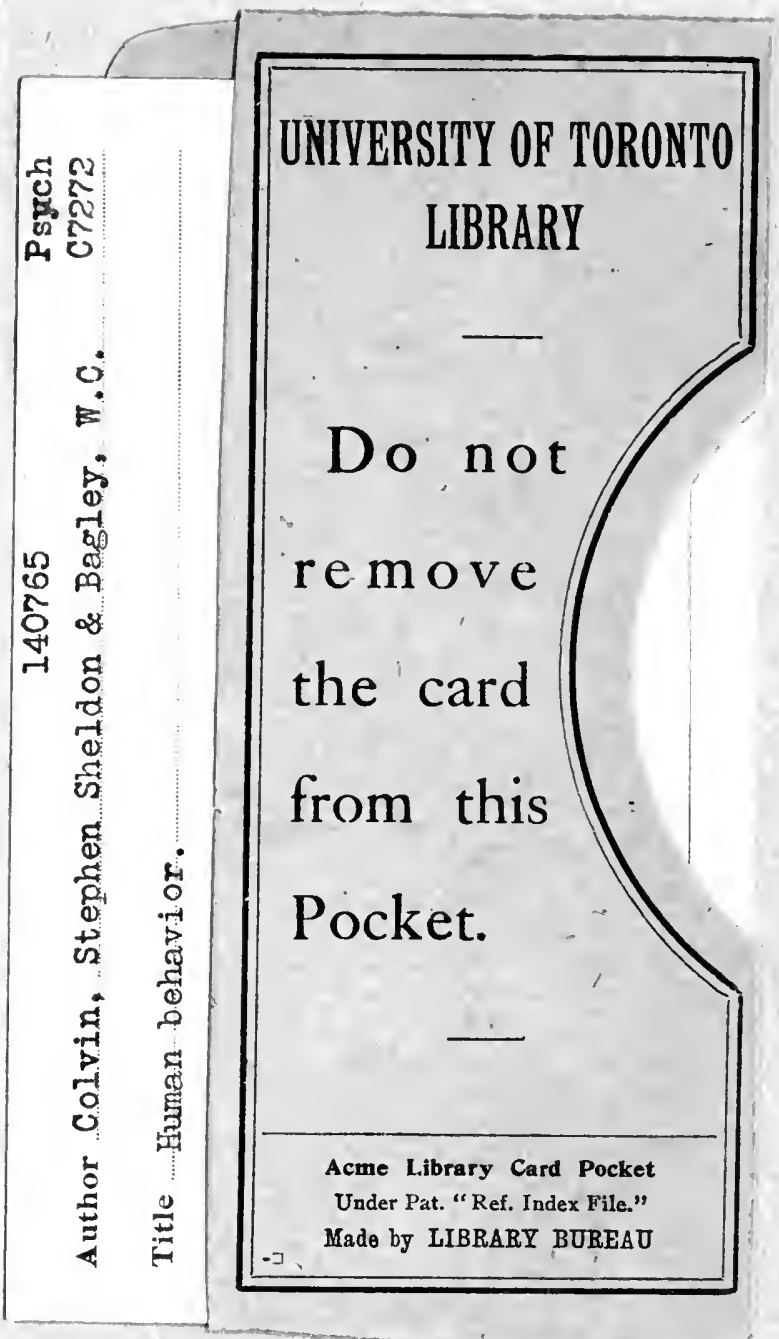


